\title{
Cellular immunotherapy : from stem cell to lymphocyte
}

Citation for published version (APA):

Huijskens, M. J. A. J. (2015). Cellular immunotherapy : from stem cell to lymphocyte. [Doctoral Thesis, Maastricht University]. Maastricht University. https://doi.org/10.26481/dis.20150212mh

Document status and date:

Published: 01/01/2015

DOI:

10.26481/dis.20150212mh

Document Version:

Publisher's PDF, also known as Version of record

\section{Please check the document version of this publication:}

- A submitted manuscript is the version of the article upon submission and before peer-review. There can be important differences between the submitted version and the official published version of record.

People interested in the research are advised to contact the author for the final version of the publication, or visit the DOI to the publisher's website.

- The final author version and the galley proof are versions of the publication after peer review.

- The final published version features the final layout of the paper including the volume, issue and page numbers.

Link to publication

\footnotetext{
General rights rights.

- You may freely distribute the URL identifying the publication in the public portal. please follow below link for the End User Agreement:

www.umlib.nl/taverne-license

Take down policy

If you believe that this document breaches copyright please contact us at:

repository@maastrichtuniversity.nl

providing details and we will investigate your claim.
}

Copyright and moral rights for the publications made accessible in the public portal are retained by the authors and/or other copyright owners and it is a condition of accessing publications that users recognise and abide by the legal requirements associated with these

- Users may download and print one copy of any publication from the public portal for the purpose of private study or research.

- You may not further distribute the material or use it for any profit-making activity or commercial gain

If the publication is distributed under the terms of Article $25 \mathrm{fa}$ of the Dutch Copyright Act, indicated by the "Taverne" license above, 


\section{Cellular immunotherapy From stem cell to lymphocyte}

Mirelle J.A.J. Huijskens 
(c) Mirelle J.A.J. Huijskens, Maastricht 2015.

All rights reserved. No part of this thesis may be reproduced, stored in a retrieval system of any nature, or transmitted in any form or by any means, electronic, mechnical, photocopying, recording or otherwise without prior written permission of the author.

ISBN:

9789461088949

Cover art: Hiroshi Kawamoto

Figure design ch. 1: Thomas Habets

Layout:

Mirelle J.A.J. Huijskens

Production: Gildeprint

Financial support for the publication of this thesis was kindly provided by the Dutch Cancer Society (KWF kankerbestrijding). 


\title{
Cellular immunotherapy From stem cell to lymphocyte
}

\author{
PROEFSCHRIFT
}

ter verkrijging van de graad van doctor aan de Universiteit Maastricht,

op gezag van de Rector Magnificus, Prof. dr. L.L.G. Soete

volgens het besluit van het College van Decanen,

in het openbaar te verdedigen

op donderdag 12 februari 2015 om 14.00 uur

door

Mirelle Johanne Angelina Jacobus Huijskens

geboren op 17 juli 1987 te Naarden. 


\section{Promotores}

Prof. dr. G. M. J. Bos

Prof. dr. H. Kawamoto, Kyoto University, Japan

\section{Co-promotor}

Dr. W. T. V. Germeraad

\section{Beoordelingscommissie}

Prof. dr. M. Vooijs (Voorzitter)

Prof. dr. J. J. Cornelissen, Erasmus Medisch Centrum, Rotterdam

Dr. ir. Y. M. C. Henskens

Prof. dr. F. C. S. Ramaekers

Prof. dr. F. J. T. Staal, Leiden Universitair Medisch Centrum, Leiden 


\section{Contents}

List of abbreviations

Chapter 1 General Introduction 9

Chapter 2 Thymic epithelial cells induce formation of mesenchymal network 43 structure after abrogation of thymic crosstalk

Chapter 3 Induced developmental arrest of early haematopoietic progenitors leads to the generation of leukocyte stem cells

Chapter 4 T cells fail to develop in the human skin-cell explant system; an inconvenient truth

Chapter 5 Ascorbic acid induces development of double-positive T cells from human haematopoietic stem cells in the absence of stromal cells

Chapter 6 Ascorbic acid promotes proliferation of NK cell populations in culture systems applicable for NK cell therapy

Chapter 7 Ascorbic acid serum levels are reduced in patients with haematological malignancies

Chapter 8 General Discussion

Summary

Samenvatting

Valorisation 


\section{List of abbreviations}

\begin{tabular}{|c|c|c|c|}
\hline $3 \mathrm{D}$ & Three dimensional & $\mathrm{DC}$ & Dendritic cell \\
\hline 4-OHT & 4-hydroxytamoxifen & dGUO & Deoxyguanosine \\
\hline 7AAD & 7-Amino-actinomycin D & $\mathrm{DHH}$ & Desert hedgehog \\
\hline AA & Ascorbic acid & $\mathrm{DiO}$ & 3,3'-Dioctadecyloxa \\
\hline \multirow[t]{2}{*}{ ACE } & Agiotensin-converting & & carbocyanineperchlorate \\
\hline & enzyme & DLBCL & Diffuse large B cell \\
\hline \multirow[t]{2}{*}{$\mathrm{ADCC}$} & Antibody-dependent cell- & & lymphoma \\
\hline & mediated cytotoxicity & DLI & Donor lymphocyte infusion \\
\hline \multirow[t]{2}{*}{ AIDS } & Acquired immunodeficient & $\mathrm{DL} / \mathrm{DLL}$ & Delta-like ligand \\
\hline & syndrome & $\mathrm{DN}$ & Double negative \\
\hline AIRE & Autoimmune regulator & DP & Double positive \\
\hline ALL & Acute lymphatic leukemia & EBV & Epstein-Barr virus \\
\hline AML & Acute myeloid leukemia & EGF & Epidermal growth factor \\
\hline APC & Allophycocyanin & ER & Estrogen receptor \\
\hline APC & Antigen presenting cell & ES & Embryonic stem \\
\hline ARP & Acidic ribosomal protein & ETP & Early thymic progenitor \\
\hline B6 & $\mathrm{C} 57 \mathrm{BL} / 6$ & FBS & Foetal bovine serum \\
\hline $\mathrm{BM}$ & Bone marrow & FCS & Foetal calf Serum \\
\hline bME & 2-Mercaptoethanol & $\mathrm{Fe}^{3+} \mathrm{TPTZ}$ & Ferrous ion and \\
\hline BPS & Bovine pituitary extract & & 2,4,6-Tris(2-Pyridyl)-s- \\
\hline BrdU & Bromodeoxyuridine & & Triazine \\
\hline $\mathrm{CB}$ & Cord blood & FGF & Fibroblast growth factor \\
\hline $\mathrm{CD}$ & Cluster of differentiation & FGFR & Fibroblast growth factor \\
\hline CK & Cytokeratins & & receptor \\
\hline CLL & Chronic lymphoid leukemia & FITC & Fluorescein isothiocyanate \\
\hline \multirow[t]{2}{*}{ CLP } & Common lymphoid & $\mathrm{FL}$ & Foetal liver \\
\hline & progenitor & Flt3-L & FMS-like tyrosine kinase 3 \\
\hline \multirow[t]{2}{*}{ CMEP } & Common myeloid- & & ligand \\
\hline & erythroid progenitor & FT & Foetal thymus \\
\hline CML & Chronic myeloid leukemia & FTOC & Foetal thymic organ culture \\
\hline \multirow[t]{2}{*}{ CMLP } & Common myeloid- & G-CSF & Granulocyte-colony \\
\hline & lymphoid progenitor & & stimulating factor \\
\hline CMV & Cytomegalovirus & $\mathrm{GH}$ & Growth hormone \\
\hline cTEC & $\begin{array}{l}\text { Cortical thymic epithelial } \\
\text { cell }\end{array}$ & GMP & $\begin{array}{l}\text { Good manufacturing } \\
\text { practice }\end{array}$ \\
\hline CTL & Cytotoxic T lymphocyte & GVHD & Graft-versus host disease \\
\hline CTLA-4 & Cytotoxic T lymphocyte & GVL & Graft versus leukaemia \\
\hline & associated protein-4 & $\mathrm{h}$ & human \\
\hline
\end{tabular}




\begin{tabular}{|c|c|c|c|}
\hline HES & Hairy enhancer of split & MM & Multiple myeloma \\
\hline HLA & Human leukocyte antigen & MNC & Mononuclear cells \\
\hline HOS & High oxygen submersion & mTED & Medullary thymic epithelial \\
\hline \multirow[t]{2}{*}{ HPE } & Homeostatic peripheral & & cell \\
\hline & expansion & MTP & Myeloid-T cell progenitor \\
\hline HSC & Haematopoietic stem cell & MUD & Matched unrelated donor \\
\hline \multirow[t]{2}{*}{ HSCT } & Haematopoietic stem cell & NAC & $\mathrm{N}$-acetyl-L-cysteine \\
\hline & transplantation & NEAA & Non-essential amino acids \\
\hline \multirow[t]{2}{*}{ iCD } & Intracellular cluster of & NHL & Non-Hodgkin lymphoma \\
\hline & differentiation & NICD & Notch intracellular domain \\
\hline Id3 & Inhibitor of DNA binding 3 & NK & Natural killer \\
\hline \multirow[t]{2}{*}{ IdHP } & Induced haematopoietic & $\mathrm{NO}$ & Nitric oxide \\
\hline & progenitor & NOS & Nitric oxide synthase \\
\hline IGF & Insulin-like growth factor & OncM & Oncostatin M \\
\hline IL & Interleukin & pan & Polyclonal \\
\hline iLS cell & Induced leukocyte stem cell & $\operatorname{panK}$ & Pancytokeratin \\
\hline \multirow[t]{2}{*}{ iPS cell } & Induced pluripotent stem & PBMC & Peripheral blood \\
\hline & cell & & mononuclear cells \\
\hline IRF1 & IFN- $\gamma$ responsive factor 1 & PBS & Phosphate buffered saline \\
\hline iSP & immature Single positive & PDGF & Platelet-derived growth \\
\hline KGF & Keratinocyte growth factor & & factor \\
\hline \multirow[t]{2}{*}{ KIR } & Killer immunoglobulin-like & $\mathrm{PE}$ & Phycoerythrin \\
\hline & receptor & PerCP & Peridinin-chlorophyll \\
\hline \multirow[t]{3}{*}{ LHRH-A } & Luteinizing hormone & & protein \\
\hline & releasing hormone & ph-AA & 2-phospho-L-ascorbic acid \\
\hline & antagonist & PI & Propidium iodide \\
\hline \multirow[t]{2}{*}{ L-NMMA } & $\mathrm{N}^{\mathrm{G}}$-monomethyl-L- & $\mathrm{P} / \mathrm{S}$ & Penicillin/Streptomycin \\
\hline & arginine-monoacetate salt & RAG & Recombinant activating \\
\hline LOS & Low oxygen submersion & & gene \\
\hline LKS & $\mathrm{Lin}^{-} \mathrm{c}-\mathrm{Kit}^{+} \mathrm{Sca}-1^{+}$ & rh & recombinant human \\
\hline $\mathrm{m}$ & mouse & $\mathrm{rm}$ & recombinant murine \\
\hline mAbs & monoclonal Antibodies & ROS & Reactive oxygen species \\
\hline MBP & Myeloid-B cell progenitor & RTC & Reaggregate thymus culture \\
\hline $\mathrm{mCD} 4^{+}$ & mobilized CD $34^{+}$ & RTE & Recent thymic emigrants \\
\hline \multirow[t]{2}{*}{ M-CSF } & Macrophage colony- & SCF & Stem cell factor \\
\hline & stimulation factor & SCID & Severe combined immune \\
\hline MFI & Mean fluorescence intensity & & deficiency \\
\hline \multirow[t]{2}{*}{ MHC } & Major histocompatibility & SP & Single positive \\
\hline & complex & TACE & Tumour-necrosis factor \\
\hline MLR & Mixed lymphocyte reaction & & a-converting enzyme \\
\hline
\end{tabular}




$\begin{array}{ll}\text { TCR } & \text { T cell receptor } \\ \text { TEC } & \text { Thymic epithelial cell } \\ \text { TGF } & \text { Transforming growth factor } \\ \text { TPO } & \text { Thrombopoietin } \\ \text { TREC } & \text { T cell receptor excision } \\ & \text { circle } \\ \text { TSP } & \text { Thymic seeding progenitor } \\ \text { VEGF } & \text { Vascular endothelial growth } \\ & \text { factor } \\ \text { WT } & \text { Wild type }\end{array}$




\section{General \\ Introduction}




\section{Cancer}

Cancer is the collective term for a large group of diseases characterized by the uncontrolled growth of abnormal cells that have the capacity to migrate and invade other tissues. Cancer is one of the major causes of death in the Western world and even the second cause of death in developing countries, with a global growing incidence of 22.2 million estimated cases in $2030^{1-3}$. One in two men and one in three women will develop cancer during their lifetime 4. In 2012, 14.1 million people were diagnosed with cancer and 8.2 million cancer deaths were counted ${ }^{5}$. The increase in cancer incidence is because of the aging and growth of the population in combination with earlier detection ${ }^{4}$. Even though cancer mortality declines because of more effective early detection in combination with early treatment, the burden on society remains enormous.

The treatment of the majority of the cancer patients consists of a combination of surgery and/ or chemo- and radiotherapy. Because not all cancers can be cured with these conventional methods, an urgent need for other therapies exists. More recently, other therapies like immunotherapy became of great interest. The major aims of immunotherapy are to trigger the patient's immune system to enhance the response against cancer cells or to supply immune cells or components to the patient providing a strong immune reaction after administration.

Within the field of cancer immunotherapy, a multitude of approaches exist, like immune modulating agents, anti-tumour antibodies, cancer vaccines and adoptive cellular therapies. Thus far, one of the most successful forms of immunotherapy is antibody therapy. A wellknown example is anti-CD20/Rituximab that is used as therapy for B cell lymphomas ${ }^{6}$. These antibodies induce cell-mediated cytotoxicity of CD20 expressing cells, eliminating malignant cells but also healthy B cells. Another successful antibody therapy with immune modulating effects is anti-cytotoxic $\mathrm{T}$ lymphocyte associated protein-4 (anti-CTLA-4)/ Ipilimumab used in the treatment of melanoma patients. It enhances anti-tumour effects because of neutralizing inhibitory signals on $\mathrm{T}$ cells resulting in enhanced survival of advanced melanoma patients of $\sim 3.5$ months ${ }^{7,8}$. In the field of cellular immunotherapy, currently only one cell-based vaccine, sipuleucel-T/Provenge, has been clinically approved in 2010 for the treatment of metastatic hormone-refractory prostate cancer 9 . This vaccine consists of the patient's own peripheral blood mononuclear cells (PBMCs) including antigen presenting cells (APCs) that have been activated ex vivo and loaded with a prostate specific protein called prostatic acid phosphatase, stimulating the patient's immune system to induce anti-tumour activity resulting in a prolonged survival of 4.1 months ${ }^{9}$. Although the accomplished successes, where the above mentioned strategies only represent a fraction of existing therapies, immunotherapy is often only effective in certain patients and results in moderate prolonged survival instead of complete remission. Many other immunotherapies are currently under investigation as extensively reviewed by others 
10-12. Some studies target the improvement of current therapies, while others focus on the generation of novel cancer immunotherapies, for example adoptive immunotherapy where immune cells are used in the battle against cancer.

\section{Haematopoietic stem cell transplantation as cancer therapy}

Although chemotherapy, with or without radiotherapy, is the standard treatment for various haematological malignancies, in many patients this is not sufficient for complete remission. The addition of haematopoietic stem cell transplantation (HSCT) to the treatment reduces the risk of relapse ${ }^{13}$. HSCT is the most common cellular immunotherapy used for the treatment of haematological malignancies but also for some solid tumours, anemia and autoimmune disorders ${ }^{14}$. Allogeneic HSCT from human leukocyte antigen (HLA) matched donors is the transplant of choice for a variety of haematological diseases.

Unfortunately, in only $30 \%$ of the cases a HLA matched donor is found ${ }^{15}$. Moreover, finding a matched unrelated donor (MUD) in the required time period is limited because of the complexity of the HLA matching and logistic challenges, especially for ethnic minorities ${ }^{16}$, ${ }^{17}$. An alternative source of stem cells for transplantation is umbilical cord blood (CB). CB grafts allow a higher HLA disparity between donor and recipient, they contain less $\mathrm{T}$ cells and because of cryopreservation, grafts are directly available ${ }^{18}$. Unfortunately, obtained cell numbers are low and are therefore not suitable for every patient. Furthermore, the use of double CB transplantation - aiming for higher cell numbers - increases the risk of graft versus host disease (GVHD) ${ }^{19}$. Besides exploring the use of CB for transplantation because of a lack of HLA-matched related or unrelated donors ${ }^{20}$, haplo-identical transplants are introduced in the last two decades. Each parent, child and 50\% of the patient's siblings could immediately serve as a donor. Donor granulocyte-colony stimulating factor (G-CSF) treatment results in HSC mobilization from the bone marrow (BM) to the periphery, via apheresis and subsequent $\mathrm{CD} 4^{+}$cell isolation, adequate cell numbers can be obtained. Furthermore, the same donor could be used for additional adoptive immunotherapy. Nonetheless, initial studies with transplantation across the HLA-barrier resulted in high treatment related mortality because of severe GVHD ${ }^{21}$. Extensive T cell depletion in combination with a mega dose of HSCs resulted in less GVHD and overcame graft rejection ${ }^{22}$. A preliminary study showed that removal of $\alpha \beta \mathrm{CD}^{+} \mathrm{T}$ cells and $\mathrm{CD} 19^{+} \mathrm{B}$ cells instead of CD34 ${ }^{+}$HSC selection, leaving other cells that may be important for immune function in the graft, resulting in minor GVHD risk and promoted faster immune recovery in children receiving haplo-identical transplantation for non-malignant disorders. This protocol is currently also tested in patients with malignancies 23, 24. A major advantage of HLA-mismatched transplantation is the strong beneficial graft versus leukaemia (GVL) effect mediated by the alloreactive natural killer (NK) cells ${ }^{25}$. 


\section{Immune recovery after haematopoietic stem cell transplantation}

Delayed immune reconstitution is common to all types of HSCT. However, this delay is more pronounced for $\mathrm{CB}$ and haplo-idential HSCT ${ }^{26}$. Major reasons are extensive T cell depletion, HLA mismatching, immunosuppressive regimens to prevent GVHD and a decreased thymic function because of age-related involution, treatment and GVHD ${ }^{15,27}$. As a consequence, patients suffer from uncommon and opportunistic infections resulting in high mortality ${ }^{19}$, 22,28 .

Immune recovery, as illustrated in Figure 1, depends on several factors such as disease, age, conditioning, transplant type and graft manipulation, e.g. T cell depletion and the HSC selection method ${ }^{26}$. In general, the innate immunity recovers within weeks, while adaptive immunity recovers only within months to years. In more detail, neutrophils, monocytes, macrophages, dendritic cells (DCs, in blood) and NK cells recover within weeks, while CD8 ${ }^{+}$ $\mathrm{T}$ cells and B cells recover in months. Especially $\mathrm{CD} 4^{+} \mathrm{T}$ cells recover slow, which may take up to several years (reviewed in ${ }^{26,29}$ ). Specifically, the new development of naive $\mathrm{CD}^{+}$or $\mathrm{CD}^{+} \mathrm{T}$ cells takes several years because of thymus dependency. Low $\mathrm{CD} 4^{+} \mathrm{T}$ cell counts are associated with increased infection score ${ }^{30}$. Moreover, patients with low thymic output after allogeneic HSCT are at higher risk of experiencing infections ${ }^{31}$. Most patients suffer from Cytomegalovirus (CMV) infection or reactivation and fungal infection (Aspergillosis) ${ }^{15}$. Furthermore, slow T cell reconstitution is associated with risk of graft rejection and relapse. Relapsing patients are characterized by less naive $\mathrm{T}$ cells counts compared to non-relapsing patients ${ }^{32}$. Recovery of the immune system partially depends on peripheral expansion of residual or graft derived immune cells. However, generation of immune cells from stem cells is required for the recovery of a robust and protective immune system.

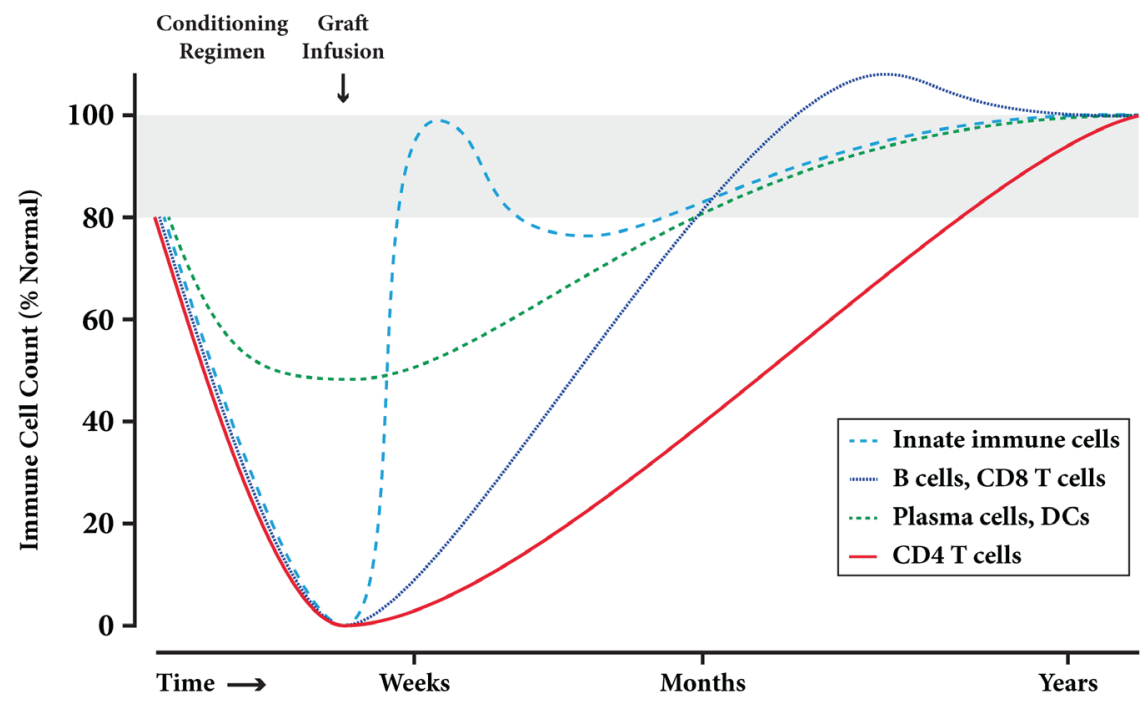


Figure 1: Approximate immune cell counts after myeloablative haematopoietic stem cell transplantation. Immune cell counts are represented as percentage of normal (80-100\%). The dashed light blue line represents innate immune cells (for example, neutrophils, monocytes and NK cells). The dotted dark blue line represents the recovery of $\mathrm{CD} 8^{+} \mathrm{T}$ cells and $\mathrm{B}$ cells. The dashed green line represents the recovery of relatively radiotherapy/chemotherapy resistant cells such as plasma cells and tissue dendritic cells (DCs). The red line represents $\mathrm{CD} 4^{+} \mathrm{T}$ cells, the recovery of which is influenced primarily by the $\mathrm{T}$ cell content of the graft and patient age (faster in children than in adults). Figure is based on reference ${ }^{26}$.

\section{Haematopoiesis}

Haematopoietic stem cells are located in the bone marrow. The unique features of stem cells are self-renewal capacity and multi-lineage potential. This multi-lineage potential results in the generation of all mature blood cells, a process defined as haematopoiesis. Mature blood cells consist of erythrocytes, thrombocytes (cell fragments) and leukocytes. Leukocytes are the cells of the immune system and can be divided into the myeloid and lymphocyte lineage. The myeloid lineage consists of granulocytes, monocytes, macrophages and dendritic cells, whereas the majority of lymphocytes consist of B cells, T cells, NK cells and NKT cells.

The development from stem cell to mature blood cell is a highly organized process. Of each lineage, different (multi-potent) progenitor cell types exist that have the capacity to grow into mature effector cells. For more than 30 years, the classical model of branching was the gold standard ${ }^{33}$. This model describes a clear separation between a common myeloid-erythroid progenitor (CMEP) and a common lymphoid progenitor (CLP) as illustrated in Figure 2A. However, recent research proposed an alternative model: the myeloid-based model as shown in Figure 2B. In this model myeloid potential is reserved after the segregation of erythroid, $\mathrm{B}$ and $\mathrm{T}$ cells ${ }^{34}$.

Lineage differentiation is dependent on genetic and epigenetic control. Lymphocytes are generated through a lineage restriction process, starting with pluripotent stem cells. Concerning lineage differentiation from HSC, for B cell differentiation the transcription factors PAX5, E2A and EBF are important while Notch1, TCF and GATA3 are important for $\mathrm{T}$ lineage development and Id2 for NK cell development ${ }^{35,36}$. 


\section{A Classical Model}

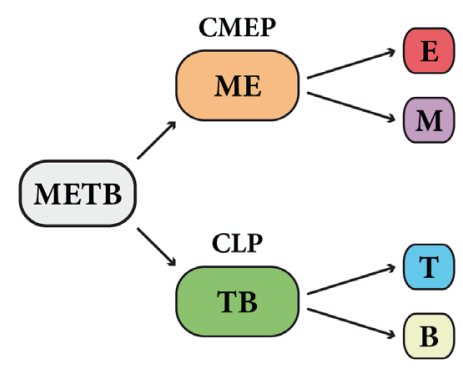

B Myeloid-based Model

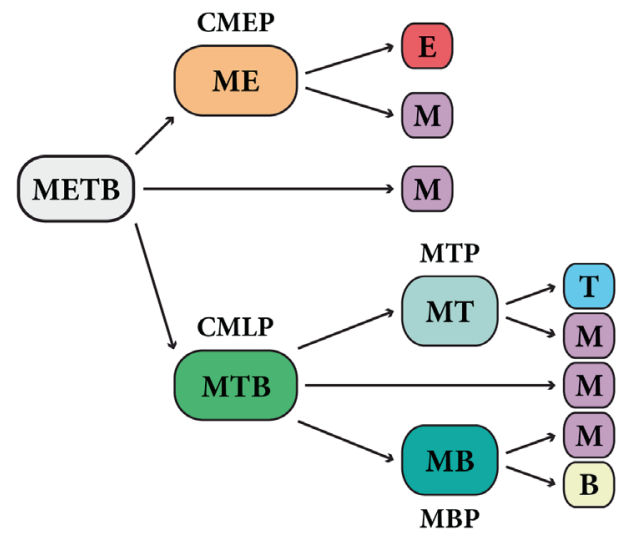

Figure 2: Models of haematopoiesis. A: The classical model proposes that HSCs first diverge into common myeloid-erythroid progenitors (CMEPs) and common lymphoid progenitors (CLPs). E, M, $\mathrm{T}$ and $\mathrm{B}$ represent the progenitor potential for erythroid, myeloid, $\mathrm{T}$ and $\mathrm{B}$ cells, respectively. $\mathrm{B}$ : The myeloid-base model proposes that the first branching point generates CMEPs and common myeloidlymphoid progenitors (CMLPs). The myeloid potential persists in the $\mathrm{T}$ and $\mathrm{B}$ cell branches (myeloid- $\mathrm{T}$ cell progenitor (MTP) and myeloid-B cell progenitor (MBP) respectively) even after these lineages have diverged. Figure is based on reference ${ }^{34}$.

\section{T cell development and the thymus}

$\mathrm{T}$ lymphocytes are involved in cell-mediated immunity and express $\mathrm{T}$ cell receptors (TCRs) enabling these cells to recognize major histocompatibility complex (MHC)-bound antigens. Upon TCR triggering of naive $\mathrm{T}$ cells, proliferation and differentiation towards a specific immune response occurs. T cells can be divided based on their TCR expression, namely $\alpha \beta$ or $\gamma \delta$. Over $90 \%$ of the T cells express TCR $\alpha \beta$ and are either $\mathrm{CD}^{+}$and MHCII restricted or $\mathrm{CD}^{+}$and MHCI restricted ${ }^{37}$. CD4 $\alpha \beta$ T cells can polarize towards different $\mathrm{T}$ helper or regulatory subsets and facilitate activation of other immune cells. CD8 $\alpha \beta \mathrm{T}$ cells differentiate into cytotoxic T lymphocytes (CTLs) capable of killing virus infected or tumour cells. TCR $\alpha \beta$ $\mathrm{T}$ cells are mainly found in the blood, thymus and lymph nodes while $\gamma \delta \mathrm{T}$ cells mainly reside in the epithelium and mucosa-associated lymphoid tissues ${ }^{37-39}$.

\section{The thymus}

The bone marrow supports the differentiation of multi-potent haematopoietic stem cells towards specific haematopoietic lineages, but is insufficient for $\mathrm{T}$ cell maturation what makes migration of early progenitors to the thymus essential ${ }^{40}$. 
The thymus is a highly structured organ located behind the sternum just above the heart and originates at least in part from the third pharyngeal pouch (Figure 3A) ${ }^{41}$. The thymus is encapsuled by a thick layer of mesenchymal cells. The organ itself is composed of developing T lymphocytes that closely interact with the thymic stroma. The stroma provides the structure of the thymus and consists of thymic epithelial cells (TECs), mesenchymal cells, connective tissue and endothelial cells that form the vasculature ${ }^{42}$. The three dimensional (3D) thymic microenvironments consist of cortical thymic epithelial cells (cTECs) in the outer regions and medullary TECs (mTECs) in the center regions ${ }^{43}$. These cells are phenotypically and also functionally different but may originate from a common bipotent thymic epithelial progenitor cell ${ }^{44}$. At the cortico-medullary junction, thymic seeding progenitor (TSPs) enter the thymus via blood vessels. The interactions between the thymocytes and the TECs, a process that is commonly termed thymic crosstalk, are required for proper thymus and T cell development ${ }^{45-50}$. TECs provide important signals varying from adhesion molecules, chemokines, cytokines, Notch ligands, and MHC to thymocytes to proliferate and differentiate from early progenitors to highly specialized $\mathrm{T}$ cells with either helper, killer or regulatory function ${ }^{51}$. In turn, thymocytes generate signals to which TECs can respond and also differentiate to either cortical or medullary TECs ${ }^{45}$. However, TECs do not only need thymocyte derived signals, they can also be influenced by mesenchymal fibroblast derived signals ${ }^{52,53}$. It has been shown that for proper TEC network development, production of epidermal growth factor (EGF), transforming growth factor- $\alpha$ (TGF- $\alpha)^{54}$ and fibroblast growth factors (FGFs) ${ }^{55}$ is necessary. Besides providing signalling required for TEC development and to provide structure in the thymus, the mesenchymal network provides interleukin (IL)-7 ${ }^{56}$ and extracellular matrix components needed for proper $\mathrm{T}$ cell development ${ }^{57}$. In contrast to the knowledge of $\mathrm{T}$ cell and TEC development, the formation of the mesenchymal network in the thymus remains to be elucidated.

The thymus undergoes age-associated involution, although the exact mechanisms of involution are not yet understood, they are believed to be intrinsic and extrinsic ${ }^{58}$. Initially it was believed to be dependent on increased levels of steroid hormones during puberty. However, other factors like HSC function, changes in the thymic stroma and intrathymic cytokine production are thought to be involved as well ${ }^{59}$. Involution is characterized by expansion of adipocytes and stroma, simultaneous with a decrease of the cortical and medullary regions together with loss of tissue organization ${ }^{60}$. Thymic function is measured by $\mathrm{T}$ cell receptor excision circles (TRECs), which are circular DNA fragments released as a result of $\mathrm{T}$ cell receptor rearrangement during thymocyte development ${ }^{61}$. TRECs are stable and do not replicate, therefore only recent thymic emigrants (RTE) have high TREC counts. Thymic output, and thereby TREC levels, reduces during aging, but the thymus keeps producing $\mathrm{T}$ cells throughout life ${ }^{62}$. 
A

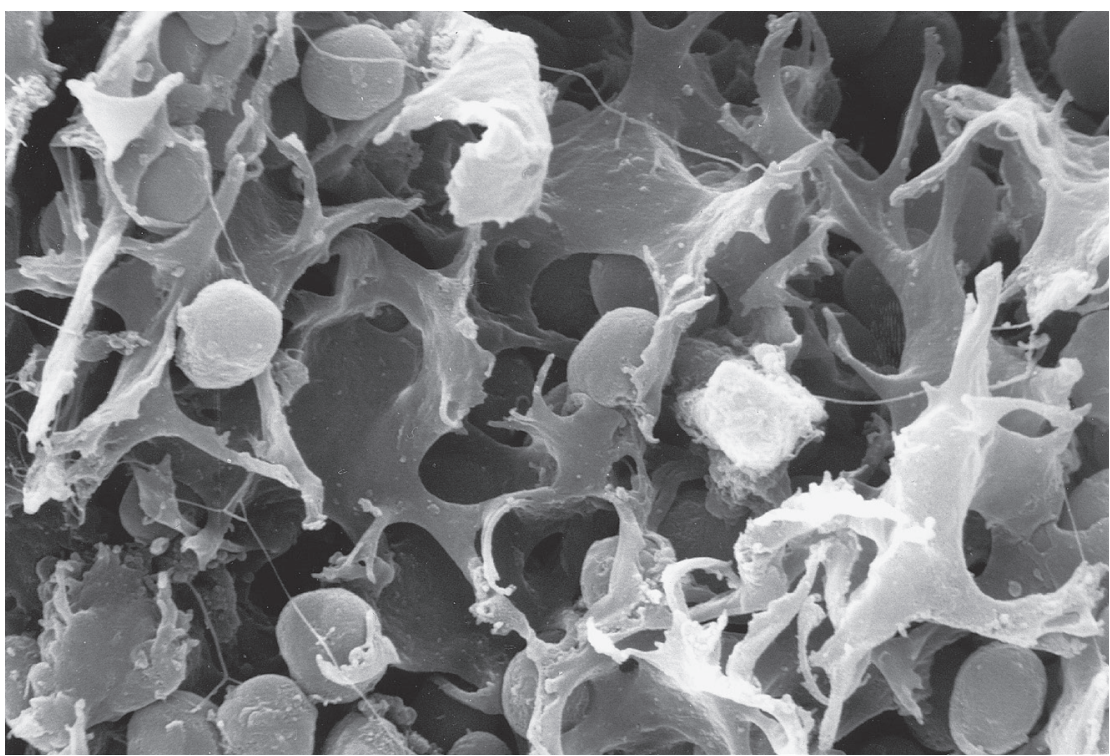

B

Cortico-

Sub-

medullary

capsular

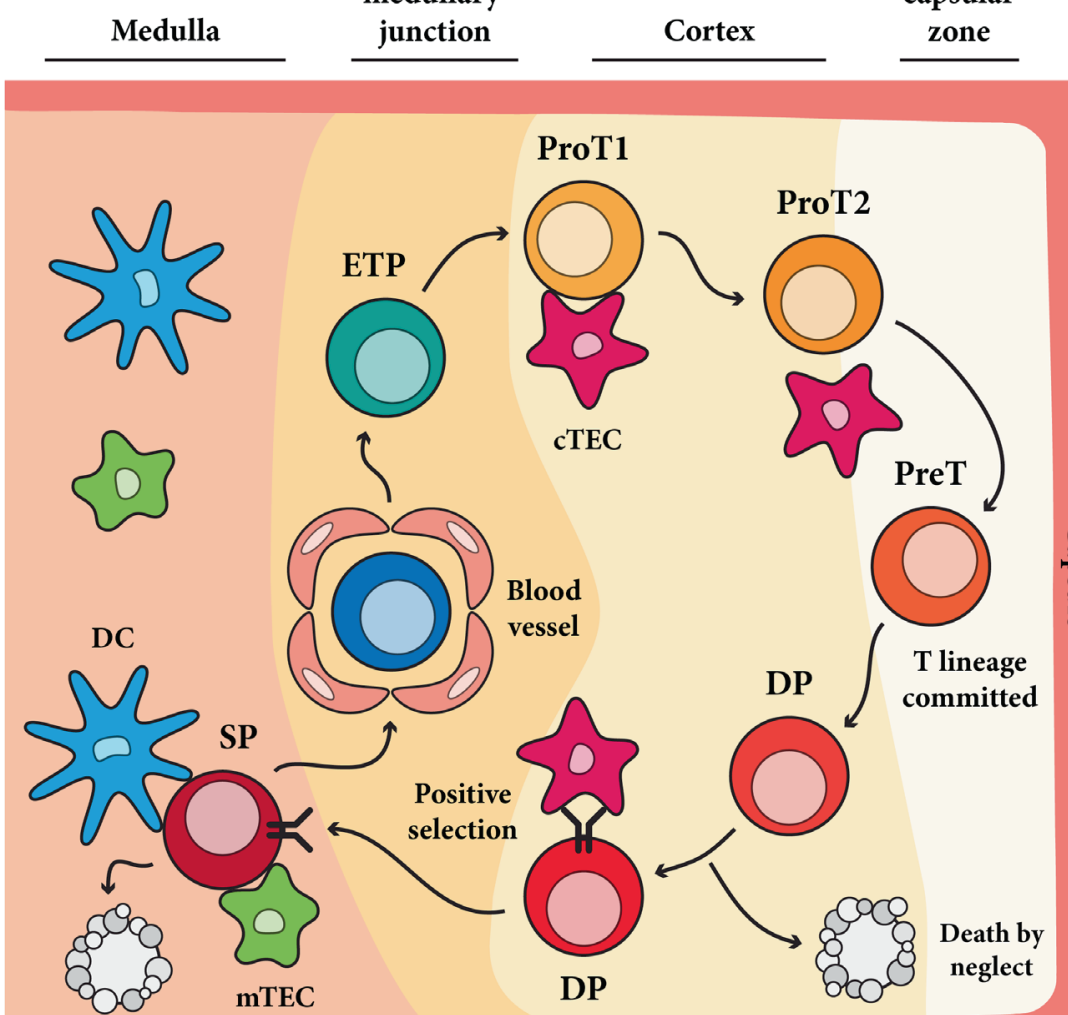

Negative selection 
Figure 3: The thymus. A: Electron microscopic picture of the cortical area of a murine thymus, kindly provided by Prof. dr. Willem van Ewijk. B: Schematic overview of a human thymic microenvironment with migrating and developing thymocytes. Migration of thymocytes (ETP: early thymic progenitor, DP: double positive, SP: single positive) through the defined regions of the thymus, in combination with stroma cell (TECs: thymic epithelial cells, DC: dendritic cell) interaction, is required for proper differentiation to mature $\mathrm{T}$ cells.

\section{Migration of thymocytes to and through the thymus}

Migration of progenitors from the bone marrow to the thymus is required for $\mathrm{T}$ cell development. During murine foetal development, progenitors are derived from the foetal liver. The thymic anlage is initially colonized by T lineage committed progenitor cells ${ }^{63,64}$. These progenitors can be defined by the expression of paired immunoglobulin-like receptors in the foetal blood and liver ${ }^{65}$. In the subsequent murine foetal to neonatal stage, the thymus is colonized by progenitors that retain B and myeloid potential ${ }^{66}$. In contrast, the identity of TSPs in adults is not yet known. Multiple progenitors can contribute to T cell development in vitro and in vivo and are therefore candidate TSPs. Furthermore, thymus settling is a very rare event, which makes the contribution of each population under physiological conditions very difficult to assess ${ }^{66-69}$. Additionally, it has been shown that early progenitors in the murine thymus can sustain T cell development for months when no TSPs enter, suggesting the presence of primitive progenitors with self-renewing capacity ${ }^{70,71}$. TSPs lost their megakaryocyteerythrocyte lineage potential, however, cells are not fully $\mathrm{T}$ lineage restricted ${ }^{72}$.

Both movement through defined thymic regions and interaction with certain cell types are required for thymocyte maturation ${ }^{73}$, as depicted in Figure 3B. Chemokines expressed in the thymic microenvironments have a pivotal role in directing thymocyte migration, while thymocytes on their turn express sequentially different chemokine receptors ${ }^{74}$. Furthermore, integrins in combination with CCR7 and CCR9 are important for thymocyte recruitment to the thymus and thymic settling ${ }^{75}$. When TSPs enter the thymus in the cortical-medullary junction, they first migrate through the cortex to the subcapsular zone before they migrate back to the medulla ${ }^{76}$. Chemokines important in this process are PSGL-1 during thymus entry, CXCR4, CCR7 and CCR9 for migration through the cortex and subcapsular zone,

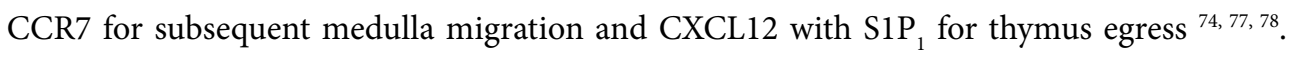
In addition, many other factors like chemokines, integrins, selectins, matrix proteins and metalloproteinases are thought to be involved in this process but their precise role still needs to be elucidated. Further research is also needed with regard to the human translatability of these results, since the majority of these studies are performed in mice. 


\section{Stages of T cell development}

The different stages of $\mathrm{T}$ cell development can be characterized by the expression of surface markers and the rearrangement of $\mathrm{T}$ cell receptor genes (Figure 4).

T cell development can be divided based on the expression of CD4 and CD8, and can be separated into double negative (DN), double positive (DP) and single positive (SP) stages in both mice and men ${ }^{79}$. The earliest DN thymocytes are located in the cortex. Murine DN stages are divided into DN1-4 stages, characterized by their expression of CD25 and CD44 or c-Kit ${ }^{80}$. In humans, these DN stages are subdivided into proT1, proT2 and preT cell stages that can be characterized by the reduction in expression of the HSC marker CD34 and acquisition of CD7, CD5 and CD1a, respectively ${ }^{81-84}$. CD1a expression in the preT cell stage defines $\mathrm{T}$ lineage commitment ${ }^{85}$. DN stages are followed by the expression of CD8 in mice and CD4 in humans (immature SP cells). In the subsequent $\mathrm{CD} 4^{+} \mathrm{CD} 8^{+} \mathrm{DP}$ stage, thymocytes also express CD3 and TCRa ${ }^{81,86,87}$.

During the DP stage, positive selection occurs in the cortex. Low to moderate interaction of TCR with self-peptides-MHC complexes presented on cTECs is essential for thymocyte selection and further maturation to the SP $\mathrm{CD}^{+}$(MHCII restricted) or $\mathrm{CD}^{+}$(MHCI restricted) stage. DP $\mathrm{T}$ cells that fail to interact with $\mathrm{MHC}$ complexes will die by neglect ${ }^{37}$. cTECs use an unique proteasome, $\beta 5 \mathrm{~T}$, to generate self-peptides that are presented in $\mathrm{MHCI}$ and MHCII. Self-reactive lymphocytes are eliminated by negative selection in the medulla ${ }^{88}$. Defects in the medulla result in autoimmunity ${ }^{89}$. Because of promiscuous gene expression, to a large extend mediated by AIRE (autoimmune regulator), mTECs express peripheral tissuespecific self-antigens and present these to thymocytes ${ }^{43,90,91}$. Furthermore, different DC subsets sample blood-borne and mTEC derived self-antigens, all required to induce central tolerance ${ }^{88}$.

Non self-reactive, fully matured naive T cells will exit the thymus and enter the bloodstream to circulate through peripheral lymphoid tissues where they keep scanning DCs to encounter TCR-matching antigens. Upon TCR interaction and CD28 co-stimulation, T cells proliferate in response to autocrine IL-2, differentiate into effector cells and exert their helper, regulatory or cytotoxic function.

Briefly, $\mathrm{CD} 4^{+}$helper T cells activate macrophages at specific tissue sites via cytokine production and help B cells to differentiate into antibody producing plasma cells in the peripheral lymphoid tissues. Furthermore, they produce cytokines stimulating CTL differentiation directly or via APC stimulation. The $\mathrm{CD} 4^{+}$regulatory $\mathrm{T}$ cell subset controls the immune response by for example expression of IL-10, inhibiting macrophage and DC function and TGF- $\beta$, inhibiting macrophage and lymphocyte function. $C D 8^{+}$cytotoxic $\mathrm{T}$ cells eliminate virus-infected and tumour cells via degranulation and activate phagocytes via cytokine 
production. The generation of a memory $\mathrm{T}$ cell pool guarantees rapid responses upon reencounter with the antigen ${ }^{37,92}$.

\section{$T$ cell receptor rearrangement}

Rearrangement of $\mathrm{T}$ cell receptor genes is necessary to generate a $\mathrm{T}$ cell pool that can recognize a broad spectrum of peptides presented on the MHC of other cells. The receptor consists of either an $\alpha$ - and $\beta$-chain or a $\gamma$ and $\delta$-chain, linked by disulfide bonds. Each chain consists of a constant and variable region. The variable domains of TCRA, TCRB, TCRG and TCRD genes are responsible for the recognition of peptide-MHC complexes and are assembled by rearrangement of variable (V), diversity (D) and joining (J) gene segments during $\mathrm{V}(\mathrm{D}) \mathrm{J}$ recombination ${ }^{37}$. In addition to the combinatorial diversity, non-homologous DNA end joining generates additional junctional diversity after cleavage of gene segments. Rearrangement starts during the DN stage and is mediated by recombinant activating gene (RAG) 1 and RAG2 ${ }^{93}$. The rearrangement process starts within the proT1 stage with the TCRD gene followed by TCRG gene, resulting in TCR $\gamma \delta$ expression or further TCRB rearrangement, TCRD deletion and subsequent TCRA rearrangement resulting in TCR $\alpha \beta$ expression. The recombination process starts with $\mathrm{D}$ to J rearrangement followed by $\mathrm{V}$ to $\mathrm{D}-\mathrm{J}$ rearrangement in case of TCRB and TCRD genes. TCRA and TCRG genes undergo directly $\mathrm{V}$ to J rearrangement ${ }^{81}$.

Regarding $\alpha \beta$ T cell formation, completion of TCRB gene rearrangement results in expression of the TCR $\beta$ chain protein on the cell surface in association with an invariant protein, the preTa. Together with CD3 and $\zeta$ it forms the pre-T cell receptor complex that is expressed during the late DN stage. $\beta$ selection, which is mediated through pre-TCR signalling, is important for proliferation, survival and transition to the $\mathrm{CD} 4^{+} \mathrm{CD} 8^{+} \mathrm{DP}$ stage. When TCRA rearrangement is completed in the DP stage, expression of TCR complex consisting of CD3 and $\zeta$ protein and the TCR $\beta \beta$ heterodimers occurs and positive and negative selection are initiated ${ }^{81,94,95}$. 

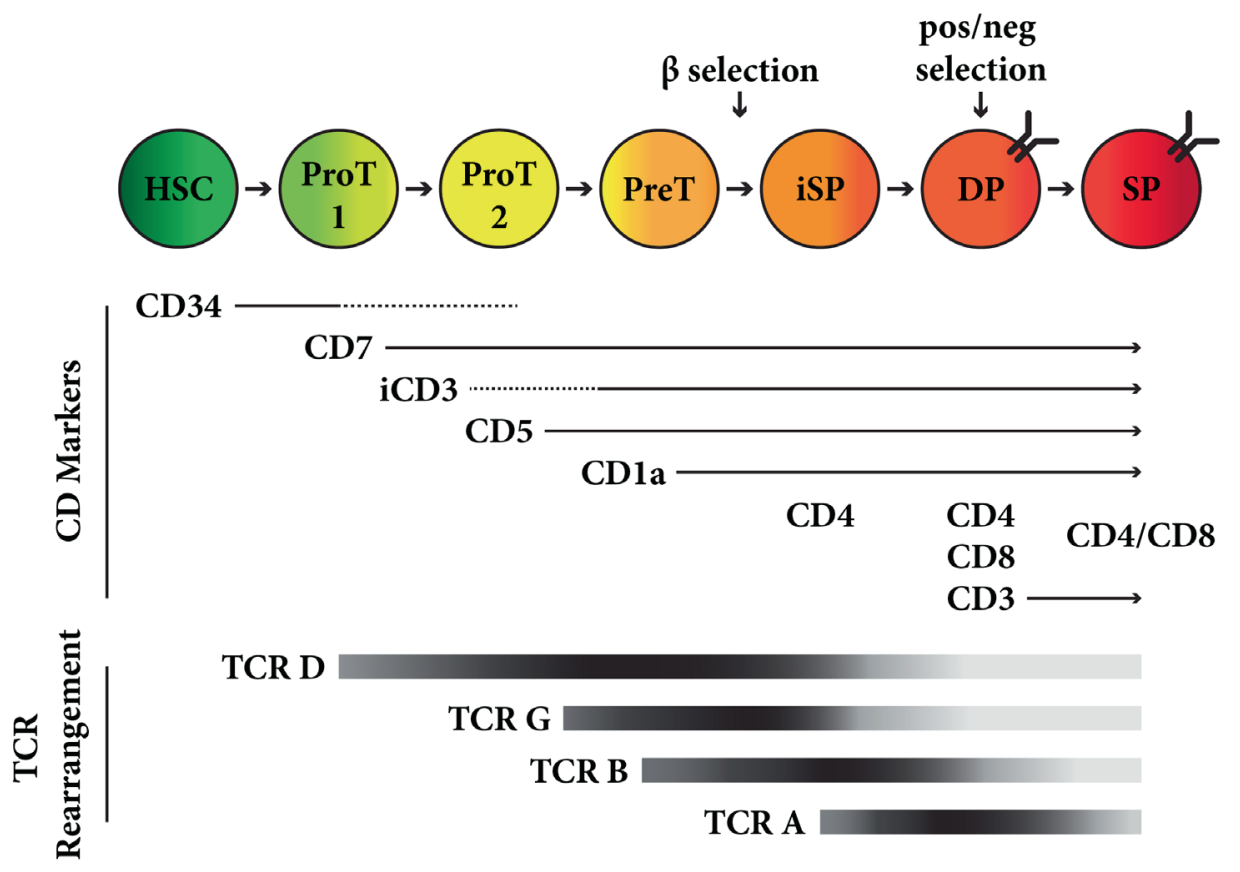

Figure 4: Schematic overview of human $\mathrm{T}$ cell development from $\mathrm{CD}_{4} 4^{+}$stem cells. During $\mathrm{T}$ lineage development several clusters of differentiation (CD) are upregulated, representing different developmental stages. (HSC: haematopoietic stem cell, iSP, immature single positive, DP: double positive, SP: single positive). T cell receptor (TCR) rearrangement is initiated during early development where different TCR genes rearrange at specific stages during development.

\section{Regulation of $\mathrm{T}$ cell development}

Many pathways and transcription factors are involved in $\mathrm{T}$ cell development, from which most are studied in mice. Examples are Notch, GATA3, E-box proteins, Bcl11b, Ikaros and Wnt signalling ${ }^{35,36,96,97}$. Concerning the scope of this thesis, only Notch signalling will be described in further detail.

Crucial for $\mathrm{T}$ cell development is the interaction of the Notch receptor on progenitor cells with Notch ligands provided by the thymic stroma ${ }^{98}$. The evolutionary conserved Notch signalling pathway plays a key role in the fate decision of multipotent precursor cells and differentiation processes during foetal and postnatal development. TECs provide ligands for the Notch receptor that initiate and support T cell maturation ${ }^{99}$. Notch signalling is essential for $\mathrm{T}$ cell development, especially during the T/B lineage decision where Notch 1 induces differentiation towards the $\mathrm{T}$ cell lineage and blocks development towards the $\mathrm{B}$ cell lineage 100, 101. Notch is for example also involved in TCR rearrangement, $\beta$ selection and $\alpha \beta$ or $\gamma \delta$ lineage determination ${ }^{102-104}$. Both Notch ligands Delta-like ligand 1 (DLL1) and DLL4 are 
able to drive $\mathrm{T}$ lineage development in vitro ${ }^{105}$, while in vivo only DLL4 gives the instructive signal to the thymus seeding cells ${ }^{106,107}$. Notch signalling is high before $\beta$ selection and is downregulated as a result of pre-TCR signalling ${ }^{108}$. Especially DP thymocytes have low levels of Notch signalling, probably because positive and negative selection are the main signalling events at this stage ${ }^{98}$.

Notch encodes transmembrane receptors (in mammals Notch1-4) that can be activated by cell surface ligands; Delta (Delta-1, -3 and -4) and Serrate (Jagged-1 and -2). Ligand binding initiates a series of proteolytic cleavages in the transmembrane domain of the receptor. The Notch extracellular domain is proteolytically cleaved by the ADAM metalloprotease TACE (tumour-necrosis factor $\alpha$-converting enzyme) that is endocytosed by the ligand expressing cell ${ }^{109,110}$. A presenilin complex dependent $\gamma$-secretase releases the intracellular domain of the Notch receptor, NICD ${ }^{98}$. NICD subsequently translocates to the nucleus where it interacts with nuclear proteins to activate target genes expression, like hairy enhancer of split (HES), cell cycle proteins and genes for early T lineage commitment; GATA3, IL7Ra, TCF1 and pTa 96,111 .

\section{Cytokines involved in $\mathrm{T}$ cell development}

Cytokines also play an important role in T cell development ${ }^{112}$. The thymic stroma produces a wide range of cytokines, however, only few cytokines are crucial for $\mathrm{T}$ cell development as has been investigated in knock out mice ${ }^{113}$.

IL-7 signalling plays a crucial role in the development, survival and homeostasis of T cells. A variety of cells including thymic and bone marrow stromal cells produce IL- ${ }^{114}$. The IL-7 receptor is a heterodimer consisting of an IL-7 Receptor alpha unit and the common gamma chain (IL2RG). The latter is shared with IL-2, -4, -9, -15 and -21 cytokine receptors. IL-7R on thymocytes increases upon the encounter with Notch1, while the expression gradually decreases towards the DP stage, which is required for $\beta$ selection and T lineage commitment $69,115,116$. However, this decrease is less pronounced in humans ${ }^{117}$. Elimination of IL-7 or IL-7R in mice results in a complete loss of $\mathrm{T}$ and $\mathrm{B}$ cells ${ }^{118,119}$. Moreover, mutations in the IL-7RA cause severe combined immune deficiency (SCID) in humans, characterized by the absence of T cells ${ }^{120}$.

Stem cell factor (SCF) receptor, or c-Kit, is expressed on HSCs and on early DN thymocytes. Mutations in this receptor or its ligand result in severe reduction of HSCs and the earliest DN thymocytes, suggesting a regulatory role for the expansion and differentiation of early thymocytes ${ }^{80,121}$. The role of the cytokine FMS-like tyrosine kinase 3-ligand (Flt3-L) is debatable, since knock-out studies do not show severe abnormalities, however, in vitro cultures show great benefit. Although Flt-3L does not seem crucial for T cell development, it does enhance proliferation of thymocytes ${ }^{122,123}$. 


\section{In vitro $\mathrm{T}$ cell development}

Already in the 1970s, attempts to generate T cells in vitro were performed. In a foetal thymic organ culture (FTOC) using murine foetal thymic lobes, T cell development was studied in a 3D environment ${ }^{124,125}$. Seeded HSCs can develop to fully mature SP T cells in this culture 126. Later, also xenogeneic models using murine thymus lobes, depleted from resident $\mathrm{T}$ cell progenitors with deoxyguanosine, seeded with human HSCs were successfully applied 127. Reaggregate thymus cultures (RTCs) were introduced to study the role of individual thymic stromal components required for $\mathrm{T}$ cell development ${ }^{128}$. For a long time, the organ based cultures were the only cultures that could successfully support $\mathrm{T}$ cell development. Unfortunately, these cultures were very laborious and expensive. Furthermore, removal of thymocytes from the thymic microenvironment resulted in subtle changes in the environment. Moreover, reconstitution of murine lobes with human HSCs remained low. Therefore, many attempts to generate $\mathrm{T}$ cells on stromal cells have been performed.

In mice, foetal liver or bone marrow LKS $\left(\mathrm{Lin}^{-} \mathrm{c}-\mathrm{Kit}^{+} \mathrm{Sca}^{+}\right)$cells are used as haematopoietic stem cell source ${ }^{129}$. In humans, CD34 ${ }^{+}$Lin $^{-}$cells from bone marrow, cord blood or (G-CSF mobilized) peripheral blood are used as haematopoietic stem/progenitor cell sources as both clinical and research source ${ }^{130}$. Different bone marrow derived cell lines, S17, MS5 and the OP-9 cell line generated from macrophage colony-stimulation factor (M-CSF) deficient mice, are able to support haematopoietic differentiation from murine and human HSCs. Especially OP-9 is supportive for the development of B cells because M-CSF is important for myeloid development that is excluded in OP-9 cells ${ }^{131}$. However, neither of these cell lines supported $\mathrm{T}$ lineage development. Unfortunately, thymic stromal cells rapidly lose their ability to support $\mathrm{T}$ cell development in vitro. For example, culturing thymic stomal cells in monolayer culture results in loss of MHC class II expression ${ }^{132}$. The murine thymic fibroblast cell line TSt-4 was also able to support T cell development. However, T lineage development from murine progenitor cells was incomplete as only $\mathrm{CD}^{+} \mathrm{SP}$ cells developed while other lineage cells developed as well ${ }^{133}$. In the meantime, several studies showed the importance of Notch signalling for T cell development ${ }^{100,101}$. After confirmation of the presence of the Notch ligand in the thymus, several previously tested cell lines were genetically modified to express Notch ligands. Jaleco and colleagues developed the S17/DL-1 cells. In combination with human CD34+ HSCs, T/NK progenitors and low numbers of DP cells developed ${ }^{134}$. Coculture of human G-CSF mobilized and CB HSCs with TSt-4 cells expressing DLL1 or DLL4 resulted in a mixture of early DN progenitors ${ }^{83,135}$. In this culture, only murine DP but no human DP or SP cells could be generated. After introduction of DL1 in the OP-9 cell line, T lineage development from murine foetal liver and bone marrow stem cells could be supported to the SP stage ${ }^{136}$. This system has also shown to support the full range of T cell development from human HSCs to $\mathrm{CD}^{+}$and $\mathrm{CD}^{+} \mathrm{SP} \alpha \beta$ T cells ${ }^{137-139}$. Knowing that DLL4 is the natural ligand in the thymus, also OP-9/DL4 cells were generated. In Delta ligand over-expressing cocultures, both ligands are efficient. However, limited expression levels of both ligands revealed 
that DLL4 is still efficient in inducing T cell development at low levels in contrast to DLL1 ${ }^{140}$. Importantly, not all stromal cells genetically engineered to express DLLs are capable of supporting T lineage development ${ }^{141}$.

To study the essentials required for $\mathrm{T}$ cell development and to produce $\mathrm{T}$ cells suitable for therapy, efforts have been made to generate $\mathrm{T}$ cell progenitors in vitro without the use of (genetically modified) feeder cells. First attempts to induce Notch signalling with soluble DLL were unsuccessful. Only when the extracellular domains of the DLL were fused to the Fcfragment of human IgG and were plate-bound offered to HSCs, proper Notch signalling was induced ${ }^{142}$. These stromal-free cultures in the presence of cytokine cocktails resulted in the development of both murine DN2 and human proT1 T cells ${ }^{143-146}$. These human progenitor populations are capable of $\mathrm{CD}^{+} \mathrm{T}$ cell reconstitution in the thymi of immunodeficient mice 145, 146. The addition of Wnt3a to the human culture resulted in more cells expressing CD7 and iCD3, but not further development ${ }^{147}$. By reducing IL-7 concentration in the murine stromalfree DLL culture, Ikawa and colleagues were able to generate murine DP cells ${ }^{115}$. Also by the addition of the CXCL4 ligand CXCL12 in the murine DLL4 culture, DP cells were generated ${ }^{148}$. Fernandez et al. showed that CB HSCs cultured with immobilized DLL1, MHC-tetramers, anti-CD28, anti-CD3 and OP-9/DL1 conditioned medium resulted in the generation of a small population of antigen specific cytotoxic CD ${ }^{+}$cells ${ }^{149}$. However, feeder based cultures are more efficient in supporting $\mathrm{T}$ cell development, arguing that not all crucial factors for proper $\mathrm{T}$ lineage development have been identified.

\section{Lineage potential of $\mathrm{T}$ cell progenitors}

Lineage potential of early $\mathrm{T}$ cell progenitors is well studied in mice, while human data is limited available. TSPs retain besides T lineage potential also myeloid, B and NK cell potential. After bifurcation of the $\mathrm{B}$ and $\mathrm{T}$ cell lineage ${ }^{150}$, both populations still possess myeloid potential also when cells already entered the thymus ${ }^{72}$. The thymocytes retain besides myeloid (macrophage and dendritic cell) potential also NK cell potential ${ }^{72}$. Within the DN2 stage, $\mathrm{T}$ lineage commitment occurs at the transition from DN2mt (Myeloid-T cell) to DN2t (T cell) marked by Bcl11b expression ${ }^{72,96,115}$. Also in humans it is known that after Notch signalling, B cell potential of CD $34^{+} \mathrm{HSC}$ is shut off, while at least NK cell potential is still present ${ }^{151}$. Previously, we showed that a mixed population of early $\mathrm{T}$ cell progenitors retained NK cell potential, however, it was unsure from which population these cells developed ${ }^{83}$. Weerkamp and colleagues determined the lineage potential of $\mathrm{CD} 34^{+} \mathrm{CD} 1 \mathrm{a}^{-}$and $\mathrm{CD} 34^{+} \mathrm{CD} 1 \mathrm{a}^{+}$progenitor $\mathrm{T}$ cells and showed $\mathrm{T}$ lineage commitment of the $\mathrm{CD} 1 \mathrm{a}^{+}$population, while the $\mathrm{CD} 1 \mathrm{a}^{-}$cells where besides T cells able to differentiate to B cells, NK cells and myeloid cells ${ }^{85}$. Unfortunately, this CD1a population was not further separated for example based on CD7 or CD5 expression. 


\section{Natural killer cells}

Besides B and T cells, NK cells are the most prominent lymphocyte subset covering up to $20 \%$ of the blood lymphocyte population. NK cells are group 1 innate lymphoid cells that can exert rapid effector functions without direct prior sensitization to infected, malignant cells, and MHC mismatched grafts ${ }^{152}$. NK cells have a broad repertoire of activating and inhibitory receptors, where the balance of these receptors results in cytokine, chemokine production and/or cytotoxicity. In humans, NK cells are defined as CD56 ${ }^{+}$and CD3 . In blood, two major NK cell populations exist, CD56 ${ }^{\mathrm{dim}}$ and $\mathrm{CD} 56^{\text {bright }}$ cells ${ }^{153}$. The bright population represents $10 \%$ of the circulating NK cells that have regulatory functions by the production of cytokines like IFN- $\gamma$, TNF $\alpha$ and GM-CSF, while the dim population ( $90 \%)$ has enhanced cytotoxicity capacity marked by high intracellular perforin levels and high expression of the low affinity FC receptor III allowing them to mediate antibody-dependent cell-mediated cytotoxicity $(\mathrm{ADCC})^{154}$.

The bone marrow is considered as the major site of NK cell development, subsequently there is further differentiation in secondary lymphoid tissues like the liver, spleen, lymph nodes and thymus ${ }^{154}$. Different NK cell stages are described in literature but the complete pathway has not yet been described ${ }^{155}$. Education during NK cell development is important, resulting in mature NK cells that are fully functional ("licensed to kill") and are tolerant to self. This means that the NK cells require encounter with a MHC class I ligand before it can become activated because of the absence of that specific ligand ${ }^{156}$.

NK cell activation is dependent on both receptors/ligands expressed by the potential target cell and the NK cell itself (Figure 5). NK cells recognize the absence of self MHC class I to discriminate between normal and stressed cells (e.g. tumour cells), called "missing self" 157. In the normal situation, NK cell activation is inhibited by the interaction of killer immunoglobulin-like receptors (KIRs) that interact with MHC class I. Each NK cell expresses a different combination of inhibitory and activating receptors so that at least one inhibitory KIR specific for a self MHC class I is present. Additionally, NK cells express receptors that are specific for other ligands on target cells. A mechanism called "stress-induced self recognition" is exerted when target cells express activating ligands that can overcome inhibitory signals ${ }^{158}$, 159 . 


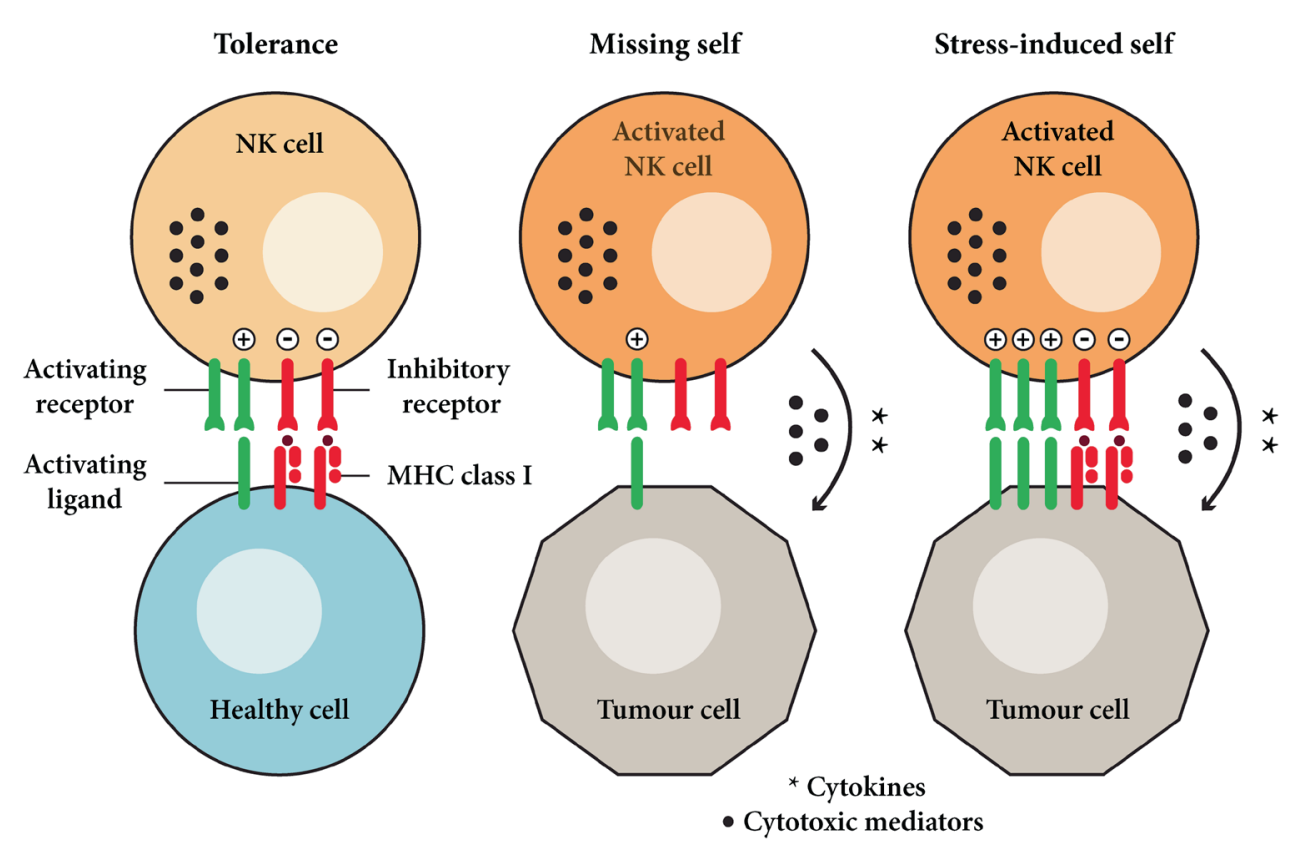

Figure 5: Natural killer cell tolerance and activation. Natural killer (NK) cell tolerance is achieved when there is a balance between activating signals and inhibitory signals provided by healthy cells in favour of inhibition. Missing self NK activation is induced when tumour cells lost expression of MHC class I molecules. Stressed-induced self NK cell activation is induced when stressed cells (e.g. tumour or virus infected cells) upregulate activating ligands. Upon NK cell activation, NK cells produce cytotoxic mediators for immediate cytotoxicity or cytokines for indirect elimination.

\section{Natural killer cell therapy}

Adoptive transfer of NK cells is a promising approach to induce anti-tumour responses and is currently under extensive investigation. Pre-clinical and clinical studies have shown that NK cells can be used to eliminate malignant cells ${ }^{160}$. As source, autologous and allogeneic NK cells are used, and cells from both sources are able to effectively eliminate cancer cells in vitro ${ }^{161,162}$. Allogeneic NK cell transfer could lead to higher tumour cytotoxicity because of KIR-ligand mismatching, which lowers the activation threshold of NK cells. Ruggeri and colleagues first demonstrated the potential of allogeneic KIR-ligand mismatched NK cells in the HLA mismatched transplantation setting where patients receiving haplo-identical transplants enabling KIR-ligand incompatibility resulted in improved survival as compared to patients receiving KIR-ligand matched transplants ${ }^{25}$. In addition, NK cells could also kill patient's APCs, leading to reduced activation of the alloreactive donor T cells and thereby reducing GVHD ${ }^{163}$. Besides effects seen in haematological cancers, NK cells are also able to respond to solid tumours as shown in both a mouse model and in patients ${ }^{164,165}$. Although clinical studies show that administration of alloreactive NK cells is safe, the efficacy of in vivo 
responses are limited, providing room for improvement ${ }^{160,162,165,166}$. Major aims of current research are the production of sufficient NK cell numbers with the correct phenotype for therapy. The latter is important since we showed in multiple myeloma and in breast cancer that KIR-ligand mismatched NK cells are much more efficient in eliminating tumour cells than matched NK cells ${ }^{164,167}$.

\section{T cell reconstitution after haematopoietic stem cell transplantation}

T cell reconstitution after HSCT can occur via thymus dependent and thymus independent mechanisms. The thymus independent reconstitution occurs via homeostatic peripheral expansion (HPE) of mature T cells that survived treatment regimen or expansion of mature $\mathrm{T}$ cells from the graft. Though, the $\mathrm{T}$ cell repertoire of this population is limited. Furthermore, the high expansion induced by relative high homeostatic cytokine levels (because of low $\mathrm{T}$ cell counts) and recognition of endogenous antigens results in a high number of apoptotic cells ${ }^{168}$. The HPE can provide some initial immune competence, but is insufficient for broad range and long term protection ${ }^{169}$.

Only de novo thymus dependent $\mathrm{T}$ cell generation can result in a naive $\mathrm{T}$ cell pool with a broad TCR repertoire. Unfortunately, delivery of progenitors to the thymus limits T lineage reconstitution after transplantation ${ }^{170}$. Furthermore, the thymus structure is influenced by treatment regimen and GVHD ${ }^{171}$. Moreover, thymic involution is accompanied by a decreased thymus size and function resulting in slower recovery after treatment, especially in older patients. The generation of naive T cells from the thymus requires 6-12 months in child patients and may take up to several years in adult patients ${ }^{172,173}$.

\section{Adoptive $\mathrm{T}$ cell progenitor therapy}

Both the generation of thymic seeding progenitors and thymus entry are known to be limiting steps for thymus dependent T cell reconstitution after HSCT ${ }^{170}$. Because of the low frequency and incomplete characterization of these TSPs, simple donor isolation and transfer is not possible ${ }^{69}$. Therefore, the generation of $\mathrm{T}$ cell progenitors from HSCs is currently under investigation as a strategy to improve T cell counts after HSCT. As described above, different culture methods are currently available for the production of T cell (progenitors) in a feederbased setting. In vivo immune reconstitution experiments with TSt-4/DLL derived T/NK progenitor cells from mobilized and CB derived proT cells from OP-9/DL1 co-cultures showed that these stroma culture derived progenitors home to the thymi of immune deficient mice and complete their development into mature $\mathrm{T}$ cells faster than non-manipulated stem cells ${ }^{83,86,87}$. Additionally, Eyrich et al. detected extrathymic mature T cells in mice after injection of $\mathrm{T}$ cell progenitors derived from OP-9/DL1 co-culture ${ }^{174}$. Moreover, injection of human $\mathrm{CB}$ derived $\mathrm{T}$ cell progenitors can restore thymus architecture in immune deficient 
mice ${ }^{87}$. Currently, the generation of a clinical applicable culture system is under investigation. Expansion of $\mathrm{CB}$ CD34+ cells in the presence of immobilized DLL1 or DLL4 and cytokines resulted in the development of a $\mathrm{CD} 34^{+} \mathrm{CD}^{+}$lymphoid progenitor population capable of $\mathrm{CD}^{+} \mathrm{T}$ cell reconstitution in the thymi of immune deficient mice ${ }^{145,146}$. T cells were also observed in the spleen and peripheral blood in a subgroup of the injected mice ${ }^{146}$. Moreover, a phase I clinical study with the transfer of CB CD $34^{+}$DLL1 culture derived progenitors showed enhanced engraftment and myeloid reconstitution ${ }^{175}$. However, the lack of improvement in $\mathrm{T}$ cell reconstitution in these patients indicates the need for more efficient methods for in vitro generation of $\mathrm{T}$ cell progenitors for adoptive therapy. 


\section{Scope of the thesis}

The field of immunotherapy is a growing area of interest, where both fundamental and translational research is performed. Although great progress has already been made, there is still an urgent need for improvement since current cellular immunotherapies are only effective in certain patient populations and many therapies are still in pre-clinical stages. Furthermore, the success of certain immunotherapies like allogeneic mismatched HSCT that can result in complete remission is hampered by post-treatment complications, in this case immune deficiency resulting in high morbidity and mortality.

The major aim of this thesis is the development of a clinical grade $\mathrm{T}$ cell progenitor therapy suitable for the adoptive transfer to immunocompromised patients after haematopoietic stem cell transplantation. Currently, research protocols are being optimized by searching for factors that are required for $\mathrm{T}$ cell development and factors that accelerate this development. Moreover, an increase in cell expansion is of high interest because great cell numbers are required for therapy. Hereafter, these protocols need to be translated into clinical protocols and clinical trials have to assess the feasibility of this suggested therapy.

As described previously, $\mathrm{T}$ cells require in vivo the microenvironment of the thymus to fully mature. We initiated this research with a fundamental study of the thymus to elucidate the role of mesenchymal network development in the thymus in chapter 2. Moreover, insight in thymus formation could contribute to the development of thymus rejuvenation therapies for patients with an involuted thymus, resulting in better thymopoiesis. In combination with $\mathrm{T}$ cell progenitor therapy, this could result in higher thymic output and faster recovery of patient's $\mathrm{T}$ cell levels. A major challenge of various immunotherapies is the generation of sufficient cell numbers required for treatment. There are different methods to achieve this, for example the expansion of the cells of interest or the expansion of haematopoietic stem/progenitor cells to use as starting population for the generation of specialized immunotherapy products. Here, we aimed to develop a method to expand stem cells by blocking their differentiation in chapter 3 . Hereafter, we focused on the production of specialized cell types suitable for immunotherapy. In chapter 4, we evaluated a skin explant system as surrogate thymus to produce $\mathrm{T}$ cells suitable for adoptive therapy. We continued with creating a more straightforward clinical grade culture method for the generation of $\mathrm{T}$ cell progenitors in chapter 5 . In this system we used immobilized DLL4 to induce Notch signalling, previously provided by feeder cells, generating a more controllable system suitable for the generation of $\mathrm{T}$ cell progenitors applicable for therapy. In this culture, we found vitamin C, also known as ascorbic acid (AA), as a potent enhancer of $\mathrm{T}$ cell development. Furthermore, vitamin $\mathrm{C}$ enhances expansion of $\mathrm{T}$ cell progenitors within this culture. Current pitfalls of NK cell therapy are the generation of insufficient cell numbers in combination with anti-cancer activity of only certain NK cell populations. Because T and NK cells share a common precursor, we assessed the effect of 
vitamin $\mathrm{C}$ on the generation of NK cells suitable for anti-cancer immunotherapy in chapter 6. Because of the potent effect of vitamin $\mathrm{C}$ on both $\mathrm{T}$ cell and $\mathrm{NK}$ cell development and expansions, we determined vitamin $\mathrm{C}$ levels in haematological oncology patients in chapter 7, anticipating on a potential clinical benefit resulting from vitamin $\mathrm{C}$ supplementation. In chapter 8, the impact of our findings in relation to other strategies to enhance $\mathrm{T}$ cell reconstitution in patients after HSCT is discussed. 


\section{References}

1. Bray F, Jemal A, Grey N, Ferlay J, Forman D. Global cancer transitions according to the Human Development Index (2008-2030): a population-based study. Lancet Oncol. 2012 Aug;13(8):790-801.

2. Umar A, Dunn BK, Greenwald P. Future directions in cancer prevention. Nat Rev Cancer. 2012 Dec;12(12):835-48.

3. Vineis P, Wild CP. Global cancer patterns: causes and prevention. Lancet. 2014 Feb 8;383(9916):549-57.

4. Siegel R, DeSantis C, Virgo K, Stein K, Mariotto A, Smith T, et al. Cancer treatment and survivorship statistics, 2012. CA Cancer J Clin. 2012 Jul-Aug;62(4):220-41.

5. GLOBOCAN I. Section of Cancer Surveillance. 2014 [cited 2014 August] available from:

6. Leget GA, Czuczman MS. Use of rituximab, the new FDA-approved antibody. Curr Opin Oncol. 1998 Nov;10(6):548-51.

7. Hodi FS. Overcoming immunological tolerance to melanoma: Targeting CTLA-4. Asia Pac J Clin Oncol. 2010 Mar;6 Suppl 1:S16-23.

8. Tosti G, Cocorocchio E, Pennacchioli E. Anti-cytotoxic T lymphocyte antigen-4 antibodies in melanoma. Clin Cosmet Investig Dermatol. 2013;6:245-56.

9. Kantoff PW, Higano CS, Shore ND, Berger ER, Small EJ, Penson DF, et al. Sipuleucel-T immunotherapy for castration-resistant prostate cancer. N Engl J Med. 2010 Jul 29;363(5):411-22.

10. Raval RR, Sharabi AB, Walker AJ, Drake CG, Sharma P. Tumor immunology and cancer immunotherapy: summary of the 2013 SITC primer. J Immunother Cancer. 2014;2:14.

11. Kono K. Current status of cancer immunotherapy. J Stem Cells Regen Med. 2014;10(1):813.

12. Kirkwood JM, Butterfield LH, Tarhini AA, Zarour H, Kalinski P, Ferrone S. Immunotherapy of cancer in 2012. CA Cancer J Clin. 2012 Sep-Oct;62(5):309-35.

13. Rowe JM, Tallman MS. How I treat acute myeloid leukaemia. Blood. 2010 Oct 28;116(17):3147-56.

14. Copelan EA. Hematopoietic stem-cell transplantation. N Engl J Med. 2006 Apr 27;354(17):1813-26.

15. Oevermann L, Lang P, Feuchtinger T, Schumm M, Teltschik HM, Schlegel P, et al. Immune reconstitution and strategies for rebuilding the immune system after haploidentical stem cell transplantation. Ann N Y Acad Sci. 2012 Aug;1266:161-70.

16. Beatty PG, Mori M, Milford E. Impact of racial genetic polymorphism on the probability of finding an HLA-matched donor. Transplantation. 1995 Oct 27;60(8):778-83.

17. Tiercy JM. Unrelated hematopoietic stem cell donor matching probability and search algorithm. Bone Marrow Res. 2012;2012:695018.

18. Solh M. Haploidentical vs cord blood transplantation for adults with acute myelogenous 
leukemia. World journal of stem cells. 2014 Sep 26;6(4):371-9.

19. Ruggeri A, Peffault de Latour R, Carmagnat M, Clave E, Douay C, Larghero J, et al. Outcomes, infections, and immune reconstitution after double cord blood transplantation in patients with high-risk hematological diseases. Transpl Infect Dis. 2011 Oct;13(5):456-65.

20. Barker JN. Umbilical Cord Blood (UCB) transplantation: an alternative to the use of unrelated volunteer donors? Hematology Am Soc Hematol Educ Program. 2007:55-61.

21. Anasetti C, Beatty PG, Storb R, Martin PJ, Mori M, Sanders JE, et al. Effect of HLA incompatibility on graft-versus-host disease, relapse, and survival after marrow transplantation for patients with leukaemia or lymphoma. Hum Immunol. 1990 Oct;29(2):79-91.

22. Aversa F, Terenzi A, Tabilio A, Falzetti F, Carotti A, Ballanti S, et al. Full haplotypemismatched hematopoietic stem-cell transplantation: a phase II study in patients with acute leukaemia at high risk of relapse. J Clin Oncol. 2005 May 20;23(15):3447-54.

23. Bertaina A, Merli P, Rutella S, Pagliara D, Bernardo ME, Masetti R, et al. HLA-haploidentical stem cell transplantation after removal of alphabeta+ $T$ and $B$ cells in children with nonmalignant disorders. Blood. 2014 Jul 31;124(5):822-6.

24. Locatelli F, Bauquet A, Palumbo G, Moretta F, Bertaina A. Negative depletion of alpha/beta+ $T$ cells and of CD19+ B lymphocytes: a novel frontier to optimize the effect of innate immunity in HLA-mismatched hematopoietic stem cell transplantation. Immunology letters. 2013 Sep-Oct;155(1-2):21-3.

25. Ruggeri L, Capanni M, Mancusi A, Aversa F, Martelli MF, Velardi A. Natural killer cells as a therapeutic tool in mismatched transplantation. Best Pract Res Clin Haematol. 2004 Sep;17(3):427-38.

26. Bosch $\mathrm{M}$, Khan FM, Storek J. Immune reconstitution after hematopoietic cell transplantation. Curr Opin Hematol. 2012 Jul;19(4):324-35.

27. Hauri-Hohl MM, Keller MP, Gill J, Hafen K, Pachlatko E, Boulay T, et al. Donor T-cell alloreactivity against host thymic epithelium limits $\mathrm{T}$-cell development after bone marrow transplantation. Blood. 2007 May 1;109(9):4080-8.

28. Szabolcs P, Niedzwiecki D. Immune reconstitution after unrelated cord blood transplantation. Cytotherapy. 2007;9(2):111-22.

29. Danby R, Rocha V. Improving engraftment and immune reconstitution in umbilical cord blood transplantation. Front Immunol. 2014;5:68.

30. Storek J, Gooley T, Witherspoon RP, Sullivan KM, Storb R. Infectious morbidity in longterm survivors of allogeneic marrow transplantation is associated with low CD4 $\mathrm{T}$ cell counts. Am J Hematol. 1997 Feb;54(2):131-8.

31. Wils EJ, van der Holt B, Broers AE, Posthumus-van Sluijs SJ, Gratama JW, Braakman E, et al. Insufficient recovery of thymopoiesis predicts for opportunistic infections in allogeneic hematopoietic stem cell transplant recipients. Haematologica. 2011 Dec;96(12):1846-54.

32. Clave E, Lisini D, Douay C, Giorgiani G, Busson M, Zecca M, et al. A low thymic function is associated with leukaemia relapse in children given T-cell-depleted HLA-haploidentical 
stem cell transplantation. Leukaemia. 2012 Aug;26(8):1886-8.

33. Kawamoto $\mathrm{H}$, Katsura $\mathrm{Y}$. A new paradigm for hematopoietic cell lineages: revision of the classical concept of the myeloid-lymphoid dichotomy. Trends Immunol. 2009 May;30(5):193-200.

34. Kawamoto H, Ikawa T, Masuda K, Wada H, Katsura Y. A map for lineage restriction of progenitors during hematopoiesis: the essence of the myeloid-based model. Immunol Rev. 2010 Nov;238(1):23-36.

35. Ikawa T. Genetic and Epigenetic Control of Early Lymphocyte Development. Curr Top Microbiol Immunol. 2014 May 22.

36. Rothenberg EV. The chromatin landscape and transcription factors in $\mathrm{T}$ cell programming. Trends Immunol. 2014 May;35(5):195-204.

37. Abbas AK, Lichtman AH, Pillai S. Cellular and molecular immunology: Saunders Elsevier, 2007.

38. Ciofani M, Zuniga-Pflucker JC. Determining gammadelta versus alphass $\mathbf{T}$ cell development. Nat Rev Immunol. 2010 Sep;10(9):657-63.

39. Lanzavecchia A, Sallusto F. Dynamics of T lymphocyte responses: intermediates, effectors, and memory cells. Science. 2000 Oct 6;290(5489):92-7.

40. Zuniga-Pflucker JC. T-cell development made simple. Nat Rev Immunol. 2004 Jan;4(1):6772.

41. Manley NR, Blackburn CC. A developmental look at thymus organogenesis: where do the non-hematopoietic cells in the thymus come from? Curr Opin Immunol. 2003 Apr;15(2):225-32.

42. Rodewald HR. Thymus organogenesis. Annu Rev Immunol. 2008;26:355-88.

43. Anderson G, Jenkinson EJ. Lymphostromal interactions in thymic development and function. Nat Rev Immunol. 2001 Oct;1(1):31-40.

44. Sun L, Li H, Luo H, Zhao Y. Thymic epithelial cell development and its dysfunction in human diseases. Biomed Res Int. 2014;2014:206929.

45. Germeraad WT, Kawamoto H, Itoi M, Jiang Y, Amagai T, Katsura Y, et al. Development of thymic microenvironments in vitro is oxygen-dependent and requires permanent presence of T-cell progenitors. J Histochem Cytochem. 2003 Sep;51(9):1225-35.

46. Hollander GA, Wang B, Nichogiannopoulou A, Platenburg PP, van Ewijk W, Burakoff SJ, et al. Developmental control point in induction of thymic cortex regulated by a subpopulation of prothymocytes. Nature. 1995 Jan 26;373(6512):350-3.

47. van Ewijk W, Hollander G, Terhorst C, Wang B. Stepwise development of thymic microenvironments in vivo is regulated by thymocyte subsets. Development. 2000 Apr;127(8):1583-91.

48. van Ewijk W, Shores EW, Singer A. Crosstalk in the mouse thymus. Immunol Today. 1994 May;15(5):214-7.

49. van Ewijk W, Wang B, Hollander G, Kawamoto H, Spanopoulou E, Itoi M, et al. Thymic microenvironments, 3-D versus 2-D? Semin Immunol. 1999 Feb;11(1):57-64. 
50. Vroegindeweij E, Crobach S, Itoi M, Satoh R, Zuklys S, Happe C, et al. Thymic cysts originate from Foxn1 positive thymic medullary epithelium. Mol Immunol. 2010 Feb;47(5):1106-13.

51. Anderson G, Takahama Y. Thymic epithelial cells: working class heroes for $\mathbf{T}$ cell development and repertoire selection. Trends Immunol. 2012 Jun;33(6):256-63.

52. Itoi $\mathrm{M}$, Amagai $\mathrm{T}$. Inductive role of fibroblastic cell lines in development of the mouse thymus anlage in organ culture. Cell Immunol. 1998 Jan 10;183(1):32-41.

53. Itoi $\mathrm{M}$, Tsukamoto $\mathrm{N}$, Yoshida $\mathrm{H}$, Amagai $\mathrm{T}$. Mesenchymal cells are required for functional development of thymic epithelial cells. Int Immunol. 2007 Aug;19(8):953-64.

54. Shinohara T, Honjo T. Epidermal growth factor can replace thymic mesenchyme in induction of embryonic thymus morphogenesis in vitro. Eur J Immunol. 1996 Apr;26(4):747-52.

55. Jenkinson WE, Jenkinson EJ, Anderson G. Differential requirement for mesenchyme in the proliferation and maturation of thymic epithelial progenitors. J Exp Med. $2003 \mathrm{Jul}$ 21;198(2):325-32.

56. Banwell CM, Partington KM, Jenkinson EJ, Anderson G. Studies on the role of IL-7 presentation by mesenchymal fibroblasts during early thymocyte development. Eur J Immunol. 2000 Aug;30(8):2125-9.

57. Anderson G, Anderson KL, Tchilian EZ, Owen JJ, Jenkinson EJ. Fibroblast dependency during early thymocyte development maps to the CD25+ CD44+ stage and involves interactions with fibroblast matrix molecules. Eur J Immunol. 1997 May;27(5):1200-6.

58. Palmer DB. The effect of age on thymic function. Front Immunol. 2013;4:316.

59. Chinn IK, Blackburn CC, Manley NR, Sempowski GD. Changes in primary lymphoid organs with aging. Semin Immunol. 2012 Oct;24(5):309-20.

60. Ventevogel MS, Sempowski GD. Thymic rejuvenation and aging. Curr Opin Immunol. 2013 Aug;25(4):516-22.

61. Fujimoto S, Yamagishi H. Isolation of an excision product of T-cell receptor alpha-chain gene rearrangements. Nature. 1987 May 21-27;327(6119):242-3.

62. Lynch HE, Goldberg GL, Chidgey A, Van den Brink MR, Boyd R, Sempowski GD. Thymic involution and immune reconstitution. Trends Immunol. 2009 Jul;30(7):366-73.

63. Harman BC, Jenkinson WE, Parnell SM, Rossi SW, Jenkinson EJ, Anderson G. T/B lineage choice occurs prior to intrathymic Notch signaling. Blood. 2005 Aug 1;106(3):886-92.

64. Masuda K, Itoi M, Amagai T, Minato N, Katsura Y, Kawamoto H. Thymic anlage is colonized by progenitors restricted to T, NK, and dendritic cell lineages. J Immunol. 2005 Mar 1;174(5):2525-32.

65. Masuda K, Kubagawa H, Ikawa T, Chen CC, Kakugawa K, Hattori M, et al. Prethymic T-cell development defined by the expression of paired immunoglobulin-like receptors. Embo J. 2005 Dec 7;24(23):4052-60.

66. Luc S, Luis TC, Boukarabila H, Macaulay IC, Buza-Vidas N, Bouriez-Jones T, et al. The earliest thymic T cell progenitors sustain B cell and myeloid lineage potential. Nat Immunol. 2012 Apr;13(4):412-9.

67. Benz C, Martins VC, Radtke F, Bleul CC. The stream of precursors that colonizes the thymus 
proceeds selectively through the early $\mathrm{T}$ lineage precursor stage of $\mathrm{T}$ cell development. J Exp Med. 2008 May 12;205(5):1187-99.

68. Haddad R, Guimiot F, Six E, Jourquin F, Setterblad N, Kahn E, et al. Dynamics of thymuscolonizing cells during human development. Immunity. 2006 Feb;24(2):217-30.

69. Six EM, Bonhomme D, Monteiro M, Beldjord K, Jurkowska M, Cordier-Garcia C, et al. A human postnatal lymphoid progenitor capable of circulating and seeding the thymus. $\mathrm{J}$ Exp Med. 2007 Dec 24;204(13):3085-93.

70. Martins VC, Ruggiero E, Schlenner SM, Madan V, Schmidt M, Fink PJ, et al. Thymusautonomous $\mathrm{T}$ cell development in the absence of progenitor import. J Exp Med. $2012 \mathrm{Jul}$ 30;209(8):1409-17.

71. Peaudecerf L, Lemos S, Galgano A, Krenn G, Vasseur F, Di Santo JP, et al. Thymocytes may persist and differentiate without any input from bone marrow progenitors. J Exp Med. 2012 Jul 30;209(8):1401-8.

72. Wada H, Masuda K, Satoh R, Kakugawa K, Ikawa T, Katsura Y, et al. Adult T-cell progenitors retain myeloid potential. Nature. 2008 Apr 10;452(7188):768-72.

73. Hayday AC, Pennington DJ. Key factors in the organized chaos of early T cell development. Nat Immunol. 2007 Feb;8(2):137-44.

74. Takahama Y. Journey through the thymus: stromal guides for T-cell development and selection. Nat Rev Immunol. 2006 Feb;6(2):127-35.

75. Zlotoff DA, Bhandoola A. Hematopoietic progenitor migration to the adult thymus. Ann N Y Acad Sci. 2011 Jan;1217:122-38.

76. Petrie HT, Zuniga-Pflucker JC. Zoned out: functional mapping of stromal signaling microenvironments in the thymus. Annu Rev Immunol. 2007;25:649-79.

77. Matloubian M, Lo CG, Cinamon G, Lesneski MJ, Xu Y, Brinkmann V, et al. Lymphocyte egress from thymus and peripheral lymphoid organs is dependent on S1P receptor 1. Nature. 2004 Jan 22;427(6972):355-60.

78. Pappu R, Schwab SR, Cornelissen I, Pereira JP, Regard JB, Xu Y, et al. Promotion of lymphocyte egress into blood and lymph by distinct sources of sphingosine-1-phosphate. Science. 2007 Apr 13;316(5822):295-8.

79. Blom B, Spits H. Development of human lymphoid cells. Annu Rev Immunol. 2006;24:287320.

80. Godfrey DI, Zlotnik A, Suda T. Phenotypic and functional characterization of c-kit expression during intrathymic T cell development. J Immunol. 1992 Oct 1;149(7):2281-5.

81. Dik WA, Pike-Overzet K, Weerkamp F, de Ridder D, de Haas EF, Baert MR, et al. New insights on human $\mathrm{T}$ cell development by quantitative $\mathrm{T}$ cell receptor gene rearrangement studies and gene expression profiling. J Exp Med. 2005 Jun 6;201(11):1715-23.

82. Haynes BF, Martin ME, Kay HH, Kurtzberg J. Early events in human T cell ontogeny. Phenotypic characterization and immunohistologic localization of $\mathrm{T}$ cell precursors in early human foetal tissues. J Exp Med. 1988 Sep 1;168(3):1061-80.

83. Meek B, Cloosen S, Borsotti C, Van Elssen CH, Vanderlocht J, Schnijderberg MC, et al. In 
vitro-differentiated $\mathrm{T} /$ natural killer-cell progenitors derived from human CD34+ cells mature in the thymus. Blood. 2010 Jan 14;115(2):261-4.

84. Reimann C, Six E, Dal-Cortivo L, Schiavo A, Appourchaux K, Lagresle-Peyrou C, et al. Human T-lymphoid progenitors generated in a feeder-cell-free Delta-like-4 culture system promote T-cell reconstitution in NOD/SCID/gammac(-/-) mice. Stem Cells. 2012 Aug;30(8):1771-80.

85. Weerkamp F, Baert MR, Brugman MH, Dik WA, de Haas EF, Visser TP, et al. Human thymus contains multipotent progenitors with T/B lymphoid, myeloid, and erythroid lineage potential. Blood. 2006 Apr 15;107(8):3131-7.

86. Awong G, Herer E, Surh CD, Dick JE, La Motte-Mohs RN, Zuniga-Pflucker JC. Characterization in vitro and engraftment potential in vivo of human progenitor $\mathrm{T}$ cells generated from hematopoietic stem cells. Blood. 2009 Jul 30;114(5):972-82.

87. Awong G, Singh J, Mohtashami M, Malm M, La Motte-Mohs RN, Benveniste PM, et al. Human proT-cells generated in vitro facilitate hematopoietic stem cell-derived T-lymphopoiesis in vivo and restore thymic architecture. Blood. 2013 Dec 19;122(26):4210-9.

88. Klein L, Kyewski B, Allen PM, Hogquist KA. Positive and negative selection of the T cell repertoire: what thymocytes see (and don't see). Nat Rev Immunol. 2014 Jun;14(6):377-91.

89. Irla M, Hollander G, Reith W. Control of central self-tolerance induction by autoreactive CD4+ thymocytes. Trends Immunol. 2010 Feb;31(2):71-9.

90. Cloosen S, Arnold J, Thio M, Bos GM, Kyewski B, Germeraad WT. Expression of tumorassociated differentiation antigens, MUC1 glycoforms and CEA, in human thymic epithelial cells: implications for self-tolerance and tumor therapy. Cancer Res. $2007 \mathrm{Apr}$ 15;67(8):3919-26.

91. Laan M, Peterson P. The many faces of aire in central tolerance. Front Immunol. 2013;4:326.

92. Delves PJ, J. MS, Burton D R, Roitt IM. Roitt's Essential Immunology: Blackwell Publishing, 2012.

93. Nishana M, Raghavan SC. Role of recombination activating genes in the generation of antigen receptor diversity and beyond. Immunology. 2012 Dec;137(4):271-81.

94. Geenen V, Poulin JF, Dion ML, Martens H, Castermans E, Hansenne I, et al. Quantification of $\mathrm{T}$ cell receptor rearrangement excision circles to estimate thymic function: an important new tool for endocrine-immune physiology. J Endocrinol. 2003 Mar;176(3):305-11.

95. van Dongen JJ, Langerak AW, Bruggemann M, Evans PA, Hummel M, Lavender FL, et al. Design and standardization of PCR primers and protocols for detection of clonal immunoglobulin and T-cell receptor gene recombinations in suspect lymphoproliferations: report of the BIOMED-2 Concerted Action BMH4-CT98-3936. Leukaemia. 2003 Dec;17(12):2257-317.

96. Rothenberg EV, Moore JE, Yui MA. Launching the T-cell-lineage developmental programme. Nat Rev Immunol. 2008 Jan;8(1):9-21.

97. Weerkamp F, Baert MR, Naber BA, Koster EE, de Haas EF, Atkuri KR, et al. Wnt signaling in the thymus is regulated by differential expression of intracellular signaling molecules. Proc Natl Acad Sci U S A. 2006 Feb 28;103(9):3322-6. 
98. Radtke F, MacDonald HR, Tacchini-Cottier F. Regulation of innate and adaptive immunity by Notch. Nat Rev Immunol. 2013 Jun;13(6):427-37.

99. Radtke F, Wilson A, Ernst B, MacDonald HR. The role of Notch signaling during hematopoietic lineage commitment. Immunol Rev. 2002 Sep;187:65-74.

100. Han H, Tanigaki K, Yamamoto N, Kuroda K, Yoshimoto M, Nakahata T, et al. Inducible gene knockout of transcription factor recombination signal binding protein-J reveals its essential role in T versus B lineage decision. Int Immunol. 2002 Jun;14(6):637-45.

101. Radtke F, Wilson A, Stark G, Bauer M, van Meerwijk J, MacDonald HR, et al. Deficient T cell fate specification in mice with an induced inactivation of Notch1. Immunity. 1999 May;10(5):547-58.

102. Ciofani M, Schmitt TM, Ciofani A, Michie AM, Cuburu N, Aublin A, et al. Obligatory role for cooperative signaling by pre-TCR and Notch during thymocyte differentiation. J Immunol. 2004 May 1;172(9):5230-9.

103. Tanigaki K, Tsuji M, Yamamoto N, Han H, Tsukada J, Inoue H, et al. Regulation of alphabeta/ gammadelta $\mathrm{T}$ cell lineage commitment and peripheral $\mathrm{T}$ cell responses by Notch/RBP-J signaling. Immunity. 2004 May;20(5):611-22.

104. Wolfer A, Wilson A, Nemir M, MacDonald HR, Radtke F. Inactivation of Notch1 impairs VDJbeta rearrangement and allows pre-TCR-independent survival of early alpha beta Lineage Thymocytes. Immunity. 2002 Jun;16(6):869-79.

105. Masuda K, Germeraad WT, Satoh R, Itoi M, Ikawa T, Minato N, et al. Notch activation in thymic epithelial cells induces development of thymic microenvironments. Mol Immunol. 2009 May;46(8-9):1756-67.

106. Hozumi K, Mailhos C, Negishi N, Hirano K, Yahata T, Ando K, et al. Delta-like 4 is indispensable in thymic environment specific for T cell development. J Exp Med. 2008 Oct 27;205(11):2507-13.

107. Koch U, Fiorini E, Benedito R, Besseyrias V, Schuster-Gossler K, Pierres M, et al. Delta-like 4 is the essential, nonredundant ligand for Notch 1 during thymic $\mathrm{T}$ cell lineage commitment. J Exp Med. 2008 Oct 27;205(11):2515-23.

108. Yashiro-Ohtani Y, He Y, Ohtani T, Jones ME, Shestova O, Xu L, et al. Pre-TCR signaling inactivates Notch1 transcription by antagonizing E2A. Genes Dev. 2009 Jul 15;23(14):166576.

109. Maillard I, Fang T, Pear WS. Regulation of lymphoid development, differentiation, and function by the Notch pathway. Annu Rev Immunol. 2005;23:945-74.

110. Radtke F, Wilson A, MacDonald HR. Notch signaling in T- and B-cell development. Curr Opin Immunol. 2004 Apr;16(2):174-9.

111. Weber BN, Chi AW, Chavez A, Yashiro-Ohtani Y, Yang Q, Shestova O, et al. A critical role for TCF-1 in T-lineage specification and differentiation. Nature. 2011 Aug 4;476(7358):63-8.

112. Zlotnik A, Moore TA. Cytokine production and requirements during T-cell development. Curr Opin Immunol. 1995 Apr;7(2):206-13.

113. Di Santo JP, Rodewald HR. In vivo roles of receptor tyrosine kinases and cytokine receptors 
in early thymocyte development. Curr Opin Immunol. 1998 Apr;10(2):196-207.

114. Tal N, Shochat C, Geron I, Bercovich D, Izraeli S. Interleukin 7 and thymic stromal lymphopoietin: from immunity to leukaemia. Cell Mol Life Sci. 2014 Feb;71(3):365-78.

115. Ikawa T, Hirose S, Masuda K, Kakugawa K, Satoh R, Shibano-Satoh A, et al. An essential developmental checkpoint for production of the $T$ cell lineage. Science. 2010 Jul 2;329(5987):93-6.

116. Zakrzewski JL, Kochman AA, Lu SX, Terwey TH, Kim TD, Hubbard VM, et al. Adoptive transfer of $\mathrm{T}$-cell precursors enhances $\mathrm{T}$-cell reconstitution after allogeneic hematopoietic stem cell transplantation. Nat Med. 2006 Sep;12(9):1039-47.

117. Garcia-Peydro M, de Yebenes VG, Toribio ML. Notch1 and IL-7 receptor interplay maintains proliferation of human thymic progenitors while suppressing non-T cell fates. J Immunol. 2006 Sep 15;177(6):3711-20.

118. Corcoran AE, Smart FM, Cowling RJ, Crompton T, Owen MJ, Venkitaraman AR. The interleukin-7 receptor alpha chain transmits distinct signals for proliferation and differentiation during B lymphopoiesis. Embo J. 1996 Apr 15;15(8):1924-32.

119. von Freeden-Jeffry U, Solvason N, Howard M, Murray R. The earliest T lineage-committed cells depend on IL-7 for Bcl-2 expression and normal cell cycle progression. Immunity. 1997 Jul;7(1):147-54.

120. Puel A, Ziegler SF, Buckley RH, Leonard WJ. Defective IL7R expression in T(-)B(+)NK(+) severe combined immunodeficiency. Nat Genet. 1998 Dec;20(4):394-7.

121. Rodewald HR, Kretzschmar K, Swat W, Takeda S. Intrathymically expressed c-kit ligand (stem cell factor) is a major factor driving expansion of very immature thymocytes in vivo. Immunity. 1995 Sep;3(3):313-9.

122. Mackarehtschian K, Hardin JD, Moore KA, Boast S, Goff SP, Lemischka IR. Targeted disruption of the flk2/flt 3 gene leads to deficiencies in primitive hematopoietic progenitors. Immunity. 1995 Jul;3(1):147-61.

123. Moore TA, Zlotnik A. Differential effects of Flk-2/Flt-3 ligand and stem cell factor on murine thymic progenitor cells. J Immunol. 1997 May 1;158(9):4187-92.

124. Kamarck ME, Gottlieb PD. Expression of thymocyte surface alloantigens in the foetal mouse thymus in vivo and in organ culture. J Immunol. 1977 Aug;119(2):407-15.

125. Mandel T, Russell PJ. Differentation of foetal mouse thymus. Ultrastructure of organ cultures and of subcapsular grafts. Immunology. 1971 Oct;21(4):659-74.

126. Owen JJ, Jordan RK, Robinson JH, Singh U, Willcox HN. In vitro studies on the ontogeny of lymphocyte populations. Ann Immunol (Paris). 1976 Nov-Dec;127(6):951-6.

127. Plum J, De Smedt M, Defresne MP, Leclercq G, Vandekerckhove B. Human CD34+ foetal liver stem cells differentiate to T cells in a mouse thymic microenvironment. Blood. 1994 Sep 1;84(5):1587-93.

128. Anderson G, Jenkinson EJ, Moore NC, Owen JJ. MHC class II-positive epithelium and mesenchyme cells are both required for T-cell development in the thymus. Nature. 1993 Mar 4;362(6415):70-3. 
129. Spangrude GJ, Aihara Y, Weissman IL, Klein J. The stem cell antigens Sca-1 and Sca-2 subdivide thymic and peripheral T lymphocytes into unique subsets. J Immunol. $1988 \mathrm{Dec}$ 1;141(11):3697-707.

130. Baum CM, Weissman IL, Tsukamoto AS, Buckle AM, Peault B. Isolation of a candidate human hematopoietic stem-cell population. Proc Natl Acad Sci U S A. 1992 Apr 1;89(7):2804-8.

131. Nakano T, Kodama H, Honjo T. Generation of lymphohematopoietic cells from embryonic stem cells in culture. Science. 1994 Aug 19;265(5175):1098-101.

132. Berrih S, Arenzana-Seisdedos F, Cohen S, Devos R, Charron D, Virelizier JL. Interferongamma modulates HLA class II antigen expression on cultured human thymic epithelial cells. J Immunol. 1985 Aug;135(2):1165-71.

133. Watanabe Y, Mazda O, Aiba Y, Iwai K, Gyotoku J, Ideyama S, et al. A murine thymic stromal cell line which may support the differentiation of CD4-8- thymocytes into CD4+8- alpha beta T cell receptor positive T cells. Cell Immunol. 1992 Jul;142(2):385-97.

134. Jaleco AC, Neves H, Hooijberg E, Gameiro P, Clode N, Haury M, et al. Differential effects of Notch ligands Delta-1 and Jagged-1 in human lymphoid differentiation. J Exp Med. 2001 Oct 1;194(7):991-1002.

135. Kato M, Masuda K, Kakugawa K, Kawamoto H, Mugishima H, Katsura Y. Quantification of progenitors capable of generating T cells in human cord blood. Eur J Haematol. 2008 Feb;80(2):151-9.

136. Schmitt TM, Zuniga-Pflucker JC. Induction of T cell development from hematopoietic progenitor cells by delta-like-1 in vitro. Immunity. 2002 Dec;17(6):749-56.

137. De Smedt M, Hoebeke I, Plum J. Human bone marrow CD34+ progenitor cells mature to T cells on OP9-DL1 stromal cell line without thymus microenvironment. Blood Cells Mol Dis. 2004 Nov-Dec;33(3):227-32.

138. Dervovic DD, Ciofani M, Kianizad K, Zuniga-Pflucker JC. Comparative and functional evaluation of in vitro generated to ex vivo CD8 T cells. J Immunol. 2012 Oct 1;189(7):341120.

139. Van Coppernolle S, Verstichel G, Timmermans F, Velghe I, Vermijlen D, De Smedt M, et al. Functionally mature CD4 and CD8 TCRalphabeta cells are generated in OP9-DL1 cultures from human CD34+ hematopoietic cells. J Immunol. 2009 Oct 15;183(8):4859-70.

140. Mohtashami M, Shah DK, Nakase H, Kianizad K, Petrie HT, Zuniga-Pflucker JC. Direct comparison of Dll1- and Dll4-mediated Notch activation levels shows differential lymphomyeloid lineage commitment outcomes. J Immunol. 2010 Jul 15;185(2):867-76.

141. Mohtashami M, Zuniga-Pflucker JC. Three-dimensional architecture of the thymus is required to maintain delta-like expression necessary for inducing $\mathrm{T}$ cell development. $\mathrm{J}$ Immunol. 2006 Jan 15;176(2):730-4.

142. Varnum-Finney B, Wu L, Yu M, Brashem-Stein C, Staats S, Flowers D, et al. Immobilization of Notch ligand, Delta-1, is required for induction of notch signaling. J Cell Sci. 2000 Dec;113 Pt 23:4313-8.

143. Delaney C, Varnum-Finney B, Aoyama K, Brashem-Stein C, Bernstein ID. Dose-dependent 
effects of the Notch ligand Deltal on ex vivo differentiation and in vivo marrow repopulating ability of cord blood cells. Blood. 2005 Oct 15;106(8):2693-9.

144. Lefort N, Benne C, Lelievre JD, Dorival C, Balbo M, Sakano S, et al. Short exposure to Notch ligand Delta-4 is sufficient to induce T-cell differentiation program and to increase the $\mathrm{T}$ cell potential of primary human CD34+ cells. Exp Hematol. 2006 Dec;34(12):1720-9.

145. Ohishi K, Varnum-Finney B, Bernstein ID. Delta-1 enhances marrow and thymus repopulating ability of human CD34(+)CD38(-) cord blood cells. J Clin Invest. 2002 Oct;110(8):1165-74.

146. Reimann C, Six E, Dal-Cortivo L, Schiavo A, Appourchaux K, Lagresle-Peyrou C, et al. Human T-lymphoid progenitors generated in a feeder-cell-free Delta-like-4 culture system promote T-cell reconstitution in NOD/SCID/gammac(-/-) mice. Stem Cells. 2012 Aug;30(8):1771-80.

147. Aoyama K, Delaney C, Varnum-Finney B, Kohn AD, Moon RT, Bernstein ID. The interaction of the Wnt and Notch pathways modulates natural killer versus $\mathrm{T}$ cell differentiation. Stem Cells. 2007 Oct;25(10):2488-97.

148. Janas ML, Varano G, Gudmundsson K, Noda M, Nagasawa T, Turner M. Thymic development beyond beta-selection requires phosphatidylinositol 3-kinase activation by CXCR4. J Exp Med. 2010 Jan 18;207(1):247-61.

149. Fernandez I, Ooi TP, Roy K. Generation of functional, antigen-specific CD8+ human T cells from cord blood stem cells using exogenous Notch and tetramer-TCR signaling. Stem Cells. 2014 Jan;32(1):93-104.

150. Benz C, Bleul CC. A multipotent precursor in the thymus maps to the branching point of the T versus B lineage decision. J Exp Med. 2005 Jul 4;202(1):21-31.

151. Benne C, Lelievre JD, Balbo M, Henry A, Sakano S, Levy Y. Notch increases T/NK potential of human hematopoietic progenitors and inhibits $B$ cell differentiation at a pro-B stage. Stem Cells. 2009 Jul;27(7):1676-85.

152. Spits H, Artis D, Colonna M, Diefenbach A, Di Santo JP, Eberl G, et al. Innate lymphoid cells-a proposal for uniform nomenclature. Nat Rev Immunol. 2013 Feb;13(2):145-9.

153. Lanier LL, Le AM, Phillips JH, Warner NL, Babcock GF. Subpopulations of human natural killer cells defined by expression of the Leu-7 (HNK-1) and Leu-11 (NK-15) antigens. J Immunol. 1983 Oct;131(4):1789-96.

154. Huntington ND, Vosshenrich CA, Di Santo JP. Developmental pathways that generate natural-killer-cell diversity in mice and humans. Nat Rev Immunol. 2007 Sep;7(9):703-14.

155. Narni-Mancinelli E, Ugolini S, Vivier E. Tuning the threshold of natural killer cell responses. Curr Opin Immunol. 2013 Feb;25(1):53-8.

156. Yokoyama WM, Kim S. How do natural killer cells find self to achieve tolerance? Immunity. 2006 Mar;24(3):249-57.

157. Karre K, Ljunggren HG, Piontek G, Kiessling R. Selective rejection of H-2-deficient lymphoma variants suggests alternative immune defence strategy. Nature. 1986 Feb 2026;319(6055):675-8. 
158. Moretta L, Bottino C, Pende D, Castriconi R, Mingari MC, Moretta A. Surface NK receptors and their ligands on tumor cells. Semin Immunol. 2006 Jun;18(3):151-8.

159. Raulet DH, Vance RE. Self-tolerance of natural killer cells. Nat Rev Immunol. 2006 Jul;6(7):520-31.

160. Cheng M, Chen Y, Xiao W, Sun R, Tian Z. NK cell-based immunotherapy for malignant diseases. Cell Mol Immunol. 2013 May;10(3):230-52.

161. Carbone E, Neri P, Mesuraca M, Fulciniti MT, Otsuki T, Pende D, et al. HLA class I, NKG2D, and natural cytotoxicity receptors regulate multiple myeloma cell recognition by natural killer cells. Blood. 2005 Jan 1;105(1):251-8.

162. Shi J, Tricot G, Szmania S, Rosen N, Garg TK, Malaviarachchi PA, et al. Infusion of haploidentical killer immunoglobulin-like receptor ligand mismatched NK cells for relapsed myeloma in the setting of autologous stem cell transplantation. $\mathrm{Br} \mathrm{J}$ Haematol. 2008 Dec;143(5):641-53.

163. Velardi A, Ruggeri L, Mancusi A, Burchielli E, Perruccio K, Aversa F, et al. Clinical impact of natural killer cell reconstitution after allogeneic hematopoietic transplantation. Semin Immunopathol. 2008 Dec;30(4):489-503.

164. Frings PW, Van Elssen CH, Wieten L, Matos C, Hupperets PS, Schouten HC, et al. Elimination of the chemotherapy resistant subpopulation of $4 \mathrm{~T} 1$ mouse breast cancer by haploidentical NK cells cures the vast majority of mice. Breast Cancer Res Treat. 2011 Dec;130(3):773-81.

165. Krause SW, Gastpar R, Andreesen R, Gross C, Ullrich H, Thonigs G, et al. Treatment of colon and lung cancer patients with ex vivo heat shock protein 70-peptide-activated, autologous natural killer cells: a clinical phase i trial. Clin Cancer Res. 2004 Jun 1;10(11):3699-707.

166. Stern M, Passweg JR, Meyer-Monard S, Esser R, Tonn T, Soerensen J, et al. Pre-emptive immunotherapy with purified natural killer cells after haploidentical SCT: a prospective phase II study in two centers. Bone Marrow Transplant. 2013 Mar;48(3):433-8.

167. Sarkar S, Van Gelder M, Willy Xu Y, Rouschop K, Groen R, Schouten H, et al. Optimal selection of Natural Killer cells to kill myeloma: the role of HLA-E and NKG2A. In submission. 2014.

168. Williams KM, Hakim FT, Gress RE. T cell immune reconstitution following lymphodepletion. Semin Immunol. 2007 Oct;19(5):318-30.

169. Fry TJ, Mackall CL. Immune reconstitution following hematopoietic progenitor cell transplantation: challenges for the future. Bone Marrow Transplant. 2005 Mar;35 Suppl 1:S53-7.

170. Zlotoff DA, Zhang SL, De Obaldia ME, Hess PR, Todd SP, Logan TD, et al. Delivery of progenitors to the thymus limits $\mathrm{T}$-lineage reconstitution after bone marrow transplantation. Blood. 2011 Aug 18;118(7):1962-70.

171. Krenger W, Blazar BR, Hollander GA. Thymic T-cell development in allogeneic stem cell transplantation. Blood. 2011 Jun 23;117(25):6768-76.

172. Hakim FT, Memon SA, Cepeda R, Jones EC, Chow CK, Kasten-Sportes C, et al. Agedependent incidence, time course, and consequences of thymic renewal in adults. J Clin 
Invest. 2005 Apr;115(4):930-9.

173. Klein AK, Patel DD, Gooding ME, Sempowski GD, Chen BJ, Liu C, et al. T-Cell recovery in adults and children following umbilical cord blood transplantation. Biol Blood Marrow Transplant. 2001;7(8):454-66.

174. Eyrich M, Schreiber SC, Wollny G, Ziegler H, Schlenker R, Koch-Buttner K, et al. Predifferentiated human committed T-lymphoid progenitors promote peripheral T-cell reconstitution after stem cell transplantation in immunodeficient mice. Eur J Immunol. 2011 Dec;41(12):3596-603.

175. Delaney C, Heimfeld S, Brashem-Stein C, Voorhies H, Manger RL, Bernstein ID. Notchmediated expansion of human cord blood progenitor cells capable of rapid myeloid reconstitution. Nat Med. 2010 Feb;16(2):232-6. 


\section{Thymic epithelial cells induce formation of mesenchymal network structure after abrogation of thymic crosstalk}

Rumi Satoh, Mirelle J.A.J. Huijskens, Kyoko Masuda, Kiyokazu Kakugawa, Tomokatsu Ikawa, Eric Vroegindeweij, Manami Itoi, Georg A. Holländer, Yoshimoto Katsura, Hiroshi Kawamoto and Wilfred T.V. Germeraad

Submitted for publication. 


\section{Abstract}

It is established that thymic epithelial cells (TECs) and thymocytes influence each other during their growth and differentiation, a process called thymic crosstalk. In the earliest step of thymic organogenesis, mesenchymal cells support the growth of TECs. However, little is known about the influence of developing thymocytes or TECs on mesenchymal cells. Here, we show that during normal thymus development fibroblast ingrowth occurs towards hypoxic areas. Similar overgrowth of mesenchymal cells is seen in a foetal thymic organ culture system under low oxygen conditions. When thymocytes were depleted by deoxyguanosine treatment, mesenchymal cells were also induced, precluding the direct effect of hypoxia. In the foetal thymus of hCD3عTg mice, which have an early block in T cell development, an overgrowth of mesenchymal cells can be seen at a very early stage of thymic organogenesis. The growth of the mesenchymal cells is due to their extensive proliferation rather than enrichment. With RNA sequence analysis comparing hCD3ETg TECs with wild type TECs, we identified candidate factors that correlate with an increased mesenchymal network formation and thus may be causally linked to the formation of an irregular thymic microenvironment. 


\section{Introduction}

The central organ for $\mathrm{T}$ cell development in jawed vertebrates is the thymus. The thymus is located just above the heart and originates at least in part from the third pharyngeal pouch 1. The organ is composed of developing T lymphocytes that closely interact with thymic stroma. The stroma provides the unique $3 \mathrm{D}$ structure of the thymus and consists of thymic epithelial cells (TECs), mesenchymal cells, connective tissue and endothelial cells that form the vasculature ${ }^{2,3}$. Haematopoietic progenitor cells originate in the bone marrow, settle in the unique environments of the thymus and mature into $\mathrm{T}$ cells during a highly organized process. After positive selection for major histocompatibility complex (MHC)-restriction and deletion of self-reactive cells, these events result in the output of naive $\mathrm{T}$ cells with a broad $\mathrm{T}$ cell receptor (TCR) repertoire. T cells have an important function in combatting infections and eradicating tumour cells.

Thymocytes and TECs directly interact with each other and determine their maturation, a process that is commonly termed thymic crosstalk ${ }^{4-7}$. TECs provide important signals like adhesion molecules, chemokines, cytokines, Notch ligands like DLL4, and MHC molecules inducing $\mathrm{T}$ cells to proliferate and differentiate from early progenitors to highly specialized $\mathrm{T}$ cells with either helper, killer or regulatory functions ${ }^{8}$. In turn, $\mathrm{T}$ cells generate signals to which TECs can react and also differentiate to either cortical or medullary TECs ${ }^{9}$. One of the possible signalling pathways that has been demonstrated to be involved in this process is again the Notch-Delta-Like ligand pathway ${ }^{10}$. Furthermore, TNF receptor family members generated by T cells, like RANKL, CD40L and LT $\beta$ R ligands, play an important role in TEC development, maintenance and thereby self-tolerance ${ }^{11-15}$.

TECs do not only need T cell derived signals for their development, they can also be influenced by mesenchymal fibroblast derived signals. Regular TEC network development is dependent on the production of EGF, TGF- $\alpha^{16}$ and various FGFs ${ }^{17}$. Besides providing signalling required for TEC development and to provide structure in the thymus, the mesenchymal network provides IL-7 ${ }^{18}$ and extracellular matrix components needed for proper T cell development ${ }^{19}$. In contrast to the wealth of cellular and molecular insight regarding T cell-TEC crosstalk, the mechanisms that form the mesenchymal network remain largely elusive.

During embryonic development, epithelial and mesenchymal interactions are essential for the formation of structures throughout the body ${ }^{20}$. Mesenchymal cells have been shown to play an essential role in foetal thymus organogenesis and are derived from neural crest cells. In contrast to their role in formation of the 3D network of TECs in the thymus ${ }^{4}$, in many other epithelial organs, mesenchymal cells produce an extracellular matrix in the form of a basement membrane on which polarized epithelial cells can adhere and grow in a $2 \mathrm{D}$ fashion 
4,21. Whether TECs influence mesenchymal cells on their turn is unknown, though in other organs, epithelial cells produce signals like epidermal growth factor (EGF), desert hedgehog $(\mathrm{DHH})$ or platelet-derived growth factor (PDGF) that are crucial for mesenchyme growth ${ }^{20}$.

In our previous experiments on T cell-TEC crosstalk ${ }^{9,22}$, we noticed that mesenchymal cell growth was paradoxically suppressed in the areas where $\mathrm{T}$ cell reconstitution had occurred, which in turn was depended on the supply of high oxygen. In contrast, mesenchymal cells were enhanced in poorly reconstituted areas due to hypoxic conditions ${ }^{9}$. Thus, mesenchymal network formation and TEC development is a more complex process than commonly believed. We therefore sought to investigate the mesenchymal network formation in the thymus. On the one hand the possibility exists that mesenchymal cells grow and autonomously invade the epithelium to form networks. On the other hand, several instructive mechanisms may cause the mesenchymal network to develop. One possible mechanism for the induction of the mesenchymal network formation is a consequence of thymic crosstalk between TECs and thymocytes that in turn promote fibroblast differentiation. Alternatively, stress factors such as hypoxia and/or malnutrition could be responsible to directly induce the mesenchymal network formation. A third possibility is that hypoxia does not directly induce mesenchymal network formation, but that hypoxia and/or malnutrition causes blockage of thymic crosstalk, resulting in underdevelopment of TEC structures and thereby indirectly inducing the mesenchymal network formation. In this manuscript, we investigate how the formation of the mesenchymal network in the thymus occurs and provide evidence for a molecular mechanism operational in this formation. 


\section{Materials and Methods}

\section{Mice}

C57BL/6 (B6) mice were purchased from CLEA Japan Inc. (Tokyo, Japan). CD3eTg mice, Foxn1-cre and CAG-CAT-EGFP reporter mice ${ }^{23}$ were maintained in our animal facility. Embryos at various stages of gestation were obtained from time-mated pregnant mice. The day of finding the vaginal plug was designated as $0 \mathrm{dpc}$.

\section{Immunohistochemistry}

All thymic lobes were embedded in OCT compound (Sakura FineTek, Tokyo, Japan) and snapfrozen in liquid nitrogen, using Leica Histomolds (Leica Microsystems, Wetzlar, Germany). Frozen blocks were cut into serial $5 \mu \mathrm{m}$ sections using a Leica CM3050S cryostat and mounted onto MAS-coated slides (Matsunami Glass Ind. LTD, Osaka, Japan). After acetone fixation for a few seconds, sections were incubated with primary antibodies, washed with PBS $/ 0.05 \%$ Tween, followed by incubation with the proper secondary reagent when no directly labelled antibodies were available. Nuclei were counterstained with DAPI (Molecular Probes, Eugene, OR, USA).

The following antibodies were used: anti-K8 (PROGEN, Heidelberg, Germany), rabbit anti-cytokeratin (Dako, Glostrup, Denmark), rabbit anti-IKAROS, anti-ER-TR7 ${ }^{24}$ and Hypoxyprobe $^{\mathrm{TT}}-1-\mathrm{Mab} 1$, as primary antibody or reagent, followed by Alexa Fluor488 donkey anti-rat IgG $(\mathrm{H}+\mathrm{L})$ conjugate, Alexa Fluor488 goat anti-rabbit IgG $(\mathrm{H}+\mathrm{L})$ conjugate, Alexa Fluor488 goat anti-rabbit IgG conjugate, Alexa Fluor546 goat anti-rat IgG $(\mathrm{H}+\mathrm{L})$ conjugate, Alexa Fluor546 goat anti-rabbit IgG $(\mathrm{H}+\mathrm{L})$ conjugate, Alexa Fluor546 streptavidin conjugate (all from Molecular Probes), as secondary reagents.

In bromodeoxyuridine (BrdU) labelling experiments, BrdU (100 $\mu \mathrm{M}$, Sigma-Aldrich, St. Louis, MO, USA) was added to the medium of a thymic organ culture for one day at the end of the culture period. Lobes were frozen and sectioned. Sections were incubated with ER-TR7, followed by incubation with goat anti-rat IgG $(\mathrm{H}+\mathrm{L})$-Alexa Fluor546 conjugate. Subsequently, sections were re-fixed with $70 \%$ ethanol at $-20^{\circ} \mathrm{C}$ for $10 \mathrm{~min}$ and treated with $2 \mathrm{~N} \mathrm{HCl}$ for $30 \mathrm{~min}$ at room temperature for DNA denaturation. After neutralization with $0.1 \mathrm{M} \mathrm{Na}_{2} \mathrm{~B}_{4} \mathrm{O}_{7}$, sections were incubated with anti-BrdU mAb (3D4, BD Pharmingen, San Diego, CA, USA), followed by the incubation with Alexa Fluor488 anti-mouse IgG, Highly Cross-Absorbed (Molecular Probe).

ER-TR7 $^{+}$areas were determined with Axiovision 4 software (Carl Zeiss, Oberkochen, Germany). 


\section{Detection of hypoxia}

Hypoxia marker and the administration hypoxia marker, pimonidazole hydrochloride (Hypoxyprobe $\mathrm{e}^{\mathrm{m}}-1$ ), and the detecting FITC-labelled mouse monoclonal antibody were obtained from NPI, Inc. (Belmont, MA, USA). Pimonidazole hydrochloride was dissolved in DPBS (Wako). Pregnant mice (13 to $15 \mathrm{dpc}$.) were intraperitoneally injected with pimonidazole hydrochloride $(60 \mathrm{mg} / \mathrm{kg}$ mice). After $2 \mathrm{~h}$, embryos were removed from the uterus of pregnant females, thymi were isolated and frozen in OCT compound (Sakura FineTek, Tokyo, Japan) for immunohistochemistry.

\section{Preparation of foetal cells}

Embryos were separated from the placenta using fine forceps. Embryos were placed in a Petri dish containing tissue culture medium while the foetal thymus (FT) was isolated by dissection.

\section{Foetal thymic organ culture}

To prepare thymocyte-depleted FT lobes, FT from 15 dpc embryos were cultured on polycarbonate filters (pore size $8.0 \mu \mathrm{m}$, Nucleopore Co., Pleasanton, CA, USA) floating on culture medium containing 1.35mM dGuo (Nacalai Tesque, Kyoto, Japan) for a period of 6 days.

\section{Preparation of foetal TECs and Fluorescent Activated Cell Sorting}

To obtain single cell suspension of thymic epithelial cells, lobes were dissected by forceps and digested in RPMI 1640 (Sigma) containing $1 \mathrm{mg} / \mathrm{ml}$ collagenase D (Roche, Basel, Switzerland) and $10 \% \mathrm{FCS}$ and incubated at $37^{\circ} \mathrm{C}$ for $2 \mathrm{~h}$. After washing, cells were passed through $40 \mu \mathrm{m}$ nylon mesh. Viable cells were counted using trypan blue dye exclusion.

After preparation of single cell suspension, cells were stained with CD45 (30-F11 eBioscience, San Diego, CA, USA), EpCAM (clone G8.8, BD Pharmingen) and PDGFRa (clone APA5, eBioscience) and sorted by using FACSAriaIII (BD, Franklin Lakes, NJ, USA). Sorted cells (CD45- $\mathrm{EpCAM}^{+}$PDGFR $\alpha$ cells) were pooled and lysed in TRIzol Reagent (Life Technologies, Carlsbad, CA, USA) and RNA was extracted.

\section{RNA sequencing}

The RNA library was prepared by the TruSeq RNA Sample Prep Kit (Illumina, San Diego, CA, USA). The sequence was read on a HiSeq 1000 (Illumina). RNA-sequences were mapped with TopHat $2{ }^{25}$ and FPKMs (Fragments Per Kilobase of exon per Million reads) were calculated with Cufflinks ${ }^{26}$. Scatter plots were made in Excel (Microsoft). The GEO ID number is GSE60520. 


\section{Results}

\section{In vivo network development of thymic mesenchymal cells}

In our previous studies of murine foetal thymic organ cultures (FTOC), we observed under low oxygen submersion (LOS) conditions an increased mesenchymal network ${ }^{9}$. Therefore, we initiated this study and examined the normal development of the mesenchymal network. The $13 \mathrm{dpc}$ foetal thymus (FT) is completely surrounded by mesenchymal cells as was characterized by ER-TR7 staining only detectable around the lobes, indicating that the capsular region was already formed (Fig. 1). During ontogeny, invagination of mesenchymal cells becomes visible at $14 \mathrm{dpc}$ mainly in the cortical areas where pancytokeratin (panK ${ }^{+}$) cells are less densely packed. At $15 \mathrm{dpc}$, large strings of ER-TR7 ${ }^{+}$cells can be seen, stretching from the capsular region, deep into the developing thymus crossing the cortex into the immature medullary areas as defined by dense panK $\mathrm{K}^{+}$cells. In the neonatal thymus, such strings of ER$\mathrm{TR}^{+}$cells can mainly be seen in medullary regions.
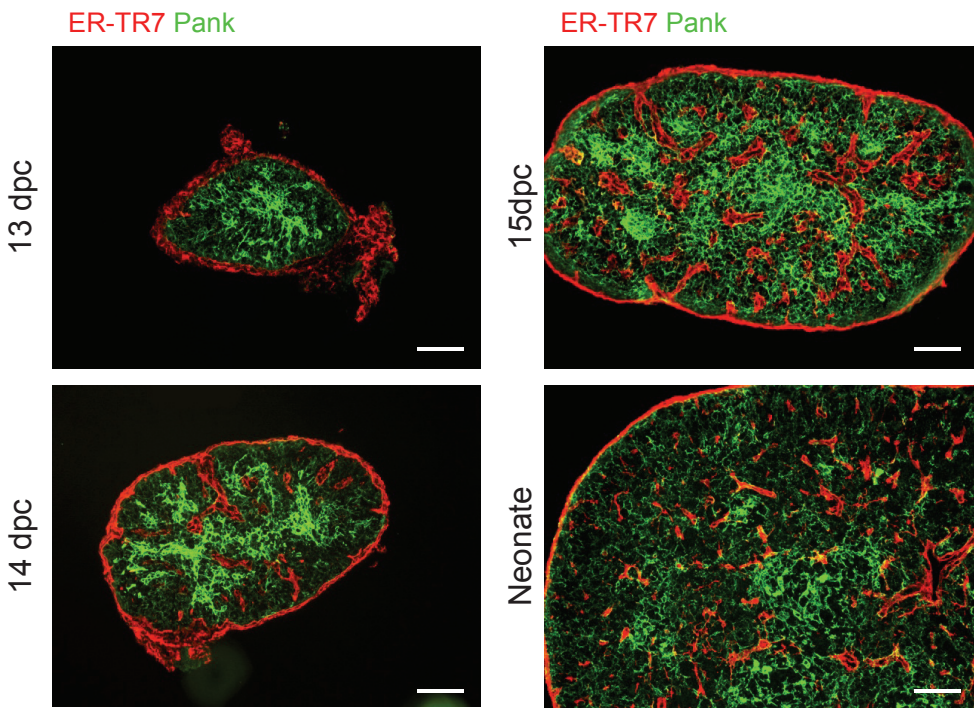

Figure 1: Epithelial cells develop together with mesenchymal cells to form the adult thymus. Immunohistochemical micrographs of thymi during ontogeny from day $13 \mathrm{dpc}$ to the neonatal thymus. The sections of the developing thymi were stained in two colours with anti-panK (green) to detect epithelial cells and ER-TR7 (red) to detect mesenchymal fibroblasts. Scale bar indicates 100 $\mu \mathrm{m}$. 


\section{Developing thymic lobes are hypoxic}

FTOCs grown under LOS conditions showed an increased mesenchymal network ${ }^{9}$. Therefore, we decided to study whether hypoxia exists in the developing thymus that may trigger the development of a mesenchymal network structure. On 13 and $15 \mathrm{dpc}$, pimonidazole hydrochloride (Hypoxiaprobe ${ }^{\mathrm{TM}}-1$ ) was injected intraperitoneally in pregnant mice that were sacrificed after $2 \mathrm{~h}$ and thymi from recovered embryos were frozen. Pimonidazole forms irreversible covalent adducts with cellular proteins when the oxygen tension is lower than $10 \mathrm{mmHg}$ and these adducts can be detected immunohistochemically ${ }^{27}$. Frozen sections were stained with ER-TR7 and the Hypoxiaprobe ${ }^{\mathrm{TM}}$ specific detecting polyclonal antibody. On $13 \mathrm{dpc}$, the thymus is completely surrounded by a ring of ER-TR7 ${ }^{+}$fibroblasts (Fig. 2, upper row). A hypoxic area is detected in the center of the small developing thymus. The gradual decrease in staining intensity from the center to the outer rim suggests a gradient of hypoxia ${ }^{28}$. Similarly on $15 \mathrm{dpc}$, thymic hypoxic areas are detected at locations distant from the developing mesenchymal network with the strongest signal the furthest away from the ER-TR7 ${ }^{+}$cells (Fig. 2, lower row). These observations together suggest that it is possible that a stressful condition such as hypoxia is involved in inducing the mesenchymal network development in the early thymus.

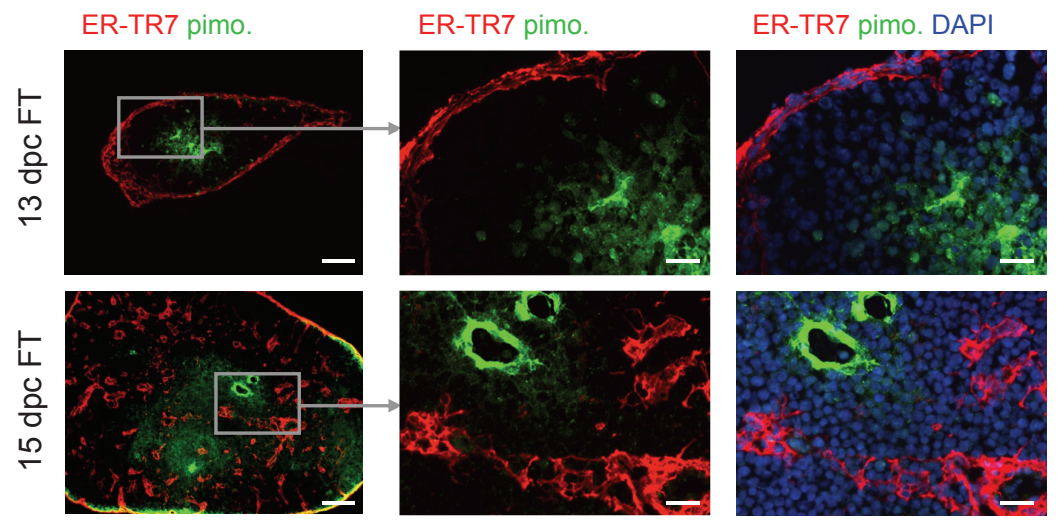

Figure 2: Hypoxic areas in the developing thymus. Immunohistochemical micrographs of thymi during ontogeny from $13 \mathrm{dpc}$ and $15 \mathrm{dpc}$. The sections of the developing thymi were stained with FITC labelled anti-pimonidazole (Hypoxyprobe ${ }^{\mathrm{TM}}-1$, green) to detect hypoxic areas, ER-TR7 (red) to detect mesenchymal fibroblasts and nuclei were counterstained with DAPI (blue). Hypoxic areas are distant from invaginating fibroblasts. Scale bar indicates $100 \mu \mathrm{m}$ in the left panel and $20 \mu \mathrm{m}$ in the middle and right panel. These data are representative for four analysed thymi. 


\section{Impaired thymocyte-TEC crosstalk induces development of mesenchymal cells}

To determine whether hypoxia directly or indirectly induces the development of the mesenchymal cells, we examined $13 \mathrm{dpc} \mathrm{FT}$, and cultured them under high oxygen submersion (HOS) and LOS conditions for 2 and 4 days (for the experimental scheme see Fig. 3A). In the pre-culture $13 \mathrm{dpc} F$, the mesenchymal cells (ER-TR7 $7^{+}$) are surrounding the developing thymus and many lymphocytes (IKAROS ${ }^{+}$) are found between the expanding TECs (panK+, Fig. 3B). If the thymocyte-TEC crosstalk induces the mesenchymal network to grow, invagination of fibroblasts into the lobe is expected to occur only under HOS conditions. In contrast, if hypoxia induces the invagination, this patterning would only occur under LOS conditions. Figure 3C shows that already after 2 days under HOS conditions the lobes were enlarged compared to the lobes under LOS conditions (upper vs. lower figures). This change in size was mainly due to an increased number of TECs and thymocytes and was largely independent of mesenchymal cells. Indeed, only a very small number of these cells had invaginated into the lobe (upper panels, upper row), which slightly increased at day 4 (lower panels, upper row). In contrast, lobes cultured under LOS conditions remained small and showed large invaginations of mesenchymal cells. Although thymocytes (IKAROS ${ }^{+}$) can be seen, the size of the lobe suggests that these thymocytes have not proliferated although they are still alive after 4 days (lower rows of both panels in Fig. 3C). These data support the hypothesis that low oxygen conditions are important for the induction of the mesenchymal cellular network.

We then investigated whether this mesenchymal cellular network is a direct consequence of hypoxia or a secondary effect of impaired thymocyte-TEC crosstalk. To this aim, we cultured $13 \mathrm{dpc}$ FT lobes under HOS conditions, with or without deoxyguanosine (dGuo), which impairs thymus crosstalk by killing thymocytes while leaving TECs alive. After two days of dGuo exposure, the immunohistological analysis revealed a large increase in mesenchymal cells surrounding the lobes as well as in the trabeculae invaginating the lobes (Fig. 4, upper panel lower row). The mesenchymal cell outgrowth was even more prominent at day 4 when compared to untreated controls where only few ER-TR7 ${ }^{+}$cells were visible at day 2 and 4 (Fig. 4, both panels, upper rows).

These data (Fig. 3 and 4) together strongly suggest that the impaired thymocyte-TEC crosstalk, rather than hypoxia directly induces the mesenchymal cell network. 

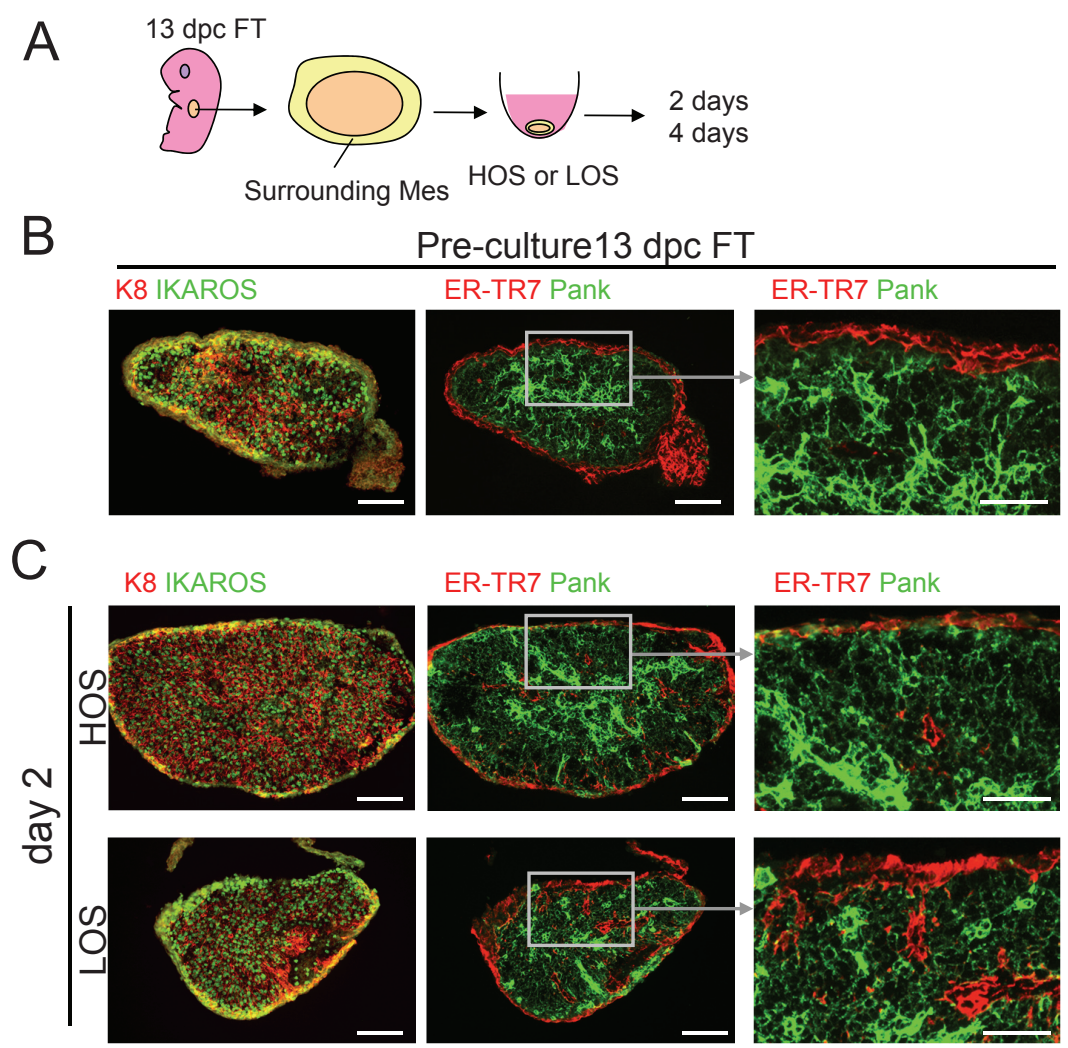

ER-TR7 Pank
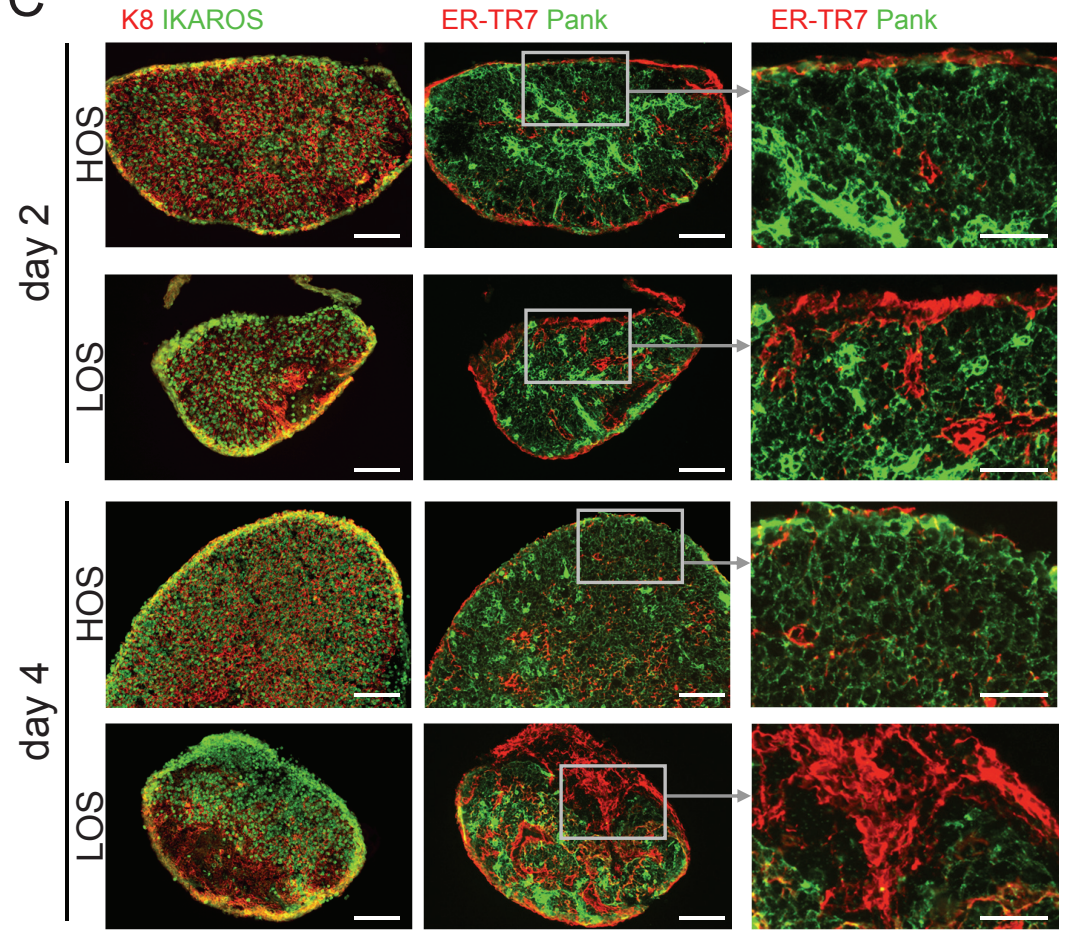

Figure 3: The mesenchymal cellular network develops under low oxygen conditions. A: The experimental procedure. $13 \mathrm{dpc}$ thymi were isolated and cultured for 2 or 4 days under HOS or LOS conditions. B: Pre-cultured lobes of 13 dpc thymi. IKAROS $^{+}$(green) lymphocytes are scattered between panK8 ${ }^{+}$TECs (red) throughout the developing lobe (left panel). ER-TR7 ${ }^{+}$(red) cells can only be seen in the surrounding capsule (middle and enlarged in right panel). C: Lobes after 2 and 4 days of culturing under HOS (panels in row 1 and 3) or LOS (panels in row 2 and 4) conditions. Staining was similar as in (B). Under LOS conditions, mesenchymal cells invaginate and are increasing in time throughout the lobes. Scale bars indicate $100 \mu \mathrm{m}$ in the left and middle panels and $50 \mu \mathrm{m}$ in the right panels. 

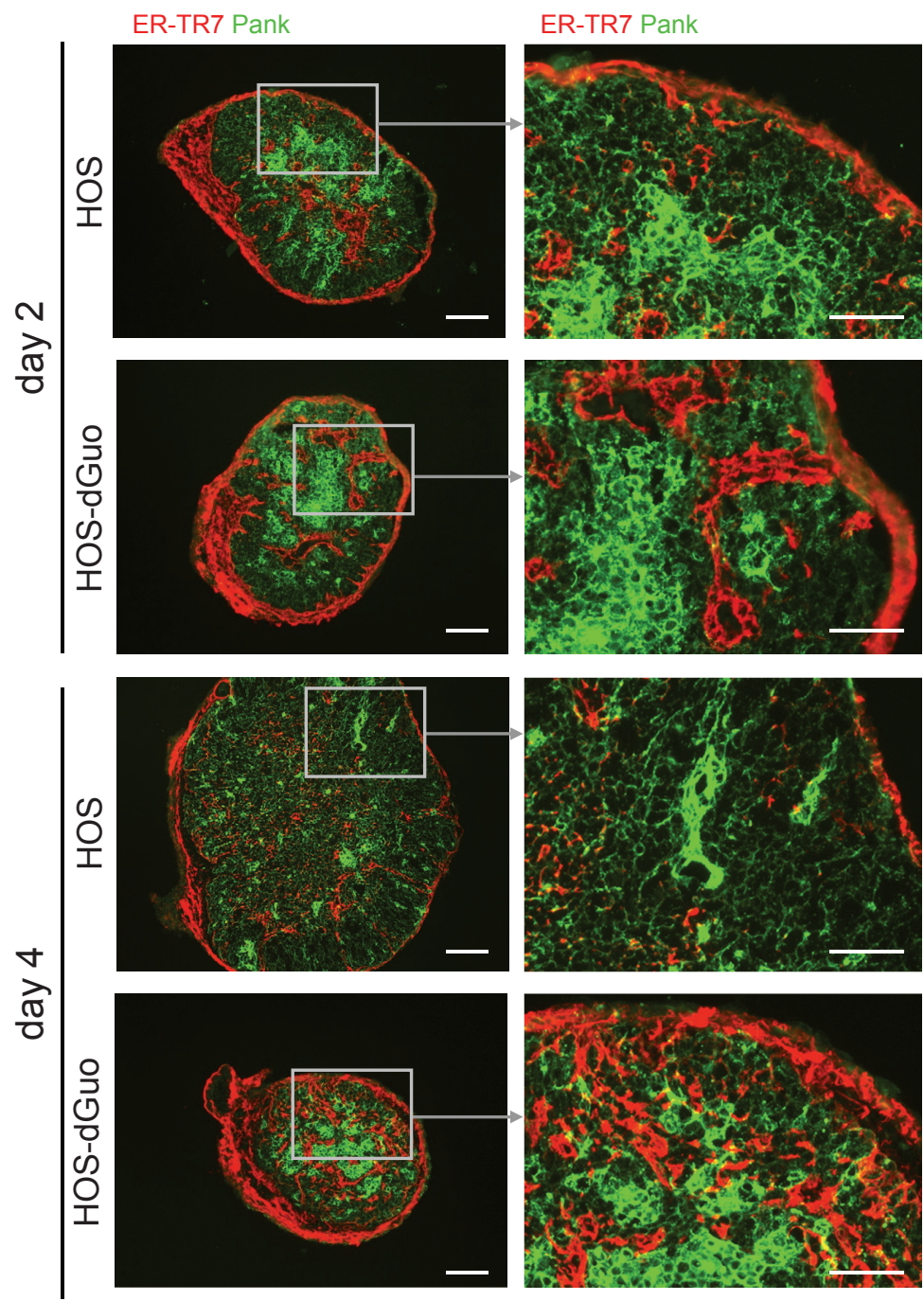

Figure 4: Impaired thymocyte-TEC crosstalk induces development of mesenchymal cells. Immunohistochemical micrographs of $13 \mathrm{dpc}$ thymi in HOS cultures without treatment (rows 1 and 3 ) or after dGuo treatment to remove thymocytes (rows 2 and 4 ) after 2 days (rows 1 and 2) or 4 days (rows 3 and 4) of culture. The right panels are enlargements of the left panels showing details of fibroblast outgrowth (ER-TR7, red) only after abrogation of thymic crosstalk by dGuo. After this treatment, TECs have collapsed (PanK, green). Scale bars indicate $100 \mu \mathrm{m}$ in the left panels and $50 \mu \mathrm{m}$ in the right panels. 


\section{Mesenchymal network develops extensively in the absence of thymocyte-TEC crosstalk}

To confirm independently that an impaired thymocyte-TEC crosstalk induces the growth of mesenchymal cells in vivo, $15 \mathrm{dpc}$ thymi from hCD3eTg mice were investigated and compared with wild type mice. In hCD3ETg mice, thymocytes cannot differentiate due to a $\mathrm{T}$ cell autonomous block at an early developmental stage, consequently, this results in the absence of most functional TECs due to a lack of cross talk signals ${ }^{29}$. If the lack of thymocyteTEC crosstalk indeed accounts for the increased mesenchymal network formation, we would expect these stromal changes to be particularly noticeable in hCD3eTg mice. Although thymi of hCD3eTg mice at $15 \mathrm{dpc}$ were similar in size, they were very different in their stromal composition compared to wild type mice. In contrast to the normal 3D thymic epithelial network of wild type mice, hCD3ETg mice demonstrate an extensive network of ER-TR7 ${ }^{+}$ mesenchymal cells (Fig. 5A), and show a 79\% increase in percentage of ER-TR7 ${ }^{+}$surface area (Fig. 5B, $\mathrm{p}=0.0012$ ). Furthermore, similar to the lobes grown under hypoxic conditions, a more strongly developed capsule is also seen in these thymi in vivo. Since the possibility remains that the increase of the ER-TR7 ${ }^{+}$cell area is just a relative occurrence due to the decrease of PanK ${ }^{+}$TECs, the absolute area or ER-TR7 $7^{+}$cells per lobe on these stained samples was calculated quantitatively, and found indeed to be increased by 1.5 fold (Fig. 5C). Therefore, we concluded that $\mathrm{T}$ cell-TEC crosstalk derived signals do not directly induce mesenchymal network formation. Rather, the absence of crosstalk itself allows specific instructive signals to promote the mesenchymal network formation and hypoxia may be one of the triggers to initiate this process.

\section{Increase of mesenchymal cells is achieved by proliferation}

Our previous experiments with the FTOC method showed that a 6 day dGuo treatment of thymic lobes completely removed thymocytes, and that the TECs were replaced by fibroblasts 9. In a time course after starting dGuo treatment of $15 \mathrm{dpc}$ thymic lobes and culturing under normal atmospheric air (Fig. 6A), we confirmed our previous findings and observed a dramatic increase in the number of ER-TR7 $7^{+}$fibroblasts (Fig. 6B). The organization of a mesenchymal network was already visible 3 days after culture when most $\mathrm{T}$ cells had disappeared. The extent of network was increased dramatically at day 6 of culture (Fig. 6B). To determine whether the fibroblasts actively proliferated, BrdU labelling experiments were performed. In the recovered lobes, we observed that the increase in fibroblast number was due to proliferation as is clearly shown by the presence of many BrdU ${ }^{+}$cells in ER-TR7 $7^{+}$fibroblasts (Fig. 6C). These results indicate that most of the mesenchymal network can be formed by proliferation of mesenchymal cells. 

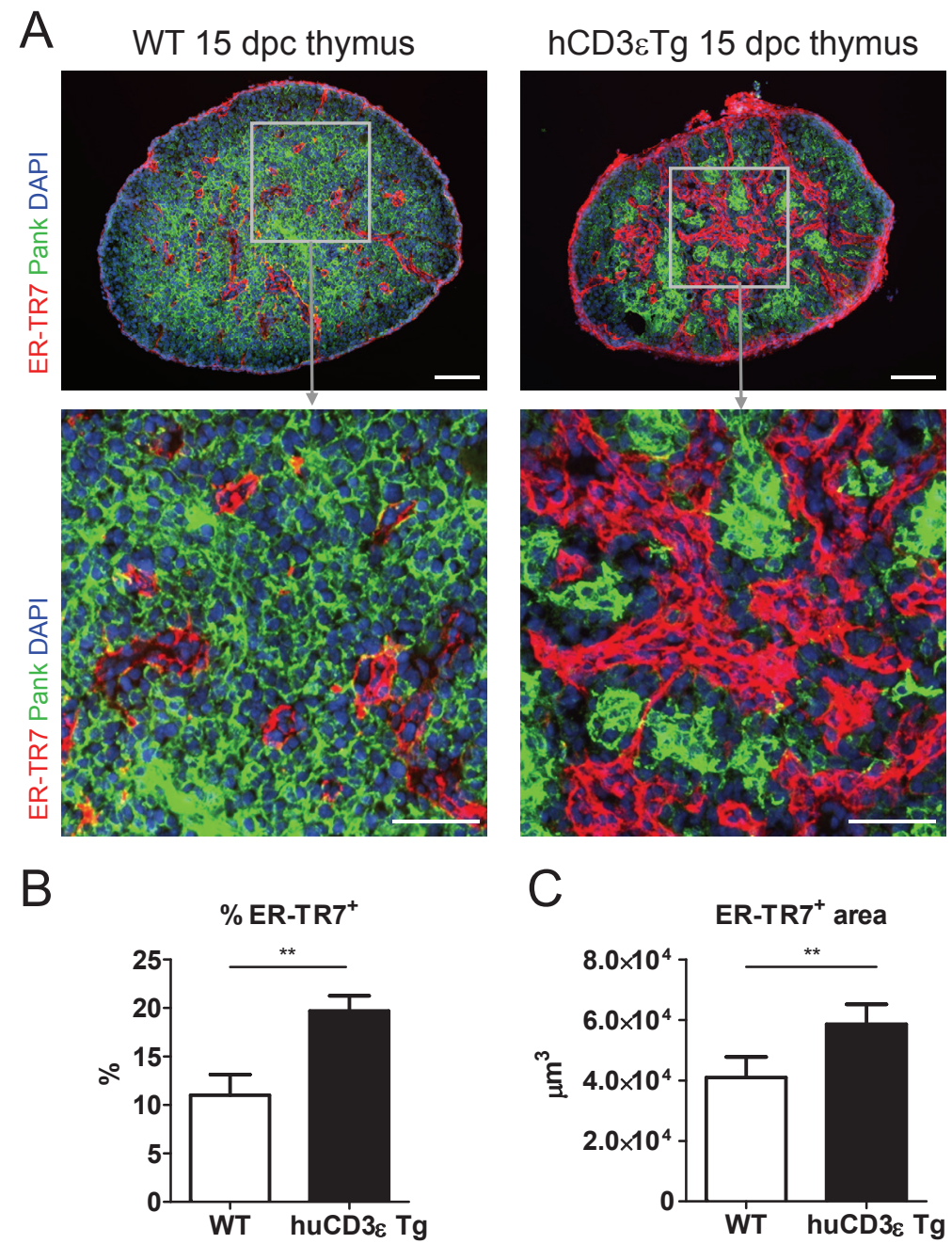

Figure 5: Thymic mesenchymal network develops extensively in the absence of thymocyte-TEC crosstalk. A: Immunohistochemical micrographs of thymi from wild type (WT; left figures) and hCD3ETg mice (right figures). The lobes are representative for 6 thymi analysed. The lobes were stained in two colours with anti-panK (green) to detect epithelial cells and ER-TR7 (red) to detect mesenchymal fibroblasts. The lower figures are magnifications of the inserts of the upper figures. Nuclei were counterstained in blue with DAPI. Right panels show the extensive mesenchymal network formation in thymi where thymocytes-TEC crosstalk is absent due to a genetic defect. Scale bars indicate $100 \mu \mathrm{m}$ in the upper panels and $50 \mu \mathrm{m}$ in the lower panels. B: The percentage of ER-TR7 ${ }^{+}$area and C: the absolute ER-

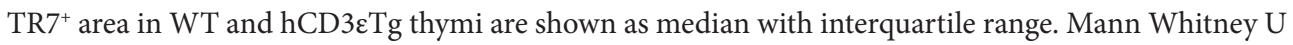
tested, ${ }^{* *}$ denotes statistical significance $(\mathrm{p}<0.01)$. 


\section{Increase of mesenchymal cells is not due to epithelial-mesenchymal transdifferentiation}

The observed increase in mesenchymal proliferating cells in dGuo treated thymic lobes was most likely the result of mesenchymal cell proliferation, but an epithelial-mesenchymal transdifferentiation could however not be excluded. To rule out this latter possibility directly, we employed a genetic labelling method to trace the fate of TECs. For this purpose, FoxN1-cre mice were crossed with CAG-CAT-EGFP reporter mice to irreversibly mark cells expressing FoxN1, the master regulator of TEC development. $15 \mathrm{dpc}$ FT lobes from the F1 offspring were treated with dGuo, and analysed after 6 days (Fig. 6D). Because none of the ER-TR7 ${ }^{+}$cells were $\mathrm{GFP}^{+}$(Fig. 6E), we concluded that the increase in thymic fibroblasts following dGuo treatment was not the consequence of epithelial-mesenchymal transdifferentiation, but from a straight fibroblast lineage from mesenchymal origin that form the network by proliferation.
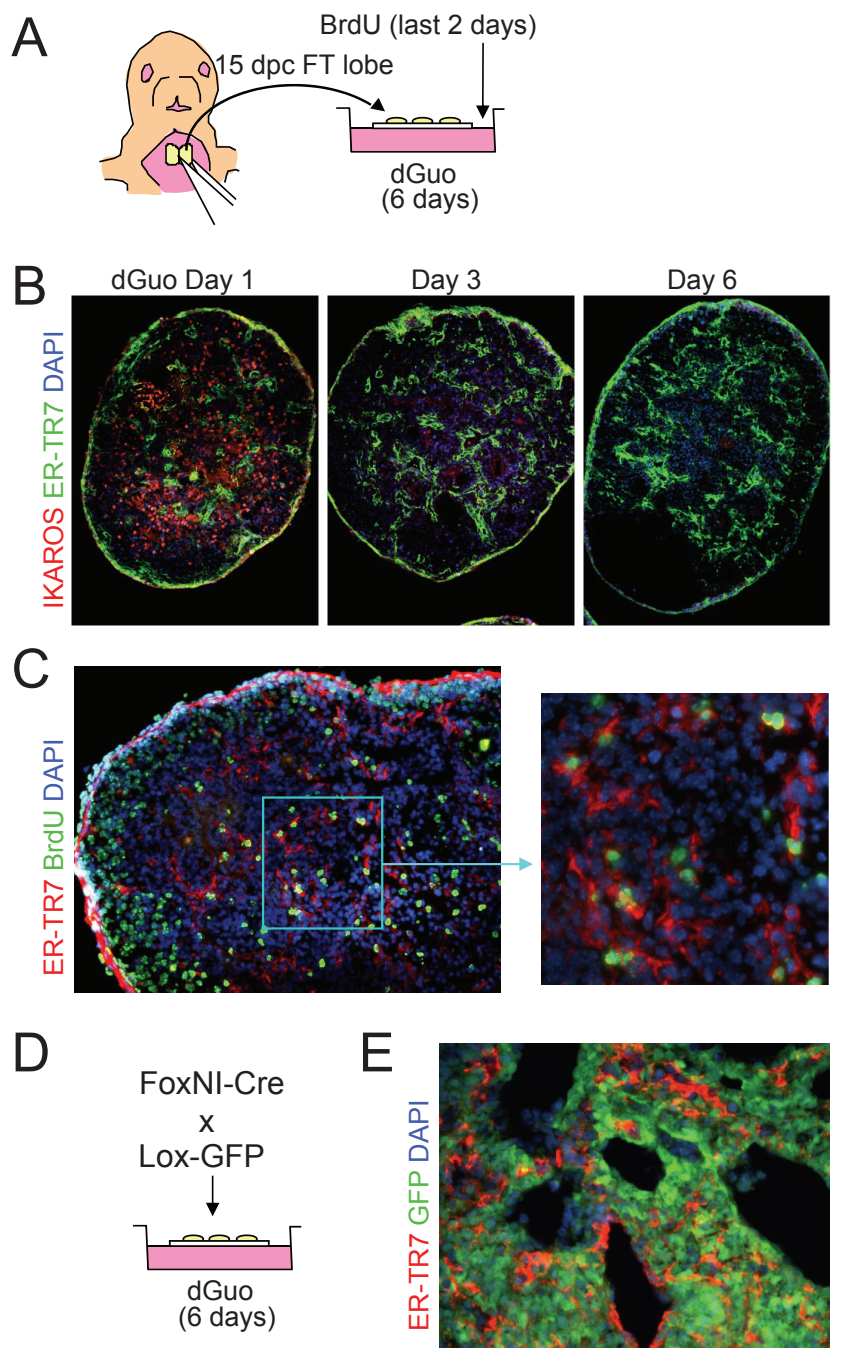
Figure 6: Thymic mesenchymal cell growth and network formation can be induced by depletion of thymocytes and is not due to epithelial-mesenchymal transdifferentiation. A: Experimental procedure. FT lobes at $15 \mathrm{dpc}$ were treated with dGuo for 6 days to deplete thymocytes. B: Immunohistochemical micrographs of lobes obtained on days 1, 3 and 6 after the start of dGuo treatment are shown. The lobes were stained with anti-IKAROS (red), ER-TR7 (green) and nuclei were counter-stained in blue with DAPI. C: Mesenchymal cells divide to form the network. Sections from $15 \mathrm{dpc}$ FT dGuo treated lobes were stained in with ER-TR7 (red) and anti-BrdU (green). Nuclei were counter-stained in blue with DAPI. The higher magnified insert shows the presence of BrdU labelling in nuclei of red ER-TR7 ${ }^{+}$cells.

D: Experimental procedure. FoxN1-Cre mice were mated with Lox-GFP animals. From the offspring, FT lobes at 15 dpc were treated with dGuo for 6 days to deplete thymocytes. E: Immunohistochemical micrograph of a thymic lobe from a WT mouse. The lobe was stained with ER-TR7 (red) while GFP (green) expression can be seen after Cre gets activated by FoxN1 in the epithelial cells. Nuclei were counter-stained in blue with DAPI. The picture shows the mesenchymal network formation of fibroblasts (red) and the clustered TECs (green). None of the fibroblasts have GFP expression indicating that they were not transdifferentiated from epithelial cells.

\section{Gene expression analysis reveals candidate factors involved in mesenchymal network formation}

To identify candidate factors involved in mesenchymal network formation, gene expression profiles of hCDeTg FT TECs were compared to WT FT TECs. In Figure 7, changes in transcripts of growth factors (A), cytokines (B) and chemokines (C) are shown. Examples of genes which expression is at least 3 fold higher in hCDeTg FT TECs are EGF, BMP4, FGF10, IL-33, and CXCL14 and are likely to contribute to mesenchymal network formation. Furthermore, expression of genes like BMP3, IL-6, CXCL9 are at least 3 fold downregulated compared to the WT TECs and are probably involved in the normal inhibition of fibroblast growth. 
A

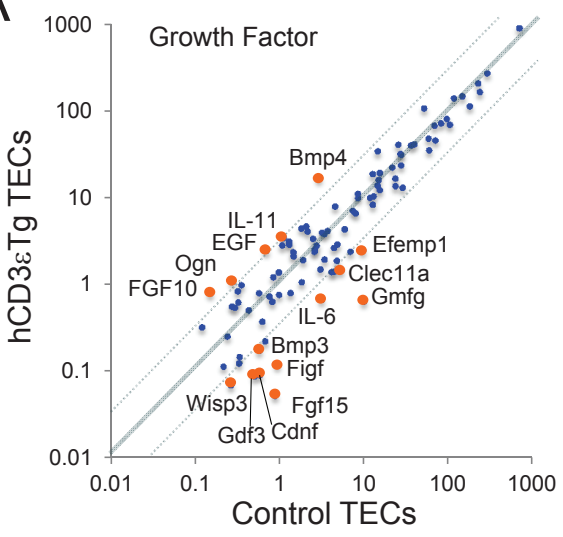

B
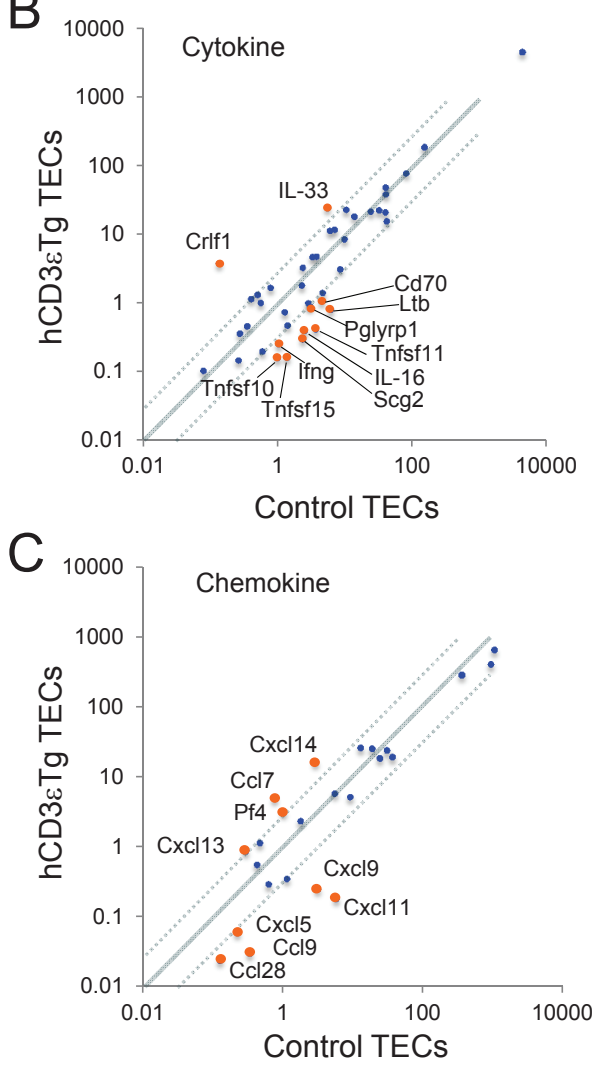

Figure 7: Expression analysis reveals candidate factors involved in mesenchymal network formation. Scatter plots showing fold changes of expression levels of hCDETg TECs compared to WT TECs of growth factors (A), cytokines (B) and chemokines (C) are shown. Diagonal line represents equal expression. Dotted lines represent a 3 times fold change. Each dot represents one gene. Orange dots are considered as differentially expressed. 


\section{Discussion and Conclusion}

In the current chapter we show that an absence of successful thymic crosstalk, in this case caused by hypoxia, is responsible for the growth of mesenchymal cells and for the construction of a network structure of mesenchymal cells during thymus development.

We investigated the interaction between epithelial cells and mesenchyme in the foetal thymus. Since the developing thymus contains hypoxic areas at a distance from the developing mesenchymal network, we hypothesized that hypoxia is the driving force to induce the mesenchymal network development. Hypoxia has been reported to be a normal phenomenon in the adult thymus, as shown by pimonidazole staining that is present in a gradient away from blood vessels ${ }^{27}$. Furthermore, it is believed that hypoxia plays an important role in $\mathrm{T}$ cell development and effector function ${ }^{30}$. In tumours, hypoxia results in angiogenesis to provide more oxygen and nutrients for the cancer cells to grow ${ }^{31}$. This is regulated by the increased expression of many hypoxia-responsive genes; however, in the thymus no such genes are upregulated, suggesting that the mature thymus has adapted to constant hypoxia ${ }^{27}$.

Our data suggest that although hypoxic areas are found in the developing thymus, in such areas thymocyte-TEC crosstalk is impaired, resulting in the development of a mesenchymal network. This was shown by mesenchymal network formation under HOS condition in the absence of thymocyte-TEC crosstalk. Furthermore, hCD3ETg mice that lack proper thymocyte crosstalk show an extensive network of mesenchymal cells. Moreover, thymi from Runx $^{-/}$mice have a defect in thymocytes resulting in impaired crosstalk and show an increased fibroblast expansion inside the lobes as well as a very thick capsule (data not shown). Impaired crosstalk likely allows the formation of new blood vessels guided by the mesenchymal cells to bring oxygen to the areas where it is needed and restoring thymocyteTEC crosstalk, forming network structures of mesenchymal cells and ultimately leading to $\mathrm{T}$ cell differentiation.

Possible mechanisms for the enhanced growth of mesenchymal cells in the absence of thymocyte-TEC crosstalk could be proliferation or epithelial-mesenchyme transition. For instance in cardiogenesis, the epicardium undergoes epithelial-mesenchymal transformation that results in the formation of fibroblasts that in turn play an important role in the further development of the myocardium, the coronary vasculature and the Purkinje fiber network ${ }^{32}$. Among the factors that are responsible for coronary vascular development, FGFs have been identified as a major factor signalling to the FGF receptors 1 and $2^{33}$. FGFR triggering results in hedgehog activation, in turn leading to VEGF and angiopoietin 2 expression with blood vessel formation as result ${ }^{34}$. These hedgehog molecules are also expressed in the thymus by thymic epithelial cells and influence different stages of $\mathrm{T}$ lineage development ${ }^{35-37}$. However, 
our experiments indicated that in the developing thymus, the mesenchymal network grows not because of transdifferentiation but by proliferation.

In the search for factors produced by TECs that are responsible for the invagination and proliferation of the mesenchymal cells, we performed gene expression profiling of TECs from wild type and hCDeTg TECs. Our focus was on growth factors, cytokines and chemokines as they are the likely molecules involved in the process. Based on these findings in light of published findings, we suggest a series of factors that could contribute to mesenchymal network formation in the thymus. The growth factors BMP4 and FGF10 are both upregulated in hCD3عTg TECs, which are known to have effects on thymocyte development ${ }^{38}$. Furthermore, it is known that abrogation of BMP4 expression results in drastically reduced thymus size and interference with stromal development ${ }^{39,40}$. BMP signals are involved in the development of multiple organs, for example the lung, heart and tooth, were BMP is involved in epithelial mesenchymal interactions ${ }^{41-43}$. Together, this suggests BMP4 as a possible inducer of mesenchyme development in the thymus. FGFs are growth factors known to be involved in tissue development. FGF receptors are present on epithelial cells and their ligands are produced by mesenchymal cells ${ }^{44}$. For proper thymus development, FGF Receptor signalling via FGF7 and 10 produced by mesenchymal cells is required ${ }^{45}$, suggesting FGF10 as another interesting candidate involved in fibroblast development in the thymus. As mentioned earlier, EGF is important for mesenchyme development in other tissues. EGF is also upregulated in hCD3ETg TECs suggesting its importance in thymus mesenchyme formation. Interestingly, the chemokine CXCL14 was upregulated in hCD3عTg TECs. CXCL14 can stimulate the growth and migration of fibroblasts in an autocrine manner in cancer ${ }^{46}$, revealing CXCL14 as an interesting candidate for the maintenance of fibroblast growth in normal tissue development. Previously it was shown that mesenchymal cells have crucial roles in epithelial cell differentiation ${ }^{47}$. In the absence of proper cues for TEC development from the mesenchyme, it is conceivable that TECs are unable to produce other growth factors to stimulate mesenchyme growth resulting in a disorganized thymus development. These potential candidates are downregulated in hCD3عTg TECs compared to WT TECs. Another possibility is that TECs produce less growth factors because of impaired crosstalk with thymocytes. One of these factors could be IL-6, which is known to be produced by TECs and is important for T cell development ${ }^{48}$. Taken together, it is highly unlikely that just one factor is involved in thymus mesenchymal network formation and our expression analysis yielded several potential factors. However, further research is needed to elucidate the role and interplay of these candidate proteins for the establishment of a regular mesenchymal network.

In Figure 8A, we propose 2 models for the induction of the thymic mesenchymal network. Model 1 suggests that crosstalk between thymocytes and TECs results in TEC derived signals that inhibit mesenchyme proliferation. Under conditions where this crosstalk is 
abrogated, mesenchymal cells enter the cell cycle because signals that inhibit mesenchymal cell proliferation are missing. In contrast, model 2 foresees the regulation of fibroblast growth to be independent when physiological thymocyte-TEC crosstalk is present. Only when this crosstalk is abrogated, signals will be released from TECs that stimulate mesenchymal fibroblast to proliferate.

Translating these findings to in vivo thymus development, it can be envisioned that initially the anlage grows until it reaches a size where in the middle a hypoxic area develops. As a result, TECs and T cells are stressed resulting in a reduced crosstalk between the two cell types. This hypoxic state may, in analogy to metastatic cancerous cells, induce the signals to fibroblasts to invaginate and allow blood vessels to be formed to meet the metabolic need for oxygen and nutrients. After that, the T cell-TEC crosstalk can continue and the developing thymus grows until several new areas of hypoxia develop followed by new stress signals that in turn further extend the mesenchymal network. This process continues until a fully-grown thymus has developed (Fig. 8B). Although it has been argued that a continuous state of hypoxia exists in cell levels deep away from the blood vessels that is required for thymocytes to develop normally ${ }^{27}$, our data suggest that hypoxia in principal is a negative regulator of $\mathrm{T}$ cell development, and when it occurs, the mesenchymal network is formed to reduce hypoxic places in the thymus.

In conclusion, our results suggest that (temporary) abrogation of thymic crosstalk initiated by hypoxia-induced stress induces the formation of a network structure of mesenchymal cells. This process is necessary for the development of a normal thymus. 
A

Model 1

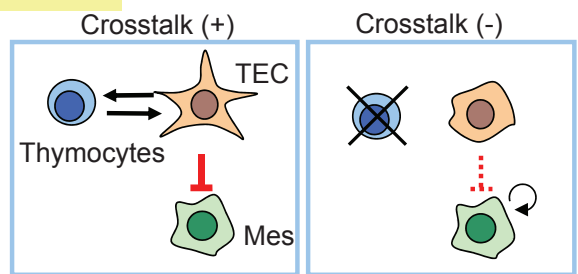

Model 2

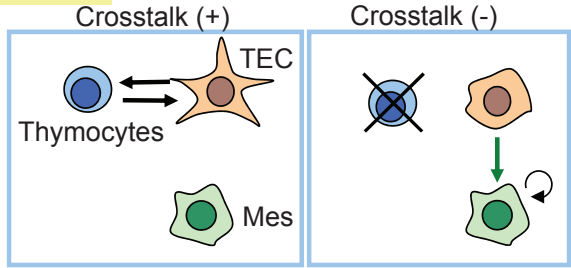

$\mathrm{B}$
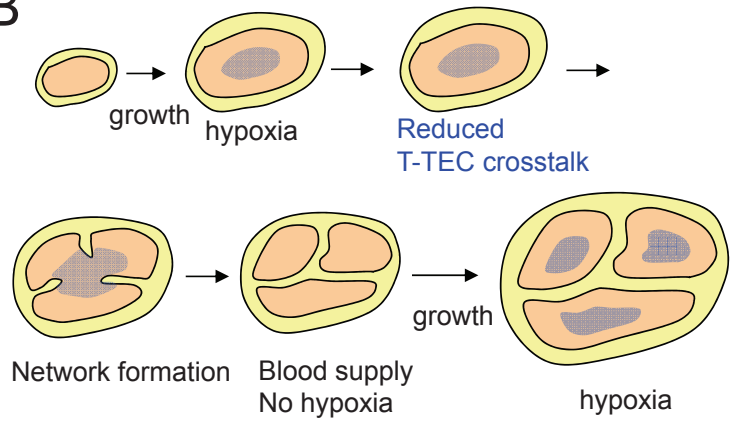

Figure 8: Proposed models through which the mesenchymal network can develop. A: Model 1 proposes that when under normal conditions thymocytes and TECs cross-talk, an active inhibition of mesenchymal network by TEC signals is present. When crosstalk is abrogated, fibroblasts can autonomously develop. Model 2 favours an independent regulation of fibroblasts during physiological $\mathrm{T}$ cell-TEC crosstalk conditions. When crosstalk is abrogated, TECs promote fibroblast proliferation. B: Schematic overview of thymus growth. 


\section{Acknowledgements}

This work was supported by a grant from RIKEN, the Dutch Cancer Society KWF: UM20104671 and with financial support from the Cancer Research Fund Limburg of the Health Foundation Limburg.

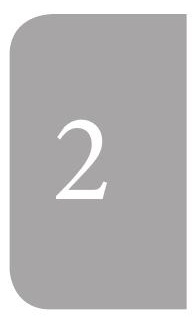




\section{References}

1. Manley NR, Blackburn CC. A developmental look at thymus organogenesis: where do the non-hematopoietic cells in the thymus come from? Curr Opin Immunol. 2003 Apr;15(2):225-32.

2. Rodewald HR. Thymus organogenesis. Annu Rev Immunol. 2008;26:355-88.

3. Adjali O, Marodon G, Steinberg M, Mongellaz C, Thomas-Vaslin V, Jacquet C, et al. In vivo correction of ZAP-70 immunodeficiency by intrathymic gene transfer. J Clin Invest. 2005 Aug;115(8):2287-95.

4. van Ewijk W, Wang B, Hollander G, Kawamoto H, Spanopoulou E, Itoi M, et al. Thymic microenvironments, 3-D versus 2-D? Semin Immunol. 1999 Feb;11(1):57-64.

5. van Ewijk W, Shores EW, Singer A. Crosstalk in the mouse thymus. Immunol Today. 1994 May;15(5):214-7.

6. van Ewijk W, Hollander G, Terhorst C, Wang B. Stepwise development of thymic microenvironments in vivo is regulated by thymocyte subsets. Development. 2000 Apr;127(8):1583-91.

7. Hollander GA, Wang B, Nichogiannopoulou A, Platenburg PP, van Ewijk W, Burakoff SJ, et al. Developmental control point in induction of thymic cortex regulated by a subpopulation of prothymocytes. Nature. 1995 Jan 26;373(6512):350-3.

8. Anderson G, Takahama Y. Thymic epithelial cells: working class heroes for $\mathbf{T}$ cell development and repertoire selection. Trends Immunol. 2012 Jun;33(6):256-63.

9. Germeraad WT, Kawamoto H, Itoi M, Jiang Y, Amagai T, Katsura Y, et al. Development of thymic microenvironments in vitro is oxygen-dependent and requires permanent presence of T-cell progenitors. J Histochem Cytochem. 2003 Sep;51(9):1225-35.

10. Masuda K, Germeraad WT, Satoh R, Itoi M, Ikawa T, Minato N, et al. Notch activation in thymic epithelial cells induces development of thymic microenvironments. Mol Immunol. 2009 May;46(8-9):1756-67.

11. Akiyama T, Shimo Y, Yanai H, Qin J, Ohshima D, Maruyama Y, et al. The tumor necrosis factor family receptors RANK and CD40 cooperatively establish the thymic medullary microenvironment and self-tolerance. Immunity. 2008 Sep 19;29(3):423-37.

12. Boehm T, Scheu S, Pfeffer K, Bleul CC. Thymic medullary epithelial cell differentiation, thymocyte emigration, and the control of autoimmunity require lympho-epithelial cross talk via LTbetaR. J Exp Med. 2003 Sep 1;198(5):757-69.

13. Hikosaka Y, Nitta T, Ohigashi I, Yano K, Ishimaru N, Hayashi Y, et al. The cytokine RANKL produced by positively selected thymocytes fosters medullary thymic epithelial cells that express autoimmune regulator. Immunity. 2008 Sep 19;29(3):438-50.

14. Irla M, Hugues S, Gill J, Nitta T, Hikosaka Y, Williams IR, et al. Autoantigen-specific interactions with CD4+ thymocytes control mature medullary thymic epithelial cell cellularity. Immunity. 2008 Sep 19;29(3):451-63. 
15. Desanti GE, Cowan JE, Baik S, Parnell SM, White AJ, Penninger JM, et al. Developmentally regulated availability of RANKL and CD40 ligand reveals distinct mechanisms of fetal and adult cross-talk in the thymus medulla. J Immunol. 2012 Dec 15;189(12):5519-26.

16. Shinohara $\mathrm{T}$, Honjo T. Epidermal growth factor can replace thymic mesenchyme in induction of embryonic thymus morphogenesis in vitro. Eur J Immunol. 1996 Apr;26(4):747-52.

17. Jenkinson WE, Jenkinson EJ, Anderson G. Differential requirement for mesenchyme in the proliferation and maturation of thymic epithelial progenitors. J Exp Med. $2003 \mathrm{Jul}$ 21;198(2):325-32.

18. Banwell CM, Partington KM, Jenkinson EJ, Anderson G. Studies on the role of IL-7 presentation by mesenchymal fibroblasts during early thymocyte development. Eur J Immunol. 2000 Aug;30(8):2125-9.

19. Anderson G, Anderson KL, Tchilian EZ, Owen JJ, Jenkinson EJ. Fibroblast dependency during early thymocyte development maps to the CD25+ CD44+ stage and involves interactions with fibroblast matrix molecules. Eur J Immunol. 1997 May;27(5):1200-6.

20. Archambeault DR, Tomaszewski J, Joseph A, Hinton BT, Yao HH. Epithelial-mesenchymal crosstalk in Wolffian duct and fetal testis cord development. Genesis. 2009 Jan;47(1):40-8.

21. Birchmeier C, Birchmeier W. Molecular aspects of mesenchymal-epithelial interactions. Annu Rev Cell Biol. 1993;9:511-40.

22. Vroegindeweij E, Crobach S, Itoi M, Satoh R, Zuklys S, Happe C, et al. Thymic cysts originate from Foxn1 positive thymic medullary epithelium. Mol Immunol. 2010 Feb;47(5):1106-13.

23. Kawamoto S, Niwa H, Tashiro F, Sano S, Kondoh G, Takeda J, et al. A novel reporter mouse strain that expresses enhanced green fluorescent protein upon Cre-mediated recombination. FEBS Lett. 2000 Mar 31;470(3):263-8.

24. Van Vliet E, Melis M, Foidart JM, Van Ewijk W. Reticular fibroblasts in peripheral lymphoid organs identified by a monoclonal antibody. J Histochem Cytochem. 1986 Jul;34(7):883-90.

25. Kim D, Pertea G, Trapnell C, Pimentel H, Kelley R, Salzberg SL. TopHat2: accurate alignment of transcriptomes in the presence of insertions, deletions and gene fusions. Genome Biol. 2013;14(4):R36.

26. Trapnell C, Williams BA, Pertea G, Mortazavi A, Kwan G, van Baren MJ, et al. Transcript assembly and quantification by RNA-Seq reveals unannotated transcripts and isoform switching during cell differentiation. Nat Biotechnol. 2010 May;28(5):511-5.

27. Hale LP, Braun RD, Gwinn WM, Greer PK, Dewhirst MW. Hypoxia in the thymus: role of oxygen tension in thymocyte survival. Am J Physiol Heart Circ Physiol. 2002 Apr;282(4):H1467-77.

28. Robinson JM. Wound infection following laryngectomy. The effect of topical ampicillin and carbenicillin. J Laryngol Otol. 1976 May;90(5):415-25.

29. Wang B, Biron C, She J, Higgins K, Sunshine MJ, Lacy E, et al. A block in both early T lymphocyte and natural killer cell development in transgenic mice with high-copy numbers of the human CD3E gene. Proc Natl Acad Sci U S A. 1994 Sep 27;91(20):9402-6.

30. Caldwell CC, Kojima H, Lukashev D, Armstrong J, Farber M, Apasov SG, et al. Differential 
effects of physiologically relevant hypoxic conditions on $\mathrm{T}$ lymphocyte development and effector functions. J Immunol. 2001 Dec 1;167(11):6140-9.

31. Nishida N, Yano H, Nishida T, Kamura T, Kojiro M. Angiogenesis in cancer. Vasc Health Risk Manag. 2006;2(3):213-9.

32. Winter EM, Gittenberger-de Groot AC. Epicardium-derived cells in cardiogenesis and cardiac regeneration. Cell Mol Life Sci. 2007 Mar;64(6):692-703.

33. Lavine KJ, Yu K, White AC, Zhang X, Smith C, Partanen J, et al. Endocardial and epicardial derived FGF signals regulate myocardial proliferation and differentiation in vivo. Dev Cell. 2005 Jan;8(1):85-95.

34. Lavine KJ, White AC, Park C, Smith CS, Choi K, Long F, et al. Fibroblast growth factor signals regulate a wave of Hedgehog activation that is essential for coronary vascular development. Genes Dev. 2006 Jun 15;20(12):1651-66.

35. Crompton T, Outram SV, Hager-Theodorides AL. Sonic hedgehog signalling in T-cell development and activation. Nat Rev Immunol. 2007 Sep;7(9):726-35.

36. Outram SV, Varas A, Pepicelli CV, Crompton T. Hedgehog signaling regulates differentiation from double-negative to double-positive thymocyte. Immunity. 2000 Aug;13(2):187-97.

37. Sacedon R, Varas A, Hernandez-Lopez C, Gutierrez-deFrias C, Crompton T, Zapata AG, et al. Expression of hedgehog proteins in the human thymus. J Histochem Cytochem. 2003 Nov;51(11):1557-66.

38. Tsai PT, Lee RA, Wu H. BMP4 acts upstream of FGF in modulating thymic stroma and regulating thymopoiesis. Blood. 2003 Dec 1;102(12):3947-53.

39. Bleul CC, Boehm T. BMP signaling is required for normal thymus development. J Immunol. 2005 Oct 15;175(8):5213-21.

40. Gordon J, Patel SR, Mishina Y, Manley NR. Evidence for an early role for BMP4 signaling in thymus and parathyroid morphogenesis. Dev Biol. 2010 Mar 1;339(1):141-54.

41. Hogan BL. Bone morphogenetic proteins in development. Curr Opin Genet Dev. 1996 Aug;6(4):432-8.

42. Peters H, Balling R. Teeth. Where and how to make them. Trends Genet. 1999 Feb;15(2):5965.

43. Vainio S, Karavanova I, Jowett A, Thesleff I. Identification of BMP-4 as a signal mediating secondary induction between epithelial and mesenchymal tissues during early tooth development. Cell. 1993 Oct 8;75(1):45-58.

44. Peters KG, Werner S, Chen G, Williams LT. Two FGF receptor genes are differentially expressed in epithelial and mesenchymal tissues during limb formation and organogenesis in the mouse. Development. 1992 Jan;114(1):233-43.

45. Revest JM, Suniara RK, Kerr K, Owen JJ, Dickson C. Development of the thymus requires signaling through the fibroblast growth factor receptor R2-IIIb. J Immunol. 2001 Aug 15;167(4):1954-61.

46. Augsten M, Hagglof C, Olsson E, Stolz C, Tsagozis P, Levchenko T, et al. CXCL14 is an autocrine growth factor for fibroblasts and acts as a multi-modal stimulator of prostate 
tumor growth. Proc Natl Acad Sci U S A. 2009 Mar 3;106(9):3414-9.

47. Itoi M, Tsukamoto N, Yoshida H, Amagai T. Mesenchymal cells are required for functional development of thymic epithelial cells. Int Immunol. 2007 Aug;19(8):953-64.

48. Tseng YL, Wu MH, Yang HC, Wang CY, Lin CF. Autocrine IL-6 regulates GRO-alpha production in thymic epithelial cells. Cytokine. 2010 Aug;51(2):195-201. 


\section{Induced developmental arrest of early haematopoietic progenitors leads to the generation of leukocyte stem cells}

Tomokatsu Ikawa, Kyoko Masuda, Mirelle J.A.J. Huijskens, Rumi Satoh, Kiyokazu Kakugawa, Yasutoshi Agata, Tomohiro Miyai, Wilfred T.V. Germeraad, Yoshimoto Katsura, and Hiroshi Kawamoto

Submitted for publication. 


\section{Abstract}

Self-renewal potential and multipotency are hallmarks of a stem cell ${ }^{1-3}$. It is generally accepted that acquisition of such "stemness" requires rejuvenation of somatic cells through reprogramming of their genetic and epigenetic status. We show here that a simple block of cell differentiation is sufficient to induce and maintain stem cells. By overexpression of the transcriptional inhibitor Id 3 in murine haematopoietic progenitor cells and cultivation under $\mathrm{B}$ cell induction conditions, the cells undergo developmental arrest and enter a self-renewal cycle. These cells can be maintained in vitro almost indefinitely and the long-term cultured cells exhibit robust multi-lineage reconstitution when transferred into irradiated mice. These cells can be cloned and re-expanded with 50\% plating efficiency, indicating that virtually all cells are self-renewing. Equivalent progenitors were produced from human cord blood stem cells and these will ultimately be useful as a source of cells for immune cell therapy. 


\section{Introduction}

Somatic tissues with high turn-over rates, such as skin, intestinal epithelium, and haematopoietic cells, are maintained by the activity of self-renewing stem cells, which are present in only limited numbers in each organ ${ }^{4-6}$. For example, the frequency of haematopoietic stem cells (HSCs) in the mouse is about 1 in $10^{5}$ of total bone marrow cells ${ }^{7}$. Once HSCs begin the differentiation process, their progeny cells have hardly any self-renewal capacity, indicating that self-renewal is a very special feature endowed only to stem cells.

Cells such as embryonic stem (ES) cells that retain self-renewal potential and multipotency only in vitro can also be included in the category of stem cells. Such stemness of ES cells is thought to be maintained by formation of a core transcriptional network and an epigenetic status unique to ES cells ${ }^{8-10}$. Indeed, a stem cell equivalent to ES cells, called the induced pluripotent stem cells (iPS cells), can be produced from somatic cells by over-expression of only a few specific transcription factors (Oct3/4, Sox2, Klf4, and c-Myc), which are thought to be the essential components in forming the core network of transcriptional factors that define the status of ES cells ${ }^{11-13}$. It is thus generally conceived that acquisition of such a network for a somatic cell depends on the "reprogramming" of both the genetic and epigenetic status of that cell.

On the other hand, it could be envisioned that the self-renewing status of cells represents a state where their further differentiation is inhibited. It is known, for example, that to maintain ES/iPS cells, factors such as LIF and bFGF are required for mouse and human cultures respectively ${ }^{14,15}$, and these factors are thought to block further differentiation of the cells. In this context, it has previously been shown that systemic disruption of transcription factors essential for the B cell lineage, such as PAX5, E2A, and EBF1, leads to the emergence of selfrenewing multipotent haematopoietic progenitors, which can be maintained under specific culture conditions ${ }^{16-19}$. Therefore, it would seem theoretically possible to make a stem cell by inducing inactivation of these factors at particular developmental stages. Conditional depletion of PAX5 in B cell lineage committed progenitors as well as mature B cells resulted in the generation of $\mathrm{T}$ cells from the $\mathrm{B}$ lineage cells ${ }^{16,20,21}$. These studies, however, were mainly focused on the occurrence of cell-fate conversion by "de-differentiation" of target cells. Therefore, the minimal requirement for the acquisition of self-renewal potential remains undetermined.

Our ultimate goal is to obtain sufficient number of stem cells by expansion to overcome the limitation of cell numbers for immune therapies. We hypothesize that stem cells can be produced by simply blocking differentiation. 


\section{Materials and methods}

\section{Mice}

C57BL/6 (B6) and B6Ly5.1 mice were purchased from CLEA Japan Inc (Tokyo, Japan). NOD/ Shi-scid, IL2R $\gamma$ null (NOG) mice were purchased from the Central Institute for Experimental Animals (Kanagawa, Japan). 6 to 8 week old female mice were used for the transfer experiments. Embryos at various stages of gestation were obtained from timed pregnancies. The day of observing the vaginal plug was designated as $0 \mathrm{dpc}$.

\section{Antibodies}

The following antibodies were purchased from BD PharMingen (San Jose, CA): Ly5.1 (A20), Ly5.2 (104), c-Kit (2B8), Sca-1 (D7), erythroid lineage cells (TER119), Mac1 (M1/70), Gr1 (RB6-8C5), CD11c (HL3), B220 (RA3-6B2), Thy1.2 (53-2.1), CD8 (53-6.7), CD4 (H129.19), NK1.1 (PK136), CD3ع (145-2C11), CD19 (1D3), anti-class II (M5/114), F4/80 (BM8), CD25 (PC61), human CD11c (B-ly6), human CD19 (H1B19), human CD33 (P67.6), human CD56 (B159) and human HLA-DR (D46-6). TER119, Mac1, Gr1, B220, CD19, NK1.1, CD3ع, CD4, and CD8 were used as Lin markers.

\section{Growth factors}

Recombinant murine (rm) SCF, IL-1 $\alpha$, IL-3, IL-7, IL-15, Flt3-ligand, G-CSF, M-CSF and GMCSF and recombinant human (rh) SCF, IL-7, IL-15, Flt3-ligand, GM-CSF and TNFa were purchased from R\&D (Cambridge, MA).

\section{Isolation of haematopoietic progenitors}

Single cell suspensions of foetal liver (FL) cells from 13-15 dpc embryos or bone marrow (BM) cells of B6CD45.1 mice were prepared as described previously ${ }^{24}$. Cells were then incubated with monoclonal antibodies specific for anti-Lineage markers (TER119, Mac1, Gr1, B220, Thy1.2) for 20min on ice. Lin ${ }^{+}$cells were depleted with Dynabeads Sheep anti-Rat IgG (Invitrogen) according to the manufacturer's protocol. The Lin' cells were used for cell sorting. The procedure for isolating $\mathrm{Lin}^{-} \mathrm{c}-\mathrm{Kit}^{+} \mathrm{Sca}^{-} 1^{+}$(LKS) populations from FL and BM and Pro B cells (IgM-B220+CD $\left.19^{+} \mathrm{CD}^{-} 3^{+}\right)$and Immature B $\left(\mathrm{IgM}^{+} \mathrm{B} 220^{+} \mathrm{CD} 19^{+}\right)$cells from $\mathrm{BM}$ has been described elsewhere ${ }^{17,23}$.

\section{Retroviral constructs, viral supernatants and transduction}

The TAC retroviral vector ( $\mathrm{pCS}$ retTAC) is based on S-001 retrovirus construct (obtained from $\mathrm{H}$. Spits) and was generated by replacing the coding sequence of EGFP with the human IL2RA gene encoding CD25. The full-length cDNA for murine Id3 (Inhibitor of DNA binding 3) was cloned into the pCSretTAC vector (mId3-TAC). The Id3-ERT2 fusion construct containing the full-length cDNA for human Id3 fused to the mutated ligand-binding domain of the 
human estrogen receptor (ERT2) was cloned into the pMCS retrovirus vector, a gift from T. Kitamura. The human Id3 cDNA was cloned into the pMX retrovirus construct (obtained from T. Kitamura). Virus was generated by transfection of the various constructs into the Plat E packaging cell line using FuGENE 6 Transfection Reagent (Roche). For generating mouse induced haematopoietic progenitor mIdHP cells, FL LKS progenitors from B6Ly5.1 mice $\left(\mathrm{CD} 45.1^{+}\right)$were isolated as described above. The LKS cells were transduced with pCSretTAC (control) and mId3-TAC virus supernatants as described previously ${ }^{17}$. After spin infection, the cells were cultured at $37^{\circ} \mathrm{C}, 5 \% \mathrm{CO}_{2}$ for 2 days. The transduced cells were harvested and stained with anti-human (h)CD25 antibody and the hCD25 cells were sorted and cultured on TSt-4 stromal cells in the presence of 10ng each of rmSCF, rmIL-7 and rmFlt3-ligand. In the case of hIdHP cells, CD $34^{+}$cells in human cord blood cells were used as a source of progenitors. Human $\mathrm{CD} 34^{+}$cells were transduced with pMX-hId3 retrovirus in a same manner as the mIdHP cells. After two days, the $\mathrm{GFP}^{+}$cells were isolated and cultured on TSt-4 stromal cells in the presence of rhSCF, rhTPO, rhIL-7 and rhFlt3-ligand.

\section{Co-culture with stromal cells}

To assess granulocyte/macrophage potential of murine Id3-IdHP cells, $1 \times 10^{4}$ cells per well were cultured with TSt- 4 stromal cells in the presence of rmG-CSF $(10 \mathrm{ng} / \mathrm{ml})$ for 14 days. Generated cells were counted, stained with Mac1, and FACS-sorted $\mathrm{Macl}^{+}$cells were centrifuged onto glass slides for Wright's staining. For the detection of B and myeloid potential of progenitors, mIdHP cells were cultured with TSt 4 cells for 14 days. Generation of myeloid and B cells was detected by flow cytometric analysis of Mac1 versus CD19 expression. For the detection of T cell potential, TSt-4 cells that had been retrovirally transduced with the murine dll1 gene (TSt-4/DLL1 cells) ${ }^{19}$ were used. Medium was supplemented with rmSCF $(2 \mathrm{ng} / \mathrm{ml}), \mathrm{rmIL}-7(2 \mathrm{ng} / \mathrm{ml})$ and $\mathrm{rmFlt}-3 \mathrm{~L}(2 \mathrm{ng} / \mathrm{ml})$. Generation of T cells was detected by subsequent flow cytometric analysis. To assess NK and DC potential of hIdHP cells, $1 \times 10^{4}$ cells were cultured with TSt-4 cells in the presence of rhIL-15 (for NK cells) or rhSCF, rhGMCSF and rhTNFa (for DCs). All co-cultures were maintained in RPMI 1640 medium (Gibco BRL, Grand Island, NY) supplemented with $10 \%$ FCS, L-glutamine $(2 \mathrm{mM})$, sodium pyruvate $(1 \mathrm{mM})$, sodium bicarbonate $(2 \mathrm{mg} / \mathrm{ml})$, nonessential amino acid solution $(0.1 \mathrm{mM}$, Gibco

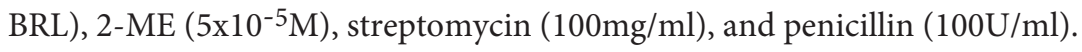

\section{Cloning of mIdHP cells}

Single mIdHP cells were seeded on TSt- 4 cells in the presence of SCF, IL-7 and Flt3-ligand in a 96 well plate. The colonies of single mIdHP cells were picked up and expanded in the same condition in larger plates for approximately 4 weeks. The cloned mIdHP cells were harvested, stained with specific markers and analysed by flow cytometry.

\section{CFU-C assay}

LKS, control and IdHP cells ( $1 \times 10^{4}$ cells per dish) were cultured in triplicate for 7 days in 
aMEM (Gibco/BRL) containing 30\% FCS, 1\% methylcellulose, 1\% bovine serum albumin, 2-ME $\left(5 \times 10^{-5} \mathrm{M}\right)$, L-Glutamine (1mM), rmSCF (10ng/ml), rmIL-3 (10ng/ml), rmGM-CSF (10ng/ml), rmIL-1 $\alpha(10 \mathrm{ng} / \mathrm{ml}), \mathrm{rmG}-\mathrm{CSF}(10 \mathrm{ng} / \mathrm{ml})$ and rmM-CSF $(10 \mathrm{ng} / \mathrm{ml})$.

\section{Adoptive transfer of mIdHP and hIdHP cells}

For mIdHP transfer, $1 \times 10^{6} \mathrm{mIdHP}$ cells $\left(\mathrm{CD} 45.1^{+}\right)$were intravenously injected into the tail vain of sublethally irradiated (650 rad) Rag1-deficient mice (CD45.2). Mice were analysed 4-6 weeks after reconstitution for donor chimerism in BM, spleen and thymus. For hIdHP transfer, $1 \times 10^{6} \mathrm{hIdHP}$ cells were intravenously injected into the tail vain of sublethally irradiated (240 rad) NOG mice. Mice were analysed 6-10 weeks after reconstitution for donor chimerism in $\mathrm{BM}$, spleen and thymus.

\section{PCR analysis of IgH gene rearrangement}

The analysis of $\operatorname{IgH}$ gene rearrangement was performed as previously described ${ }^{17}$. In brief, genomic DNA was prepared from CD $45.1^{+}$cells derived from thymus, spleen and BM in IdHP transplanted mice using DNeasy tissue kit (Qiagen). The reaction volume was $20 \mu \mathrm{l}$, containing $2 \mathrm{ul}$ of genomic DNA (approximately equivalent to $10^{4}$ cells), $2 \mu \mathrm{l}$ of $10 \mathrm{xPCR}$ buffer, $0.16 \mu \mathrm{l}$ of $25 \mathrm{mM}$ dNTPs $4 \mathrm{pmol}$ of each primer, and $0.6 \mathrm{U}$ of Taq polymerase (GE healthcare). The PCR reactions were performed as follows: $5 \mathrm{~min}$ at $94^{\circ} \mathrm{C}$ followed by 35 cycles of $1 \mathrm{~min}$ at $94^{\circ} \mathrm{C}, 1 \mathrm{~min}$ at $60^{\circ} \mathrm{C}, 2 \mathrm{~min}$ at $72^{\circ} \mathrm{C}$, and finally $10 \mathrm{~min}$ at $72^{\circ} \mathrm{C}$. Amplified DNA products were analysed on an agarose gel followed by ethidium bromide staining.

\section{RNA extraction and Quantitative RT-PCR}

Total RNA was isolated using a RNeasy kit (Qiagen). cDNA synthesis was performed using Superscript III (Invitrogen) following the manufacturer's protocol. Real-time PCR was performed using SYBR Premix EX Taq (Takara) and analysed by StepOnePlus (Applied Biosystems). The reactions were performed in duplicate at $95^{\circ} \mathrm{C}$ for $10 \mathrm{sec}$, followed by 40 cycles of $95^{\circ} \mathrm{C}$ for $5 \mathrm{sec}, 55^{\circ} \mathrm{C}$ for $30 \mathrm{sec}$. The primer sequences used are shown in Supplemental Table 1.

\section{Microarray analysis}

RNA extraction was performed as described above. The expression profiles were analysed using the 3D-Gene Mouse Oligo chip 24K (Toray Industries, Tokyo, Japan). The fluorescence intensities were detected using the Scan-Array Lite Scanner (Perkin-Elmer, Waltham, MA). The PMT levels were adjusted to achieve 0.1\%-0.5\% pixel saturation. Each TIFF image was analysed using the Gene Pix Pro 6.0 software (Molecular Devoices, Sunnyvale, CA). The data were filtered to remove low-confidence measurements and were globally normalized per array, such that the median of the signal intensity was adjusted to 50 after normalization (accession number: GSE46158). 


\section{Results}

As mentioned above, self-renewing multipotent progenitors can be produced by culturing E2A-deficient haematopoietic progenitors in B cell inducing conditions ${ }^{17}$. Since it remains unclear at which developmental stage the acquisition of self-renewing potential has occurred in the case of such a systemic deletion, we thought to develop a method in which E2A function could be inactivated and reactivated in an inducible manner. We decided to use the $\mathrm{Id} 3$ protein for this purpose, because it is known that Id proteins serve as dominant negative inhibitors of E-proteins ${ }^{19,22}$. Murine haematopoietic progenitors isolated as $\mathrm{Lin}^{-} \mathrm{C} \mathrm{Kit}^{+} \mathrm{Sca}-1^{+}$(LKS) cells from foetal liver (FL) were transduced with a retroviral vector containing Id3 or a control vector (control), and the transduced cells were cultured under B cell inducing conditions (Fig. 1A). The LKS cells transfected with the control vector differentiated into CD19+ B cells, but the Id 3 over-expressing cells showed developmental arrest at the B220 ${ }^{\text {low }} \mathrm{CD} 19^{-}$stage (Fig. 1B). Transcript levels of B lineage-associated genes (e.g. CD79a, CD79b and VpreB) in Id3induced haematopoietic progenitor (IdHP) cells were at least 10 fold lower than those in control cells. Instead, the IdHP cells prominently express genes associated with other lineages (e.g. GATA3, GATA1, and c/EBPa, Supplemental Fig. 1). Moreover, only IgH D-J but not V-DJ recombination was detectable in IdHP cells (Supplemental Fig. 2). These data indicate that the IdHP cells are phenotypically equivalent to so-called pre-pro B cells, and are almost indistinguishable from the previously reported E2A-deficient multipotent progenitors ${ }^{17}$.

The IdHP cells are relatively large blastic cells, morphologically similar to pre-pro B cells (Fig. $1 \mathrm{C}, \mathrm{D}$ ), and their gene expression profile is very similar to E2A-deficient progenitors (Fig. 1E). The IdHP cells expanded exponentially, i.e. $10^{7}$ fold in one month (Fig. 1F), and could be maintained for several months. When transferred to culture conditions inductive for myeloid, $\mathrm{B}$ or T lineages, the IdHP cells exhibited the potential to produce all these cell types (Fig. 1G, Supplemental Fig. 3); however, erythroid potential was hardly detected (data not shown). B cells were presumably produced by silencing of the retroviral expression of Id 3 as described below. 
A

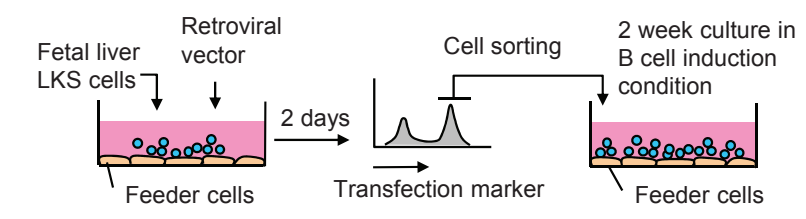

B
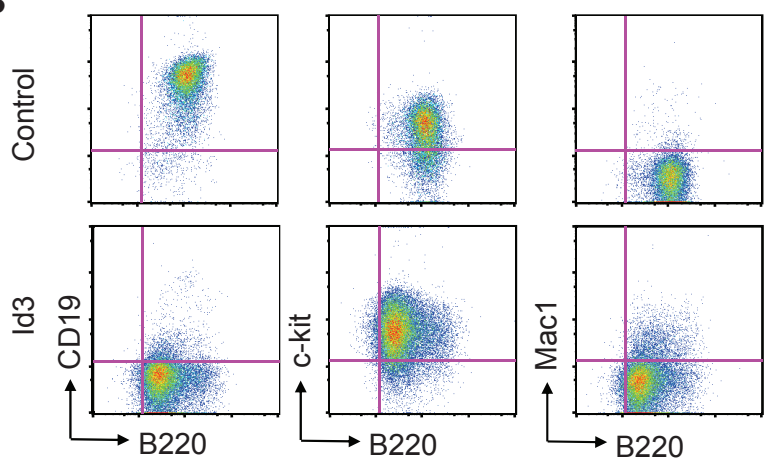

E

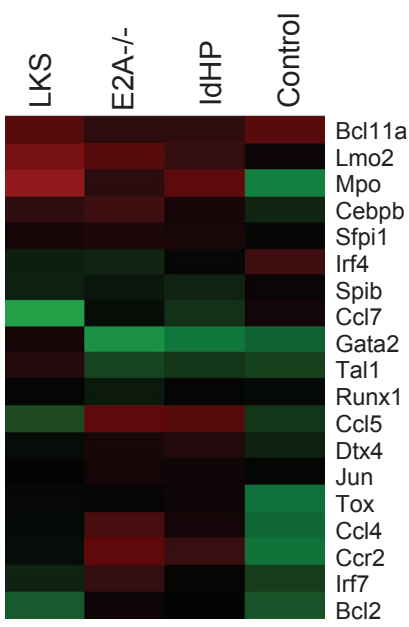

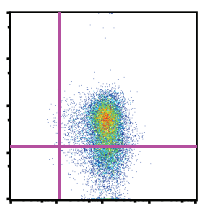

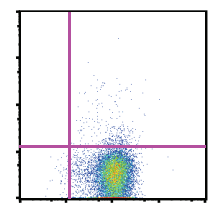

F

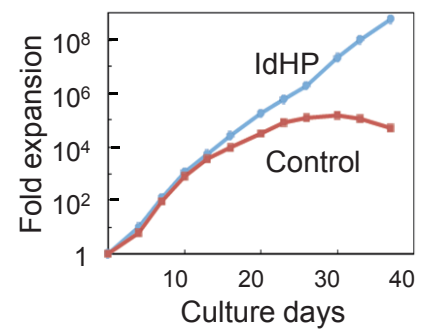

H

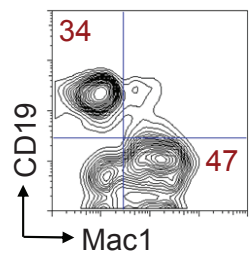

C

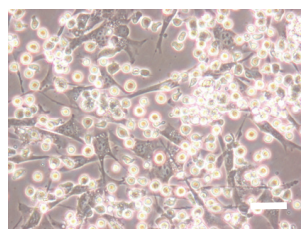

D

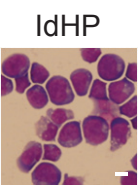

LKS

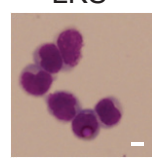

ProB

Immat B
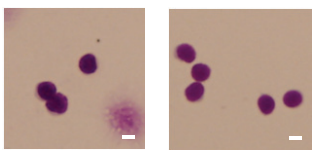

G

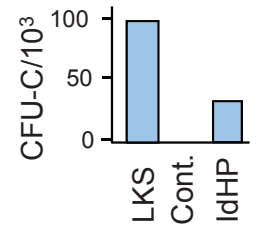

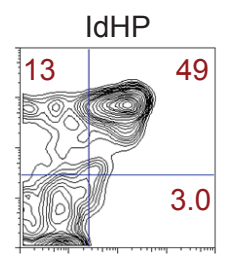

Figure 1: Generation of IdHP cells from murine haematopoietic stem/progenitor cells. A: Schematic representation of Id3-IdHP cell generation. B: Flow cytometric analysis of control (empty vector) and Id3-overexpressing FL progenitor cells. C: Photomicrograph of IdHP cells. Scale bar, 10 $\mu$ m. D: Wright's staining of IdHP cells, LKS cells, pro B cells and Immature B cells from bone marrow. Scale bars, $10 \mu \mathrm{m}$. E: Microarray analysis of gene expression in LKS cells, E2A ${ }^{-1-} \mathrm{HP}$ cells, IdHP cells, and pro B cells derived from cultures of control vector-expressing FL progenitors. F: In vitro expansion of IdHP and control cells. Viable cells were counted at each time point. G: CFU-C assay of LKS, control and IdHP cells. H: Myeloid and B cell generation from IdHP cells in vitro. Flow cytometric profiles of IdHP cells cultured on TSt- 4 stromal cells for 14 days are shown. I: T cell generation from IdHP cells in vitro. Flow cytometric profiles of control and IdHP cells cultured on TSt-4/DLL1 stromal cells for 12 days are shown. 
We then tested the developmental potential of IdHP cells in vivo. A total of $1 \times 10^{6}$ IdHP cells (CD45.1)/mouse were transferred intravenously into sublethally irradiated Rag1-deficient mice (CD45.2, Fig. 2A). After 4 weeks, myeloid cells (Mac1 ${ }^{+} \mathrm{CD} 19^{-}$cells), NK cells (CD3-NK1.1 ${ }^{+}$ cells), and T cells (CD3 ${ }^{+} \mathrm{NK} 1.1^{-}$cells) were observed in the CD45.1 $1^{+}$fraction in peripheral blood of the recipient mice (Fig. 2B). A substantial number of B cells were also detected in these recipients. In these B cells, down-regulated expression of the retroviral reporter, hCD25 was seen (Supplemental Fig. 4), which often occurs with a retrovirally introduced gene. Such B cell generation indicates that IdHP cells have the potential to produce B cells, a clear difference from E2A-deleted progenitors. T, B, and myeloid cells were generated in thymus, spleen and $\mathrm{BM}$ of mice reconstituted with the IdHP cells at 7 weeks of transplantation (Supplemental Fig. $5 \mathrm{~A}, \mathrm{~B})$. The $\mathrm{CD}^{+}{ }^{+} \mathrm{T}$ cells in spleen generated from the IdHP cells normally proliferated upon anti-CD3/28 stimulation (Supplemental Fig. 5C), confirming the multilineage differentiation potential and functionality of the IdHP cells.

To examine whether IdHP cells retain self-renewal potential, a total of 96 IdHP cells were individually seeded and cultured in the same conditions (Fig. 2C). Each clone was expanded with a plating efficiency of $50 \%$. All the clones were able to proliferate unlimitedly like IdHP cells as long as the cells were properly cultured. Three randomly selected clones were further expanded and the cells ( $1 \times 10^{6}$ cells/mouse) were subsequently transferred into sublethally irradiated recipient mice. In the peripheral blood of these recipients, reconstitution of myeloid cells, B cells, NK cells and T cells derived from transferred cells was observed (Fig. 2D). Mice transplanted with clone 5 cells were sacrificed 8 weeks after the transfer and cells from the thymus, spleen and $\mathrm{BM}$ were analysed. In $\mathrm{BM}, \mathrm{Mac1}^{+} \mathrm{Gr}^{+}$myeloid cells were observed among the CD $45.1^{+}$cells (Fig. 2E, Supplemental Fig. 6). CD $45.1^{+} \mathrm{CD} 4^{+} \mathrm{CD} 8^{+} \mathrm{DP}$ cells, as well as $\mathrm{CD}^{+} \mathrm{SP}$ and $\mathrm{CD} 8^{+} \mathrm{SP}$ cells were seen in the thymus, and $\mathrm{CD} 45.1^{+} \mathrm{B} 220^{+} \mathrm{IgM}^{+}$mature $\mathrm{B}$ cells were found in the spleen (Fig. 2E, Supplemental Fig. 6). These data indicate that production of several lineages of cells is ongoing in recipient mice. Since IdHP cells are originally derived from pre-pro B stage cells, they usually bear at least single allele of DH-JH rearrangements of the IgH genes. Clone 5 had a rearrangement involving the JH3 gene segment, and all lineages of cells from various tissues in recipient animals transferred with clone 5 cells had the same rearrangement (Fig. 2F), indicating that all progeny cells were in fact derived from clone 5.

To determine whether IdHP cells can also be generated from adult BM progenitors, the LKS cells in BM of B6Ly5.1 mice were transduced with a retroviral vector containing Id3 and the transduced cells were cultured under B cell inducing conditions. The IdHP cells were generated in one month, just like FL-derived IdHP cells. The BM-derived IdHP cells exponentially expanded and could be maintained at least for several months similar to the FL-IdHP cells. To determine the developmental potential of the BM-IdHP cells in vivo, $1 \times 10^{6} \mathrm{IdHP}$ cells/ mouse were transplanted into sublethally irradiated immunodeficient (NOG) mice. After 7 weeks, $\mathrm{Macl}^{+} \mathrm{Gr}^{+}$myeloid cells were observed among the CD45.1 ${ }^{+}$cells in BM (Supplemental 


\section{Chapter 3}

Fig. 7). CD $45 \cdot 1^{+} \mathrm{CD} 4^{+} \mathrm{CD} 8^{+} \mathrm{DP}$ cells, as well as $\mathrm{CD} 4^{+} \mathrm{SP}$ and $\mathrm{CD} 8^{+} \mathrm{SP}$ cells were seen in the thymus, and $\mathrm{CD} 45.1^{+} \mathrm{B} 220^{+} \mathrm{IgM}^{+}$mature B cells were found in the spleen (Supplemental Fig. 7). The $\mathrm{CD}^{+} \mathrm{T}$ cells in the spleen generated from BM-IdHP cells proliferated and secreted various cytokines in response to anti-CD3/28 stimulation in vitro (Supplemental Fig. 8). These data indicate that the self-renewing IdHP cells with similar developmental potential and functionality can be generated from adult BM.

To examine whether IdHP cells are really arrested early in B cell development, we utilized the Id3 protein fused with estrogen receptor, Id3-ER, a more controllable system for the expression of Id3, in which Id3-ER protein normally resides in the cytoplasm but goes into the nucleus and functions as a transcriptional inhibitor for E-proteins only when 4-hydroxytamoxifen (4OHT) is added ${ }^{23}$. LKS cells from FL of B6Ly5.1 mice that had been transduced with the Id3ER retrovirus and cultured in the presence of 4-OHT showed a similar developmental arrest and entered a self-renewal cycle similar to IdHP cells (Fig. 2G, H). Removal of 4-OHT did not have any impact on cell growth for at least 10 days, but virtually all cells became CD19+ within 7 days (Fig. 2I), indicating that arrested cells restarted differentiation towards B cells upon removal of 4-OHT. These results indicate that IdHP cells represent cells differentiating towards the B cell lineage but are arrested just prior to the B cell lineage determination step, waiting for appropriate developmental cues.

Thus, by definition, IdHP cells satisfy the criteria of "stem cells", that are restricted to production of leukocytes. We therefore designate these cells iLS (induced leukocyte stem) cells as a more general term. iLS cells are not reprogrammed or de-differentiated, but only developmentally arrested. Therefore, we propose that the blockage of differentiation due to the absence of developmental cues is sufficient to make stem cells. 
A

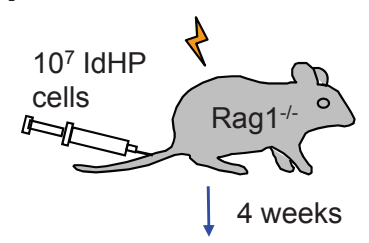

Peripheral blood

C
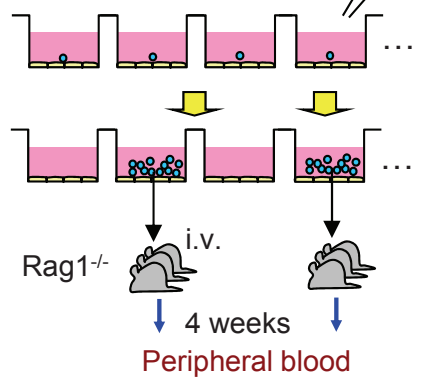

B
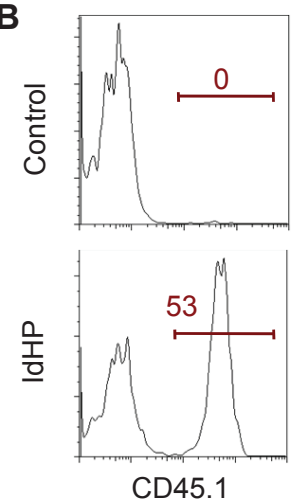

D

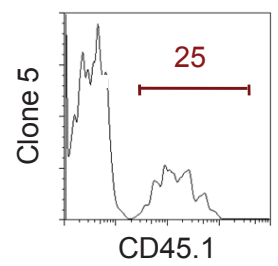

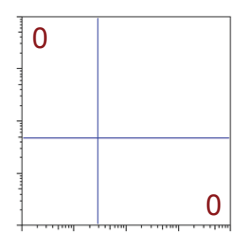
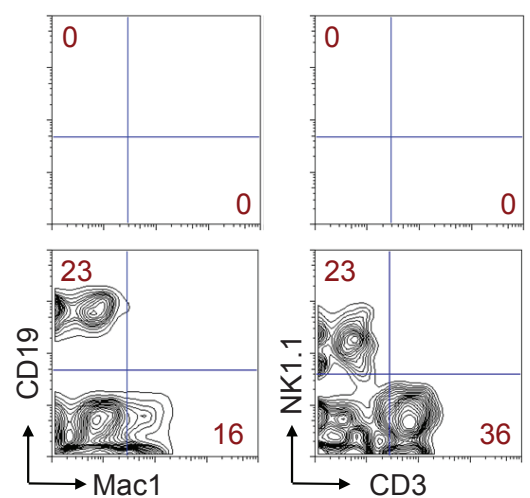
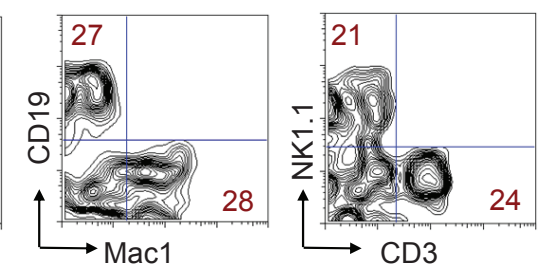

E

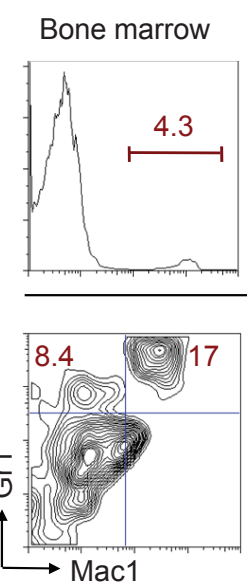

Thymus
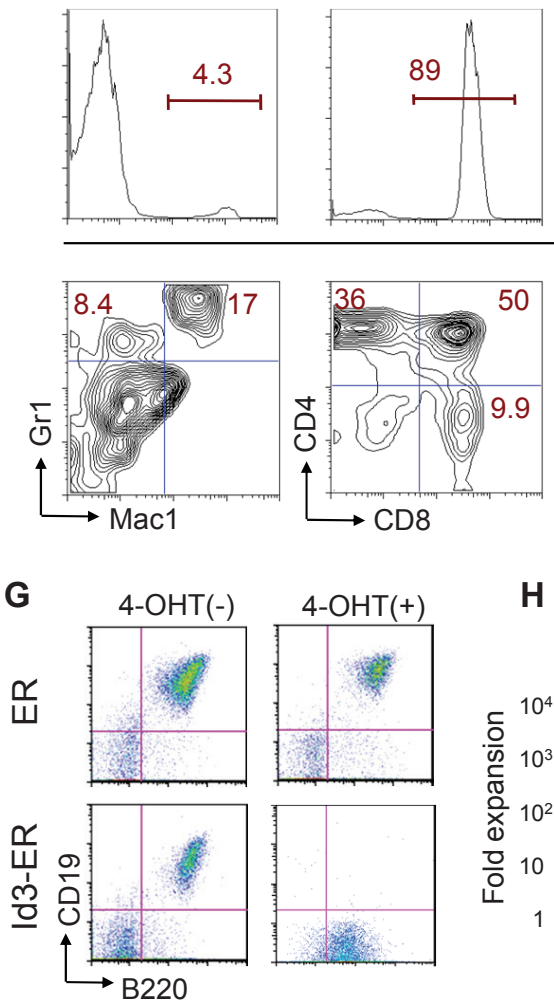

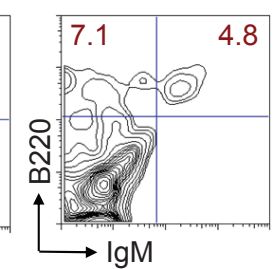

Spleen

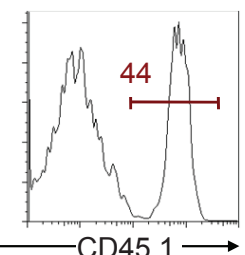

H

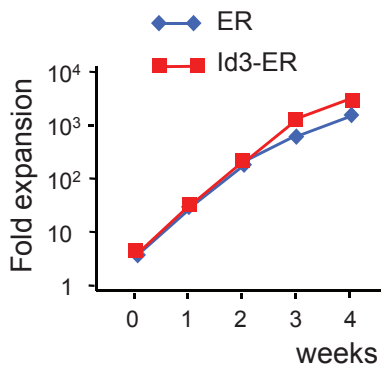

$\mathbf{F}$
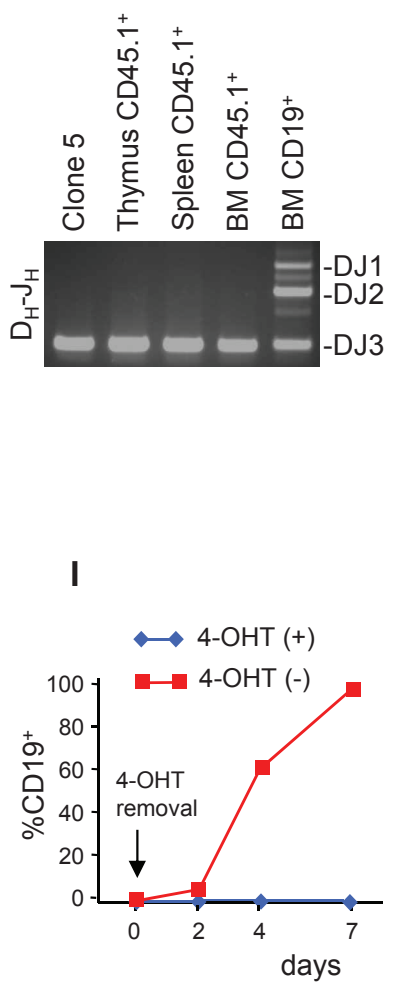
Figure 2: Lympho-myeloid lineage potential of IdHP cells. A: Schematic representation of the in vivo model for investigating the developmental potential of IdHP cells. B: Flow cytometric analysis of cells in BM of mice transplanted with control or IdHP cells 4 weeks after injection. Donor derived peripheral blood mononuclear cells (PBMCs, CD45.1 $1^{+}$were analysed for the expression of Mac1 versus CD19 and CD3 versus NK1.1. C: Schematic representation of cloning of IdHP cells and analysis of the developmental potential of individual IdHP clones. D: Generation of lymphoid and myeloid lineage cells in Rag1 ${ }^{-1}$ recipients transplanted with cloned IdHP cells. Flow cytometric profiles of donor type (CD45.1 $1^{+}$PBMCs are shown. E: Analysis of thymus, spleen, and bone marrow cells in the mice generated in experiment (B). F: Analysis of IgH D-J rearrangement in the donor type (CD45.1 $1^{+}$cells of thymus, spleen and BM of mice used in experiment (B and C). G: Developmental potential of foetal liver (LKS) progenitors transduced with control (ER) and Id3-ER retrovirus. After transduction, GFP ${ }^{+}$ cells were sorted and cultured on TSt-4 stromal cells supplemented with SCF, IL-7 and Flt3-ligand in the presence or absence of 4-OHT for 4 weeks. Flow cytometric profiles for CD19 versus B220 are shown. H: Expansion of foetal liver (LKS) progenitors transduced with control and Id3-ER retrovirus in the presence of 4-OHT. Viable cells were counted at the indicated time points. I: B cell generation from Id3-ER transduced cells after withdrawal of 4-OHT. The percentage of $\mathrm{CD} 19^{+}$cells at the indicated time points is shown.

Self-renewing progenitor cells whose development can be controlled are a potential source for human immune cell therapy. We therefore attempted to produce human iLS cells. CD34 ${ }^{+}$ cord blood cells were transduced with a retrovirus encoding the human Id 3 gene and cultured under B cell inducing conditions. In the control vector group, cells differentiated into CD19+ $\mathrm{B}$ cells, although cells expressing the myeloid marker CD33 were also generated under this condition (Fig. 3A). In the Id3 over-expression group, cells exhibited higher forward/side scatter properties (Fig. 3A), with larger size and more cytoplasm (Fig. 3B), indicating that these are blastic cells. Just like murine iLS cells, human iLS cells showed exponential growth for at least several weeks (Fig. 3C), although with a slower growth rate. These human iLS cells retained the potential to give rise to NK cells and dendritic cells (DCs) in vitro (Fig. 3D, E). When transferred into sublethally irradiated NOG mice (Fig. 3F), human iLS cells gave rise to $\mathrm{B}$ cells $\left(\mathrm{CD} 19^{+} \mathrm{CD} 33^{-}\right)$and monocytes $\left(\mathrm{CD} 33^{+} \mathrm{CD} 14^{+}\right)$in $\mathrm{BM}$ of the reconstituted mice (Fig. 3G, Supplemental Fig. 9). 
A
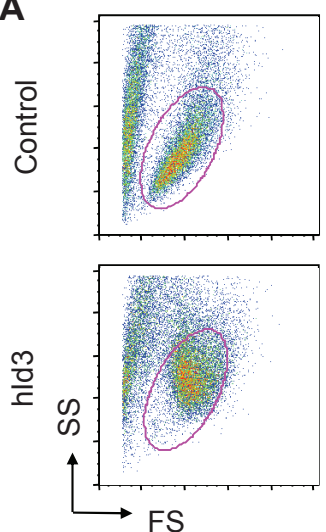

C

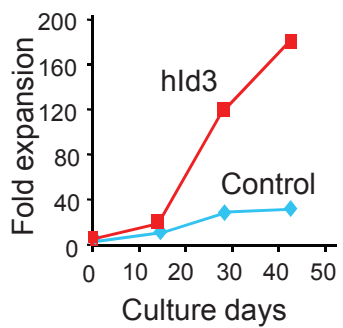

$\mathbf{F}$

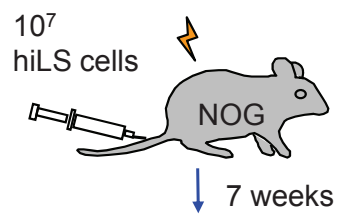

Bone marrow
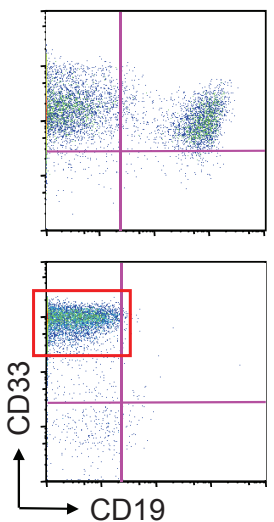

D

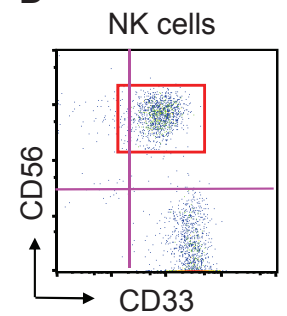

G
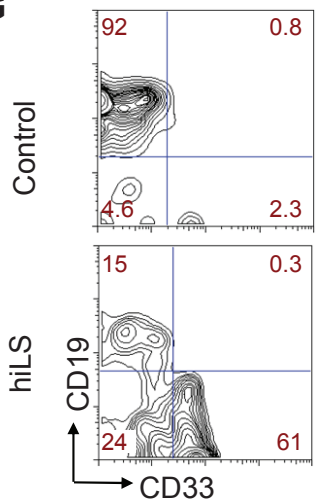

B

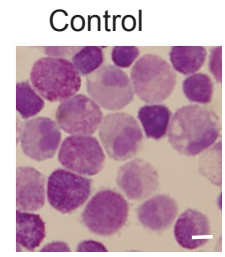

hld3

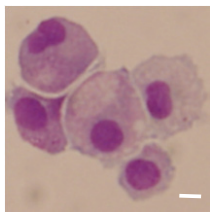

E

Dendritic cells

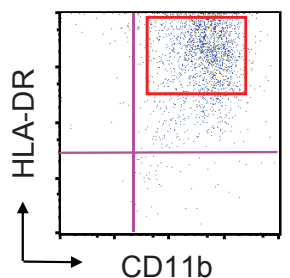

Figure 3: Generation of IdHP cells from human cord blood HSCs. A: Flow cytometric analysis of cells derived from $\mathrm{CD}_{3} 4^{+}$human cord blood cells transduced with control and human Id3 retrovirus. After transduction, $\mathrm{GFP}^{+}$cells were sorted and cultured on TSt- 4 stromal cells in the presence of SCF, IL-7, Flt3-ligand and TPO for 4 weeks. B: Wright's stain of human IdHP and control cells. Scale bars, $10 \mu \mathrm{m}$. C: Expansion of human IdHP and control cells on TSt-4 stromal cells in the presence of human SCF, IL-7, Flt3-ligand and TPO. Viable cells were counted at indicated time points. D and E: NK cell and DC generation from human IdHP cells in vitro. Flow cytometric analysis is shown. F and G: Generation of $\mathrm{CD} 19^{+}$and $\mathrm{CD} 14^{+}$cells from human IdHP cells in NOG mice. Schematic representation of the examination of the developmental potential of human IdHP cells, shown in (F). Flow cytometric profiles for $\mathrm{CD} 33$ versus $\mathrm{CD} 19$ and $\mathrm{CD} 33$ versus $\mathrm{CD} 14$ of BM cells from transplanted mice, shown in $(\mathrm{G})$. 


\section{Discussion and Conclusion}

In the present study, we showed that an artificially induced block of differentiation in uncommitted progenitors is sufficient to produce multipotent stem cells that retain selfrenewal activity. Once the differentiation block is released, the cells start differentiating into mature cells both in vivo and in vitro. Thus, this method could be applicable for establishing somatic stem cells from other organs in a similar manner, which would be useful for regenerative medicine. The relative ease of making stem cells leads us to conceive that a block in differentiation is also essential not only in other types of artificially engineered stem cells, such as ES cells and iPS cells, but also in any type of physiological somatic stem cell. In this context, it is tempting to speculate that it could have been easy for multicellular organism to establish somatic stem cells by this mechanism during evolution.

Immune cell therapy has become a major field of interest in the last decades. However, the required high cell numbers restrain application and success of immune reconstitution or anticancer treatment. For example, DCs are already being used in cell therapy against tumours. One of the major limitations of DC vaccine therapy is the difficulty to obtain sufficient cell numbers, as DCs do not proliferate in the currently used systems. The novel method of making iLS cells could be applied to such cell therapies. Taken together, the simplicity of this method in combination with the high expansion rate and retainment of multilineage potential of the cells make this cell source appealing for regenerative medicine or immune cell therapy. 


\section{Acknowledgements}

We thank Y. Motomura, M. Moro and S. Koyasu for sharing protocols, supporting the project and helpful comments; P. Burrows for critical reading the manuscript; A. Shibano-Sato, M. Ohno, and M. Nakano-Ikegaya, for technical assistance. This work was supported in part by grants from the Japan Society for the Promotion of Science (21689027 to T.I.), the Japan Science and Technology Agency (T.I.), RIKEN RCAI Young Chief Investigator program (T.I.), Kanae Foundation for the Promotion of Medical Science (T.I.), as well as the Dutch Cancer Society KWF: UM2010-4671 (W.G.) and with financial support from the Cancer Research Fund Limburg of the Health Foundation Limburg (W.G.). 


\section{References}

1. Li L, Xie T. Stem cell niche: structure and function. Annual review of cell and developmental biology. 2005;21:605-31.

2. Akala OO, Clarke MF. Hematopoietic stem cell self-renewal. Curr Opin Genet Dev. 2006 Oct;16(5):496-501.

3. Wilson A, Trumpp A. Bone-marrow haematopoietic-stem-cell niches. Nat Rev Immunol. 2006 Feb;6(2):93-106.

4. Barker N, van Oudenaarden A, Clevers H. Identifying the stem cell of the intestinal crypt: strategies and pitfalls. Cell Stem Cell. 2012 Oct 5;11(4):452-60.

5. Copley MR, Beer PA, Eaves CJ. Hematopoietic stem cell heterogeneity takes center stage. Cell Stem Cell. 2012 Jun 14;10(6):690-7.

6. Fuchs E, Chen T. A matter of life and death: self-renewal in stem cells. EMBO reports. 2013 Jan;14(1):39-48.

7. Spangrude GJ, Heimfeld S, Weissman IL. Purification and characterization of mouse hematopoietic stem cells. Science. 1988 Jul 1;241(4861):58-62.

8. Meissner A. Epigenetic modifications in pluripotent and differentiated cells. Nature biotechnology. 2010 Oct;28(10):1079-88.

9. $\mathrm{Ng} \mathrm{HH}$, Surani MA. The transcriptional and signalling networks of pluripotency. Nature cell biology. 2011 May;13(5):490-6.

10. Lund RJ, Narva E, Lahesmaa R. Genetic and epigenetic stability of human pluripotent stem cells. Nature reviews Genetics. 2012 Oct;13(10):732-44.

11. Takahashi K, Yamanaka S. Induction of pluripotent stem cells from mouse embryonic and adult fibroblast cultures by defined factors. Cell. 2006 Aug 25;126(4):663-76.

12. Takahashi K, Tanabe K, Ohnuki M, Narita M, Ichisaka T, Tomoda K, et al. Induction of pluripotent stem cells from adult human fibroblasts by defined factors. Cell. $2007 \mathrm{Nov}$ 30;131(5):861-72.

13. Yamanaka S. Induced pluripotent stem cells: past, present, and future. Cell Stem Cell. 2012 Jun 14;10(6):678-84.

14. Williams RL, Hilton DJ, Pease S, Willson TA, Stewart CL, Gearing DP, et al. Myeloid leukaemia inhibitory factor maintains the developmental potential of embryonic stem cells. Nature. 1988 Dec 15;336(6200):684-7.

15. Xu RH, Peck RM, Li DS, Feng X, Ludwig T, Thomson JA. Basic FGF and suppression of BMP signaling sustain undifferentiated proliferation of human ES cells. Nature methods. 2005 Mar;2(3):185-90.

16. Nutt SL, Heavey B, Rolink AG, Busslinger M. Commitment to the B-lymphoid lineage depends on the transcription factor Pax5. Nature. 1999 Oct 7;401(6753):556-62.

17. Ikawa T, Kawamoto H, Wright LY, Murre C. Long-term cultured E2A-deficient hematopoietic progenitor cells are pluripotent. Immunity. 2004 Mar;20(3):349-60. 
18. Pongubala JM, Northrup DL, Lancki DW, Medina KL, Treiber T, Bertolino E, et al. Transcription factor EBF restricts alternative lineage options and promotes $B$ cell fate commitment independently of Pax5. Nat Immunol. 2008 Feb;9(2):203-15.

19. Mercer EM, Lin YC, Benner C, Jhunjhunwala S, Dutkowski J, Flores M, et al. Multilineage priming of enhancer repertoires precedes commitment to the $B$ and myeloid cell lineages in hematopoietic progenitors. Immunity. 2011 Sep 23;35(3):413-25.

20. Rolink AG, Nutt SL, Melchers F, Busslinger M. Long-term in vivo reconstitution of T-cell development by Pax5-deficient B-cell progenitors. Nature. 1999 Oct 7;401(6753):603-6.

21. Cobaleda C, Jochum W, Busslinger M. Conversion of mature B cells into $\mathbf{T}$ cells by dedifferentiation to uncommitted progenitors. Nature. 2007 Sep 27;449(7161):473-7.

22. Norton JD, Deed RW, Craggs G, Sablitzky F. Id helix-loop-helix proteins in cell growth and differentiation. Trends in cell biology. 1998 Feb;8(2):58-65.

23. Sayegh CE, Quong MW, Agata Y, Murre C. E-proteins directly regulate expression of activation-induced deaminase in mature B cells. Nat Immunol. 2003 Jun;4(6):586-93.

24. Ikawa T, Masuda K, Lu M, Minato N, Katsura Y, Kawamoto H. Identification of the earliest prethymic T-cell progenitors in murine foetal blood. Blood. 2004 Jan 15;103(2):530-7. 


\section{Supplemental information}

A
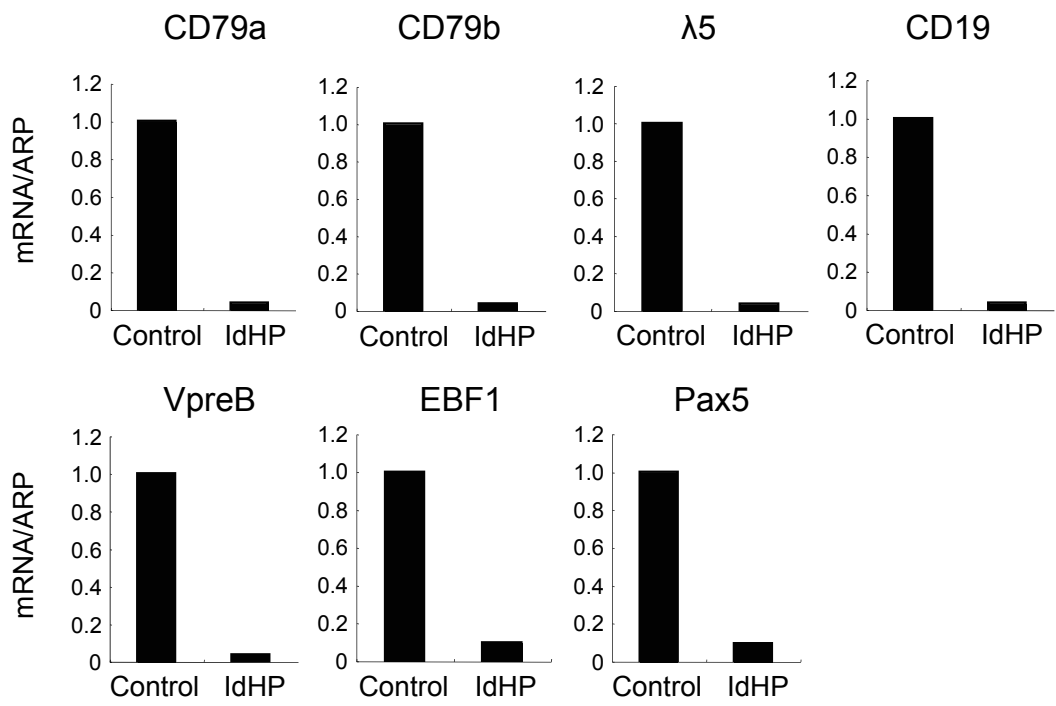

B
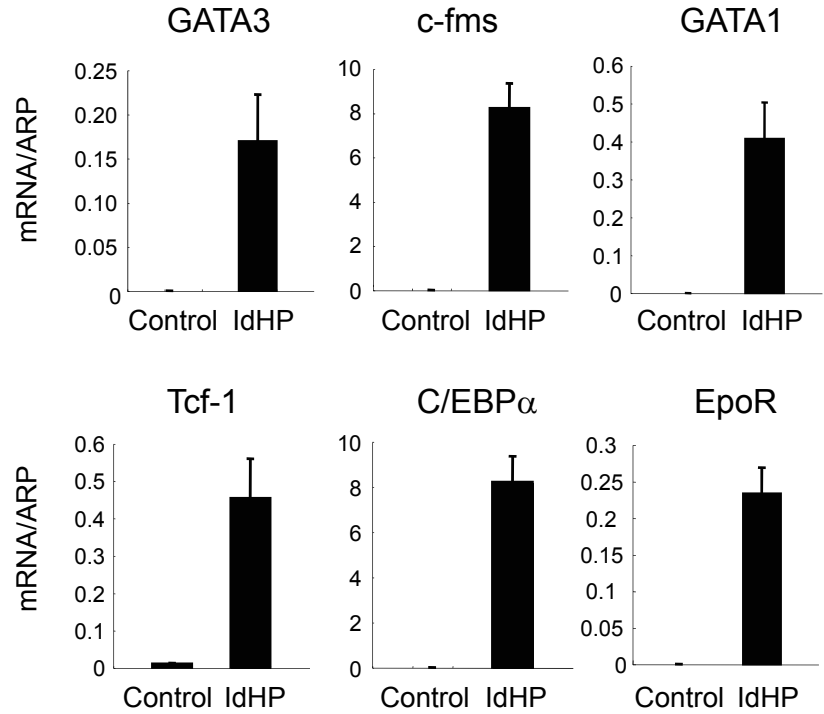

Supplemental Figure 1: Gene expression analysis of murine IdHP cells. A and B: Quantitative RTPCRs for the indicated genes in IdHP cells as well as control (control vector infected) cells are shown. Genes downregulated (A) and upregulated (B) in IdHP cells compared to Control cells are shown. Transcript levels of IdHP cells and control cells were normalized to the expression of acidic ribosomal protein (ARP) mRNA. Data are representative of three independent experiments. 


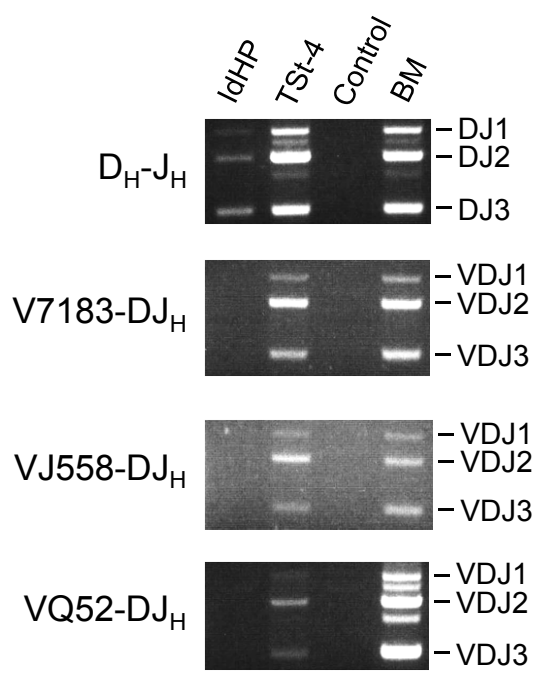

A

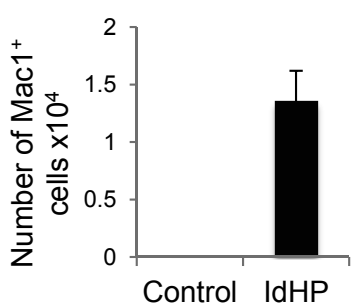

Supplemental Figure 2: Analysis of IgH D-J and $\mathrm{V}(\mathrm{D}) \mathrm{J}$ rearrangements in IdHP cells. Genomic DNA was isolated from IdHP cells, control (control vector infected) cells, TSt-4 cells and BM cells are analysed by PCR for the presence of IgH DJ and V(D)J rearrangements using the indicated primers.

B

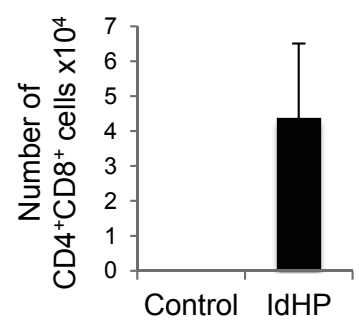

Supplemental Figure 3: In vitro generation of myeloid and T cells from IdHP cells. A: The number of $\mathrm{Macl}^{+}$cells generated from IdHP cells as well as control cells on TSt-4 stromal cells is shown. The FACS profile from IdHP cells is shown in Fig. $1 \mathrm{H}$. B: The number of $\mathrm{CD} 4^{+} \mathrm{CD} 8^{+}$cells generated from IdHP cells on TSt-4/DLL1 stromal cells is shown. The FACS profiles are shown in Fig. 1I. Data are representative of at least three independent experiments.

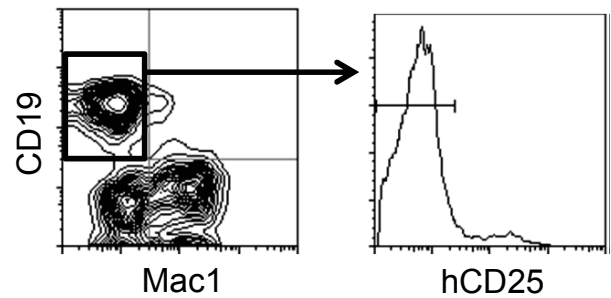

Mac1
hCD25
Supplemental Figure 4: Loss of hCD25 expression by $\mathrm{CD}^{+}{ }^{+}$cells generated from IdHP cells in Rag1 $^{-1-}$ mice. Flow cytometric analysis of hCD25 expression by $\mathrm{Macl}^{-} \mathrm{CD} 19^{+}$cells was performed on the PBMCs of chimeras generated by the injection of IdHP cells into sublethally irradiated Rag1deficient mice. The mice were analysed 4 weeks after transplantation. 
A
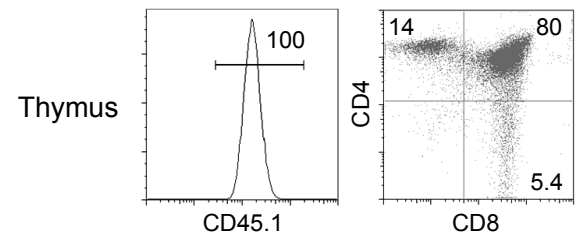

CD8

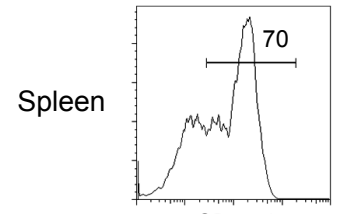

CD45.1

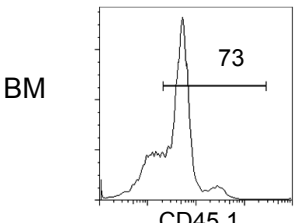

CD45.1

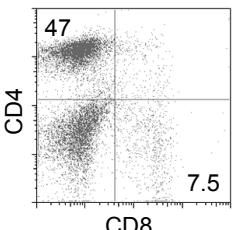

CD8

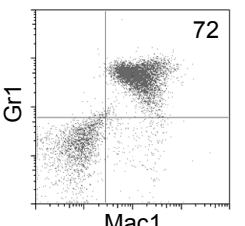

B
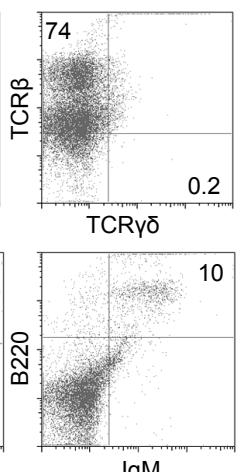

C

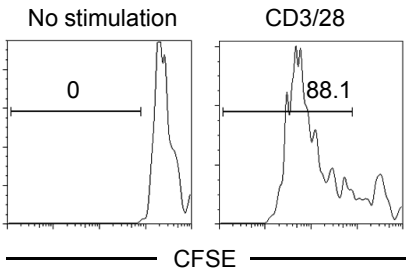

Supplemental Figure 5: In vivo generation of myeloid, B and T cells from FL-derived IdHP cells. IdHP cells were generated from LKS cells in FL of B6Ly5.1 mice. The FL-IdHP cells were cultured for two months on the TSt-4 stromal cells in the presence of SCF, IL-7 and Flt3-L. 1x10 FL IdHP cells were intravenously injected into sublethally-irradiated NOG mice. A: Flow cytometric analysis of cells in thymus, spleen and BM of mice transplanted with FL-IdHP cells 7 weeks after injection. B: The number of $\mathrm{T}\left(\mathrm{CD}^{+} \mathrm{CD}^{+}\right)$cells in the thymus, $\mathrm{B}\left(\mathrm{IgM}^{+}\right)$cells in the spleen and myeloid $\left(\mathrm{Macl}^{+} \mathrm{Gr}^{+}\right)$cells in the $\mathrm{BM}$ generated from the IdHP cells. C: $\mathrm{CD}^{+} \mathrm{T}$ cells in the spleen generated from IdHP cells were sorted and labelled with CFSE. The labelled cells were stimulated with plate-coated anti-CD3/28 for 4 days. Flow cytometric analysis of cells after stimulation is shown. Data are representative of three independent experiments.

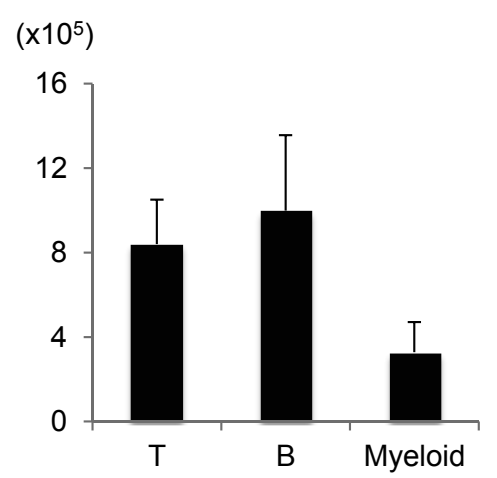

Supplemental Figure 6: In vivo generation of T, B and myeloid cells from an IdHP clone. The number of $\mathrm{T}\left(\mathrm{CD} 4^{+} \mathrm{CD} 8^{+}\right)$cells in the thymus, $\mathrm{B}$ $\left(\mathrm{IgM}^{+}\right)$cells in the spleen and myeloid $\left(\mathrm{Macl}^{+} \mathrm{Grl}^{+}\right)$ cells in the $\mathrm{BM}$ of $\mathrm{Rag} 1^{-/}$recipients generated from cloned IdHP cells is shown. The mice were analysed at 6-8 weeks after the transplantation of IdHP clones. The representative FACS profiles of each lineage cells are shown in Fig. 2E. Data are representative of at least three independent experiments. 
A
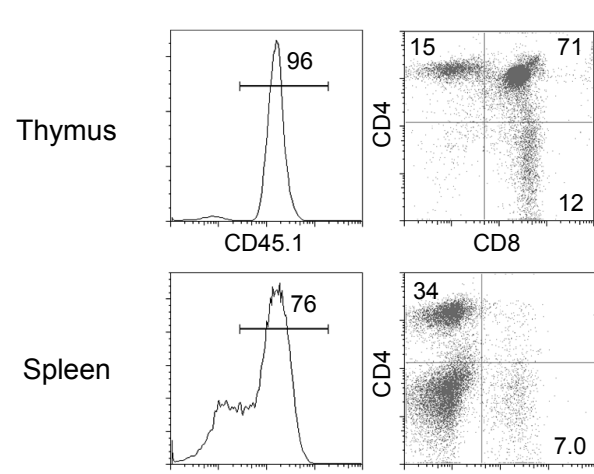

CD45.1

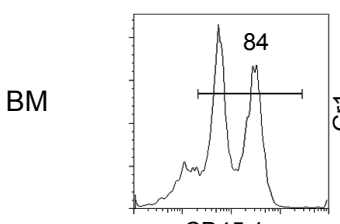

CD45.1

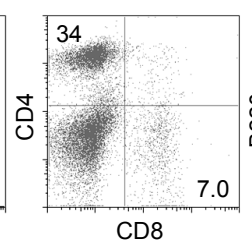

74

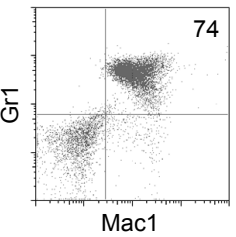

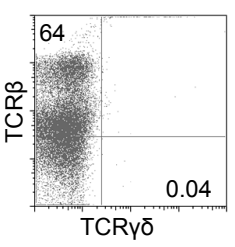

B
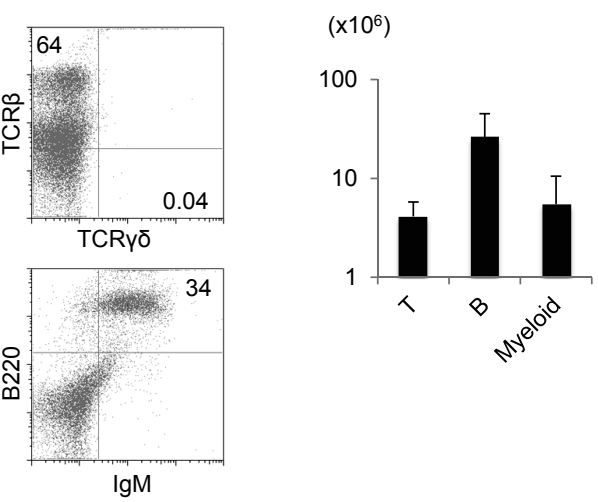

Supplemental Figure 7: In vivo generation of myeloid, B and T cells from BM-derived IdHP cells. IdHP cells were generated from LKS cells in BM of B6Ly5.1 mice similar to FL-IdHP cells. The BMIdHP cells were cultured for two months in the same condition with FL-IdHP cells. 1x10 $10^{6}$ B-IdHP cells were intravenously injected into sublethally-irradiated NOG mice. A: Flow cytometric analysis of cells in thymus, spleen and BM of mice transplanted with BM IdHP cells 7 weeks after injection. B: The number of $\mathrm{T}\left(\mathrm{CD}^{+} \mathrm{CD}^{+}\right)$cells in the thymus, $\mathrm{B}\left(\mathrm{IgM}^{+}\right)$cells in the spleen and myeloid $\left(\mathrm{Macl}^{+} \mathrm{Grl}^{+}\right)$ cells in the BM generated from the IdHP cells. Data are representative of at least three independent experiments. 
A

No stimulation $\quad$ CD3/28

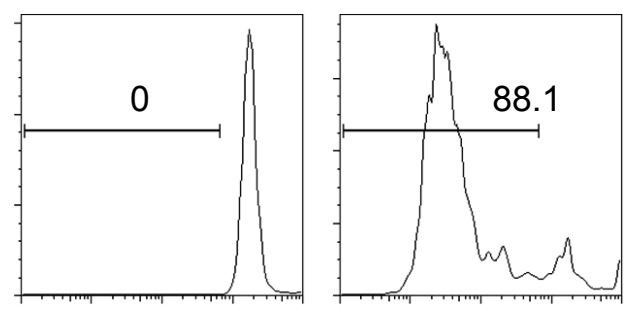

CFSE

3 в

IL-2

IL-4

IL-5

IL-10
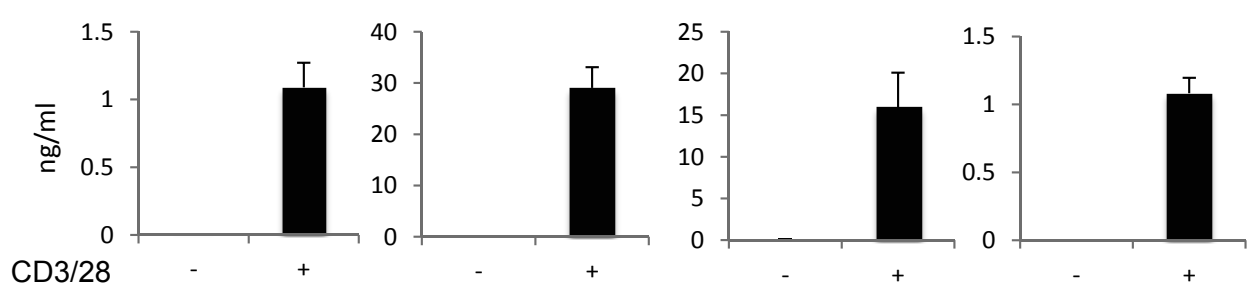

GM-CSF

IFN- $\gamma$

TNF- $\alpha$
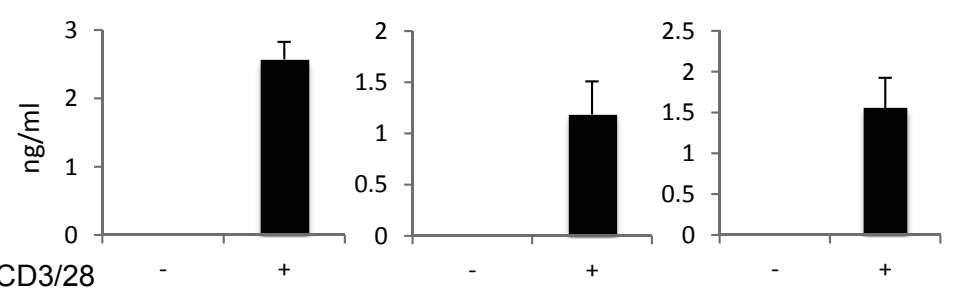

Supplemental Figure 8: In vitro stimulation of $\mathrm{CD4}^{+} \mathrm{T}$ cells isolated from spleen of NOG mice generated from BM-derived IdHP cells. A: $\mathrm{CD}^{+} \mathrm{T}$ cells in the spleen generated from BM IdHP cells were sorted and labelled with CFSE. The labelled cells were stimulated with or without plate-coated antiCD3/28 for 4 days. Flow cytometric analysis of cells after stimulation is shown. B: Cytokine secretion of the $\mathrm{CD} 4^{+} \mathrm{T}$ cells in response to plate-coated anti-CD3/28 stimulation for 4 days were measured by Bio-Plex analysis. Data are representative of at least three independent experiments. 


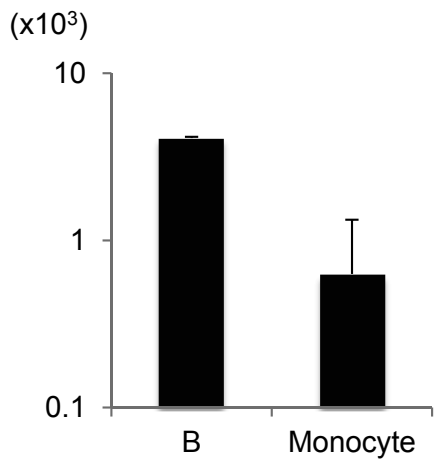

Supplemental Figure 9: Generation of B cells and monocytes in BM of NOG mice derived from hiLS cells. The number of $\mathrm{B}\left(\mathrm{CD} 33^{-} \mathrm{CD} 19^{+}\right)$cells and monocytes $\left(\mathrm{CD} 33^{+} \mathrm{CD} 14^{+}\right)$in $\mathrm{BM}$ generated from hiLS cells are shown. Flow cytometric profiles are shown in Fig. 3G. Data are representative of three independent experiments.

Supplemental Table 1. RT-PCR primer sequences.

\begin{tabular}{|l|l|l|}
\hline Gene Name & Forward & Reverse \\
\hline \hline CD79a & TATGTCTGACTCCAGCATCC & GGGAAGGACAAGATTAGGTG \\
\hline CD79b & CTCTGGGGATAGACTTGACC & GAACCATGGTCCTCCTAGCA \\
\hline 15 & GTTCTAATGGGATGCTAGGC & AGCGTCCTTCTCTTATCAGG \\
\hline CD19 & CAGTGATGGGACTAGCAGAC & GTAGTGTTGCCAGAAACTCG \\
\hline VpreB & GAGTGGGAAGGAGAAAGTC & CCTTCCCATACCAGACTAGC \\
\hline EBF1 & TGGGTTACAGGTCATATTCG & GAACTGCTTGGACTTGTACG \\
\hline Pax5 & CATTCGGACAAAAGTACAGC & GATGCCACTGATGGAGTATG \\
\hline GATA3 & AGGCAAGATGAGAAAGAGTGCCTC & CTCGACTTACATCCGAACCCGGTA \\
\hline c-fms & CTTAATGGCACAAAACAAGG & ACGTCACAGAACAGGACATC \\
\hline GATA1 & ATTCCACAGGTTTCTTTTCC & GTAGTAGGCCAGTGCTGTAG \\
\hline Tcf-1 & TGCTGTCTATATCCGCAGGAAG & CGATCTCTCTGGATTTTATTCTCT \\
\hline C/EBPa & CAAGAACAGCAACGAGTACC & GGTDATTGTCACTGGTCAAC \\
\hline EpoR & CCAGCTTTGAGTACACCATC & TCGGACACCACAAGGTATAG \\
\hline
\end{tabular}




\section{T cells fail to develop in the human skin-cell explant system; an inconvenient truth}

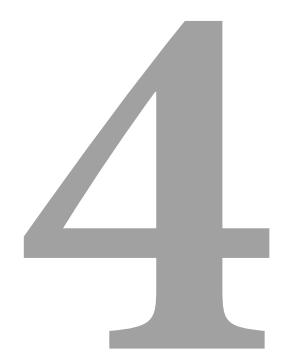

Bob Meek, Catharina H.M.J. Van Elssen, Mirelle J.A.J. Huijskens, Sjoukje J.C. van der Stegen, Siebe Tonnaer, Stijn B.J. Lumeij, Joris Vanderlocht, Mark A. Kirkland, Reinout Hesselink, Wilfred T.V. Germeraad, Gerard M.J. Bos

BMC Immunol. 2011 Feb 18;12:17. doi: 10.1186/1471-2172-12-17. 


\section{Abstract}

Haplo-identical haematopoietic stem cell (HSC) transplantation is very successful in eradicating haematological tumours, but the long post-transplant T-lymphopenic phase is responsible for high morbidity and mortality rates. Clark et al. have described a skin-explant system capable of producing host-tolerant donor-HSC derived T cells. Because this T cell production platform has the potential to replenish the $\mathrm{T}$ cell levels following transplantation, we set out to validate the skin-explant system.

Following the published procedures, while using the same commercial components, it was impossible to reproduce the skin-explant conditions required for HSC differentiation towards mature $\mathrm{T}$ cells. The keratinocyte maturation procedure resulted in fragile cells with minimum expression of Delta-like ligand (DLL). In most experiments the generated cells failed to adhere to carriers or were quickly outcompeted by fibroblasts. Consequently it was not possible to reproduce cell-culture conditions required for HSC differentiation into functional T cells. Using cell-lines over-expressing DLL, we showed that the antibodies used by Clark et al. were unable to detect native DLL, but instead stained $7 \mathrm{AAD}^{+}$cells. Therefore, it is unlikely that the observed T lineage commitment from HSCs is mediated by DLL expressed on keratinocytes. In addition, we did confirm expression of the Notch-ligand Jagged-1 by keratinocytes.

Currently, and unfortunately, it remains difficult to explain the development or growth of $\mathrm{T}$ cells described by Clark et al., but for the fate of patients suffering from lymphopenia it is essential to both reproduce and understand how these co-cultures really "work". Fortunately, alternative procedures to speed-up $\mathrm{T}$ cell reconstitution are being established and validated and may become available for patients in the near future. 


\section{Introduction}

Lymphopenia results in high mortality and morbidity among cancer patients receiving a haematopoietic stem cell (HSC) transplantation, or suffering from HIV infection ${ }^{1-5}$. Eradication of haematological cancers is very successful using haplo-identical HSC transplantation ${ }^{6}$, but many patients succumb to opportunistic infections that are the direct consequence of the lymphopenia, mainly involving the $\mathrm{T}$ cell pool ${ }^{7}$; it often takes more than 200 days before (mainly $\mathrm{CD}^{+}{ }^{+}$) $\mathrm{T}$ cell levels have normalized again. This underlines the need for, and explains the general interest in, methods capable of enhancing $\mathrm{T}$ cell reconstitution ${ }^{8,9}$.

Two important problems associated with slow recovery of $\mathrm{T}$ cell levels involve the thymus: slow thymic reconstitution by blood-borne progenitors and thymic involution ${ }^{10-14}$. Because it is still not possible to control and/or reverse either of these processes, there is an obvious need to establish methods that generate a de novo $\mathrm{T}$ cell repertoire in vitro. However, the development of such systems is hampered because most processes that occur in the thymus are still enigmatic, especially how the thymus is capable to enforce self versus non-self recognition on developing thymocytes ${ }^{15}$. Understanding the process of positive/negative selection, and reproducing this process in vitro, would potentially help to reduce lymphopenia, especially in older patients as the thymus involutes with age. In this context, the results on thymusindependent $\mathrm{T}$ cell development previously described by Clark et al. are remarkable. This method involves a seemingly simple co-culture system consisting of skin keratinocytes and fibroblasts grown on a three dimensional (3D) tantalum covered scaffold (Statamatrix ${ }^{\otimes}$ ) that, after 4 weeks of co-culture with allogenic HSCs, results in a population containing 3-5\% $\mathrm{T}$ cells tolerant to the skin-donor ${ }^{16}$. Even though $\mathrm{T}$ cells were detected, only a limited fraction of the expanded HSCs actually became T lineage committed; many cells differentiated towards Class $\mathrm{II}^{+}$antigen presenting cells (APCs), a convenient aspect since it was suggested to be important for $\mathrm{CD}^{+}{ }^{+} \mathrm{T}$ cell development ${ }^{16}$. Additional explanations for the extra-thymic development of $\mathrm{T}$ cells were the co-incidental expression of various components known to be important for HSC differentiation and thymus-function, such as Delta-like ligand (DLL) ${ }^{8}$ and autoimmune regulator (AIRE) ${ }^{17}$ by keratinocytes and fibroblasts ${ }^{16}$, respectively.

Even though direct mechanistic explanations for the extra-thymic development of $\mathrm{T}$ cells are lacking, and despite limited numbers, it still remains the only published method potentially capable of generating functional, clinical-grade, mature T cells ex vivo. Because of the clinical importance, we made an effort to establish the skin-cell system in our laboratory and to characterize it in more detail. We observed that keratinocytes do express the Notch ligand Jagged-1, but we did not find the abundant expression of DLL protein previously reported by Clark et al. on keratinocytes. Furthermore, due to the growth characteristics of keratinocytes and fibroblasts in the Statamatrix ${ }^{\circledR}$, we could not reproduce the co-cultures as described by 
Clark et al. ${ }^{16}$. As a result, we never observed any T lineage differentiation. The various reasons for the unsuccessful reproduction of this method are described in this report. 


\section{Materials and methods}

\section{Cells}

Abdominal or breast-skin was obtained from healthy individuals (donor A-E) undergoing reconstructive surgery, and processed within $24 \mathrm{~h}$. When required, skin was kept in RPMI

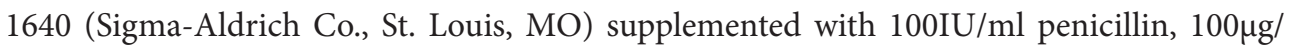
$\mathrm{ml}$ streptomycin (P/S) and $0.5 \mu \mathrm{g} / \mathrm{ml}$ fungizone (all from Invitrogen Ltd., Paisley, UK) until processing. After removal of subcutaneous fat (if applicable), skin was cut into small fragments and incubated in phosphate buffered saline (PBS, Sigma) containing 2.4U/mL Dispase II (Roche, Indianapolis, USA) overnight at $4^{\circ} \mathrm{C}$. Epidermis and dermis were separated by tweezers.

To isolate keratinocytes, up to 20 epidermal sheets were digested using $2 \mathrm{ml}$ Trypsin/EDTA (Lonza, Verviers, Belgium) for $5 \mathrm{~min}$ at $37^{\circ} \mathrm{C}$. Following quick neutralization by Trypsin Neutralizing solution (TNS, Lonza), suspension was vortexed after which undigested tissue was removed by subsequent filtration through $500 \mu \mathrm{m}$ (Nedfilter, Almere, the Netherlands) and $70 \mu \mathrm{m}$ strainers (BD Biosciences, Erembodegem, Belgium). Cells were spun down at 250g for $10 \mathrm{~min}$, and resuspended at approximately $2 \times 10^{5}$ cells $/ \mathrm{ml}$ in Keratinocyte-SFM medium containing $1 \% \mathrm{P} / \mathrm{S}, 0.39 \mathrm{mM} \mathrm{CaCl}_{2}$, bovine pituitary extract (BPS) and epidermal growth factor (EGF) according to the manufacturer's descriptions (keratinocyte medium, Invitrogen). Medium was changed after 2-3 days, and islands appeared after 1-2 weeks. Keratinocytes were passed to new flasks when islands contained 30-50 cells; overall density of flasks was kept at $30-40 \%$. For experiments, keratinocytes used were passaged $6 x$ or less.

To isolate fibroblasts, $10-20$ dermal fragments were incubated at $37^{\circ} \mathrm{C}$ for $1 \mathrm{~h}$ in DMEM/F12 (Invitrogen) medium containing $2.5 \mathrm{mg} / \mathrm{mL}$ Trypsin, $0.2 \mathrm{U} / \mathrm{mL}$ Liberase Bz3, and $0.2 \mathrm{mg} / \mathrm{ml}$ DNAse. Following neutralization with DMEM/F12 containing 15\% foetal calf serum (FCS, Greiner Bio-one, Solingen, Germany), cell-suspensions were filtrated and spun down as described above. Cells were seeded at $2 \times 10^{5}$ cells/ml in DMEM/F12 containing P/S, 15\% FCS and $10 \mathrm{ng} / \mathrm{ml}$ EGF (fibroblast medium). Fibroblast cultures were split when density reached $100 \%$. These cells were never split more than $8 \mathrm{x}$ before use in co-cultures.

\section{Mobilized $\mathrm{CD} 34^{+}$stem cells}

CD34 ${ }^{+}$cells were isolated from peripheral blood mononuclear cells (PBMC) obtained from healthy volunteers (V1-3) treated with G-CSF (Neupogen, Amgen Inc., Thousand Oaks, $\mathrm{CA})$ at $\mathrm{MUMC}^{+}$(Maastricht, the Netherlands). Isolation was performed with the Isolex 300i Magnetic cell selection system v2.5 (Baxter oncology, Brussels, Belgium) using the Isolex stem cell reagent kit (Miltenyi Biotec $\mathrm{GmbH}$, Bergisch Gladbach, Germany) according to the manufacturer's instructions. The positive fraction containing $>94 \% \mathrm{CD} 34^{+}$cells was frozen at 
a concentration of $5 \times 10^{6}$ cells per $\mathrm{ml}$ per vial. $\mathrm{CD} 133^{+}$cell preparations were obtained from Lonza.

Skin and CD34 ${ }^{+}$stem cells were obtained according to protocols approved by, and guidelines stipulated by the local medical ethical committee, and with consent from the donors.

\section{Maturation/differentiation of keratinocytes}

Keratinocytes at 30-40\% density were harvested using Trypsin/EDTA and TNS (Lonza), quantified and seeded at 100\% density in a 1:1 (vol/vol) mix of Keratinocyte-SFM and DF-K medium. DF-K medium is a 1:1 ( $\mathrm{vol} / \mathrm{vol}$ ) mix of DMEM and Ham's F12 containing P/S, $0.2 \mathrm{ng} / \mathrm{ml} \mathrm{EGF}, 25 \mu \mathrm{g} / \mathrm{ml}$ BPS and $1.5 \mathrm{mM}$ L-Glutamine (Invitrogen). Medium was refreshed daily. This procedure only worked for keratinocytes isolated from breast-skin and not for abdominal skin.

\section{The skin-cell construct}

Sterilized Statamatrix ${ }^{\circledast}$ (Cytomatrix, Australia) were coated by incubation in PBS containing $100 \mu \mathrm{g} / \mathrm{ml}$ rat tail collagen $\mathrm{I}$ (Roche) at $37^{\circ} \mathrm{C}$, after which the coated matrices were washed twice in PBS, and maintained in PBS until use. Prior to use, matrices were transferred to non-tissue culture treated petridishes (Greiner), and PBS was aspirated. Keratinocytes and fibroblasts were harvested, resuspended in a 1:1 mixture of keratinocyte and fibroblast-medium (ker-fib medium), and quantified. Subsequently, keratinocytes and fibroblasts were combined at $2 \times 10^{6}$ and $1 \times 10^{6}$ cells $/ \mathrm{ml}$, respectively, and $50-100 \mu \mathrm{l}$ of this mix was dripped onto a matrix. After $3 \mathrm{~h}$ at $37^{\circ} \mathrm{C}, 5 \% \mathrm{CO}_{2}$, matrices were moved to 24 -well plates and $2 \mathrm{ml} \mathrm{ker-fib} \mathrm{medium} \mathrm{was} \mathrm{added.}$ The skin-cell constructs were cultured for 6 days and medium was changed every other day.

Seeding of $\mathrm{CD} 34^{+} / \mathrm{CD} 133^{+}$cells

After 6 days, medium was replaced by IMDM (Invitrogen) supplemented with 10\% FCS (Greiner), 20ng/ml IL-7 and IL-15, and 100ng/ml Flt3-L (all R\&D systems, Abingdon, UK), then $1 \times 10^{4} \mathrm{CD} 34^{+}$or $\mathrm{CD}_{133^{+}}$cells were dripped onto each matrix. Half medium change was done 3 times weekly.

\section{TSt-4}

Thymic stromal cell lines TSt-4 and TSt- 4 transduced with hDLL1 or hDLL4 were kindly supplied by Prof. dr. H. Kawamoto (RCAI-RIKEN, Yokohama, Japan) and maintained in RPMI 1640 containing 5\% foetal bovine serum (FBS), $1 \%$ PS, $1 \mathrm{mM}$ sodium pyruvate, $0.1 \mathrm{mM}$ MEM non-essential amino acids (NEAA), and $5 \times 10^{-5} \mathrm{M} 2$-mercaptoethanol (bME) (all from Invitrogen Ltd., Paisley, UK).

\section{Flowcytometry}

All antibodies, materials and equipment were obtained from BD Biosciences (Erembodegem, 
Belgium), unless stated otherwise, and were used according to manufacturer's instructions. At different time points, cells were analysed using different combinations of fluorescein isothiocyanate (FITC), R-phycoerithrin (PE), peridinin chlorophyll proteins (PerCP)-, and allophycocyanin (APC) conjugated monoclonal antibodies (mAbs). The following antibodies (clones) were used: CD1a (HI149), CD3 (UCHT1, SK7), CD4 (SK3), CD5 (UCHT2, L17F12, MEM32 - Immunotools, Friesoythe, Germany), CD7 (M-T701, 7F3 - Sanquin), CD8a (HIT8a, RPA T8), CD14 (M5E2), CD19 (HIB19), CD34 (8G12), CD38 (HB7), CD45 (2D1, HI30), CD45RA (HI100), CD46 (E4.3), CD56 (B159), CD90 (AS02, Dianova, Hamburg, Germany), CD271 (C40-1457), IFN- $\gamma$ (25723.11), NKG2A (131411, R\&D Systems, Minneapolis, MN), NKp46 (9E2), TCR $\alpha \beta$ (IP26 - eBioscience), and TCR $\gamma \delta$ (B1.1 - eBioscience). Unconjugated goat and rabbit antibodies used were DLL1 (\#H20 and \#H265), nitric oxide synthase 2 (NOS2), IFN- $\gamma$ responsive factor 1 (IRF1), angiotensin-converting enzyme (ACE) (all Santa Cruz Biotechnology, Santa Cruz, USA), for which the following conjugates were used according to manufacturer's instructions: donkey anti-goat FITC and donkey anti-rabbit FITC or APC (all Jackson ImmunoResearch, West Grove, USA). 7-amino-actinomycin D (7AAD) was used to differentiate between viable and dead cells. For intracellular stainings, cells were permeabilized using perm/wash. Cells were analysed on a FACSCalibur or FACScan with WinMDI (Joe Trotter, http://facs.scripps.edu/) software.

\section{Fluorescence activated cell sorting}

Prior to differentiation, $\mathrm{CD}^{+} 4^{+}$cell preparations were depleted of $\mathrm{CD} 38^{\text {bright }}$ cells and contaminating $\mathrm{T}$ and NK cells by cell-sorting using conjugated anti-CD3,-CD4, -CD8, -CD38 and -CD56 antibodies. All CD $34^{+}$cell preparations had $\leq 0.05 \%$ contaminating mature lymphoid cells. Sorting was performed on a FACS ARIA (BD) with FACS DIVA software.

\section{Immunofluorescence}

Upon aspiration of media, monolayers or cells were washed with PBS and fixed with cold methanol: acetone (Merck) 1:1 for 10min on ice. Following fixation, preparations were washed 3 times with PBS at RT, with each wash for $4 \mathrm{~min}$ on an orbital shaker. Blocking was done for 30 min with $1 \%$ normal donkey serum (JIR) in PBS, after which preparations were washed twice with PBS. The following primary antibodies were used, each at the proper, predetermined dilution: CD46 (BD Biosciences), CD90 (Dianova), DLL1, Jagged-1 (both Santa Cruz), pancytokeratin (Acris, Hiddenhausen, Germany), Keratin-10 (RKSE60), -14 (RCK107) and -16 (LL025) (all MuBio, Maastricht, the Netherlands). Preparations were incubated with primary antibodies for $1 \mathrm{~h}$ at RT in the dark, after which they were washed 5 times with PBS, followed by incubation with secondary antibody for $1 \mathrm{~h}$ at RT in the dark. Appropriate Texas Red or FITC-labelled donkey anti-rabbit, anti-goat or anti-mouse antibodies were obtained from Jackson Immunoresearch. Following another washing procedure, preparations were postfixed for $15 \mathrm{~min}$ with $2 \%$ paraformaldehyde in PBS. Then, preparations were washed twice, and covered with mounting medium containing 4',6-diamidino-2-phenylindole (Vector 
Laboratories, Burlingame, USA). Preparations were analysed using an Axioplan 2 microscope and Axiovision software (Zeiss, Jena, Germany).

\section{PCR analysis}

RNA was extracted from immature and matured keratinocytes using Trizol according to manufacturer's instructions (Invitrogen). Following quantification and DNAse treatment, cDNA was synthesized using Superscript III according to manufacturer's instructions (Invitrogen). PCR was carried out in $20 \mu \mathrm{l}$ reaction volumes containing $\leq 80 \mathrm{ng}$ or $40 \mathrm{ng}$ RNA equivalent from keratinocytes or TSt-4 cells, respectively. All PCR components were used according to manufacturer's instructions (iTaq, BioRad, Hercules, CA) 100nM of each primer (Eurogentec, Liege, Belgium). Primers used were (anneal temperature, optimal $\mathrm{MgCl} 2$ ): Keratin-14 f-CACCTCTCCTCCTCCCAGTT r-CATCGTGCACATCCATGAC $\left(63^{\circ} \mathrm{C}\right.$, $3 \mathrm{mM})$, DLL1 f-CGTCGACTCCTTCAGTCTGC r-TTCTGTTGCGAGGTCATCAG $\left(60.5^{\circ} \mathrm{C}\right.$, $3 \mathrm{mM})$, DLL4 f-TCCAACTGCCCTTCAATTTC $\mathrm{r}$-ACTGCAGATGACCCGGTAAG $\left(57^{\circ} \mathrm{C}\right.$, $5 \mathrm{mM}$ ), and Jagged-1 f-CGGCCTCTGAAGAACAGAAC r-CCTCAGAGGCTGAGTGTGTG $\left(62^{\circ} \mathrm{C}, 3 \mathrm{mM}\right)$. All PCR products were validated by TA-cloning and sequencing according to standard procedures. 


\section{Results}

The in vitro $\mathrm{T}$ cell development from donor $\mathrm{CD} 34^{+}$cells as described by Clark et al. ${ }^{16}$ requires a co-culture of (recipient $=$ patient) keratinocytes and fibroblasts. To confirm expression of determinants reported to be important for in vitro differentiation, and establish co-cultures, we prepared keratinocyte and fibroblast cell banks from various donors and different skin sources. Sufficient numbers of early passage stocks were available from 5 donors for all experiments.

\section{Is DLL expressed by keratinocytes?}

Many papers have described the necessity for Notch signalling in $\mathrm{T}$ cell determination and differentiation from CD $34^{+}$cells (reviewed in ${ }^{8}$ ). One of the most obvious and logical explanations provided by Clark et al. ${ }^{16}$ for the generation of T cells was the innate potential of matured keratinocytes to express DLL protein. To detect/confirm DLL expression on intact keratinocytes, we used three different methods.

\section{FACS analysis}

In the paper by Clark et al. ${ }^{16}$, it was not specified at what stage the keratinocytes were harvested, and which DLL was detected by the polyclonal H265 antibody. In our hands, the differentiation procedure resulted in a mixture of undifferentiated and early-differentiated cells; none of the "differentiated" keratinocytes ever lost CK14 expression, which is a marker for mature keratinocytes (Fig. 1). By using murine cell-lines (genetically) over-expressing human DLL1 or 4 it became clear that the H265 antibody used for flowcytometry (FACS) and immunofluorescence does recognize DLL1, but not DLL4 (Fig. 2A). Using a murine stromal cell line transduced with human DLL1 as positive control, which shows intense staining of DLL1 on immunoblot (Fig. 2A), we found that it was possible to detect DLL1 on vital cells by FACS, albeit with difficulty (Fig. 2B). When matured keratinocytes were indirectly stained with $H 265$ for analysis by FACS, we were never able to detect a specific signal from $\mathrm{H} 265$ on vital, 7AAD keratinocytes (Fig. 3A). Other primary rabbit antibodies specific for intracellular antigens, normally not expressed by keratinocytes like NOS2 and IRF1, also stained 7AAD keratinocytes (Fig. 3A), indicating that these antibody-preparations may not be suitable for analysis by FACS. We did find that $7 \mathrm{AAD}^{+} / \mathrm{DAPI}^{+}$cells were intensely stained by all primary rabbit antibodies, including $H 265$ (Fig. 3B), generating a false positive $H 265 /$ SSC picture very similar as published by Clark et al. ${ }^{16}$. Apparently, it is possible to use the FACS procedure in combination with H265 to detect DLL1 expression on the surface of DLL1-transfected celllines, but it cannot be used to reliably stain DLL on vital keratinocytes.

Another question that arose was whether $\mathrm{H} 265$ is suitable for detection of intact DLL. Because the antibody was generated against a peptide spanning the membrane and the first twenty 
amino-acids of the extracellular domain, it may recognize processed DLL only (the epitope could be shielded by the 3D folding of the protein), thereby underrepresenting the actual level of DLL surface-expression. Therefore, using a goat-polyclonal antibody capable of binding to a known, accessible epitope in the extracellular domain of DLL1, H2O, we repeated the experiments with DLL-transduced cells (Fig. 2A and 2B) and keratinocytes (Fig. 3C), but no specific staining on intact keratinocytes was detected. When considering the weak specific signals obtained with either $\mathrm{H} 20$ or $\mathrm{H} 265$ on cell-lines over-expressing DLL, it is obvious to conclude that it is impossible to demonstrate spontaneous DLL expression on intact primary cells with these antibodies.

\section{Immunofluorescence}

To confirm DLL expression by FACS, Clark et al. ${ }^{16}$ used immunofluorescence on fixed keratinocytes prepared by cytospin, which is an application reported suitable for both H265 and H2O. However, again no detection of any DLL staining of intact, differentiated keratinocytes was observed; the occasional green cell we did see (resembling Fig. 5C in ${ }^{16}$ ) proved to have no nucleus (Fig. 4A). In contrast, keratinocytes did stain positive for Notch ligand Jagged-1 (Fig. 4A).

\section{PCR}

Since it was not possible to reliably detect DLL1 or DLL4 protein, we reverted to PCR to find out whether matured keratinocytes are at least capable to express high levels of DLL RNA. As shown in Figure 4B, compared with gene-products normally expressed by keratinocytes, cDNA encoding for DLL4 required 35 cycles before detection. Clearly, expression of DLL is far from abundant in differentiated or immature keratinocytes (Fig. 4B). In contrast to DLL expression, the high level of Jagged-1 expression was confirmed by detecting PCR products after 30 cycles (Fig. 4B). This observation is in line with a previous report demonstrating high levels of Jagged-1 expression at various stages of keratinocyte-development ${ }^{18}$.

In summary, using three different methods we could not detect any DLL expression by keratinocytes, which makes it unlikely that HSC differentiation towards $\mathrm{T}$ lineage as observed by Clark et al. ${ }^{16}$ is initiated by T lineage commitment induced by DLL expressed on keratinocytes. Of course, we do not know whether (or why) keratinocytes start to express DLL during co-culture with fibroblasts, or whether DLL-expression by keratinocytes is actually required for the extra-thymic $\mathrm{T}$ cell development. On the other hand, keratinocytes do show abundant expression of Jagged-1. Even though Jagged-1 by itself is not particularly efficient in induction of $\mathrm{T}$ lineage differentiation of cord blood derived $\mathrm{CD} 34^{+}$cells ${ }^{19}$, and its expression in the murine thymus is not abundant ${ }^{20,21}$, Jagged-1-mediated activation of murine thymic precursors does result in T/NK progenitors ${ }^{20}$. Therefore, it cannot be excluded that Jagged-1 does so as well in the context of the skin-explant system. 

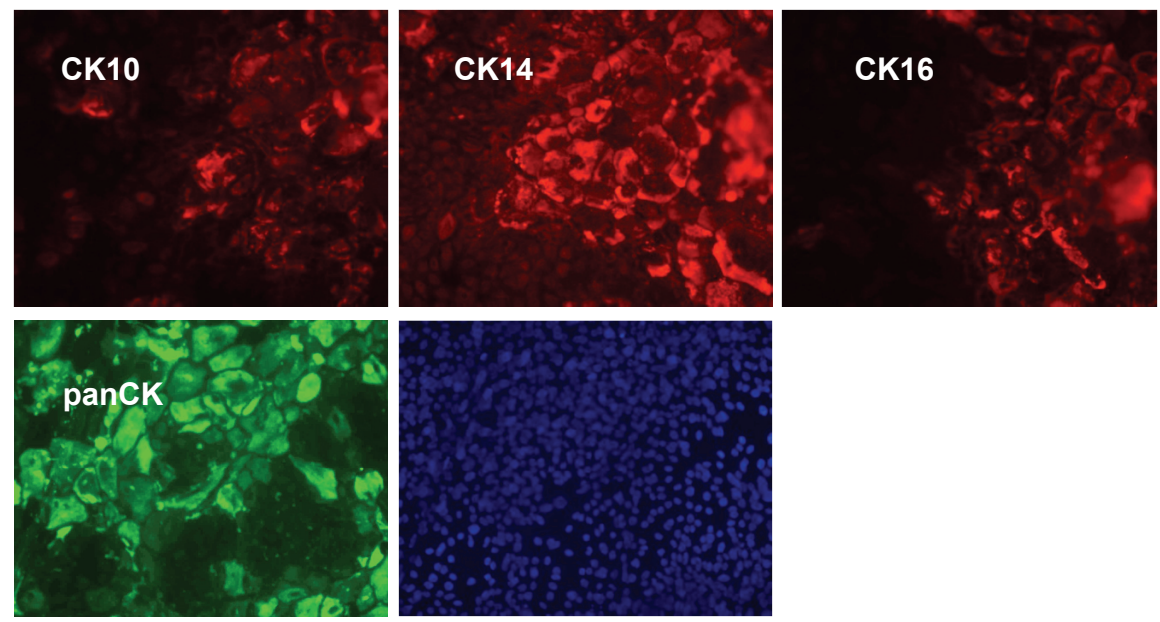

Figure 1: Differentiation of keratinocytes results in a mixture of immature and semi mature cells. Keratinocytes of a representative donor were differentiated in chamber-slides for 6 days. Following fixation, cells were stained for the indicated cytokeratins (CK) using a panel of monoclonal (CK10, CK14, CK16) and polyclonal antibodies (pan). Duration of fluorescence detection was kept constant. Though variable, all cells were positive for CK14, while staining of CK10 and CK16 was limited to areas with blast-like keratinocytes.

A
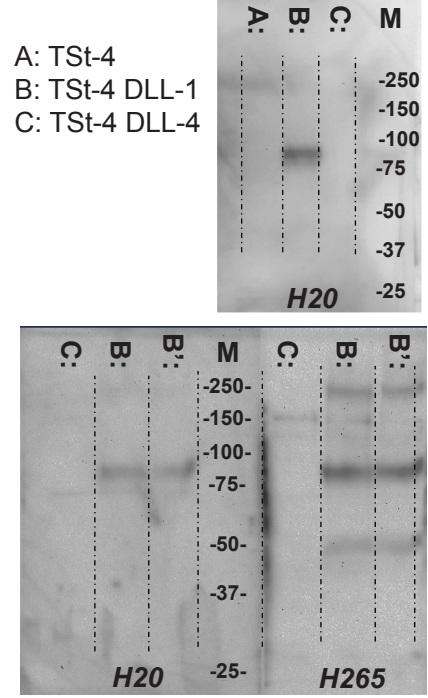

B
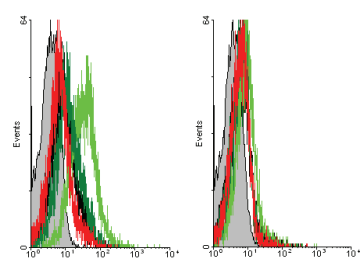

- TSt-4

TSt-4 DLL-1

H265 APC

IRF1 APC
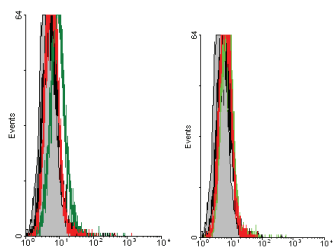

TSt-4 DLL-1-GFP

TSt-4 DLL-4

Blank

Gated on

7AAD- cells

H2O Fitc ACE Fitc 
Figure 2: Analyses of DLL expression by immunoblot and FACS using cell-lines over-expressing DLL. A: Protein blots were prepared from TSt-4 thymic stromal cell-lines over-expressing human DLL1 or 4, and incubated with polyclonal antibodies specific for DLL. Both H2O and H265 only stained lanes containing TSt-4-DLL1 extracts, with a main band at $78 \mathrm{kDa}$. $H 265$ stained additional bands at $50 \mathrm{kDa}$ and $230 \mathrm{kDa}$, which could represent processed and glycosylated DLL1, respectively. In contrast to H2O, H265 also heavily stained the marker-lane, indicating that the specificity of this polyclonal antibody preparation is not limited to DLL. B: Indicated cells were harvested using trypsin-EDTA, and incubated with $\mathrm{H} 265$ and $\mathrm{H} 20$ with control polyclonal antibodies specific for IRF1 and ACE. Control antibodies were selected based on species-origin and specificity for non-surface antigens. Both H265 and H2O showed weak, yet specific staining of TSt4-DLL1.

A

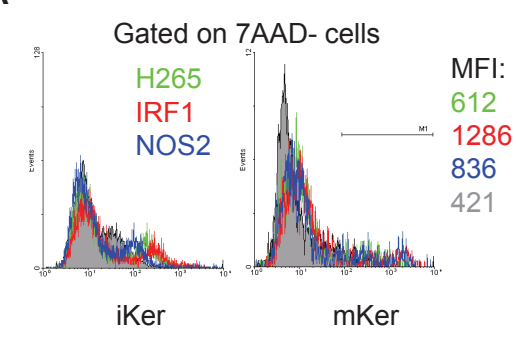

C

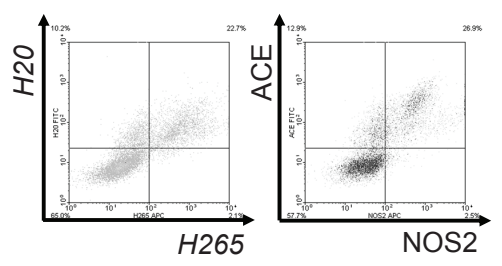

B

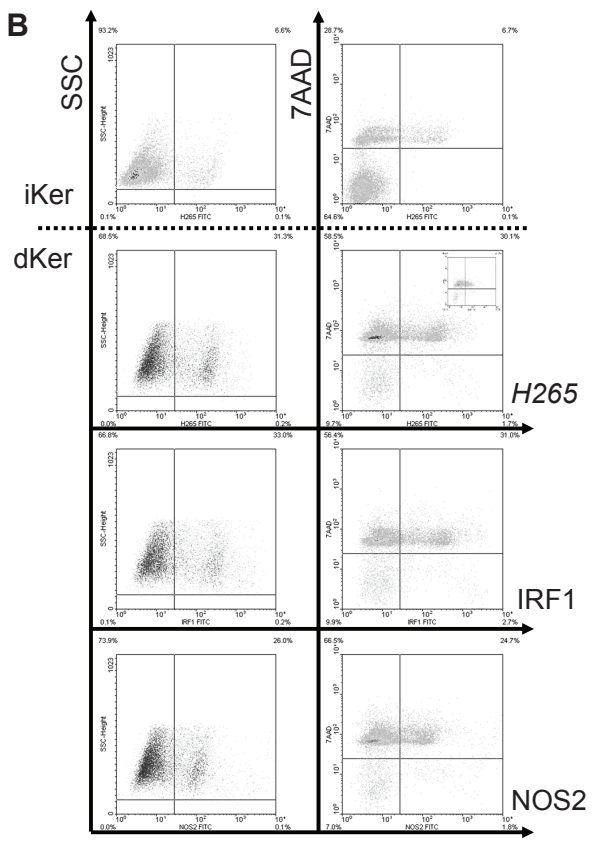

Figure 3: $7 \mathrm{AAD}^{+}$keratinocytes show intense staining with any polyclonal primary antibody. Keratinocytes of donor $\mathrm{C}$ were harvested following high-density culture for 6 days, either in standard keratinocyte (iKer) or maturation medium (dKer). A: All cells being stained with indicated rabbit pan antibodies were $7 \mathrm{AAD}^{+}$. Left column shows FACS plots as used by Clark et al. ${ }^{16}$, right column contains additional information regarding viability. Within experiments, the percentage of positively stained cells was always similar with any pan-antibody. Insert shows background staining by the secondary antibody used. Even though staining intensity was lower after incubation with the secondary antibody, when compared with unstained cells (LL quadrant of the right column), the percentage of cells with signal was similar. This staining-pattern was observed for all donors. B: When gated on 7AAD cells, any pan- antibody stained a low percentage of keratinocytes (donor C, donor D showed similar inconclusive 
staining profile). C: Almost all cells that were stained with $H 265$, co-stained with $H 20$. A nearly similar plot could be obtained with any pan rabbit (eg. ACE) and pan goat antibody combination (eg. NOS2), and invariably involved 7AAD cells (donor $\mathrm{C}$, donor $\mathrm{D}$ showed similar co-staining).

A
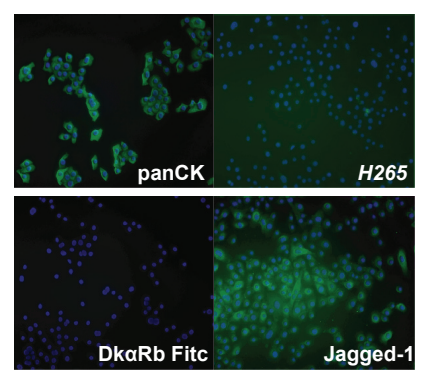

\section{B}

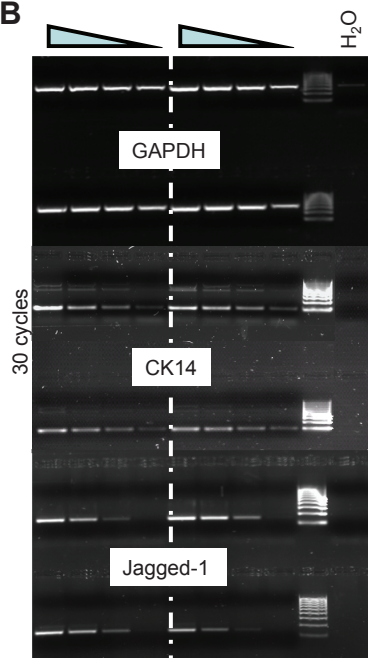

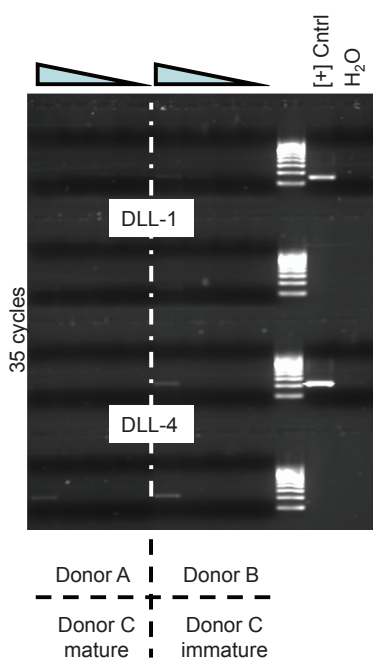

Figure 4: Keratinocytes have very low expression of DLL. A: Next to FACS, Clark et al. ${ }^{16}$ used immunofluorescence to demonstrate DLL expression in immature keratinocyte cultures. While the secondary antibody did not give any background staining (LL), there were occasional H265-FITC positive cells (UR), but these always proved to be DAPI negative. In contrast to DLL, immature keratinocytes were reliably stained for the Notch-ligand Jagged-1. B: For PCR, 4 dilutions (5x-20x-80x320x) were prepared from cDNA of mKer from 3 donors (A, B, and C), iKer from donor C. Positive controls were prepared from murine TSt- 4 cells constitutively expressing DLL1 or DLL4. At 35 cycles, DLL4-specific PCR product was only detected in the 5x diluted samples, while mRNA encoding for Jagged-1 was easily amplified in 30 cycles.

\section{A balanced co-culture?}

The system requires co-culture of keratinocytes and fibroblasts on the Statamatrix ${ }^{\oplus}$. However, "matured" keratinocytes showed limited capacity to adhere to collagen-coated Statamatrices in contrast to fibroblasts, and these latter cells always overgrew in keratinocyte-fibroblast cocultures in matrices within 7 days (Fig. $5 \mathrm{~A}$ and B). 
A Day 5 after seeding matrix
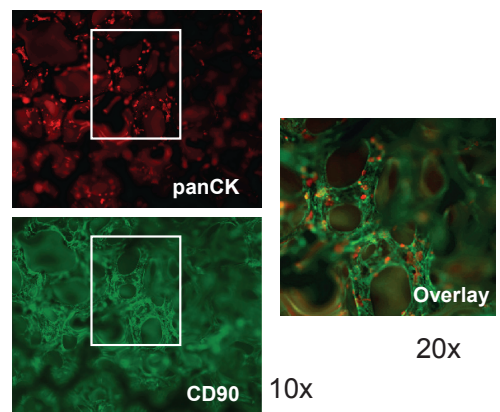

B Week 4 after seeding matrix

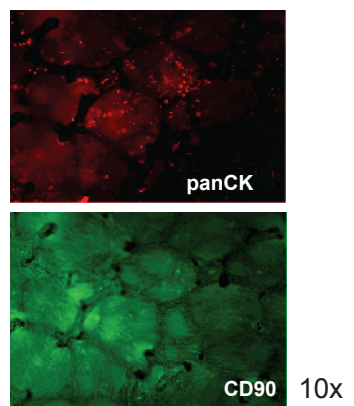

Figure 5: Keratinocytes are out-competed by fibroblasts. A: Matrix was stained for keratinocytes and fibroblasts using panCK and CD90, respectively, six days after matrices were seeded at a 2:1 ratio. At this stage, matrices were carefully seeded with HSCs. B: After 4 weeks, matrices were completely covered with $\mathrm{CD} 90^{+}$fibroblasts. HSC derived cells could only be retrieved from the matrix following collagenasedispase treatment. Fibroblasts from all donors grew similarly.

\section{Skin-explant procedure did not result in $T$ lineage development}

We found that HSCs (expressing either $\mathrm{CD} 34^{+}$or $\mathrm{AC}_{133^{+}}$) were never able to differentiate towards $\mathrm{T}$ lineage cells in matrices containing isolated and cultured fibroblasts and keratinocytes; most HSCs did up-regulate CD7 and lost the CD34 marker, but no expression of early T lineage markers like CD5 (Fig. 6), nor the CD56 NK cell marker were observed (data not shown). In contrast, the same batches of HSCs demonstrated excellent T lineage differentiation capacity when grown on murine stromal cell lines expressing human DLL ${ }^{22}$. 


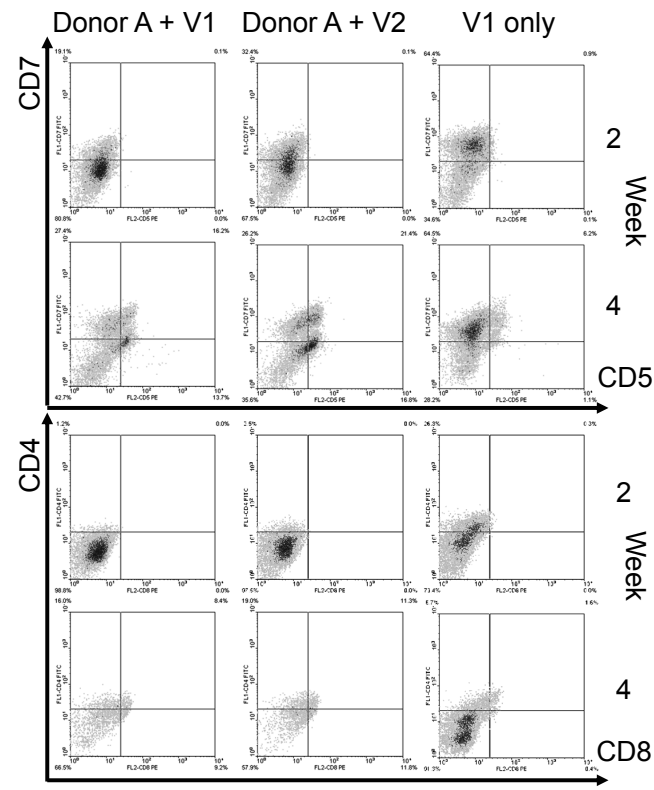

Figure 6: HSCs expand, but do not differentiate in the skin-cell explants. HSCs from donor V1 and V2 were seeded into skin-cell explants from donor A and B. As controls, HSCs were expanded for 1 week using a HSC expansion-mix, followed by maintenance with IL-7. For reasons unknown, cellnumbers declined after 2-3 weeks in culture with skin-cell explants (not shown). The phenotype of the haematopoietic cells was analysed at various time-points after seeding, and the results of week 2 and 4 are depicted. Of markers associated with T lineage commitment, only CD7 was detected on 20$30 \% / 60 \%$ of the cells in skin-cell explants/controls, and its expression-level increased from week 2 to 4 .

\section{DLL-independent development?}

As indicated, the phenotype of the differentiated HSCs suggested lack of Notch signalling, which could be due to the lowered keratinocyte/fibroblast ratio. Since it seems very difficult to alter that ratio with the published protocol, it may be difficult to routinely use the skin-explant procedure. However, the explant system remains unique in the fact that it encompasses complete $\mathrm{T}$ cell development resulting in functional, single-positive $\mathrm{CD} 4^{+}$and $\mathrm{CD}^{+} \mathrm{T}$ cells, which includes the poorly understood process of positive/negative selection. Because canonical T cell development roughly consists of 3 phases -1 ) DLL-dependent T lineage commitment, 2) DLL-independent beta-chain selection and 3) DLL-(in)dependent positive/negative selection, we investigated whether T cell development could occur with cells that already have received DLL-signalling and are T/NK or completely T lineage committed ${ }^{22}$. Unfortunately, when T/NK lineage committed cells were seeded in skin-explants, most 
became NK lineage committed CD56 ${ }^{+}$cells (Fig. 7), in the presence of additional IL-15. Thymocyte-like cells were never detected. When IL-15 was omitted, the viability and yield of the cultures were reduced considerably, and most cells lost CD5 and iCD3 expression (Fig. 7), indicating that even in the presence of only IL-7 and Flt3-L, the keratinocyte/fibroblast co-cultures were not able to maintain the $\mathrm{T}$ lineage committed status of cells. The few cells remaining also displayed a $\mathrm{CD} 56^{+}$phenotype.

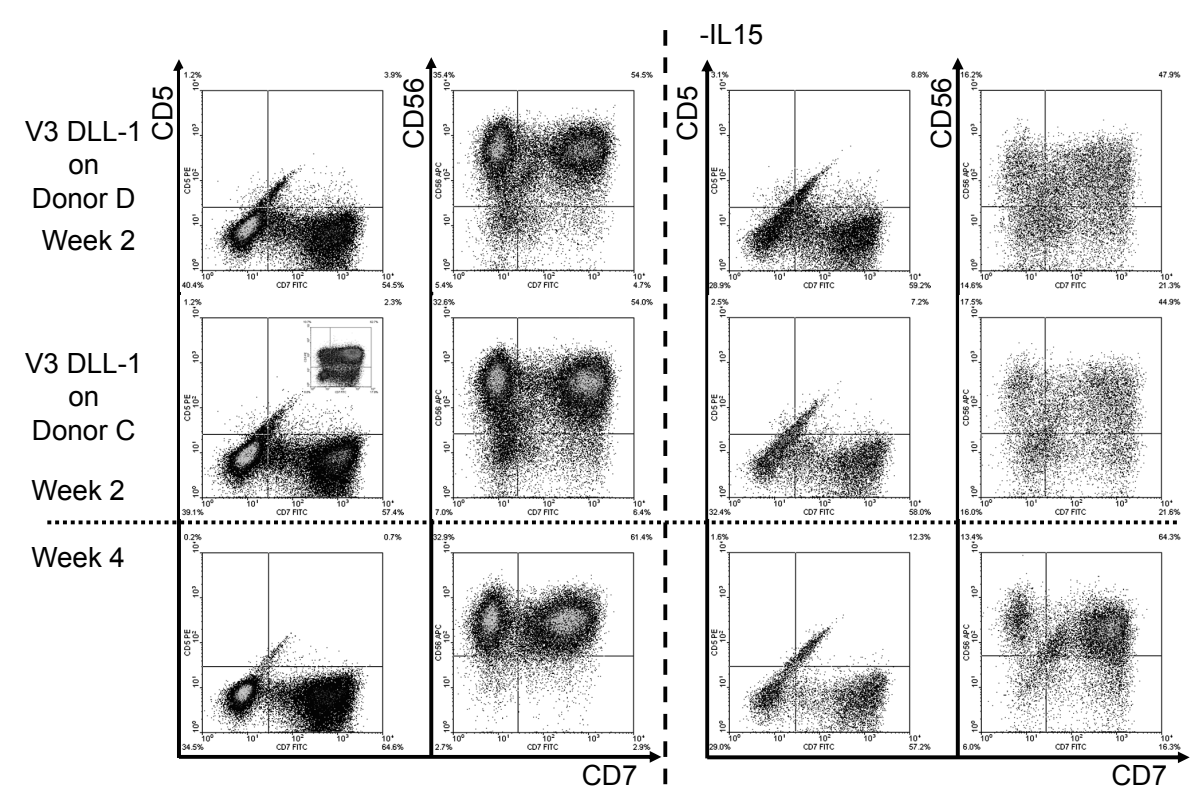

Figure 7: Skin-cell explants cannot maintain T lineage committed cells. HSCs from indicated donors were pre-differentiated on monolayers of thymic stromal cells expressing hDLL1 (see Fig. 2). After 4 weeks, $55-65 \%$ of the cells were $\mathrm{CD}^{+} \mathrm{CD}^{+}$(see insert), and $>90 \% \mathrm{iCD}^{+} \mathrm{CD} 45 \mathrm{RA}^{+}$(NS). $1 \times 10^{5}$ cells were seeded in skin-cell explants and cultured for 2 and 4 weeks. In the presence of IL15, the population expanded 10-15x. Already at 2 weeks, all cells had lost expression of CD5 and become CD56 ${ }^{+} \mathrm{NK}$ lineage committed cells. The same phenotype was observed when IL-15 was omitted, although overall expansion was strongly reduced to $1-1.5 \mathrm{x}$. 


\section{Discussion}

Our results clearly demonstrate that the keratinocyte differentiation procedure results either in fragile cells that fail to adhere to any structure or plate, or cells that do adhere but are outcompeted by fibroblasts within a week. Furthermore, differentiated keratinocytes do not express detectable levels of DLL (protein nor RNA), and therefore the T lineage commitment observed by Clark et al. ${ }^{16}$ must be mediated by other factors. Jagged-1 may be responsible for steering development towards the T lineage of a limited fraction of $\mathrm{CD} 34^{+}$cells in their coculture system, because it is abundantly expressed by keratinocytes. As stated in the results section, certain T lineage committed stadia can complete their development into DP and SP $\mathrm{T}$ cells independent of Notch signalling ${ }^{23}$.

However, even if $\mathrm{T}$ cells can be generated ex vivo using the skin-explant system, the question remains whether they will be functional. Extra-thymic development of $\mathrm{T}$ cells has been described for oncostatin $\mathrm{M}$ (OncM) transgenic mice, where lymph nodes take over the function of the thymus ${ }^{24}$. Even though in OncM mice the T cells appear to go through the same developmental stages as regular thymocytes, they are less functional, which may be the result of positive selection by other haematopoietic cells instead of thymic epithelium ${ }^{25}$. This, however, remains to be elucidated for T cells derived in any in vitro cell differentiation system.

The past decade knowledge-driven research has revealed how T lineage commitment can be induced in HSCs in vitro, using cell-lines transfected with hDLL ${ }^{8,26,27}$, or, to a certain extent, with recombinant hDLL ${ }^{28,29}$. In contrast to mouse, differentiation of human progenitors rarely get past the DP-stage of thymocyte development, indicating it is difficult to push them through the positive-negative selection process. Interestingly, experiments with human T-progenitors sorted as or arrested at a DN2-3-like stage, obtained from either OP9-DLL or TSt-4-DLL -HSC co-cultures, respectively, demonstrated that these cells were capable of rapidly reconstituting the thymus of Rag2 ${ }^{-1-} \gamma \mathrm{c}^{-/-}$mice, where they completed their maturation ${ }^{22,30}$. Similar experiments with murine $\mathrm{T}$ progenitors have shown that this approach considerably enhanced the generation of functional T cells after HSC transplantation ${ }^{31,32}$. This approach will certainly be applicable to patients in the near future, but still relies on the functional capacity of the thymus, which is limited in older patients. In this regard, more pragmatic research has resulted in several viable approaches capable of improving thymic function ${ }^{33-35}$, which are now being tested in clinical trials ${ }^{36,37}$. The solutions to both problems concerning $\mathrm{T}$ cell reconstitution are expected to meet within the next decade. 


\section{Conclusion}

The results described by Clark et al. ${ }^{16}$ are fascinating and unique, but remain elusive. The results in the current paper show that by following the published procedure we could not obtain enough evidence to support the basic skin-cell co-culture conditions suggested to be required for HSC differentiation towards mature T cells. Recent advancements in the field of $\mathrm{T}$ cell lineage differentiation and thymic rejuvenation will generate alternative procedures to reconstitute the $\mathrm{T}$ cell population following HSC transplantation of man. 


\section{Acknowledgements}

Prof. dr. Frans Ramaekers (MuBio and University Maastricht, the Netherlands) kindly provided the RKSE60, RCK107 and LL025 anti-keratin antibodies. This work was supported by SenterNovem (Project: IS055002 to WTVG and GMJB). 


\section{References}

1. Storek J, Gooley T, Witherspoon RP, Sullivan KM, Storb R. Infectious morbidity in longterm survivors of allogeneic marrow transplantation is associated with low CD4 T cell counts. Am J Hematol. 1997 Feb;54(2):131-8.

2. Mackall CL, Stein D, Fleisher TA, Brown MR, Hakim FT, Bare CV, et al. Prolonged CD4 depletion after sequential autologous peripheral blood progenitor cell infusions in children and young adults. Blood. 2000 Jul 15;96(2):754-62.

3. Connors M, Kovacs JA, Krevat S, Gea-Banacloche JC, Sneller MC, Flanigan M, et al. HIV infection induces changes in CD4+ T-cell phenotype and depletions within the CD4+ T-cell repertoire that are not immediately restored by antiviral or immune-based therapies. Nat Med. 1997 May;3(5):533-40.

4. Lum LG. The kinetics of immune reconstitution after human marrow transplantation. Blood. 1987 Feb;69(2):369-80.

5. Ochs L, Shu XO, Miller J, Enright H, Wagner J, Filipovich A, et al. Late infections after allogeneic bone marrow transplantations: comparison of incidence in related and unrelated donor transplant recipients. Blood. 1995 Nov 15;86(10):3979-86.

6. Ruggeri L, Capanni M, Urbani E, Perruccio K, Shlomchik WD, Tosti A, et al. Effectiveness of donor natural killer cell alloreactivity in mismatched hematopoietic transplants. Science. 2002 Mar 15;295(5562):2097-100.

7. Storek J, Zhao Z, Lin E, Berger T, McSweeney PA, Nash RA, et al. Recovery from and consequences of severe iatrogenic lymphopenia (induced to treat autoimmune diseases). Clin Immunol. 2004 Dec;113(3):285-98.

8. Zuniga-Pflucker JC. T-cell development made simple. Nat Rev Immunol. 2004 Jan;4(1):6772.

9. Aqui NA, June CH. Post-transplant adoptive T-cell immunotherapy. Best Pract Res Clin Haematol. 2008 Sep;21(3):503-19.

10. Douek DC, McFarland RD, Keiser PH, Gage EA, Massey JM, Haynes BF, et al. Changes in thymic function with age and during the treatment of HIV infection. Nature. $1998 \mathrm{Dec}$ 17;396(6712):690-5.

11. Haynes BF, Markert ML, Sempowski GD, Patel DD, Hale LP. The role of the thymus in immune reconstitution in aging, bone marrow transplantation, and HIV-1 infection. Annu Rev Immunol. 2000;18:529-60.

12. Mackall CL, Fleisher TA, Brown MR, Andrich MP, Chen CC, Feuerstein IM, et al. Age, thymopoiesis, and CD4+ T-lymphocyte regeneration after intensive chemotherapy. $\mathrm{N}$ Engl J Med. 1995 Jan 19;332(3):143-9.

13. Uchida N, Tsukamoto A, He D, Friera AM, Scollay R, Weissman IL. High doses of purified stem cells cause early hematopoietic recovery in syngeneic and allogeneic hosts. J Clin Invest. 1998 Mar 1;101(5):961-6. 
14. Chen BJ, Cui X, Sempowski GD, Domen J, Chao NJ. Hematopoietic stem cell dose correlates with the speed of immune reconstitution after stem cell transplantation. Blood. 2004 Jun 1;103(11):4344-52.

15. Rodewald HR. Thymus organogenesis. Annu Rev Immunol. 2008;26:355-88.

16. Clark RA, Yamanaka K, Bai M, Dowgiert R, Kupper TS. Human skin cells support thymusindependent $\mathbf{T}$ cell development. J Clin Invest. 2005 Nov;115(11):3239-49.

17. Mathis D, Benoist C. Aire. Annu Rev Immunol. 2009;27:287-312.

18. Nickoloff BJ, Qin JZ, Chaturvedi V, Denning MF, Bonish B, Miele L. Jagged-1 mediated activation of notch signaling induces complete maturation of human keratinocytes through NF-kappaB and PPARgamma. Cell Death Differ. 2002 Aug;9(8):842-55.

19. Jaleco AC, Neves H, Hooijberg E, Gameiro P, Clode N, Haury M, et al. Differential effects of Notch ligands Delta-1 and Jagged-1 in human lymphoid differentiation. J Exp Med. 2001 Oct 1;194(7):991-1002.

20. Heinzel K, Benz C, Martins VC, Haidl ID, Bleul CC. Bone marrow-derived hemopoietic precursors commit to the $\mathrm{T}$ cell lineage only after arrival in the thymic microenvironment. J Immunol. 2007 Jan 15;178(2):858-68.

21. Felli MP, Maroder M, Mitsiadis TA, Campese AF, Bellavia D, Vacca A, et al. Expression pattern of notch1, 2 and 3 and Jagged 1 and 2 in lymphoid and stromal thymus components: distinct ligand-receptor interactions in intrathymic $\mathbf{T}$ cell development. Int Immunol. 1999 Jul;11(7):1017-25.

22. Meek B, Cloosen S, Borsotti C, Van Elssen CH, Vanderlocht J, Schnijderberg MC, et al. In vitro-differentiated $\mathrm{T} /$ natural killer-cell progenitors derived from human CD34+ cells mature in the thymus. Blood. 2010 Jan 14;115(2):261-4.

23. Taghon T, Van de Walle I, De Smet G, De Smedt M, Leclercq G, Vandekerckhove B, et al. Notch signaling is required for proliferation but not for differentiation at a well-defined betaselection checkpoint during human T-cell development. Blood. 2009 Apr 2;113(14):325463.

24. Boileau C, Houde M, Dulude G, Clegg CH, Perreault C. Regulation of extrathymic T cell development and turnover by oncostatin M. J Immunol. 2000 Jun 1;164(11):5713-20.

25. Blais ME, Brochu S, Giroux M, Belanger MP, Dulude G, Sekaly RP, et al. Why T cells of thymic versus extrathymic origin are functionally different. J Immunol. 2008 Feb 15;180(4):2299312.

26. De Smedt M, Hoebeke I, Plum J. Human bone marrow CD34+ progenitor cells mature to T cells on OP9-DL1 stromal cell line without thymus microenvironment. Blood Cells Mol Dis. 2004 Nov-Dec;33(3):227-32.

27. La Motte-Mohs RN, Herer E, Zuniga-Pflucker JC. Induction of T-cell development from human cord blood hematopoietic stem cells by Delta-like 1 in vitro. Blood. 2005 Feb 15;105(4):1431-9.

28. Dallas MH, Varnum-Finney B, Martin PJ, Bernstein ID. Enhanced T-cell reconstitution by hematopoietic progenitors expanded ex vivo using the Notch ligand Delta1. Blood. 2007 
Apr 15;109(8):3579-87.

29. Delaney C, Varnum-Finney B, Aoyama K, Brashem-Stein C, Bernstein ID. Dose-dependent effects of the Notch ligand Deltal on ex vivo differentiation and in vivo marrow repopulating ability of cord blood cells. Blood. 2005 Oct 15;106(8):2693-9.

30. Awong G, Herer E, Surh CD, Dick JE, La Motte-Mohs RN, Zuniga-Pflucker JC. Characterization in vitro and engraftment potential in vivo of human progenitor $\mathrm{T}$ cells generated from hematopoietic stem cells. Blood. 2009 Jul 30;114(5):972-82.

31. Zakrzewski JL, Kochman AA, Lu SX, Terwey TH, Kim TD, Hubbard VM, et al. Adoptive transfer of $\mathrm{T}$-cell precursors enhances $\mathrm{T}$-cell reconstitution after allogeneic hematopoietic stem cell transplantation. Nat Med. 2006 Sep;12(9):1039-47.

32. Ikawa T, Hirose S, Masuda K, Kakugawa K, Satoh R, Shibano-Satoh A, et al. An essential developmental checkpoint for production of the $\mathrm{T}$ cell lineage. Science. $2010 \mathrm{Jul}$ 2;329(5987):93-6.

33. Rossi SW, Jeker LT, Ueno T, Kuse S, Keller MP, Zuklys S, et al. Keratinocyte growth factor (KGF) enhances postnatal T-cell development via enhancements in proliferation and function of thymic epithelial cells. Blood. 2007 May 1;109(9):3803-11.

34. Goldberg GL, King CG, Nejat RA, Suh DY, Smith OM, Bretz JC, et al. Luteinizing hormone-releasing hormone enhances $\mathrm{T}$ cell recovery following allogeneic bone marrow transplantation. J Immunol. 2009 May 1;182(9):5846-54.

35. Kelly RM, Highfill SL, Panoskaltsis-Mortari A, Taylor PA, Boyd RL, Hollander GA, et al. Keratinocyte growth factor and androgen blockade work in concert to protect against conditioning regimen-induced thymic epithelial damage and enhance $T$-cell reconstitution after murine bone marrow transplantation. Blood. 2008 Jun 15;111(12):5734-44.

36. Napolitano LA, Schmidt D, Gotway MB, Ameli N, Filbert EL, Ng MM, et al. Growth hormone enhances thymic function in HIV-1-infected adults. J Clin Invest. 2008 Mar;118(3):108598.

37. Levine JE, Blazar BR, DeFor T, Ferrara JL, Weisdorf DJ. Long-term follow-up of a phase I/ II randomized, placebo-controlled trial of palifermin to prevent graft-versus-host disease (GVHD) after related donor allogeneic hematopoietic cell transplantation (HCT). Biol Blood Marrow Transplant. 2008 Sep;14(9):1017-21. 


\section{Ascorbic acid induces development of double-positive $T$ cells from human haematopoietic stem cells in the absence of stromal cells}

Mirelle J.A.J. Huijskens, Mateusz Walczak, Nicole Koller, Jacob J. Briedé, Birgit L.M.G. Senden-Gijsbers, Melanie C. Schnijderberg, Gerard M.J. Bos, Wilfred T.V. Germeraad

J Leukoc Biol. 2014 Dec; 96(6): 1165-75. 


\section{Abstract}

The efficacy of donor haematopoietic stem cell (HSC) transplantations is partly reduced due to slow post-transplantation immune recovery. In particular, $\mathrm{T}$ cell regeneration is generally delayed, resulting in high infection-related mortality in the first years post-transplantation. Adoptive transfer of in vitro generated human T cell progenitors seems a promising approach to accelerate $\mathrm{T}$ cell recovery in immunocompromised patients. Ascorbic acid (AA) may enhance $\mathrm{T}$ cell proliferation and differentiation in a controlled, feeder-free environment containing Notch-ligands and defined growth factors. Our experiments show a pivotal role for AA during human in vitro T cell development. Blocking Nitric Oxide Synthase diminished this effect, indicating a role for the citrulline/NO cycle. AA promotes both the transition of proT1 to proT2 cells and of preT to double positive (DP) T cells. Furthermore, the addition of AA to feeder co-cultures resulted in development of DP and single positive (SP) T cells, whereas without AA a preT cell stage arrest occurred. We conclude that neither DLL4expressing feeder cells nor feeder cell conditioned media are required for generating DP T cells from cord blood and G-CSF mobilized HSCs and that generation and proliferation of proT and DP T cells is greatly improved by AA. This technology could potentially be used to generate $\mathrm{T}$ cell progenitors for adoptive therapy. 


\section{Introduction}

Haematopoietic stem cell transplantation (HSCT) is one of the current treatments of haematological malignancies. However, slow post-transplantation immune recovery may result in high infection-related mortality, especially if the donor source comes from haploidentical or cord blood (CB) donors ${ }^{1,2}$. In particular, immune reconstitution is hindered by a delayed $\mathrm{T}$ cell regeneration. Important reasons for this delay are age-related thymic involution, impaired thymus function and a decreased repopulation of the thymus by stem/progenitor cells ${ }^{3-6}$. Only de novo $\mathrm{T}$ cell generation in the thymus ensures a broad $\mathrm{T}$ cell repertoire that guarantees complete immune recovery after HSCT.

T cell development is a highly regulated process that starts with HSCs in the bone marrow and proceeds in the thymus. Maturation of T cell progenitors in the thymus can be divided into several stages. Based on the expression of CD4 and CD8, T cell development can be separated into double negative (DN), double positive (DP) and single positive (SP) stages ${ }^{7}$. The DN stages can be subdivided based on the expression of early $\mathrm{T}$ cell markers with cluster of differentiation (CD)7 as the first marker expressed (proT1) and subsequent CD5 expression (proT2, previously described as DN2) ${ }^{8-11}$. CD1a is present on T lineage committed precursors (preT, previously described as DN3) and is followed by expression of CD4 (immature single positive cells; iSP) ${ }^{11-13}$. In the subsequent DP stage, CD3 and T cell receptor (TCR) $\alpha \beta$ are expressed, and after positive and negative selection in the thymic microenvironments cells enter the periphery as mature naive SP T cells. Crucial for T cell development is the interaction of the Notch receptor on progenitor cells with Notch ligands provided by the thymic stroma ${ }^{14}$. Both Notch ligands Delta-like ligand-1 (DLL1) and DLL4 are able to drive T lineage development in vitro ${ }^{15}$, where in vivo only DLL4 gives the instructive signal to the thymus seeding cells ${ }^{16,17}$. Due to the importance of Notch signalling during T lineage development, DLL-expressing feeder cells have been used in vitro to generate $\mathrm{T}$ cell progenitors for adoptive immunotherapy.

Adoptive transfer of in vitro generated (progenitor) $\mathrm{T}$ cells has evolved as a promising approach to accelerate $\mathrm{T}$ cell recovery in immune compromised patients. In recent years, methods to generate $\mathrm{T}$ cell progenitors in vitro have been developed ${ }^{9,11,18}$. It is shown that these progenitors can enhance $\mathrm{T}$ cell reconstitution in vivo ${ }^{9,11,19}$. We have reported that mobilized $\mathrm{CD}^{+} 4^{+}$(mCD34) cells in co-culture with thymic stroma derived TSt-4/DLL feeder cells differentiate into T/NK progenitors ${ }^{11}$. Similar results have been obtained with $\mathrm{CB}$ and bone marrow derived $\mathrm{CD}^{+} 4^{+}$cells in co-culture with the bone marrow derived OP-9/DL1 feeder cells ${ }^{9,18}$. Together with some other stromal cell lines like S17/DL1 ${ }^{20}$, the DLL-expressing feeder cell lines have the unique capacity to support $\mathrm{T}$ cell development in contrast to other stromal cells, for example NIH3T3 expressing DLL ${ }^{21}$. Additionally, OP-9/ 
DL1 can support T cell development in vitro to the DP/SP stage in contrast to TSt-4/DLL ${ }^{22}$. In vivo immune reconstitution experiments showed that TSt-4/DLL derived progenitor cells from $\mathrm{mCD}_{3} 4^{+}$and $\mathrm{CB}$ derived proT cells from OP-9/DL1 co-cultures home to the thymi of immune deficient mice and complete their development into mature $\mathrm{T}$ cells faster than unmanipulated stem cells ${ }^{9,11}$. Additionally, Eyrich et al. detected extrathymic mature $\mathrm{T}$ cells in mice after injection of $\mathrm{T}$ cell progenitors derived from OP-9/DL1 co-cultures ${ }^{19}$.

Efforts have been made to generate in vitro clinical grade $\mathrm{T}$ cell progenitors without the use of feeder cells ${ }^{23,24}$. Ohishi et al. showed that expansion of $\mathrm{CB} \mathrm{CD} 34^{+}$cells in the presence of immobilized DLL1 and cytokines resulted in the development of a $\mathrm{CD} 34^{+} \mathrm{CD} 7^{+}$lymphoid progenitor population capable of $\mathrm{CD}^{+} \mathrm{T}$ cell reconstitution in the thymi of immune deficient mice ${ }^{23}$. Moreover, a phase I clinical study with the transfer of CB CD $34^{+}$DLL1 culture derived progenitors showed enhanced engraftment and myeloid reconstitution ${ }^{25}$. However, the lack of improvement in $\mathrm{T}$ cell reconstitution in these patients indicates the need for more efficient methods for in vitro generation of $\mathrm{T}$ cell progenitors.

To extend on our previous work ${ }^{11,26}$ we searched for factors to enhance $\mathrm{T}$ cell differentiation and proliferation, and investigated the role of ascorbic acid (AA) in the current study. Ascorbic acid plays a multitude of roles in the immune system and is abundantly present in $\mathrm{T}$ cells ${ }^{27}$, but its role during human $\mathrm{T}$ cell development is not known. In our present study, we have investigated the role of different forms of AA on $\mathrm{T}$ cell maturation and proliferation from HSCs and show the influence of AA in both feeder and feeder-free conditions. 


\section{Materials and methods}

\section{Isolation and purification of $\mathrm{CD}^{2} 4^{+}$cells}

$\mathrm{CB} \mathrm{CD} 34^{+}$and $\mathrm{mCD} 34^{+}$cells were obtained at the Maastricht University Medical Center after informed consent in accordance with the Declaration of Helsinki and with approval of the local Medical Ethical Committee (METC 12-2-044). mCD34 ${ }^{+}$cells were obtained from healthy volunteers treated with G-CSF (Neupogen, Amgen, Thousand Oaks, CA, USA). Mononuclear cells were isolated from fresh 1:1 phosphate buffered saline (PBS, PAA, Pasching, Austria) diluted CB by Lymphoprep (Axis shield, Oslo, Norway) density gradient centrifugation. $\mathrm{CD}^{+} 4^{+}$cells were enriched using immunomagnetic beads according to manufacturer's instructions (CD34 $4^{+}$microbead kit and cliniMACS CD34 ${ }^{+}$selection kit for CB CD34 and mCD34, respectively, Miltenyi, Bergisch Gladbach, Germany). CD34 ${ }^{+} \mathrm{CD} 38^{\text {-/dim }}$ cells were further purified and depleted from contaminating $\mathrm{T}$ and $\mathrm{NK}$ cells by fluorescenceactivated cell sorting using FACS ARIA (BD, Erembodegem, Belgium). For cell-sorting, the following antibodies were used at proper dilutions: fluorescein isothiocyanate (FITC)-anti$\mathrm{CD} 38$, phycoerythrin (PE)-anti-CD34, peridinin-chlorophyll proteins (PerCP)-anti-CD4, -CD8, -CD3 and allophycocyanin (APC)-anti-CD56 or horizon V450-anti-CD56 (all BD). To obtain sufficient number of starting cells, $\mathrm{CB}$ units from different healthy donors were obtained and pooled. Purity of mobilized and $\mathrm{CB}$ CD $34^{+}$cells was more than or equal to $98 \%$ $\mathrm{CD} 34^{+}$cells and less than or equal to $0.1 \%$ contaminating $\mathrm{CD} 3 / \mathrm{CD} 4 / \mathrm{CD} 8$ or $\mathrm{CD} 56^{+}$cells.

\section{Co-cultures with feeder cells}

TSt-4 cells, an earlier gift of Prof. dr. H. Kawamoto (Kyoto University, Japan) were grown in standard RPMI 1640 medium (Sigma-Aldrich Co., St. Louis, MO, USA) containing 5\% FBS (Greiner bio one, Kremsmuenster, Austria), 1\% penicillin-streptomycin, 1mM sodium pyruvate, $0.1 \mathrm{mM}$ MEM non-essential amino acids, and $5 \times 10^{-5} \mathrm{M}$ 2-mercaptoethanol (all from Invitrogen Ltd., Paisley, UK). OP-9 cells were cultured in aMEM medium reconstituted from powder (Life Technologies, Carlsbad, CA, USA) containing 20\% FBS (Hyclone Thermo Scientific, Logan, UT, USA), 5g/L sodium bicarbonate (Sigma-Aldrich Co.) and 1\% Penicillin/ Streptomycin (Invitrogen Ltd.). Liquid aMEM medium (Life technologies) without ascorbic acid was used when indicated. L-Ascorbic acid (Sigma-Aldrich Co.) was supplemented to RPMI 1640 and liquid aMEM medium when indicated. OP-9 cells were a kind gift from dr. R. Schotte and dr. B. Blom (AMC, Amsterdam, the Netherlands). $\mathrm{mCD} 34^{+}$cells were seeded at a density of $2.6 \times 10^{3}$ cells $/ \mathrm{cm}^{2}$ on monolayers of TSt -4 cells expressing Notch ligands DLL1 or DLL4 or monolayers of OP-9/DL1. After addition of CD34 $4^{+}$cells, media were supplemented with human interleukin (IL)-7, stem cell factor (SCF) and FMS-like tyrosine kinase 3 ligand (Flt3-L, Miltenyi). Co-cultures were refreshed by half medium change 3 times per week. During the first week, $50 \mathrm{ng} / \mathrm{ml}$ and from the second week onwards, $5 \mathrm{ng} / \mathrm{ml}$ of each cytokine was added to the cultures. Differentiating cells were transferred to fresh monolayers every 
week. For transfer, cells were separated from the monolayers by disruption of the monolayers using cell scrapers (BD), resuspension by pipetting, and filtration through a $70 \mu \mathrm{m}$ mesh (BD) directly onto the new monolayer. Co-cultures were maintained for 7 weeks.

\section{Feeder-free culture}

Non-tissue culture-treated culture plates (Falcon, BD) were incubated for $1 \mathrm{~h}$ at RT with $10 \mu \mathrm{g} /$ $\mathrm{ml}$ rabbit anti-human IgG Fc antibody (Jackson ImmunoResearch Laboratories, West Grove, PA, USA) and subsequently with DLL4:Fc (Sinobiological, Beijing, China) diluted in PBS for 1 h. For the second protocol, non-tissue culture-treated culture plates (Falcon) were incubated overnight at $4^{\circ} \mathrm{C}$ with DLL4:Fc diluted in PBS together with $5 \mathrm{ug} / \mathrm{ml}$ RetroNectin (r-fibronectin fragment CH-296, Takara Shuzo, Otsu, Japan), washed extensively, and further incubated for at least $1.5 \mathrm{~h}$ with $2 \%$ human serum albumin diluted in PBS. $\mathrm{CD} 34^{+} \mathrm{CD} 38^{-/ \mathrm{dim}}$ cells were seeded at a density of $3.9 \times 10^{3}$ cells $/ \mathrm{cm}^{2}$ and cultured in RPMI 1640, aMEM or Stemspan SFEM II medium (Stemcell Technologies, Grenoble, France) with or without L-ascorbic acid (L-AA) or 2-phospho-L-ascorbic acid (ph-AA, Sigma-Aldrich Co.) supplementation. Co-cultures were refreshed by half medium change 3 times per week and weekly exposed to fresh DLL4:Fc and fibronectin. All cultures were supplemented with human IL-7, SCF, Flt3-L (all 50ng/ml) and $100 \mathrm{ng} / \mathrm{ml}$ thrombopoietin (TPO, all Miltenyi). Cultures were maintained for 5 weeks. For experiments depicted in Fig. 4A, cultures were supplemented with $1 \mathrm{mM} \mathrm{N}$-acetyl-L cysteine (NAC), 20nM sodium selenite (Selenite) or $200 \mu \mathrm{M} \alpha$ Tocopherol acetate ( $\alpha$ Tocopherol, all Sigma Aldrich). Concentrations were selected based on Esteban et al. ${ }^{28}$. For experiments depicted in Fig. 4D and E, cultures were supplemented with $5 \mathrm{mM} \mathrm{N}^{\mathrm{G}}$-monomethyl-Larginine-monoacetate salt (L-NMMA, Abcam, Cambridge, UK).

\section{Flow cytometry}

In vitro cultured cells were stained at indicated time points. Cells were incubated with antibodies at proper dilutions for 20min at RT. Staining for cytoplasmic CD3 was performed by first permeabilizing cells using permwash (BD).

The following antibodies were used: CD4 (SK3), CD7 (M-T701), CD45 (HI30), TCRaß (IP26, eBioscience, San Diego, CA, USA), CD38 (HB7) and CD197 (CCR7, 150503, R\&D systems, Minneapolis, USA), all FITC-labelled; CD1a (HI149), CD7 (M-T701), CD8 (RPA-T8), CD18 (Integrin $\beta 2$, MEM-48, Immuno tools, Friesoythe, Germany), CD34 (8G12), CD45 (HI30), CD127 (M21), CD135 (4G8). CD162 (P-Selectin glycoprotein-1, PSGL-1, KPL-1) and CD183 (CXCR3, 205410, R\&D systems, Minneapolis, MN, USA), all PE-labelled; CD3 (SK7), CD4 (SK3), CD8 (SK1), CD45 (2D1) and CD196 (CCR6, 53103, R\&D systems), all PerCP-labelled; CD199 (CCR9, 112509), Alexa Fluor 647-labelled; CD3 (UCHT1), CD5 (UCHT2), CD45 (2D1), CD110 (REA250, Miltenyi), CD117 (A3C6E2, Miltenyi), CD184 (CXCR4, 12G5) and CD197 (CCR7, 150503, R\&D systems), all APC-labelled; CD29 (Integrin $\beta 1$, TS2/16, Biolegend, San Diego, CA, USA), APC-Cy7-labelled; CD8 (RPA-T8), CD56 (B159) and 
CD45 (HI30), all Horizon V450-labelled. For apoptosis detection, PE Annexin V Apoptosis Detection Kit was used. All antibodies, materials, and equipment were obtained from BD Biosciences, unless stated otherwise. A minimum of 20,000 cells per sample was measured with the flow cytometer Canto II (BD). Flow cytometric analysis was performed with BD FACS DIVA software version 6.1.2 (BD) or FlowJo software version 10.0.6 (Treestar, Ashland, OR, USA). Living cells were gated on forward and sideward scatter pattern with subsequent doublet removal.

\section{PCR}

Genomic DNA was extracted from cells using QIAamp DNA mini kit according to manufacturer's protocol (Qiagen, Venlo, the Netherlands). PCR was performed in $20 \mu \mathrm{l}$ reaction volume containing 60ng DNA from progenitors cultured in the presence of DLL4:Fc, T cells from peripheral blood, CD $34^{+}$cells or CD $34^{+}$cells cultured with RetroNectin (Takara Shuzo) only. All PCR components were used according to manufacturer's instructions (iTaq, BioRad, Hercules, CA, USA) together with 500nM of each primer (Eurogentec, Liege, Belgium). D $\delta 2-$ $\mathrm{J} \delta 1$ and $\mathrm{V} \delta 1-\mathrm{J} \delta 1$ primers are described in Dik et al. ${ }^{12}$. Annealing temperature of $65^{\circ} \mathrm{C}$ with $3 \mathrm{mM} \mathrm{MgCl}_{2}$ and 35 cycles were used for both primer sets. EZ load 100bp Molecular Ruler (Biorad) was used as marker. D $\beta 1.1-\mathrm{J} \beta 1.3$ primers are described in Kato et al. ${ }^{15}$. Annealing temperature of $60^{\circ} \mathrm{C}$ with $1.5 \mathrm{mM} \mathrm{MgCl}_{2}$ and $35 \mathrm{cycles}$ were used. Gene ruler $100 \mathrm{bp}$ plus DNA ladder (Fermentas Thermo Scientific) was used as marker.

\section{Statistical analysis}

Data are presented as median. All statistical analyses were performed using the Prism program (GraphPad Software Inc, San Diego, CA, USA). Differences between experimental conditions were evaluated for statistical significance with non-parametric Wilcoxon matched pairs test or with Mann-Whitney U test. Significance was accepted at the level of $p<0.05,{ }^{\star} p=0.01-0.05$, ${ }^{* *} \mathrm{p}=0.01-0.001,{ }^{* * *} \mathrm{p}<0.001$. 


\section{Results}

\section{Generation of $\mathrm{CD}^{+}$proT cells from human $\mathrm{CD}^{+} 4^{+}$cells in a feeder-free system}

To evaluate the $\mathrm{T}$ cell differentiation potential of $\mathrm{CD} 34^{+}$cells in a system without feeder cells, optimal culture conditions were first determined. $\mathrm{CB} \mathrm{CD} 34^{+}$cells were initially cultured in the presence of $\alpha \mathrm{IgG}-\mathrm{Fc}$ and surface-immobilized DLL4:Fc in RPMI medium as was established by Ikawa et al. ${ }^{24}$. Phenotype and fold expansion of $\mathrm{T}$ cell progenitors were defined after 3 and 4 weeks of culture. The optimal concentration of DLL4:Fc was found to be $5 \mu \mathrm{g} / \mathrm{ml}$ resulting in the highest percentage and number of CD7 expressing cells (Fig. 1A, Supplemental Fig. 1). To further improve maturation of $\mathrm{T}$ cell progenitors, different coating protocols were tested. Coating with r-fibronectin fragment CH-296 (fibronectin, $5 \mu \mathrm{g} / \mathrm{ml},{ }^{29}$ ) and DLL4:Fc resulted in higher CD7 expression (93\%) compared to the combination of rabbit-anti-human IgG-Fc antibody with DLL4:Fc (61\%, Fig. 1B). Additionally, fold expansion in the fibronectin DLL4:Fc condition was 5 times higher than in the IgG condition. Therefore, in further experiments $5 \mu \mathrm{g} / \mathrm{ml}$ DLL4:Fc in combination with $5 \mu \mathrm{g} / \mathrm{ml}$ fibronectin was used.

The stromal cell lines TSt-4/DLL4 ${ }^{15}, 30$ and OP-9/DL1 ${ }^{31}$ are known to support $\mathrm{T}$ cell differentiation and are always cultured in RPMI and aMEM, respectively. We therefore decided to compare the influence of these media on human $\mathrm{T}$ cell differentiation in the feeder-free culture (Fig. 1C and 1D). Although similar percentages of $\mathrm{CD} 7^{+}$and $\mathrm{iCD} 3^{+}$cells were present in both conditions, $\mathrm{CD}^{+}$proT2 cells were only abundantly present in $\mathrm{MMEM}$ (median $88 \%$ ). Furthermore, $\mathrm{CD} 7{ }^{+} \mathrm{CD} 1 \mathrm{a}^{+}$preT cells were only present in aMEM medium (median $7 \%$ ). In addition, fold expansion of $\mathrm{T}$ cell progenitors was 10 times increased in aMEM compared to RPMI after 3 weeks of culture (Fig. 1E). Fold expansions varied among different donors, but similar trends were observed in all experiments. Taken together, our data indicate that both $\mathrm{T}$ cell maturation and proliferation were improved in aMEM medium compared to RPMI. 

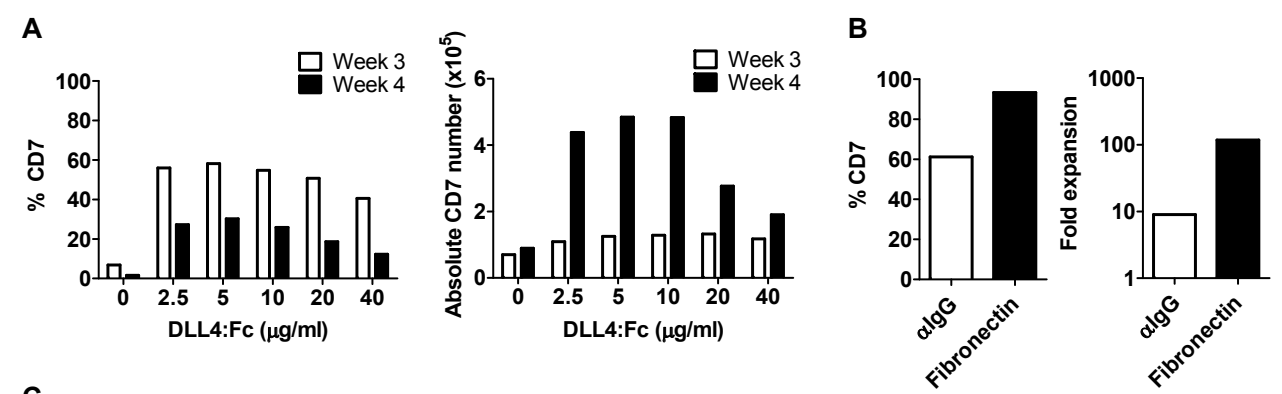

C

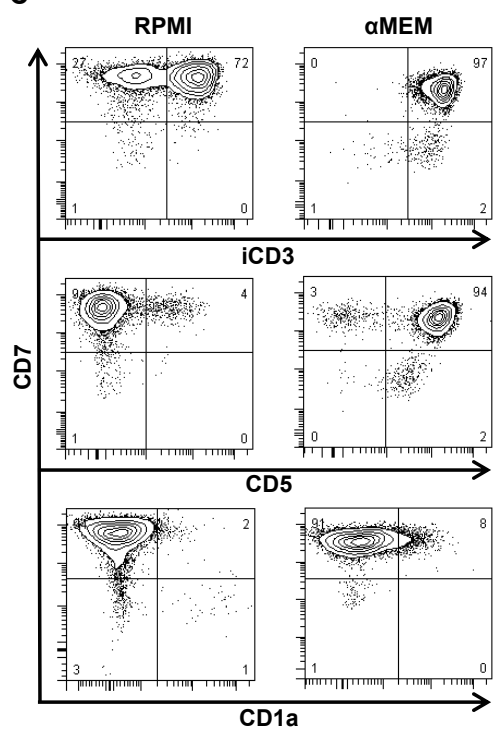

D

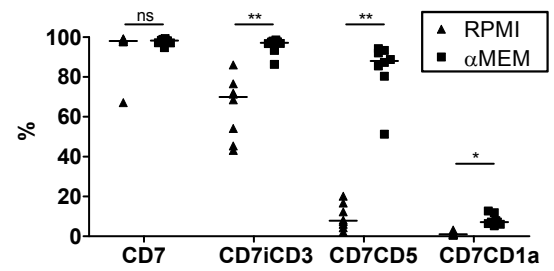

E

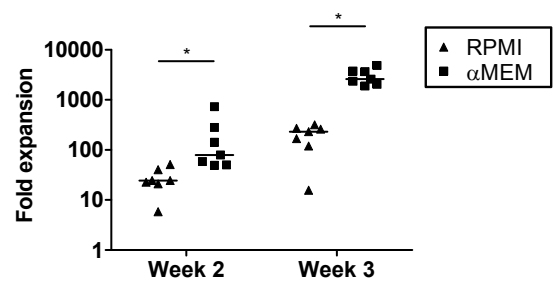

Figure 1: $\mathrm{T}$ lineage development of $\mathrm{CD}^{+} 4^{+} \mathrm{CD}^{-/ \mathrm{dim}} \mathrm{CB}$ cells after exposure to immobilized Deltalike ligand 4 in a feeder-free culture. $\mathrm{CB}$ derived $\mathrm{CD} 34^{+} \mathrm{CD} 38^{-/ \mathrm{dim}}$ cells were cultured in RPMI medium without feeder cells. Culture plates were coated with different concentrations of DLL4:Fc $(\mu \mathrm{g} / \mathrm{ml})$ and aIgG. A: Percentage and absolute number of $\mathrm{CD}^{+}$cells after 3 and 4 weeks of culture are shown. B: Percentage of $\mathrm{CD}^{+}$cells and expansion after 3 weeks of culture with $5 \mu \mathrm{g} / \mathrm{ml}$ DLL4:Fc and $\alpha \mathrm{IgG}$ or $5 \mu \mathrm{g} /$ $\mathrm{ml}$ DLL4:Fc and fibronectin in RPMI medium are shown. Representative results of 2 experiments are shown. C and D: Representative flow cytometry plots (C) and percentages of $n=8$ experiments (D) shows early $\mathrm{T}$ cell marker expression after 3 weeks of culture in the DLL4:Fc fibronectin culture in RPMI or aMEM. Wilcoxon matched pairs test; $\mathrm{p}=\mathrm{ns}$ for $\mathrm{CD} 7,{ }^{*} \mathrm{p}=0.0078$ for $\mathrm{CD} 7 \mathrm{iCD} 3,{ }^{* *} \mathrm{p}=0.0078$ for CD7CD5, ${ }^{\star} \mathrm{p}=0.014$ for CD7CD1a. E: Fold expansion of total cells in the feeder-free culture in both media in the presence of DLL4:Fc fibronectin is shown. Wilcoxon matched pairs test; ${ }^{*} \mathrm{p}=0.0156$ for week 2 and ${ }^{*} \mathrm{p}=0.0156$ for week $3(\mathrm{n}=7)$. 


\section{Ascorbic acid promotes proT1 to proT2 differentiation in the feeder-free system}

Since proT2 $\left(\mathrm{CD}^{+}{ }^{+} \mathrm{CD}_{3}{ }^{+} \mathrm{CD}^{+}\right)$cells could develop in a feeder-free system in aMEM, but were almost absent in RPMI medium, the composition of both media was compared to reveal compounds possibly accounting for this discrepancy. The addition of different types or higher percentages of foetal bovine serum (FBS) to RPMI medium did not result in the expression of CD5 or CD1a on progenitor cells (data not shown). Another difference in medium composition is the presence of L-ascorbic acid (L-AA) in aMEM and its absence in RPMI. The natural occurring L-AA is highly unstable to atmospheric oxygen, $\mathrm{pH}$, light and temperature ${ }^{32}$. Therefore, the more stable form of AA, 2-phospho-L-ascorbic acid (ph-AA), in which a hydroxylgroup is substituted by a phosphate group, was also tested ${ }^{32}$. To determine the influence of AA on T cell development, different concentrations of L-AA and ph-AA were added to RPMI medium and compared to aMEM (containing $284 \mu \mathrm{M} \mathrm{L-AA}$ ). CD7 expression was slightly influenced by the addition of AA, as almost all progenitors expressed CD7 to a similar extent in both L-AA and ph-AA conditions after 3 weeks (Fig. 2A and Supplemental Fig. 2B). In contrast to CD7, the intracellular CD3 (iCD3) expression on cells differed substantially between aMEM and RPMI conditions ( $85 \%$ versus $41 \% \mathrm{iCD}^{+}$cells, respectively). Strikingly, addition of both L-AA and ph-AA led to a concentration-dependent increase of $\mathrm{CD} 5$ expression on $\mathrm{CD}^{+}$cells. The highest percentage of $\mathrm{CD}^{+}$cells was present in the condition with $95 \mu \mathrm{M}$ ph-AA $(75 \%)$. Cell proliferation substantially increased by the addition of AA to RPMI (Fig. 2B and Supplemental Fig. 2B), without influencing cell viability (Supplemental Fig. 3). Interestingly, L-AA revealed a higher toxicity compared to ph-AA since all cells in the presence of the highest concentration died within 1 week. Taken together, $95 \mu \mathrm{M}$ ph-AA was the most optimal tested concentration for both maturation and proliferation in the feeder-free cultures, leading to high expression of iCD3, CD5, and CD7.

\section{Characterization of feeder-free derived $\mathrm{T}$ cell progenitors}

The chemokine receptor and integrin profile of generated $\mathrm{T}$ cell progenitors was determined to gain insight into the thymus-homing capacity of these cells. Expression of selected markers on feeder-free generated $\mathrm{T}$ cell progenitors was compared to TSt-4/DLL4 derived $\mathrm{T}$ cell progenitors after 3 weeks of culture. We have previously shown that the TSt-4/DLL4 derived progenitors are able to home to the thymus and complete $\mathrm{T}$ cell development in the thymi of immune deficient mice ${ }^{11}$. Feeder-free generated $\mathrm{T}$ cell progenitors expressed the chemokine receptors described to be necessary for thymus homing capability. Most of the tested chemokine receptors had higher expression on feeder-free derived progenitors than on TSt4/DLL4 co-culture derived progenitors, especially CCR4, as well as the adhesion molecules needed for thymus entry, integrin $\beta 1, \beta 2$ and PSGL-1 (Fig. 2C). In contrast, CCR7 was lower expressed on feeder-free progenitors than on co-culture derived progenitors. 

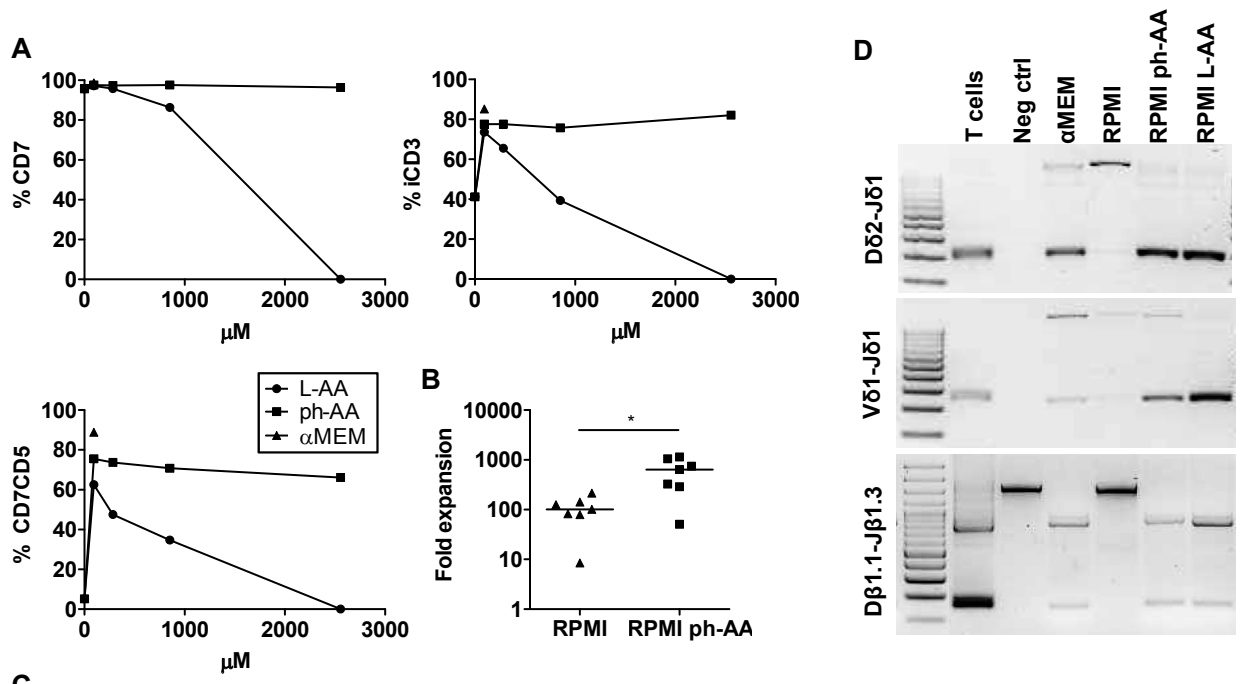

B
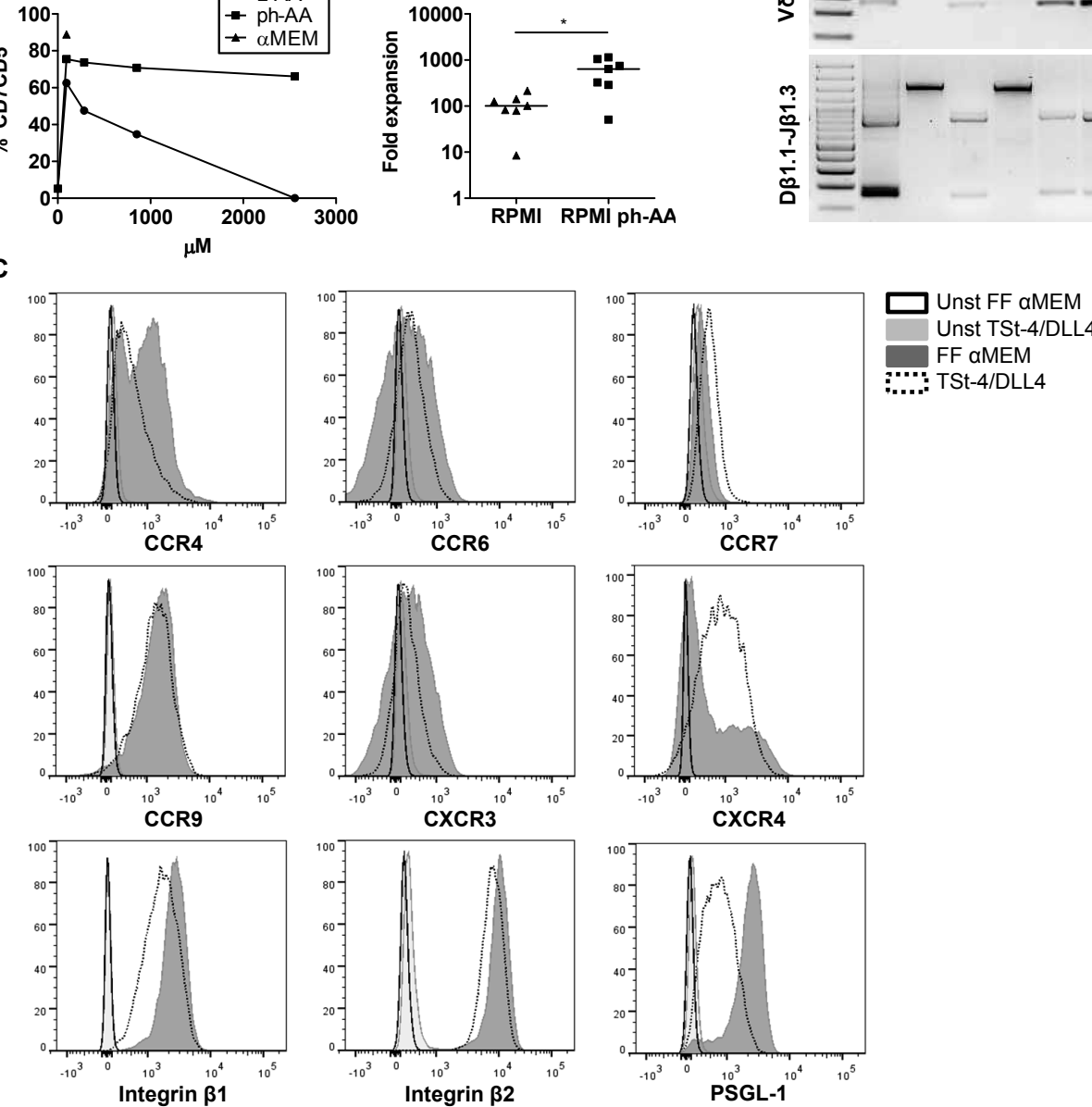

Figure 2: Ascorbic acid promotes preT cell development from $\mathrm{CD}_{34}{ }^{+} \mathrm{CD} 38^{-/ \mathrm{dim}}$ cells in the feederfree culture in the presence of DLL4:Fc and fibronectin. $\mathrm{CD} 34^{+} \mathrm{CD} 38^{-/ \mathrm{dim}}$ cells were cultured for 3 weeks in the presence of DLL4:Fc and fibronectin in RPMI medium supplemented with ph-AA or L-AA in different concentrations and in aMEM. A: Representative T lineage marker expression $(n=2)$ and fold expansion (B) of total cells is shown, median of $n=7$, Wilcoxon matched pairs test $p<0.0156$. C: Chemokine receptor, integrin and PSGL-1 profile of feeder cell free derived progenitor cells and TSt-4/ 
DLL4 feeder derived progenitors compared to unstained corresponding cells after 3 weeks of culture, values are normalized to event count. Representative plots of feeder-free $(n=2)$ and feeder culture $(n=4)$. D: $\mathrm{D}$ and $\mathrm{B}$ gene rearrangement of peripheral blood $\mathrm{CD}^{+} \mathrm{T}$ cells (positive control), $\mathrm{CB} \mathrm{CD} 34^{+} \mathrm{CD} 38^{-/ \mathrm{dim}}$ cells cultured with fibronectin (negative control) or fibronectin and DLL4:Fc in aMEM, RPMI, RPMI ph-AA or RPMI L-AA medium. Results for D $\delta 2-\mathrm{J} \delta 1, \mathrm{~V} \delta 1-\mathrm{J} \delta 1$ and $\mathrm{D} \beta 1.1-\mathrm{J} \beta 1.3$ are shown.

Next, TCR rearrangement was analysed to assess the maturation status of generated T cell progenitors in feeder-free derived progenitors cultured with aMEM or RPMI supplemented with L-AA or ph-AA. RPMI cultured progenitors only showed a weak $\mathrm{D} \delta$-J $\delta$ rearrangement band and no subsequent $\mathrm{V} \delta$-J $\delta$ rearrangement (Fig. 2D), while aMEM grown progenitors show both $\mathrm{D} \delta$-J $\delta$ and $\mathrm{V} \delta$-J $\delta$ rearrangement. Upon addition of L-AA or ph-AA to RPMI, progenitors showed rearrangement of both $\mathrm{D} \delta$ - $\mathrm{J} \delta$ and $\mathrm{V} \delta$-J $\delta$, confirming the different maturation stage of $\mathrm{T}$ cell progenitors in the presence or absence of AA. In contrast to positive controls, 2 products were amplified from the DNA of progenitor cells. Sequence analysis had previously demonstrated that the larger products are partial rearrangements of the $\delta$-locus ${ }^{11}$. Rearrangement of the TCR $\beta$ locus was present in cells cultured with aMEM and RPMI with AA; in contrast, in RPMI conditions only a germline band was detected. Together, these data confirm that $\mathrm{T}$ cell development is further advanced in conditions with AA.

\section{Ascorbic acid promotes $\mathrm{T}$ cell development in a GMP culture setting}

Besides $\mathrm{CB} \mathrm{CD} 34^{+}$, G-CSF mobilized CD34 ${ }^{+}$cells are often used in clinical HSCT due to the high numbers of cells that can be obtained, and as such also available for adoptive (progenitor) T cell therapy. Therefore, $\mathrm{mCD} 34^{+}$cells were cultured in the presence and absence of ph-AA. After three weeks of culture, the majority of $\mathrm{mCD} 4^{+}$cells had upregulated $\mathrm{CD} 7$ and iCD3 (Fig. 3A). Furthermore, a clear cell population co-expressing CD5 and CD1a was observed, whereas in culture without AA, cells expressed less CD7 (maximal 52\%), less iCD3 (maximal $22 \%$ ) and were unable to upregulate CD5 (Fig. 3A). Expansion of G-CSF mobilized progenitors was only detected in the presence of ph-AA (median 4 folds), albeit lower than of CB cells (Fig. 3B). Together, the positive influence of AA on $\mathrm{T}$ cell proliferation and maturation was clearly observed.

To examine $\mathrm{T}$ cell development in feeder-free good manufacturing practice (GMP) conditions, $\mathrm{CB} \mathrm{CD} 34^{+}$cells were cultured in serum-free medium (Stemspan ${ }^{\circledast}$ ) with or without $95 \mu \mathrm{M}$ ph-AA. In general, less $\mathrm{T}$ cell progenitors $\left(\mathrm{CD}^{+}\right)$developed in Stemspan ${ }^{\circledast}$ medium compared to the serum containing media. The addition of ph-AA to the culture increased the percentage of CD7, iCD3 and CD5 expression (Fig. 3C). CD1a expression was hardly influenced. Furthermore, expansion of total cells was positively influenced by the addition of ph-AA (504 to 4,648 fold, Fig. 3D). Thus, CB CD34 ${ }^{+}$stem cells can be expanded in serum-free medium under the positive influence of AA. 
A

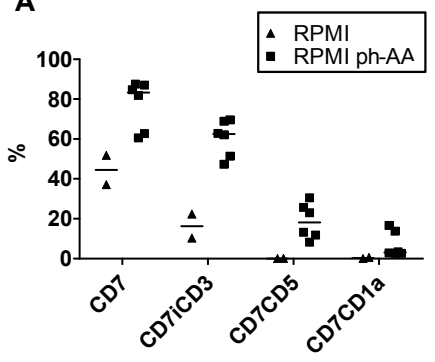

B

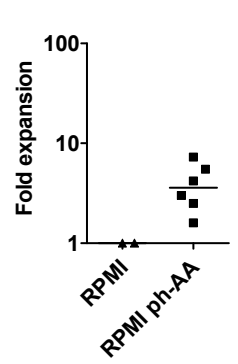

D

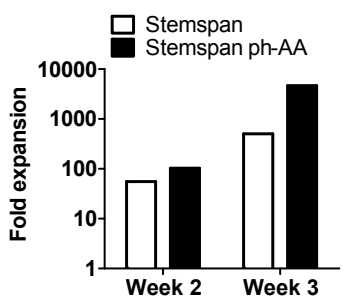

C

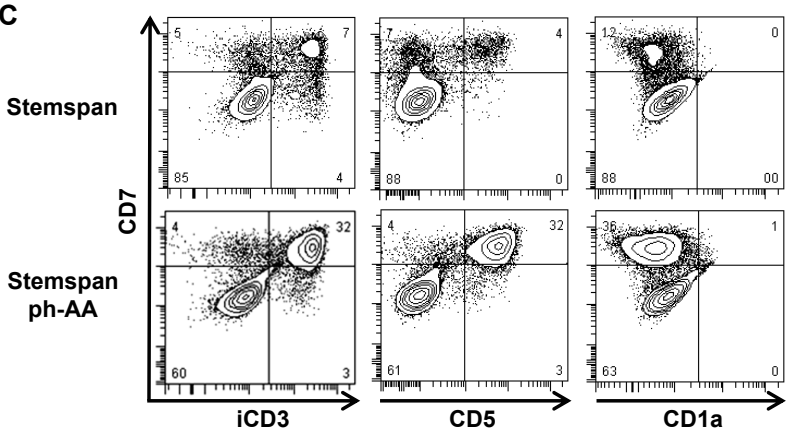

Figure 3: Ascorbic acid promotes T cell development in a GMP culture condition. A: T cell progenitor marker expression and fold expansion (B) of G-CSF mobilized CD $34^{+} \mathrm{CD} 38^{- \text {dim }}$ cells after 3 weeks of DLL4:Fc fibronectin culture in RPMI or RPMI with $95 \mu \mathrm{M}$ ph-AA. Median of $n=2$ and $n=6$ with 2 and 4 different donors, respectively, for RPMI and RPMI ph-AA are shown. C: T cell progenitor marker expression and expansion (D) of $\mathrm{CB} \mathrm{CD} 34^{+} \mathrm{CD} 38^{-/ d i m}$ cells in Stemspan ${ }^{\circledast}$ medium with and without $95 \mu \mathrm{M}$ ph-AA. Representative results of $\mathrm{n}=2$ are shown.

\section{Other antioxidants than AA lack the potential to drive preT cell development}

To investigate whether the effect of AA on T cell maturation was due to its antioxidant function, four other antioxidants were tested (Fig. 4A). CD7 and iCD3 expression were minimally influenced by the addition of the different antioxidants compared to RPMI. Interestingly, CD5 co-expression was also similar to standard RPMI and did not increase upon addition of different antioxidants than ph-AA. Furthermore, antioxidants other than AA did not have a positive influence on expansion of the progenitor cells (Fig. 4B). Taken together, from the investigated antioxidants, only AA was able to drive preT cell development.

\section{Cytokine receptor expression is not altered in the presence of AA}

To examine whether the influence of AA on maturation and proliferation of $\mathrm{T}$ cell progenitors was due to alterations of cytokine receptor expression, the receptors of cytokines provided to the culture were analysed in the presence or absence of ph-AA. The expression of CD110 (TPO Receptor), CD127 (IL-7 Receptor $\alpha$ ) and CD135 (Flt) were not differentially expressed 
upon addition of ph-AA to the culture (Fig. 4C). Although CD117 (SCF Receptor) expression differed between the conditions, when evaluating proT1 $\left(\mathrm{CD}^{+} \mathrm{CD} 5\right)$ and proT2 $\left(\mathrm{CD}^{+}{ }^{+} \mathrm{CD} 5^{+}\right)$ progenitors separately, no difference was observed (Fig. 4C). Therefore, the difference in expression of the whole population can be explained because the RPMI culture contains more proT1 cells that express more CD117.

A

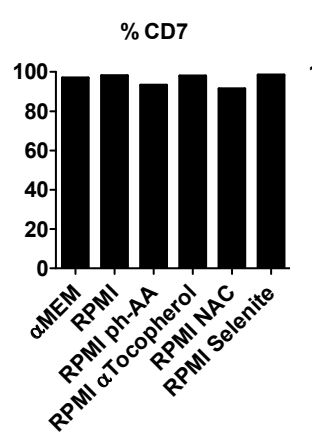

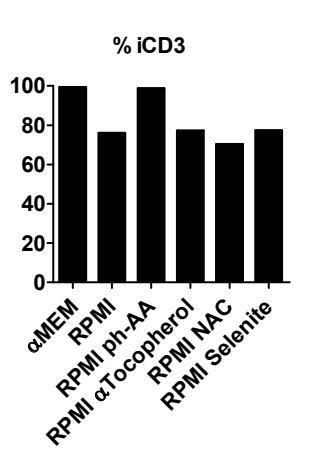

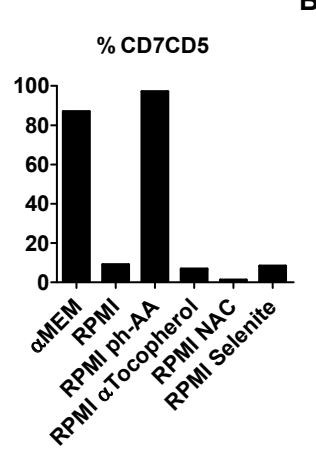

B

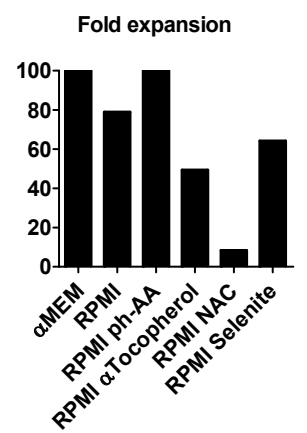

c
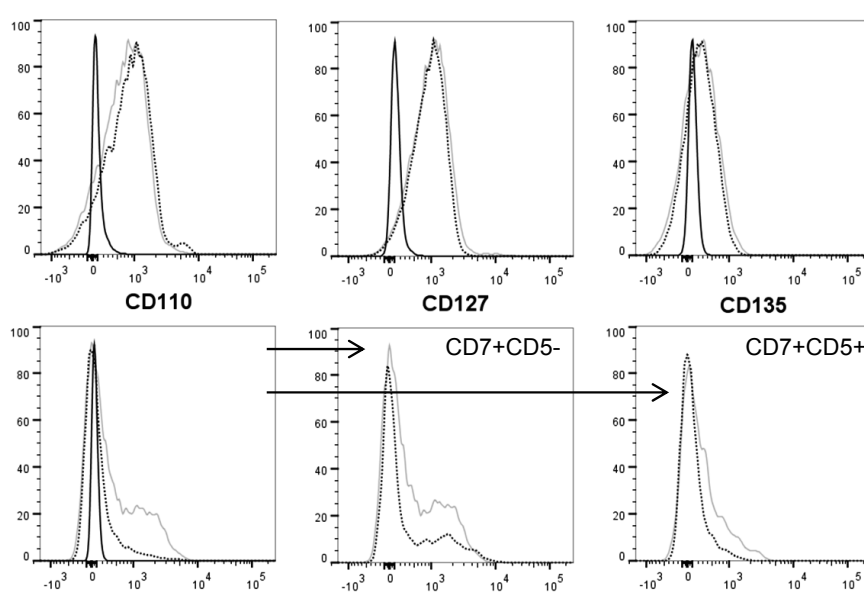

CD117
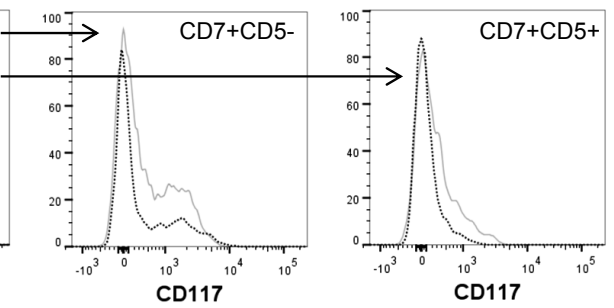

D

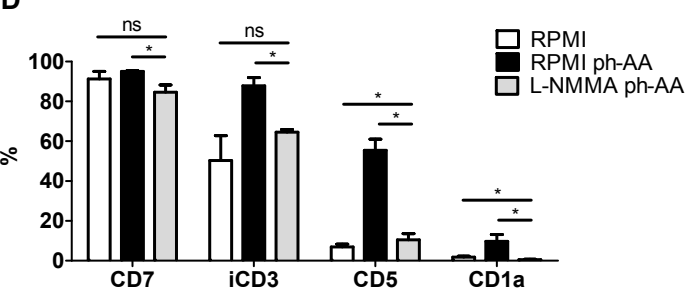

E

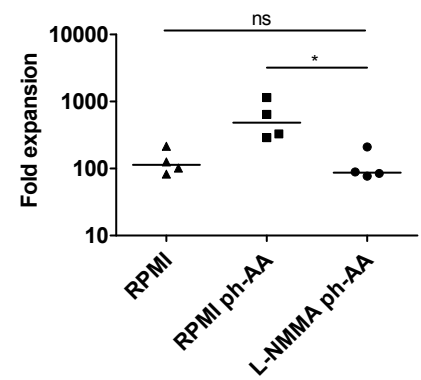


Figure 4: Mechanism of action of ascorbic acid on $\mathrm{T}$ lineage differentiation of $\mathrm{CB} \mathrm{CD} 34^{+} \mathrm{CD} 38^{-/ \mathrm{dim}}$ cells in the feeder-free culture in the presence of DLL4:Fc and fibronectin. A: Flow cytometric analysis of CD7, iCD3, CD7CD5 expression on CB derived progenitor cells and fold expansion (B) after 3 weeks of DLL4:Fc fibronectin culture in the presence of different antioxidants. C: Flow cytometric analysis of CD110, CD127, CD135 and CD117 expression on CB derived progenitor cells cultured in RPMI or RPMI ph-AA. Representative data of $\mathrm{n}=5$ are shown. D: Flow cytometric analysis of CD7, iCD3, CD5 and $\mathrm{CD} 1 \mathrm{a}$ expression on $\mathrm{CB}$ derived progenitor cells in the presence of ph-AA and L-NMMA after 2 weeks of culture. Mann Whitney $\mathrm{U}$ test, $\mathrm{n}=4,{ }^{*} \mathrm{p}<0.05$ and corresponding fold expansion after 3 weeks of culture (E).

\section{Blockage of the citrulline/NO cycle results in less $\mathrm{T}$ cell progenitor development}

Since AA has been shown to increase nitric oxide (NO) production in endothelial cells ${ }^{33}$ and because $\mathrm{NO}$ is involved in the differentiation of $\mathrm{T}$ helper cell populations ${ }^{34-35}$, the role of the citrulline/NO pathway ${ }^{36}$ was investigated during early $\mathrm{T}$ cell development. $\mathrm{N}^{\mathrm{G}}$-monomethylL-arginine-monoacetate salt (L-NMMA), an L-Arginine analogue that competitively inhibits nitric oxide synthase (NOS), was added to the culture in the presence of ph-AA. Blocking NO production resulted in less $\mathrm{T}$ cell development, indicated by significantly decreased percentages of CD7, iCD3, CD5 and CD1a expression compared to cells in the presence of ph-AA only (Fig. 4D). Furthermore, the positive effect on proliferation mediated by ph-AA was abolished in the presence of L-NMMA. These results hint for a role for the citrulline/NO pathway during $\mathrm{T}$ cell development driven by AA.

\section{Ascorbic acid is a key factor in DP T cell development in feeder cell co-cultures}

We have previously reported that development of $\mathrm{mCD} 4^{+}$cells is blocked at the pro/preT cell stage in co-culture with TSt-4/DLL ${ }^{11}$. Since AA results in the progression of T cell maturation in the feeder-free system, the effect of AA was also investigated in the TSt-4/DLL4 co-culture system, which is normally performed in standard RPMI medium lacking AA. Our previously published results with $\mathrm{mCD} 34^{+}$cells were confirmed with $\mathrm{CB} \mathrm{CD}_{3} 4^{+}$cells (Fig. 5A, upper panels). In the standard condition, CD7, iCD3 and CD 5 were expressed but CD4, CD8, TCR $\beta \beta$ and CD3 were absent. Upon addition of L-AA, both CD5 and CD1a expression increased (Fig. 5A, lower panels). Interestingly, in contrast to the standard condition, iSP CD4 ${ }^{+}\left(\mathrm{CD}^{-}\right)$ cells were detected in the presence of L-AA (26\%) together with a percentage of $\mathrm{CD}^{+}$and $\mathrm{CD} 8^{+} \mathrm{DP}$ cells (12\%). TCRa $\beta^{+} \mathrm{CD} 3^{+}$cells were also present in the condition with L-AA (6\%). Most of these cells were $\mathrm{CD} 4^{+} \mathrm{CD} 8^{+}$positive as visualized after backgating. Moreover, $\mathrm{CD} 4^{+}$ and $\mathrm{CD} 8^{+}$SP cells were present, in populations of 10 and $24 \%$, respectively.

Since DP cells could develop in the TSt-4/DLL4 feeder cell system that never before showed support of DN to DP maturation, it was further studied if DP/SP cells could develop in the OP-9/DL1 co-culture system due to the presence of L-AA in aMEM medium. To this end, 
different formulations of aMEM were used. Liquid aMEM without AA was supplemented with fresh L-AA to the same concentration present in the standard powder aMEM. Without $\mathrm{L}-\mathrm{AA}, \mathrm{CD}^{+} \mathrm{CD}^{+}$cells developed, although less efficiently than in aMEM with L-AA (Fig. 5B). Moreover, CD1a expressing cells were almost absent in the condition without L-AA. Additionally, only with the addition of L-AA, iSP $(69 \%)$ and $\mathrm{CD} 4^{+} \mathrm{CD} 8^{+}$DP cells were detected (27\%). TCRa $\beta^{+} \mathrm{CD} 3^{+}$cells were also present (14\%), most of these cells appear to be $\mathrm{CD} 4^{+} \mathrm{CD}^{+} \mathrm{DP}(88 \%)$, even minor populations of CD4 and CD8 SP cells were detected of $10 \%$ and $2 \%$, respectively. Strikingly, in both feeder cell cultures the full range of $\mathrm{T}$ cell development was only observed in the presence of AA indicating that $\mathrm{AA}$ is the crucial component that promotes maturation of $\mathrm{T}$ cells in vitro.

\section{Feeder cells are not necessary to generate $\mathrm{CD}^{+} \mathrm{CD8}^{+} \mathrm{DP} \mathrm{T}$ cells from $\mathrm{HSCs}$}

Since the development of DP T cells seems to rely on AA and not on feeder cells, later stages of $\mathrm{T}$ cell development were investigated in the feeder-free culture. In standard RPMI conditions $\mathrm{CD} 4^{+} \mathrm{CD} 8^{+} \mathrm{DP}, \mathrm{TCR} \alpha \beta$ or $\mathrm{CD} 3$ expressing cells could never be detected. In contrast, cells cultured in RPMI plus AA and aMEM did not arrest as preT cells expressing CD7, iCD3 and $\mathrm{CD} 5$ but were able to upregulate $\mathrm{CD} 4$ and $\mathrm{CD} 8$ (7\% for RPMI plus ph-AA or L-AA, Fig. 5C). Furthermore, a small population of TCRa $\beta^{+} \mathrm{CD}^{+}$cells was detected (2\%). Together, these observations further indicate that feeder cells and feeder cell conditioned media are not necessary for generation of DP T cells from human stem cells. 

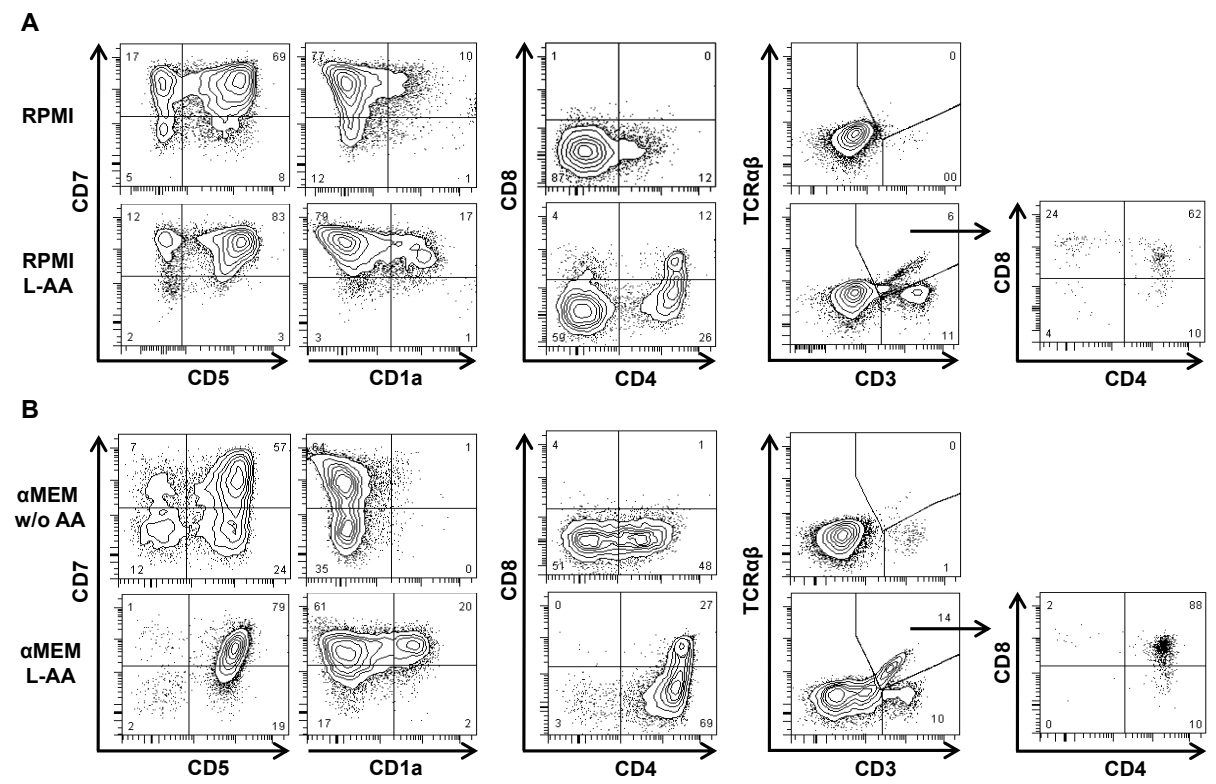

C
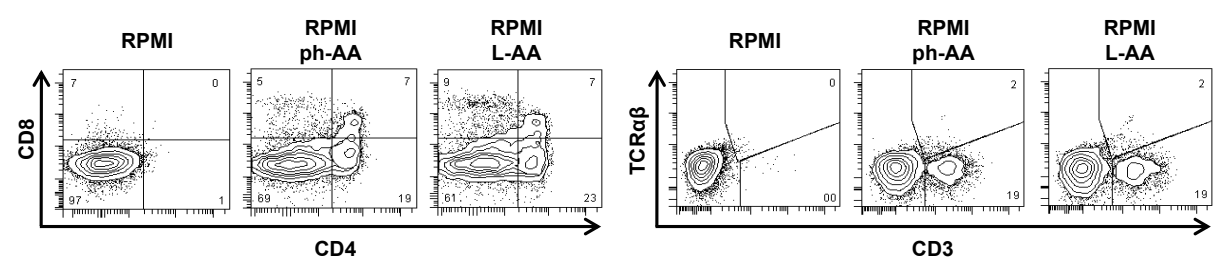

Figure 5: Effect of ascorbic acid on late $\mathrm{T}$ cell development in feeder cell co-cultures with TSt4/DLL4 or OP-9/DL1 cells and feeder-free culture with CB CD34 ${ }^{+} \mathrm{CD}^{-/ / \mathrm{dim}}$ cells. A and B: Flow cytometric analysis of $\mathrm{T}$ lineage markers of progenitor cells after 7 weeks of culture on TSt-4/DLL4 (A) and OP-9/DL1 (B) with and without ascorbic acid after 5 weeks of co-culture. CD4, CD8, CD3 and TCR $\alpha \beta$ expression was analysed on $\mathrm{CD}^{+}$cells. TCR $\alpha \beta^{+} \mathrm{CD}^{+}$population is backgated on $\mathrm{CD} 8$ and $\mathrm{CD} 4$ expression. Representative plots of $\mathrm{n}=3$ are shown. C: Flow cytometric analysis of CD4, CD8, CD3 and $\mathrm{TCR} a \beta$ expression on $\mathrm{CD}^{+}$cells after 5 weeks of DLL4:Fc fibronectin culture of $\mathrm{CB} \mathrm{CD} 34^{+} \mathrm{CD} 38^{-/ \mathrm{dim}}$ in different media, RPMI, RPMI $95 \mu \mathrm{M}$ ph-AA and RPMI $285 \mu \mathrm{M}$ L-AA. Representative plots are shown ( $n=3$ out of 9 ). 


\section{Discussion and Conclusion}

This study shows a pivotal role for ascorbic acid during in vitro human $\mathrm{T}$ cell development as it promotes proT1 to proT2 cell transition as well as progression from DN to DP T cells in both feeder and feeder-free cultures. Furthermore, we show that feeder cells or feeder cell conditioned media are not required for in vitro generation of DP T cells. Finally, AA has a beneficial role in the differentiation of mobilized and CB HSCs in serum-free medium. These findings might be of great importance for the development of an efficient clinical method for in vitro generation of $\mathrm{T}$ cell progenitors.

The effect of AA on early T cell development was studied in the feeder-free DLL4:Fc culture. $\mathrm{CD} 34^{+}$cells cultured in RPMI showed a block in the very early $\mathrm{CD}^{+}$proT1 cell stage. To our knowledge, only Reimann et al. ${ }^{13}$ showed up to $10 \%$ CD5 proT2 expressing cells on immobilized DLL4 ${ }^{23,29,37}$ and it is unknown if the medium used contained AA. Culture medium has a major effect on $\mathrm{T}$ cell differentiation. Six et al. showed that fresh reconstituted aMEM medium from powder resulted in more DP $\mathrm{T}$ cells in the OP-9/DL1 co-culture system compared to ready-to-use aMEM ${ }^{38}$. This observed effect could be due to AA, which decays rapidly ${ }^{39}$. Fresh medium contains more AA that can have a beneficial effect on $\mathrm{T}$ cell development. Here, we confirm the influence of medium on $\mathrm{T}$ cell development since the proT2/preT cell $\left(\mathrm{CD}^{+} \mathrm{CD}^{+} \mathrm{CD} 1 \mathrm{a}^{+}\right)$development occurred only in the presence of $\mathrm{aMEM}$. By adding AA to RPMI medium, we show that AA is responsible for this effect. Ph-AA results in more T cell development and proliferation than L-AA. Ph-AA is taken up by the cells after phosphatases remove the phosphate group, after which it enters the cells as L-AA. The removal of the phosphate group is the rate limiting step in this process and therefore ensures that phAA is available for the cells ${ }^{32}$. Therefore, the influence of AA on T lineage development can be maintained longer. Our results thus show that addition of AA to the feeder-free culture results in more proliferation and improved $\mathrm{T}$ lineage development. We are able to culture a large population of $\mathrm{CD}^{+} \mathrm{CD}^{+} \mathrm{CD} 1^{+}$proT2/preT cells in the absence of feeder cells, while others mainly observed upregulation of CD7.

Furthermore, we show that it is possible to generate $\mathrm{T}$ cell progenitors from G-CSF $\mathrm{mCD} 34^{+}$ cells in the feeder-free system. The $\mathrm{mCD} 34^{+}$population is a highly clinical relevant population, since cell numbers obtained via G-CSF mobilization and subsequent leukapheresis are much higher compared to $\mathrm{CB}$ CD $34^{+}$cells (average $\sim 35 \times 10^{6}$ and $\sim 0.2 \times 10^{6}$ after CD $34^{+} \mathrm{CD} 38^{\mathrm{dim} / \mathrm{neg}}$ cell sorting respectively). However, since $\mathrm{CB}$ cells can expand more than 1,000 fold, both CD $34^{+}$ populations (patient dependent) can be a suitable source for adoptive $\mathrm{T}$ lineage therapy. However, preferred usage of each population in the clinic remains to be proven as the homing capacity, the maturation potential and the number of cell divisions in each population is likely to be different and has not been determined in the current study. 
The expression patterns of molecules important for thymus homing on feeder-free generated $\mathrm{T}$ cell progenitors largely resemble the phenotype of TSt-4/DLL4 derived T cell progenitors. Feeder-free generated T cell progenitors strongly expressed CCR4, CCR9, CXCR3, CXCR4, Integrin $\beta 1 / \beta 2$ and PSGL-1, while CCR6 and CCR7 were slightly upregulated. Since, the feeder culture derived cell population is able to migrate to the thymus and give rise to fully mature $\mathrm{T}$ cells ${ }^{11}$, it seems more than likely that also feeder-free generated $\mathrm{T}$ cell progenitors possess this capacity. Chemokine receptors, integrins and PSGL-1 are involved in migration and entry to and within the thymus, and can further be involved in maturation of $\mathrm{T}$ cell progenitors ${ }^{40}$. CXCR4 has a role in cell egress from the bone marrow, the earliest step of migration to the thymus since anti-CXCR4 antibodies reduce stem cell migration (reviewed in reference ${ }^{41}$ ). The key molecules involved in murine thymic settling are CCR7, CCR9 and PSGL-1, although the precise mechanism is not yet unravelled. Thymus seeding cells appear to require expression of CCR7, CCR9 or both for T lineage development ${ }^{40}$. Therefore, it remains unknown whether the low CCR7 expression on our progenitor cells could be compensated by CCR9 or even by high PSGL-1 expression or other integrins. Additionally, in vivo experiments in immune deficient mice need to confirm the potency of the feeder free derived progenitor cells to home to the thymus and complete their maturation.

Taken together, we are capable of generating proT2/preT cell precursors, confirmed with surface marker expression, chemokine receptor and integrin profile and TCR rearrangement pattern, in the presence of ascorbic acid and importantly without the use of any feeder cells. We earlier argued that these cells are the ideal population to inject into patients, because of their retained thymus homing capacity and further education in the thymus to prevent the emergence of auto-reactive T cells ${ }^{11}$.

Because of the effectiveness of AA in the early $\mathrm{T}$ lineage stages, we also decided to investigate the role of AA in the later stages of T cell development. TSt-4/DLL and OP-9/DL1 feeder cells can support $\mathrm{T}$ cell development to a different extent. We argue, based on our results, that this is caused by different media used in these cultures and not because of unique properties of these feeder cells. Usually, cell lines and cultures are established in a particular medium without paying attention to its content. Indeed, the addition of AA to the TSt-4/DLL4 culture resulted in the generation of DP T cells, whereas the removal of AA from the OP-9/DL1 culture abrogated the capacity to produce DP and SP cells in these cultures. The effect of AA could be cell intrinsic on the feeder cells. However, we demonstrated that in the presence of AA DP T cells could develop from both $\mathrm{CB}$ and $\mathrm{mCD} 34^{+}$cells without any feeder cells. We thus show that feeder cells are not needed for differentiation, but that simple cues such as Notch signalling, cytokines, ascorbic acid and perhaps other fresh media components are sufficient to drive in vitro generation of DP T cells. However, more signals seem to be necessary for proper TCR $\alpha \beta$ upregulation and the development of SP T cells in the feeder-free culture, for example, the presence of MHC molecules. MHC-tetramers, anti-CD28, anti-CD3 and OP-9/ 
DL1 conditioned medium have been required for the generation of antigen specific cytotoxic $\mathrm{CD}^{+}$cells in the feeder-free system ${ }^{42}$. This suggests that our current system could possibly be used for the generation of antigen specific T cells. All together these data suggest that the unique $3 \mathrm{D}$ thymus structure is not necessary for complete $\mathrm{T}$ cell differentiation. However, the thymus microenvironments facilitate positive and negative selection of generated thymocytes and ensure a broad $\mathrm{T}$ cell repertoire ${ }^{43}$.

Recently, Manning and colleagues demonstrated a role for AA in murine DP T lineage development ${ }^{44}$. These data correlate well with our study using human cells, where we show an important role for AA not only in DP T lineage development, but also in early $\mathrm{T}$ lineage development. Manning et al. show that the effect of AA is likely through epigenetic modulation of gene expression, possibly via the enhancement of enzyme activity of methyl marks on regulatory regions of the DNA ${ }^{44}$. Recently, others have shown that besides transcriptional regulation dynamic epigenetic regulations control $\mathrm{T}$ cell development in murine progenitor cells ${ }^{45,46}$. Our findings indicate that it is indeed not the general antioxidant function of AA that is likely to drive T cell development. However, based on our L-NMMA NOS blocking experiments, it seems likely that the citrulline/NO cycle plays a role during $\mathrm{T}$ cell development. To confirm this indication, extensive research has to be performed. Since AA has many mechanisms of action, it would be likely that not one mechanism solely can account for the enormous influence of AA on $\mathrm{T}$ cell development. Currently we are performing extensive molecular studies to further elucidate the mechanism by which AA induces $\mathrm{T}$ cell development, thus far a definite conclusion cannot be drawn.

In conclusion, we unravelled an important role for AA during several steps of $\mathrm{T}$ cell development. Both $\mathrm{CB}$ and G-CSF mobilized $\mathrm{CD} 34^{+}$cells have the capacity to become preT cell progenitors in a well-defined, feeder-free culture in the presence of Notch ligands, defined cytokines, and AA. In this system, AA induces the transition from proT1 to proT2/preT cells and greatly enhances cell expansion. Moreover, DP cells develop as well. Furthermore, we show that only in the presence of AA, DP and even SP cells develop in co-culture with OP-9/ DL1 and TSt-4/DLL4. In the absence of AA in these feeder cultures, T cell progenitors arrest as CD4CD8 negative. Together, these findings indicate that feeder cells or co-culture derived conditioned media are not crucial to direct DP T cell development but that AA is a driving force in this process. 


\section{Acknowledgements}

This work was supported by a grant from the Dutch Cancer Society KWF: UM2010-4671 and with financial support from the Cancer Research Fund Limburg of the Health Foundation Limburg. We thank Prof. dr. Hiroshi Kawamoto and Dr. Tomokatsu Ikawa for valuable discussion. 


\section{References}

1. Aversa F, Tabilio A, Velardi A, Cunningham I, Terenzi A, Falzetti F, et al. Treatment of highrisk acute leukaemia with T-cell-depleted stem cells from related donors with one fully mismatched HLA haplotype. N Engl J Med. 1998 Oct 22;339(17):1186-93.

2. Aversa F, Terenzi A, Tabilio A, Falzetti F, Carotti A, Ballanti S, et al. Full haplotypemismatched hematopoietic stem-cell transplantation: a phase II study in patients with acute leukaemia at high risk of relapse. J Clin Oncol. 2005 May 20;23(15):3447-54.

3. Lynch HE, Goldberg GL, Chidgey A, Van den Brink MR, Boyd R, Sempowski GD. Thymic involution and immune reconstitution. Trends Immunol. 2009 Jul;30(7):366-73.

4. Krenger W, Blazar BR, Hollander GA. Thymic T-cell development in allogeneic stem cell transplantation. Blood. 2011 Jun 23;117(25):6768-76.

5. Zlotoff DA, Bhandoola A. Hematopoietic progenitor migration to the adult thymus. Ann N Y Acad Sci. 2011 Jan;1217:122-38.

6. Ringhoffer S, Rojewski M, Dohner H, Bunjes D, Ringhoffer M. T-cell reconstitution after allogeneic stem cell transplantation: assessment by measurement of the sjTREC/ betaTREC ratio and thymic naive T cells. Haematologica. 2013 Oct;98(10):1600-8.

7. Blom B, Spits H. Development of human lymphoid cells. Annu Rev Immunol. 2006;24:287320 .

8. Haynes BF, Martin ME, Kay HH, Kurtzberg J. Early events in human T cell ontogeny. Phenotypic characterization and immunohistologic localization of $\mathrm{T}$ cell precursors in early human foetal tissues. J Exp Med. 1988 Sep 1;168(3):1061-80.

9. Awong G, Herer E, Surh CD, Dick JE, La Motte-Mohs RN, Zuniga-Pflucker JC. Characterization in vitro and engraftment potential in vivo of human progenitor $\mathrm{T}$ cells generated from hematopoietic stem cells. Blood. 2009 Jul 30;114(5):972-82.

10. Awong G, Singh J, Mohtashami M, Malm M, La Motte-Mohs RN, Benveniste PM, et al. Human proT-cells generated in vitro facilitate hematopoietic stem cell-derived T-lymphopoiesis in vivo and restore thymic architecture. Blood. 2013 Dec 19;122(26):4210-9.

11. Meek B, Cloosen S, Borsotti C, Van Elssen CH, Vanderlocht J, Schnijderberg MC, et al. In vitro-differentiated $\mathrm{T} /$ natural killer-cell progenitors derived from human $\mathrm{CD} 34+$ cells mature in the thymus. Blood. 2010 Jan 14;115(2):261-4.

12. Dik WA, Pike-Overzet K, Weerkamp F, de Ridder D, de Haas EF, Baert MR, et al. New insights on human $\mathrm{T}$ cell development by quantitative $\mathrm{T}$ cell receptor gene rearrangement studies and gene expression profiling. J Exp Med. 2005 Jun 6;201(11):1715-23.

13. Reimann C, Six E, Dal-Cortivo L, Schiavo A, Appourchaux K, Lagresle-Peyrou C, et al. Human T-lymphoid progenitors generated in a feeder-cell-free Delta-like-4 culture system promote T-cell reconstitution in NOD/SCID/gammac(-/-) mice. Stem Cells. 2012 Aug;30(8):1771-80.

14. Radtke F, Wilson A, Ernst B, MacDonald HR. The role of Notch signaling during 
hematopoietic lineage commitment. Immunol Rev. 2002 Sep;187:65-74.

15. Kato M, Masuda K, Kakugawa K, Kawamoto H, Mugishima H, Katsura Y. Quantification of progenitors capable of generating T cells in human cord blood. Eur J Haematol. 2008 Feb;80(2):151-9.

16. Koch U, Fiorini E, Benedito R, Besseyrias V, Schuster-Gossler K, Pierres M, et al. Delta-like 4 is the essential, nonredundant ligand for Notch 1 during thymic $\mathrm{T}$ cell lineage commitment. J Exp Med. 2008 Oct 27;205(11):2515-23.

17. Hozumi K, Mailhos C, Negishi N, Hirano K, Yahata T, Ando K, et al. Delta-like 4 is indispensable in thymic environment specific for T cell development. J Exp Med. 2008 Oct 27;205(11):2507-13.

18. De Smedt M, Hoebeke I, Plum J. Human bone marrow CD34+ progenitor cells mature to T cells on OP9-DL1 stromal cell line without thymus microenvironment. Blood Cells Mol Dis. 2004 Nov-Dec;33(3):227-32.

19. Eyrich M, Schreiber SC, Wollny G, Ziegler H, Schlenker R, Koch-Buttner K, et al. Predifferentiated human committed T-lymphoid progenitors promote peripheral T-cell reconstitution after stem cell transplantation in immunodeficient mice. Eur J Immunol. 2011 Dec;41(12):3596-603.

20. Jaleco AC, Neves H, Hooijberg E, Gameiro P, Clode N, Haury M, et al. Differential effects of Notch ligands Delta-1 and Jagged-1 in human lymphoid differentiation. J Exp Med. 2001 Oct 1;194(7):991-1002.

21. Mohtashami M, Zuniga-Pflucker JC. Three-dimensional architecture of the thymus is required to maintain delta-like expression necessary for inducing $\mathrm{T}$ cell development. J Immunol. 2006 Jan 15;176(2):730-4.

22. Dervovic DD, Ciofani M, Kianizad K, Zuniga-Pflucker JC. Comparative and functional evaluation of in vitro generated to ex vivo CD8 T cells. J Immunol. 2012 Oct 1;189(7):341120.

23. Ohishi K, Varnum-Finney B, Bernstein ID. The notch pathway: modulation of cell fate decisions in hematopoiesis. Int J Hematol. 2002 Jun;75(5):449-59.

24. Ikawa T, Hirose S, Masuda K, Kakugawa K, Satoh R, Shibano-Satoh A, et al. An essential developmental checkpoint for production of the $\mathrm{T}$ cell lineage. Science. $2010 \mathrm{Jul}$ 2;329(5987):93-6.

25. Delaney C, Heimfeld S, Brashem-Stein C, Voorhies H, Manger RL, Bernstein ID. Notchmediated expansion of human cord blood progenitor cells capable of rapid myeloid reconstitution. Nat Med. 2010 Feb;16(2):232-6.

26. Meek B, Van Elssen CH, Huijskens MJ, van der Stegen SJ, Tonnaer S, Lumeij SB, et al. T cells fail to develop in the human skin-cell explants system; an inconvenient truth. BMC Immunol. 2011;12:17.

27. Pohanka M, Pejchal J, Snopkova S, Havlickova K, Karasova JZ, Bostik P, et al. Ascorbic acid: an old player with a broad impact on body physiology including oxidative stress suppression and immunomodulation: a review. Mini Rev Med Chem. 2012 Jan;12(1):35-43. 
28. Esteban MA, Wang T, Qin B, Yang J, Qin D, Cai J, et al. Vitamin C enhances the generation of mouse and human induced pluripotent stem cells. Cell Stem Cell. 2010 Jan 8;6(1):71-9.

29. Delaney C, Varnum-Finney B, Aoyama K, Brashem-Stein C, Bernstein ID. Dose-dependent effects of the Notch ligand Delta1 on ex vivo differentiation and in vivo marrow repopulating ability of cord blood cells. Blood. 2005 Oct 15;106(8):2693-9.

30. Watanabe Y, Mazda O, Aiba Y, Iwai K, Gyotoku J, Ideyama S, et al. A murine thymic stromal cell line which may support the differentiation of CD4-8- thymocytes into CD4+8- alpha beta T cell receptor positive T cells. Cell Immunol. 1992 Jul;142(2):385-97.

31. La Motte-Mohs RN, Herer E, Zuniga-Pflucker JC. Induction of T-cell development from human cord blood hematopoietic stem cells by Delta-like 1 in vitro. Blood. 2005 Feb 15;105(4):1431-9.

32. May JM. The SLC23 family of ascorbate transporters: ensuring that you get and keep your daily dose of vitamin C. Br J Pharmacol. 2011 Dec;164(7):1793-801.

33. Heller R, Unbehaun A, Schellenberg B, Mayer B, Werner-Felmayer G, Werner ER. L-ascorbic acid potentiates endothelial nitric oxide synthesis via a chemical stabilization of tetrahydrobiopterin. J Biol Chem. 2001 Jan 5;276(1):40-7.

34. Lee SW, Choi H, Eun SY, Fukuyama S, Croft M. Nitric oxide modulates TGF-betadirective signals to suppress Foxp3+ regulatory $T$ cell differentiation and potentiate Th1 development. J Immunol. 2011 Jun 15;186(12):6972-80.

35. Jianjun Y, Zhang R, Lu G, Shen Y, Peng L, Zhu C, et al. T cell-derived inducible nitric oxide synthase switches off Th17 cell differentiation. J Exp Med. 2013 Jul 1;210(7):1447-62.

36. Racké K, Warnken M. L-Arginine Metabolic Pathways. The Open Nitric Oxide Journal. 2010;2(2):9-19.

37. Lefort N, Benne C, Lelievre JD, Dorival C, Balbo M, Sakano S, et al. Short exposure to Notch ligand Delta-4 is sufficient to induce T-cell differentiation program and to increase the $\mathrm{T}$ cell potential of primary human CD34+ cells. Exp Hematol. 2006 Dec;34(12):1720-9.

38. Six EM, Benjelloun F, Garrigue A, Bonhomme D, Morillon E, Rouiller J, et al. Cytokines and culture medium have a major impact on human in vitro T-cell differentiation. Blood Cells Mol Dis. 2011 Jun 15;47(1):72-8.

39. Feng J, Melcher AH, Brunette DM, Moe HK. Determination of L-ascorbic acid levels in culture medium: concentrations in commercial media and maintenance of levels under conditions of organ culture. In Vitro. 1977 Feb;13(2):91-9.

40. Zlotoff DA, Zhang SL, De Obaldia ME, Hess PR, Todd SP, Logan TD, et al. Delivery of progenitors to the thymus limits $\mathrm{T}$-lineage reconstitution after bone marrow transplantation. Blood. 2011 Aug 18;118(7):1962-70.

41. Lapidot T, Petit I. Current understanding of stem cell mobilization: the roles of chemokines, proteolytic enzymes, adhesion molecules, cytokines, and stromal cells. Exp Hematol. 2002 Sep;30(9):973-81.

42. Fernandez I, Ooi TP, Roy K. Generation of Functional, Antigen-Specific CD8+ Human T Cells from Cord-Blood Stem Cells using Exogenous Notch and Tetramer-TcR Signaling. 
Stem Cells. 2013 Aug 13.

43. van Ewijk W, Wang B, Hollander G, Kawamoto H, Spanopoulou E, Itoi M, et al. Thymic microenvironments, 3-D versus 2-D? Semin Immunol. 1999 Feb;11(1):57-64.

44. Manning J, Mitchell B, Appadurai DA, Shakya A, Pierce LJ, Wang H, et al. Vitamin C Promotes Maturation of T-Cells. Antioxid Redox Signal. 2013 Feb 5.

45. Vigano MA, Ivanek R, Balwierz P, Berninger P, van Nimwegen E, Karjalainen K, et al. An epigenetic profile of early $\mathrm{T}$-cell development from multipotent progenitors to committed T-cell descendants. Eur J Immunol. 2013 Dec 27.

46. Zhang JA, Mortazavi A, Williams BA, Wold BJ, Rothenberg EV. Dynamic transformations of genome-wide epigenetic marking and transcriptional control establish $\mathrm{T}$ cell identity. Cell. 2012 Apr 13;149(2):467-82. 


\section{Supplemental information}
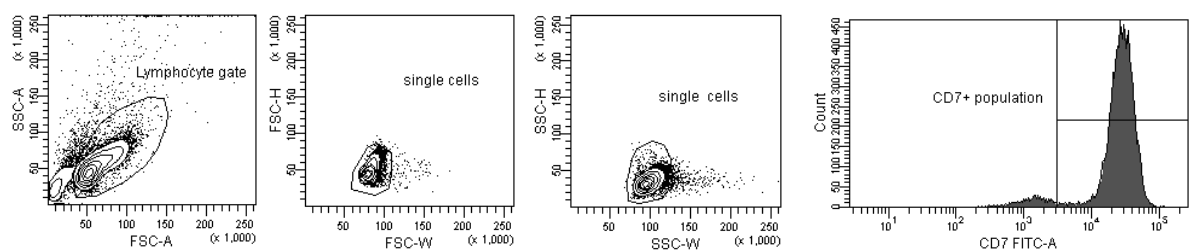

Supplemental Figure 1: Gating strategy. Lymphocyte life gate based on SSC and FSC area. Removal of doublets based on FSC-h/FSC-w and SSC-h/SSC-w. When indicated, $\mathrm{CD} 7^{+}$cells were gated.
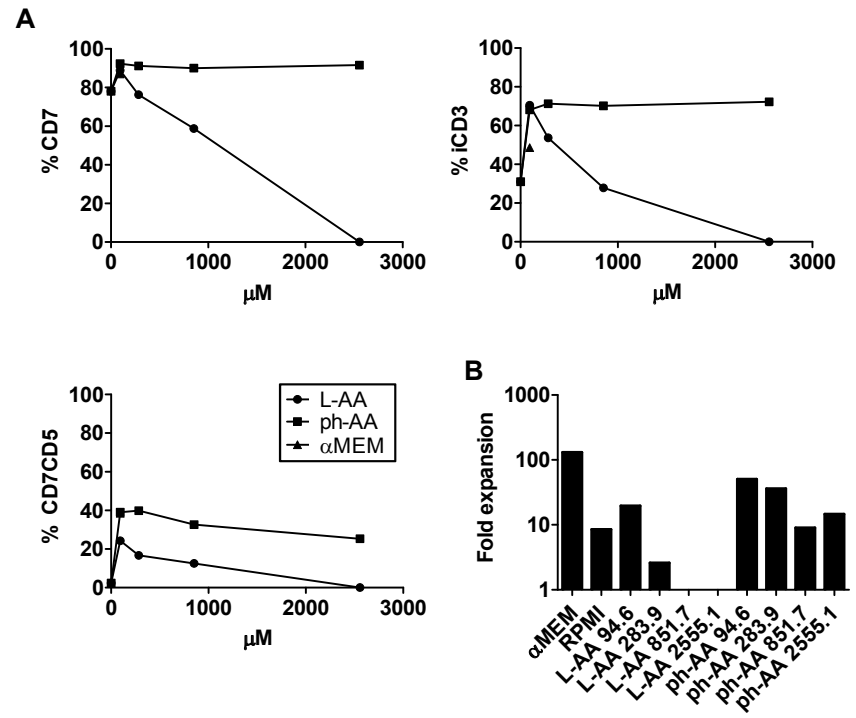

Supplemental Figure 2: Influence of ascorbic acid on $\mathrm{T}$ lineage development from $\mathrm{CD}^{+} 4^{+} \mathrm{CD} 38^{-/ \mathrm{dim}}$ cells in the feeder-free culture in the presence of DLL4:Fc and fibronectin. A: CD7, iCD3, CD7CD5 expression and fold expansion (B) of $\mathrm{CB} \mathrm{CD} 34^{+} \mathrm{CD} 38^{-/ \mathrm{dim}}$ cells after 2 weeks of culture in the presence of different L-AA or ph-AA concentrations $(\mu M)$. Representative results are shown $(n=2)$.

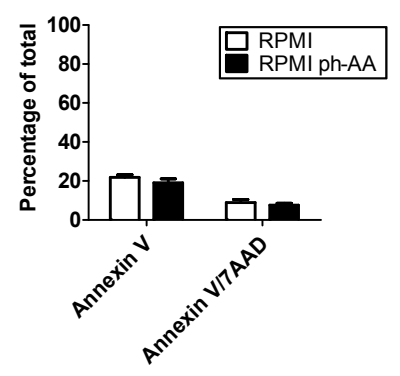

Supplemental Figure 3: Influence of ascorbic acid on viability of $T$ cell progenitors in the feeder-free culture in the presence of DLL4:Fc and fibronectin. Percentage of Annexin $\mathrm{V}$ and 7AAD positive cells cultured in the presence or absence of ph-AA are shown $(n=3)$. 


\section{Ascorbic acid promotes proliferation of NK cell populations in culture systems applicable for NK cell therapy}

Mirelle J.A.J. Huijskens, Mateusz Walczak, Subhashis Sarkar, Florance Atrafi, Birgit L.M.G. Senden-Gijsbers, Marcel G.J. Tilanus,

Gerard M.J. Bos, Lotte Wieten and Wilfred T.V. Germeraad

Submitted for publication. 


\section{Abstract}

Natural killer (NK) cell based immunotherapy is a promising treatment for a variety of malignancies. However, generating sufficient cell numbers for therapy remains a challenge. To achieve this, optimization of protocols is required.

Three different methods were used to study the influence of 2-phospho-L-Ascorbic Acid (AA) on NK cell generation. Mature NK cells were expanded from peripheral blood mononuclear cells (PBMCs) in the presence of OKT-3 and IL-2. NK cell progenitors were generated from $\mathrm{CD} 34^{+}$haematopoietic stem cells (HSCs) or from different $\mathrm{T} / \mathrm{NK}$ cell progenitor populations. Generated NK cells were extensively phenotyped and functionality was determined by cytotoxicity assay.

Addition of AA resulted in more proliferation of NK cells without influencing NK cell functionality. In more detail, PBMC derived NK cells expanded 2,362 fold (median, range 90-31,351) in the presence of AA and were capable of killing tumour cells under normoxia and hypoxia. Moreover, HSCs derived NK cell progenitors matured faster in the presence of AA, which was also observed in the NK cell differentiation from early T/NK cell progenitors. These results demonstrate that mature NK cells proliferate faster in the presence of AA, resulting in higher cell numbers with accurate functional capacity, required for adoptive immunotherapy. In addition, these data suggest that also differentiation from different stem/ progenitor cell sources can be positively influenced by AA. 


\section{Introduction}

Natural killer-cell based immunotherapy is a promising approach for treatment of malignancies. Natural killer (NK) cells can kill cancer cells without the need for prior direct sensitization ${ }^{1-3}$ and without causing graft-versus host disease (GVHD) ${ }^{4}$. NK cells are a subset of cytokine producing cytotoxic innate lymphoid cells that express CD56 and lack expression of $\mathrm{CD} 3{ }^{4}$. A well-balanced mechanism to recognize and kill infected or malignant cells while tolerating healthy cells makes infusion of NK cells a feasible method to treat malignancies ${ }^{5-6}$.

Preclinical and clinical studies have shown that, if infused in large numbers, NK cells can be used to eliminate malignant cells ${ }^{7}$. Both autologous and allogeneic NK cells are able to effectively eliminate cancer cells in vitro ${ }^{8,9}$. Furthermore, it has been shown that IL-2 activated NK cells from patients are effective against autologous cancer cells in vivo in a mouse model ${ }^{10}$. The beneficial effect on prolongation of survival in a tumour-bearing mice model has been demonstrated to be dependent on the number of infused syngeneic NK cells ${ }^{11}$. Although infusion of autologous NK cells is shown to be safe, only limited efficacy is shown in several clinical trials ${ }^{7,12,13}$. A more powerful approach proposed by Ruggeri and colleagues showed that allogeneic NK cell transfer leads to higher tumour cytotoxicity in acute myeloid leukemia because of KIR-ligand mismatching, which lowers the activation threshold of NK cells ${ }^{14-15}$. Similar effects have also been seen in responses to solid tumours in both a mouse model and in patients ${ }^{16,17}$. Taken together, adoptive NK cell studies demonstrate the possibilities of NK cell therapy for a variety of cancers but many indicate the necessity of sufficient cell numbers because of limited in vivo responses ${ }^{18-19}$.

NK cells for immunotherapy can be derived from several sources, e.g. from peripheral blood, (induced) stem cells, cord/placental blood or bone marrow. Clinical studies using enriched peripheral blood NK cells show that it is not possible to produce sufficient numbers of NK cells, with the right purity and state of activation ${ }^{20,21}$. To overcome this problem, in vitro expansion of NK cells is currently under investigation. Different methods for expansion have been developed to obtain NK cells for infusion, which is extensively reviewed by Cheng et al. ${ }^{7}$. Although great improvements in different methods of NK cell expansion and generation have been achieved, for example with certain cytokine cocktails and culture instruments, clinical success is still limited indicating that it is critical to search for additional approaches to improve NK cell maturation and/or proliferation to obtain sufficient numbers of properly selected NK cells for immunotherapy ${ }^{7,19}$. Besides the number of NK cells, also purity of the NK cell product (to prevent GVHD), culture time (reducing cost of the clinical product) and phenotype of the NK cells are important areas for improvement. The latter is essential since we showed in multiple myeloma and in breast cancer that KIR-ligand mismatched NK cells are much more efficient in eliminating tumour cells than matched NK cells ${ }^{16,22}$. However, to 


\section{Chapter 6}

obtain sufficient numbers of this relatively infrequent NK cell population requires efficient ex vivo expansion.

Previously, we have shown that T/NK cell progenitors can develop from HSCs in coculture with feeder cells ${ }^{23}$. In another recent study, we have demonstrated that especially phosphorylated ascorbic acid (AA) has a positive effect on T/NK cell progenitors; T(/NK) cell progenitors mature further and, importantly, proliferate faster in the presence of AA ${ }^{24}$. Therefore, we hypothesized in the current study that AA can be used to improve ex vivo NK cell expansion protocols. To test the hypothesis, three different culture methods were applied. In the first method, mature NK cells are expanded from peripheral blood mononuclear cells (PBMCs). In the second method, HSCs are cultured with feeder cells in NK cell skewing conditions. In the third method, NK cells are generated from T/NK cell progenitors ${ }^{23}$. 


\section{Materials and Methods}

\section{Cell lines}

TSt-4 cells, an earlier gift of Prof. dr. H. Kawamoto (Kyoto University, Japan), were grown in standard RPMI 1640 medium (Sigma-Aldrich Co., St. Louis, MO, USA) containing 5\% FBS (Greiner bio one, Kremsmuenster, Austria), 1\% penicillin-streptomycin, $1 \mathrm{mM}$ sodium pyruvate, $0.1 \mathrm{mM}$ MEM non-essential amino acids, and $5 \times 10^{-5} \mathrm{M} 2$-mercaptoethanol (all from Invitrogen Ltd., Paisley, UK), referred to as complete RPMI medium. K562 cells (ATCC) were cultured in RPMI 1640 medium (Gibco, Breda, the Netherlands) supplemented with $10 \%$ FBS (Integro, Zaandam, the Netherlands), 100U/ml penicillin (Gibco) and $100 \mathrm{mg} / \mathrm{ml}$ streptomycin (Gibco). All cultures were maintained at $37^{\circ} \mathrm{C}$ in humidified air containing $5 \%$ $\mathrm{CO}_{2}$.

\section{NK cell expansion from PBMCs}

Peripheral blood mononuclear cells (PBMCs) were isolated from healthy adult donors using Lymphoprep (Axis Shield, Oslo, Norway). PBMCs, containing NK cells, were expanded in CellGro SCGM medium (CellGenix, Freiburg im Breisgau, Germany) supplemented with 5\% human serum (BioWhittaker Lonza, Basel, Switzerland), 1000U/ml penicillin and 100mg/ $\mathrm{ml}$ streptomycin (Gibco), 10ng/ml anti-CD3 monoclonal antibody (OKT-3) and 1000IU/ $\mathrm{ml}$ IL-2 (both from Miltenyi, Bergisch Gladbach, Germany). Cells were cultured in 6-well plates in a humidified incubator at $37^{\circ} \mathrm{C}, 5 \% \mathrm{CO}_{2}$, with an initial total culture volume of $2 \mathrm{ml} /$ well with a total number of $2 \times 10^{6}$ cells/well. Parts of the cultures were supplemented with $50 \mu \mathrm{g} / \mathrm{ml} \mathrm{AA}$, a dose determined previously ${ }^{24}$. Every 3-4 days medium was refreshed together with addition of freshly prepared AA. When required, cells were counted and replated to the starting concentration. The cultures were maintained for 3-4 weeks.

\section{Isolation of $\mathrm{CD}^{+} 4^{+} \mathrm{CD}^{-/ \text {dim }}$ haematopoietic stem cells}

Both cord blood (CB) and G-CSF mobilized CD34 $4^{+}$cells were obtained at the Maastricht University Medical Center after informed consent in accordance with the Declaration of Helsinki and with approval of the local Medical Ethical Committee (METC 12-2-044) and used in experiments depicted in Figures 3 and 4. Mobilized CD34 $4^{+}$cells were obtained from healthy volunteers treated with G-CSF (Neupogen, Amgen, Thousand Oaks, CA, USA). Mononuclear cells (MNCs) were isolated from the CB using Lymphoprep (Axis Shield, Oslo, Norway) density gradient centrifugation. $\mathrm{CD} 34^{+}$cells were enriched using immunomagnetic beads according to the manufacturer's instructions (Miltenyi). $\mathrm{CD} 34^{+} \mathrm{CD} 38^{- \text {-dim }}$ haematopoietic stem cells from both sources were further purified and depleted from contaminating $\mathrm{T}$ and NK cells by fluorescence-activated cell sorting using the FACS ARIA (BD, Erembodegem, Belgium). For cell-sorting, the following antibodies were used: fluorescein isothiocyanate (FITC)-anti-CD38, phycoerythrin (PE)-anti-CD34, peridinin-chlorophyll proteins (PerCP)- 
anti-CD4, -CD8, -CD3 and allophycocyanin (APC)-anti-CD56 or horizon V450-anti-CD56 (all antibodies from $\mathrm{BD}$ ). Purity of both sources of $\mathrm{CD} 34^{+}$cells was more than or equal to $98 \% \mathrm{CD} 34^{+}$cells and less than or equal to $0.1 \%$ contaminating CD3/CD4/CD8 or CD56 cells.

\section{Generation of NK cell progenitors from haematopoietic stem cells}

NK cell progenitors were generated from sorted $\mathrm{CD} 34^{+} \mathrm{CD} 38^{- \text {dim }}$ stem cells. Stem cells were co-cultured with TSt-4 feeder cells in complete RPMI medium supplemented with $10 \%$ FBS (Greiner Bio One), 100ng/ml SCF, 100ng/ml Flt-3L, $50 \mathrm{ng} / \mathrm{ml}$ TPO (all Miltenyi) and 20ng/ml IL-15 (R\&D systems, Minneapolis, MN, USA) in the first week of culture and subsequently with 50ng/ml TPO, 20ng/ml IL-15 and 200IU/ml IL-2 (Proleukin, Novartis, Basel, Switzerland). Parts of the cultures were supplemented with $50 \mu \mathrm{g} / \mathrm{ml}$ 2-phospho-LAscorbic acid (AA, Sigma-Aldrich Co.). Medium with cytokines and AA was refreshed every 3-4 days. Cells were transferred on freshly prepared TSt-4 monolayers every 2 weeks.

\section{Generation of NK cell progenitors from T/NK cell progenitors}

NK cell progenitors were generated from T/NK cell progenitors as depicted in Supplemental Figure 3. T/NK cell progenitors were generated from sorted $\mathrm{CD} 34^{+} \mathrm{CD} 38^{-/ \mathrm{dim}}$ cells on TSt-4/ DLL4 feeder cells in the medium supplemented with SCF, Flt-3L, TPO and IL-7 as described earlier ${ }^{23}$. After 21 days of culture, $\mathrm{CD} 7{ }^{-} \mathrm{CD} 5, \mathrm{CD}^{+}{ }^{+} \mathrm{CD} 5$ and $\mathrm{CD}^{+} \mathrm{CD}^{+}$populations were separated by fluorescence-activated cell sorting using FACS ARIA (BD). Furthermore, CD56 ${ }^{+}$ cells were depleted from all sorted populations. For sorting, cells were labelled with the following antibodies: CD7 (M-T701), CD5 (UCHT2) and CD56 (B159, all from BD). Purity of all sorted populations was higher than $97 \%$ (Supplemental Fig. 3). Sorted progenitors were co-cultured with TSt- 4 feeder cells in the presence of $100 \mathrm{ng} / \mathrm{ml} \mathrm{SCF}, 100 \mathrm{ng} / \mathrm{ml} \mathrm{Flt-3L,} \mathrm{50ng/}$ $\mathrm{ml} \mathrm{TPO}$ and $20 \mathrm{ng} / \mathrm{ml} \mathrm{IL-15}$ in the first week of culture and then with $50 \mathrm{ng} / \mathrm{ml}$ TPO, 20ng/ml IL-15 and 200IU/ml IL-2. Parts of the cultures were supplemented with 50 $\mu \mathrm{g} / \mathrm{ml}$ AA. Medium was changed every 2-3 days with fresh supplements.

\section{Flow cytometry analysis of NK cells and NK cell progenitors}

The following antibodies were used for phenotypic analysis of NK cells and NK cell progenitors: CD11a/LFA1 (HI111), CD16 (3G8), CD45 (HI30), CD57 (TB01, DAKO), CD158e/3DL1 (DX9, Miltenyi Biotec) all FITC-labelled; CD45 (HI30), CD158b (2DL2/3 (Miltenyi), CD159c/NKG2C (134591, R\&D systems), CD244/2B4 (R\&D systems), CD253/ TRAIL (RIK-2.1, Miltenyi), CD335/NKp46 (9E2), all PE-labelled; CD45 (2D1) and CD159a/ NKG2A (Z199, Beckman Coulter), PerCP-labelled; CD45 (2D1), CD158a/2DL1 (143211, R\&D systems), CD178/FASL (NOK-1, Miltenyi), CD184/CXCR4 (12G5), CD226/DNAM1 (102511, R\&D systems) CD314/NKG2D (BAT221, Miltenyi) all APC-labelled; CD45 (2D1) and CD3 (SK1) APC-Cy7-labelled; CD45 (HI30) and CD56 (B159) Horizon V450-labelled. Isotypes of the equivalent antibodies were used as control references. All antibodies, materials, and equipment were obtained from BD Biosciences, unless stated otherwise. Samples were 
measured with the flow cytometer FACS Canto II (BD). Flow cytometric analysis was performed with BD FACS DIVA software version 6.1.2 (BD) or FlowJo software version 10.0.6 (Treestar, Ashland, OR, USA). Living cells were gated on forward and sideward scatter pattern with subsequent doublet removal.

\section{Cytotoxicity assay}

The cytotoxic potential of NK cells was determined in a kill assay as described previously ${ }^{25}$. K562 target cells were labelled with 3,3'-Dioctadecyloxacarbocyanine perchlorate (DiO, Sigma-Aldrich Co.). Both effector and target cells were individually pre-incubated for 14-16h at $21 \%$ or $0-2 \% \mathrm{O} 2$ and subsequently combined at different effector to target ratios (E:T) in 96-well round-bottom plates in duplicate. After $4 \mathrm{~h}$, samples were measured with the FACS Canto II (BD) and cell death of $\mathrm{DiO}^{+}$target cells was measured with propidium iodide (PI, Sigma-Aldrich Co.). Specific cytotoxicity was determined by the equation: (\% $\mathrm{PI}^{+}$target cells - \% spontaneous $\mathrm{PI}^{+}$cells) / (100 - \% spontaneous $\mathrm{PI}^{+}$cells $){ }^{\star} 100$. The cytotoxic potential of NK cell progenitors was only studied in normoxic conditions.

\section{Statistical analysis}

Data are presented as median. All statistical analyses were performed using the Prism program (GraphPad Software Inc, San Diego, CA, USA). Differences between experimental conditions were evaluated for statistical significance with the non-parametric Wilcoxon matched pairs test. Significance was accepted at the level of $\mathrm{p}<0.05$ and indicated with ${ }^{\star}$ and $\mathrm{p}<0.01$ with $^{\star *}$. 


\section{Results}

\section{Ex vivo expansion of NK cells is enhanced by addition of ascorbic acid}

To investigate whether ascorbic acid (AA) has an effect on the proliferation of mature NK cells, NK cells from total PBMCs were expanded in the presence of AA, IL-2 and OKT-3 (anti-CD3). At the start of the culture, 2.9 to $20.4 \%$ of $\mathrm{CD}^{+} 6^{+}$cells were present (Fig. 1A and B). Although variation existed among different donors, the percentage of CD56 ${ }^{+}$cells for all donors in both conditions was higher at day 21 of the culture compared with day 0 (Fig. 1B). Generally, two different culture phenotypes were observed. One resulted in a high percentage of NK cells, while the other showed comparable percentages of $\mathrm{CD}^{+}$cells and $\mathrm{CD}^{2} 6^{+} \mathrm{CD} 3^{+}$ cells (Fig. 1A-B). Addition of AA did not influence the percentage of CD56 $6^{+} \mathrm{NK}$ cells as compared to day 21 in the absence of AA. However, NK cells proliferated more efficiently in the presence of AA and the total fold expansion (number of NK cells at day 21 / number of NK cells at day 0), was higher in AA supplemented cultures than in cultures without AA (Fig. 1C; $\mathrm{p}=0.0156$ ). In summary, these data show that AA improves ex vivo proliferation of mature NK cells resulting in a 2,362 fold (median, range 90-31,351) expansion of NK cells in three weeks of culture.

\section{Ex vivo expanded NK cells produced in the presence of ascorbic acid are functional}

To characterize the functionality of ex vivo expanded mature NK cells, both phenotype and cytotoxic capacity of these cells were studied. Detailed analysis of several activation, inhibitory, functional, homing and maturation receptors was performed by flow cytometry on day 0 and day 21 of culture. Representative histograms from a selected donor for all analysed receptors are shown in Supplemental Figure 1. Expression of NKp46, CD16, KIR3DL1 and KIR2DL1 were not influenced by in vitro culture (Fig. 2A). However, expanded cells expressed more of the activation receptors NKG2D, DNAM-1 and 2B4 compared to day 0 NK cells. Furthermore, higher percentages of NKG2 $\mathrm{C}^{+}$cells were present at the end of the culture. Additionally, higher percentages of $\mathrm{CD}_{5} 6^{+}$cells expressed the inhibitory receptor NKG2A, while the expression of KIR2DL2/3 differed after culture (Fig. 2A). Expanded NK cells were characterized by lower expression of CD57. Moreover, TRAIL, LFA-1, CXCR4 and LFA1 expression were increased on $\mathrm{CD}_{56}{ }^{+}$cells after culture. Comparison of receptors present on NK cells cultured in the presence or absence of AA revealed that AA did not influence the phenotype of the expanded NK cells (Fig. 2A). 

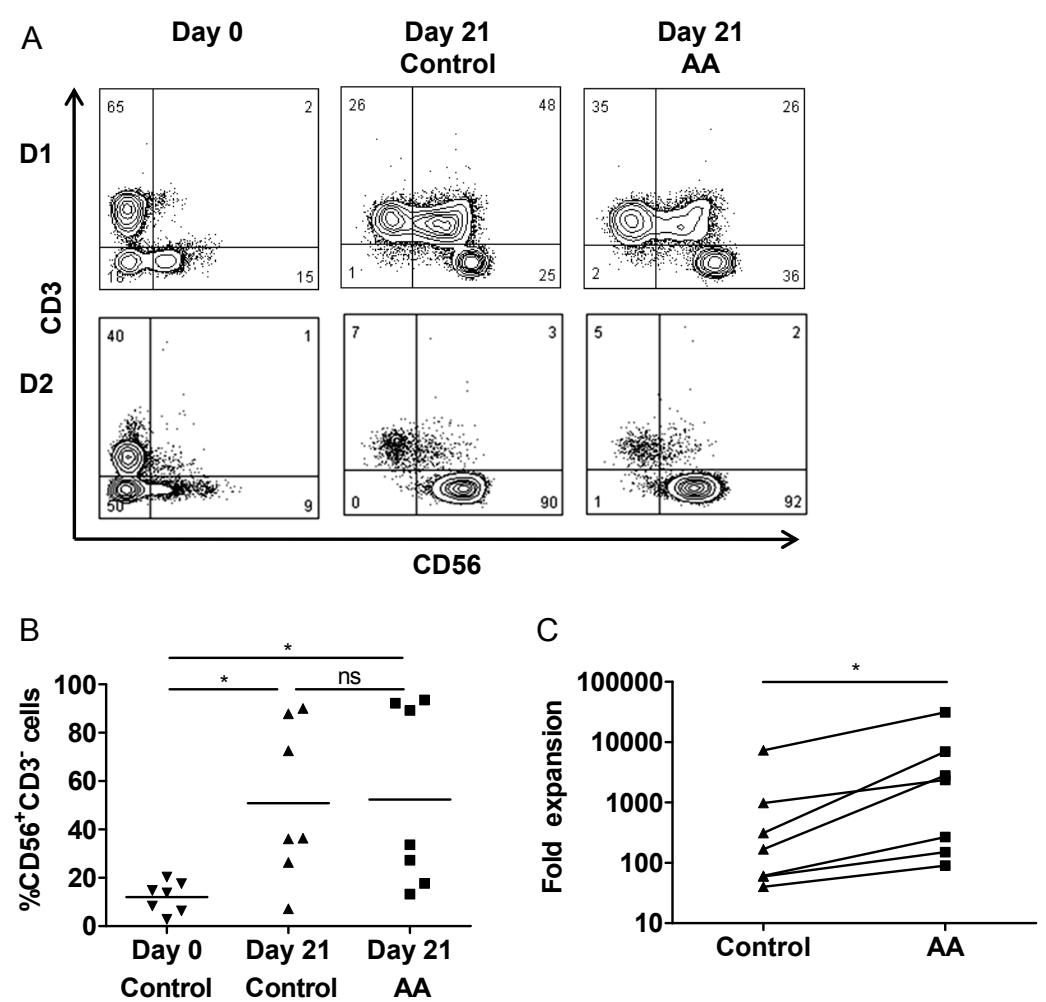

Figure 1: Ascorbic acid enhances proliferation of mature NK cells. NK cells were expanded in vitro from PBMCs in medium supplemented with OKT-3 and IL-2 for 3 weeks in the presence or absence of AA. Percentage of $\mathrm{CD}^{2} 6^{+} \mathrm{CD} 3-\mathrm{NK}$ cells and $\mathrm{CD}^{+} \mathrm{CD} 56^{-} \mathrm{T}$ cells on different days of culture from two representative donors are shown $(A)$. Percentages of $C D 56^{+} \mathrm{CD} 3-\mathrm{NK}$ cells in the presence or absence of AA are shown ( $n=7, p=0.0156$ D0 versus D21 control, $p=0.0313$ D0 versus D21 AA, B). Fold expansions of $\mathrm{CD}_{56}{ }^{+} \mathrm{NK}$ cells generated in the presence or absence of AA on day 21 of culture are shown $(n=7$, $\mathrm{p}=0.0156, \mathrm{C})$.

The ex vivo expanded NK cells were able to efficiently lyse leukemic K562 cells and the amount of lysis was comparable for NK cells expanded with or without AA (Fig. 2B). For clinical application, NK cell products should be able to kill tumour cells in a suppressive tumour environment. Hypoxia is a tumour associated factor and we recently published that hypoxia can severely reduce the killing capacity of unactivated NK cells, but upon IL-2 activation, NK cells did kill tumour cells in the hypoxic environment ${ }^{25}$. To investigate whether supplementation with AA influenced the killing capacity of NK cells, we performed killing experiments under normoxia and hypoxia. Also under hypoxic conditions, (IL-2) expanded NK cells were able to lyse target cells, indicating that expanded NK cells are efficient in eliminating tumour cells under more physiological conditions (Fig. 2C). There was no significant difference in the 
cytotoxic capacity of NK cells cultured in the presence of absence of AA (Fig. 2C).

Taken together, these data indicate that in the presence of AA during the expansion of NK cells, the phenotype was not influenced. Importantly, NK cells expanded in the presence of AA expressed all required receptors and were fully functional.

\section{A}
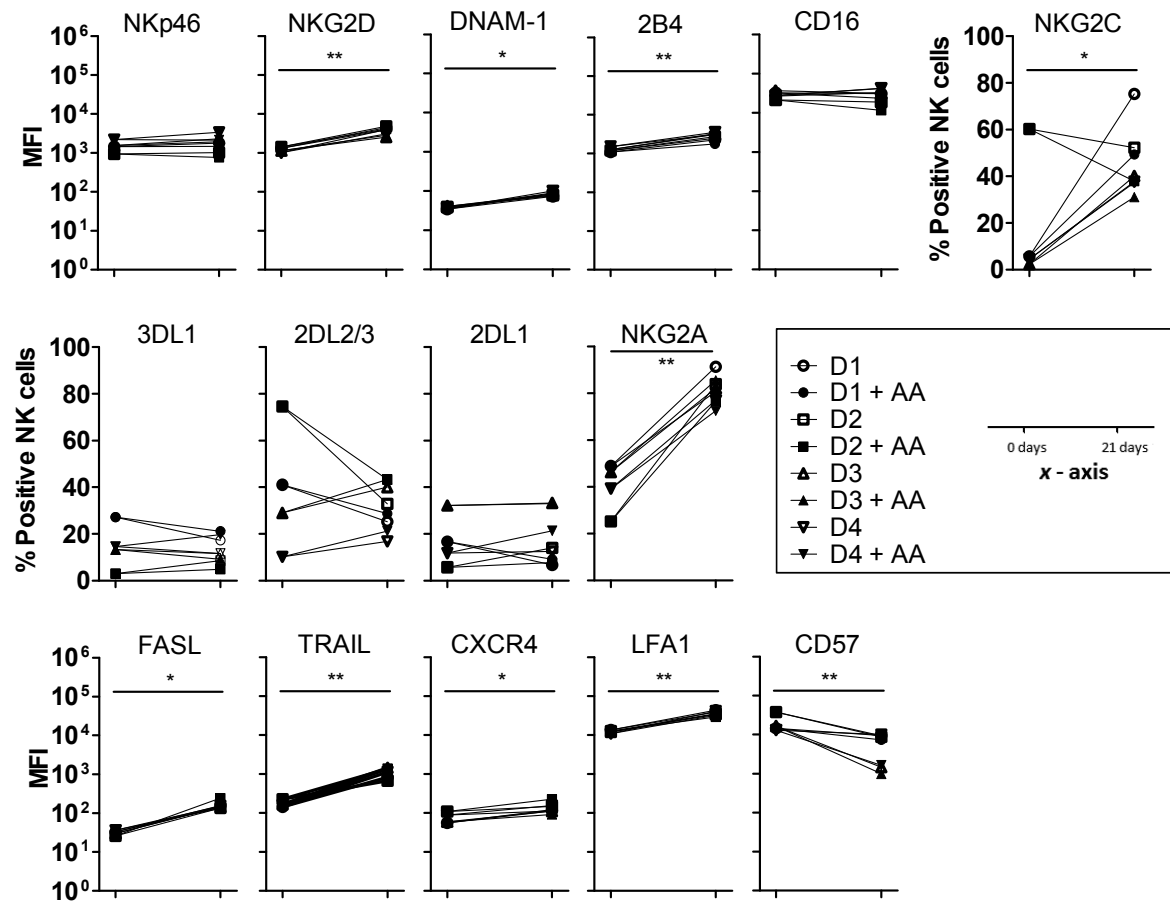

B

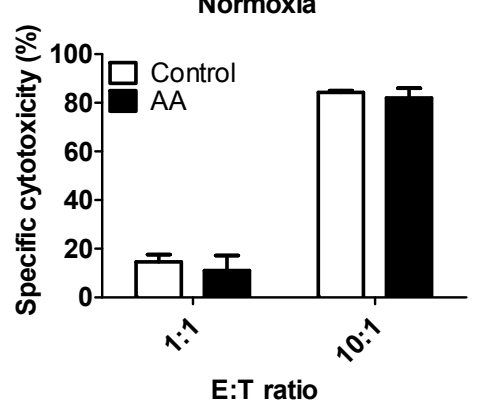

C

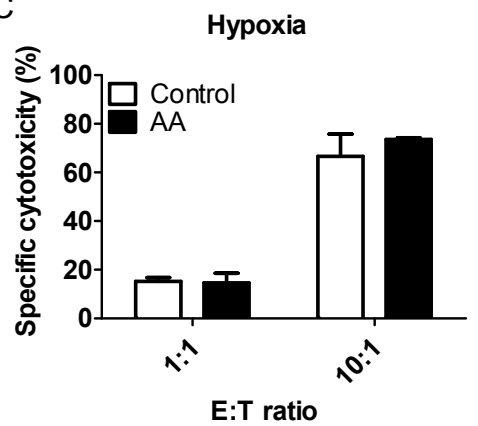


Figure 2: NK cells expanded in the presence of ascorbic acid express all required activation and inhibitory molecules and are functional. NK cells were expanded from PBMCs in medium supplemented with OKT-3 and IL-2 and in the presence or absence of AA. After 3 weeks of culture, expanded NK cells were stained with phenotypic markers. Combined data from 4 different donors is shown. Significance is indicated with ${ }^{\star}$ for $\mathrm{p}<0.05$ and ${ }^{\star \star}$ for $\mathrm{p}<0.01$ (A). Specific cytotoxicity of NK cells expanded with or without AA was measured on day 21 of culture. NK cell progenitors (effector) and K562 leukemic target cells were mixed in different E:T ratios and killing of target cells was measured after $4 \mathrm{~h}$ incubation. Specific cytotoxicity of NK cells both under normoxia $(21 \%$ O2, B) and hypoxia $(0.2 \% \mathrm{O} 2, \mathrm{C})$ is shown, $\mathrm{p}$ values indicate no significant differences $\mathrm{p}=0.5$ normoxia $1: 1, \mathrm{p}=0.75$ normoxia $1: 10, \mathrm{p}=0.85$ hypoxia $1: 1$ and $\mathrm{p}=0.25$ hypoxia $1: 10$.

\section{Ascorbic acid improves the generation and expansion of NK cell progenitors from haematopoietic stem cells}

Besides the expansion of mature NK cells, NK cells can also be generated from stem or progenitor cells. To investigate whether AA has an effect on the generation of NK cell progenitors from HSCs, NK cell progenitors were generated from $\mathrm{CD} 34^{+} \mathrm{CD} 38^{-/ \mathrm{dim}} \mathrm{HSCs} \mathrm{co}-$ cultured with TSt- 4 feeder-cells in NK cell skewing conditions in the presence or absence of AA in two independent experiments. In the presence of AA, cells acquired CD56 expression faster compared to the cells cultured without AA. After 28 days of culture, $60.1 \%$ of all (lifegated) cells were $\mathrm{CD}_{5} 6^{+}$cells in the presence of AA while only $10.8 \%$ were $\mathrm{CD}^{2} 6^{+}$without AA (Fig. 3A, Supplemental Fig. 2). After 35 days of culture, the vast majority of cells expressed CD56 (78.3\%) in the presence of AA, while the percentage of $\mathrm{CD}^{2} 6^{+}$only marginally increased to $15.8 \%$ in the absence of AA. Furthermore, NK cell progenitors generated in the presence of AA had higher expression of activating receptors including NKp46 and NKG2D, while expression of inhibitory receptors (KIR2DL1, KIR2DL2/3, KIR3DL1 or NKG2A) was comparable in both conditions as indicated by mean fluorescence intensity (MFI, Fig. $3 B$ ). Only in the presence of AA, a small population (2.7\%) of KIR2DL2/3 was observed, suggestive of a more mature NK cell population. At day 35 of culture, AA supplementation had also resulted in a higher fold expansion ( 809 fold) of CD56 ${ }^{+} \mathrm{NK}$ cell progenitors (number of $\mathrm{CD} 56^{+}$cells at day 35 / number of $\mathrm{CD} 56^{+}$cells at day 0 ) compared to the control condition without AA supplementation (78 fold; Fig. 3C). These two independent experiments support our observation that AA enhances proliferation of NK cells. In addition, they suggest that AA positively influences maturation and proliferation of NK cell progenitors generated from HSCs. 


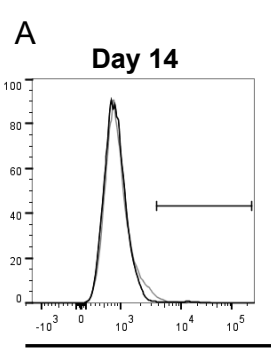

B
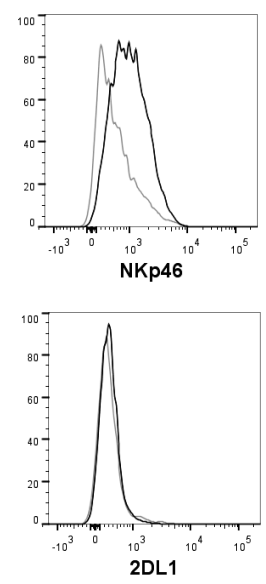

Day 28
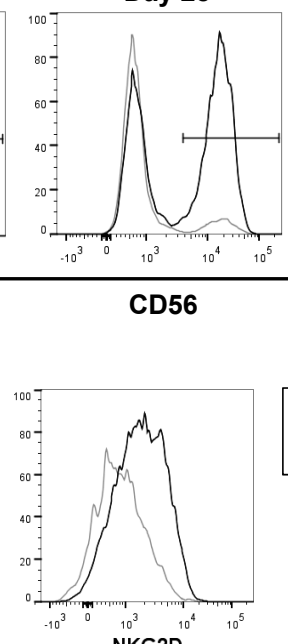

NKG2D

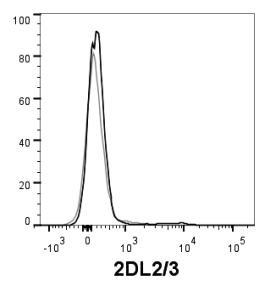

Day 35

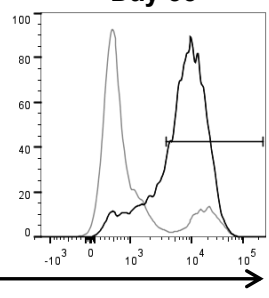

C

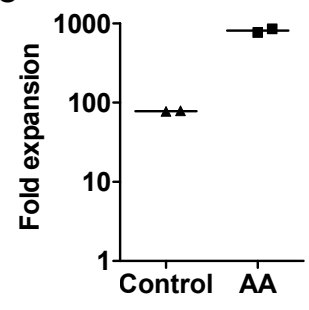

Figure 3: Ascorbic acid stimulates NK cell maturation and expansion from haematopoietic stem cells. NK cell progenitors were generated from $\mathrm{CD} 34^{+} \mathrm{CD} 38^{-/ \mathrm{dim}}$ cells in co-culture with TSt- 4 feeder cells. Maturation of NK cells was monitored by CD56 staining on different culture days in the absence (gray lines) or presence of AA (black lines) (A). Several activating and inhibitory receptors present on $\mathrm{CD}^{+} 6^{+}$cells were analysed with flow cytometry on day 35 of culture (B). Representative results of $n=2$ are shown. Fold expansion of $\mathrm{CD}^{+} 6^{+}$cells after 35 days of in vitro culture is shown (C).
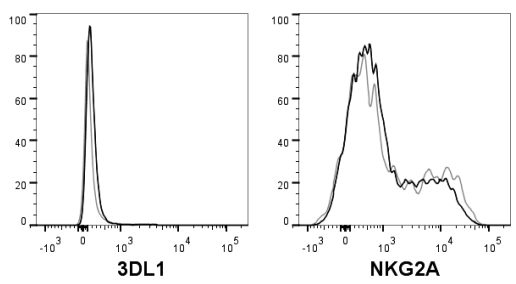


\section{Ascorbic acid improves the generation of NK cell progenitors from T/NK cell progenitors}

To provide further support for the beneficial role of AA in NK cell expansion systems, the influence of AA on the capacity to generate NK cell progenitors from T/NK cell progenitors was studied. T/NK cell progenitors were produced from HSCs in co-culture with TSt-4/DLL4 feeder cells in two independent experiments. HSCs were first co-cultured with TSt-4/DLL4 feeder cells in $\mathrm{T}$ cell skewing conditions. After 21 days of culture, three populations of $\mathrm{T}$ cell progenitors were sorted based on expression of CD7 and CD5 (CD7 CD5 ${ }^{-}, \mathrm{CD}^{+} \mathrm{CD} 5$ and $\mathrm{CD}^{+} \mathrm{CD}^{+}$) and were depleted of $\mathrm{CD}^{+} 6^{+}$cells. The purity of all obtained progenitor populations was higher than 97\% (Supplemental Fig. 3). Hereafter, the different progenitor populations were cultured in NK cell skewing conditions. $\mathrm{CD} 56^{+} \mathrm{NK}$ cell progenitors were successfully generated from both $\mathrm{CD} 7^{-} \mathrm{CD} 5{ }^{-}$and $\mathrm{CD} 7^{+} \mathrm{CD} 5$ progenitors (Fig. $4 \mathrm{~A}$ ). Remarkably, NK cell progenitors could barely be generated from the most mature $\mathrm{CD} 7^{+} \mathrm{CD} 5^{+}$population. Regardless of the presence or absence of AA, these progenitors died when cultured in NK cell skewing conditions. AA increased the percentage of $\mathrm{CD} 56^{+} \mathrm{NK}$ cell progenitors obtained from both early $\mathrm{T} / \mathrm{NK}$ cell progenitor populations, especially from the most immature CD7 CD5 population, as shown by analysis on different days during in vitro culture (Fig. 4A). The $\mathrm{CD}^{+} \mathrm{CD} 5-$ population already contained 42 and $60 \%$ of $\mathrm{CD}^{-} 6^{+}$cells at day 7 , without and with AA, respectively. This percentage further increased to approximately $90 \%$ at the end of the culture for both conditions. At day 35, 22\% and $94 \% \mathrm{CD}^{+} 6^{+}$cells were generated from CD7 ${ }^{-}{ }^{5} 5^{-}$cells in the absence and presence of AA, respectively.

Phenotypic analysis of generated NK cell progenitors from the $\mathrm{CD} 7 \mathrm{CD}^{-}$and $\mathrm{CD}^{+} \mathrm{CD} 5$ progenitors revealed that cells generated in the presence of AA expressed slightly more of the activating receptors NKp46 and NKG2D (Fig. 4B). Furthermore, AA increased expression levels of the inhibitory receptor NKG2A. The inhibitory receptors KIR2DL1 and KIR3DL1 were not altered upon $\mathrm{AA}$ addition on $\mathrm{CD}^{+} 6^{+}$cells derived from both the $\mathrm{CD} 7^{-} \mathrm{CD}^{-}$and $\mathrm{CD}^{+}{ }^{+} \mathrm{CD}^{-}$populations (Fig. $\left.4 \mathrm{~B}\right)$. Additionally, a small percentage of CD56 $6^{+}$cells $(2-4 \%)$ was KIR2DL2 $/ 3^{+}$in the presence of $\mathrm{AA}$ in both the $\mathrm{CD} 7^{-} \mathrm{CD} 5^{-}$and $\mathrm{CD}^{+} \mathrm{CD} 5^{-}$populations, suggestive of a more mature NK cell subset, while this population was absent without AA. Furthermore, proliferation of NK cell progenitors generated from the $\mathrm{CD}^{-} \mathrm{CD}^{-}$and $\mathrm{CD}^{+} \mathrm{CD}^{-}$progenitors was positively influenced by addition of AA. In the presence of AA, a 5-6 fold higher number of NK cell progenitors was generated as compared to the control condition without AA (Fig. 4C.) Moreover, generated NK cell progenitors whether cultured in the presence or absence of AA, were able to kill K562 leukemic cells (Fig. 4D), suggesting that AA does not alter NK cell functionality.

Together these data provide initial proof of concept that AA improves in vitro generation of $\mathrm{NK}$ cell progenitors from early $\mathrm{CD} 7{ }^{-\mathrm{CD}} 5^{-}$and $\mathrm{CD} 7^{+} \mathrm{CD} 5^{-}$progenitors. In contrast, $\mathrm{CD} 7^{+} \mathrm{CD} 5^{+}$ cells can barely give rise to NK cell progenitors, regardless of AA supplementation. 
Taking the experiments on differentiation to NK cells from early progenitors (HSCs and CD7CD5-T/NK cell progenitors) provided in Figure 3 and 4 together, in four out of four experiments a positive effect of AA was observed (Supplemental Fig. 4; $\mathrm{p}=0.0286$ ). This suggests that the positive influence of AA is not merely on proliferation but also on differentiation. 


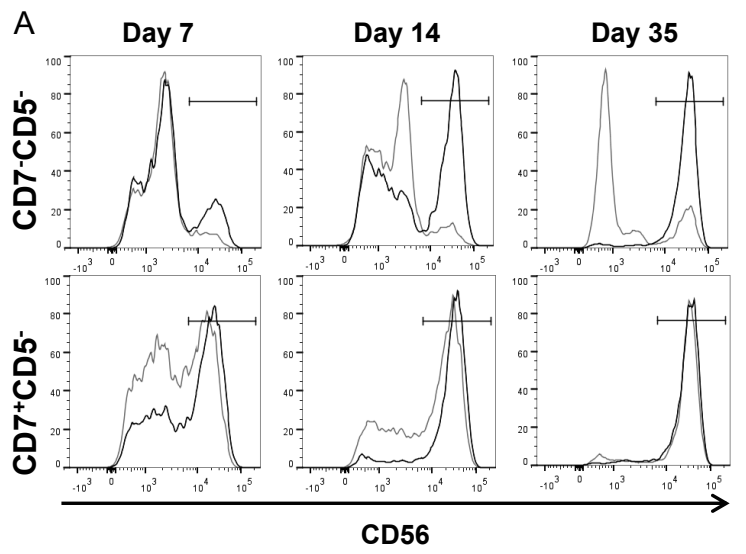

C $\operatorname{CDT}$

CD5

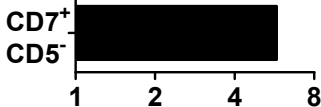

Ratio $\mathrm{CD}^{+} 6^{+}$cells AA/Control

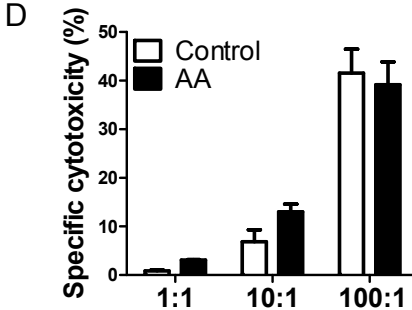

B

CD7-CD5-
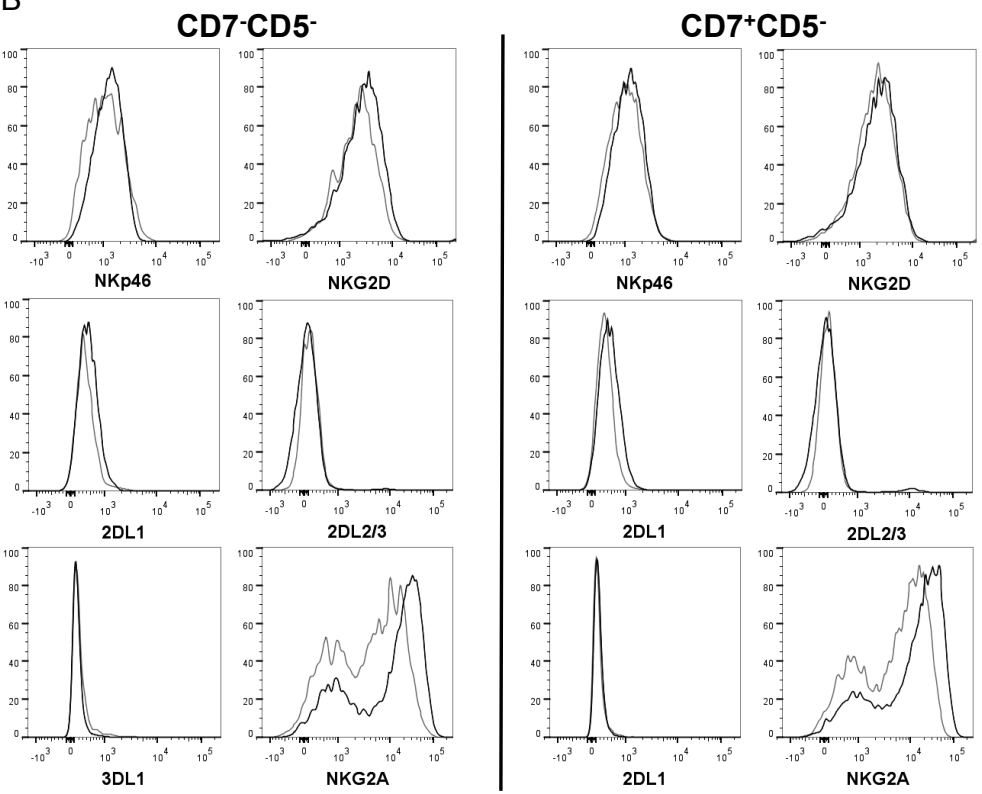

E:T ratio

Figure 4: Ascorbic acid promotes NK cell maturation from $\mathrm{T}$ cell progenitors. NK cell progenitors were generated from different $\mathrm{T}$ cell progenitor populations in co-culture with TSt-4 feeder cells. Maturation of NK cells, in the absence (gray lines) or presence of ascorbic acid (black lines), was monitored by CD56 staining on different culture days (A). Several activating and inhibitory receptors present on $\mathrm{CD}^{2} 6^{+}$cells were analysed on day 35 of culture (B). Representative results of 2 independent experiments and donors are shown. Expansion ratios of $\mathrm{CD} 56^{+}$cells generated in the presence of AA compared to control on day 35 of culture are shown $(C)$. Specific cytotoxic activity of NK cell progenitor generated with or without AA was measured on day 35 of culture. NK cell progenitors (effector) and K562 leukemic target cells were mixed in different E:T ratios and killing was measured after $4 \mathrm{~h}$ incubation (D). 


\section{Discussion and Conclusion}

This study demonstrates an important role for phosphorylated ascorbic acid on the expansion of NK cells. We show that the expansion of NK cells from peripheral blood is significantly increased in the presence of AA, resulting in functional NK cells capable of killing tumour cells under normoxia and hypoxia. Based on this observation, we additionally investigated whether AA has a positive influence on NK cells generated from HSCs in two different systems. In the first system we observed that the generation of NK cell progenitors from HSCs in the presence of AA seemed faster, resulting in a more pure NK cell population and in 900 fold more NK cells compared to the condition without AA. In the second system, we observed that the earliest $\mathrm{CD}^{-} \mathrm{CD}^{-}$and $\mathrm{CD}^{+} \mathrm{CD}^{-}$populations, but not the more mature $\mathrm{CD}^{+} \mathrm{CD}^{+}$population, can be used to efficiently differentiate into $\mathrm{CD} 56^{+} \mathrm{NK}$ cells capable of killing tumour cells. This generation, especially in the earliest $\mathrm{T}$ cell progenitor population, is greatly enhanced in the presence of AA. Although the sample size was limited, the data obtained in the latter two systems were in line with the data obtained with peripheral blood NK cells, further supporting the concept that AA has a positive effect on NK cell proliferation and suggesting a positive influence on NK cell differentiation. Together, these results indicate a positive role for AA in in vitro NK cell culture systems. Because AA is an inexpensive and readily available compound, our data provide proof of concept that AA supplementation can be an easy way to improve NK cell expansion protocols resulting in higher cell numbers as required for adoptive immunotherapy.

Different culture methods for the production of NK cells for immunotherapy exist and are currently under investigation ${ }^{7,19}$. These methods can roughly be divided in mature NK cell products (e.g. PBMC derived) or immature NK cell products (e.g. from HSCs or progenitor cells). The expansion method for mature NK cells started with PBMCs cultured in the presence of IL-2 and OKT-3. While IL-2 can act on both T and NK cells, OKT-3 (anti-CD3) presumably first exerts its effect on the T cells present in the culture, that subsequently create a milieu favourable for NK cell expansion e.g. in a contact or cytokine dependent manner. $\mathrm{T}$ cells disappear from these cultures, likely due to exhaustion (Wieten et al., unpublished observations). In combination with a mature phenotype of the expanded cells and the ability of these cells to kill cancer cells, this population is suggested to be the most suitable for therapy. However, donor variation has to be taken into account. In our hands, expansions from some donors resulted in high NK cell percentages and relatively low CD3 T cell percentages, while others resulted in increased though less than $50 \%$ NK cells in the presence of high numbers of $\mathrm{CD}^{+} \mathrm{T}$ and $\mathrm{CD}^{+} \mathrm{CD}^{+} 6^{+} \mathrm{NKT}$ cells. To prevent GVHD, $\mathrm{CD}^{+} \mathrm{T}$ cells should be excluded from the product. Nonetheless, AA improved expansion in all donors to an average of $\sim 6,000$ fold. Others have shown in clinical trials that PBMC derived expanded NK cells are safe and capable of exerting anti-tumour effects ${ }^{7}$. The benefit of using mature NK cell products is 
that donor and patients can be mismatched for their KIR receptors, which is promising for a greater anti-tumour effect ${ }^{26}$.

Because of the positive effect on mature NK cell expansion, we additionally investigated the influence of AA in other NK culture systems to find proof of concept. Also in directing cells in the NK cell lineage from both HSCs and T cell progenitors, a positive influence of AA was observed. On the one hand, it seems that addition of AA results in faster generation of NK cells; on the other hand, even after long culture in the absence of AA, less NK cells are observed. This suggests that AA makes more cells sensitive for differentiation into the NK cell lineage, possibly by increasing IL-15R expression on NK cells. However, in our previous study describing the effect of AA on $\mathrm{T}$ cell differentiation, we did not see receptor upregulation after AA treatment of the relevant receptors studied in that system ${ }^{24}$. We therefore expect the mechanism to be more complicated than upregulation of cytokine receptors.

$\mathrm{NK}$ and T cells share a common progenitor ${ }^{27}$. We previously showed that cells in a mixed $\mathrm{T} /$ $\mathrm{NK}$ cell progenitor population derived from HSCs had the potency to become NK cells ${ }^{23}$. In this latter study, the complete progenitor population was used. Here, we show that only the early $\mathrm{CD}^{-} \mathrm{CD}^{-}$and $\mathrm{CD}^{+}{ }^{+} \mathrm{CD} 5^{-}$cells gave rise to expanding $\mathrm{NK}$ cell populations. Only very few NK cells derived from the $\mathrm{CD}^{+} \mathrm{CD}^{+}$could be detected. These cells died within the first weeks of culture and were not able to expand, regardless of the presence or absence of AA. This suggests that these cells have lost most of their NK cell potential and are more committed to the $\mathrm{T}$ cell lineage compared to the more immature populations. It is believed that PreT cells, expressing CD7, CD5 and CD1a are T lineage committed ${ }^{28}$. The NK cells observed in the culture could be impurities of $\mathrm{CD} 56^{+}$cells or developed from more immature T/NK cell progenitors that were still present in the culture. Another explanation is that the $\mathrm{CD}^{+} \mathrm{CD} 5^{+}$ stage is still heterogeneous and that only a minor fraction gave rise to NK cells; for example cells can further be divided based on iCD3, CD1a expression or T cell receptor rearrangement status ${ }^{29}$.

Currently, NK cell progenitors produced from HSCs and T/NK cell progenitors are cocultured with feeder cells, which require selection of NK cells before clinical use in patients. We recently established a feeder-free culture system where in the presence of AA, T cells can be generated and adapting the growth factors to an NK cell skewing profile may likely be applicable ${ }^{24}$. The high purity of the NK cells obtained in these systems due to the presence of AA is a great advantage. Moreover, in the presence of AA the expansion of NK cells from HSCs is increased by a 100 fold. The generated NK cells in these systems are still progenitors, since they do not express KIR receptors (except for minor populations $<5 \%$ in the presence of AA). However, a recent study revealed that NK cells generated from HSCs in a clinical setting do have the capacity to inhibit growth of leukemic cells resulting in prolonged survival in a murine tumour model ${ }^{30}$. Furthermore, it has been shown that CD $34^{+}$HSC-derived NK 
cells do not show acute side effects upon injection in patients, unfortunately no anti-tumour activity of the NK cells was measured probably because of insufficient NK cell numbers ${ }^{31}$. Another advantage of the generation of NK cells from HSCs is that a minor fraction of the same HSCs injected for HSCT in the patient could be used for the generation of NK cells minimizing the risk of rejection of the NK cells.

Regardless of the source or preparation of the NK cells, they have to be able to kill tumour cells in vivo. Since many years there have been investigations in the tumour microenvironment and abundant knowledge has been generated on escape mechanisms from the immune system by tumour cells. One of these factors of the tumour microenvironment is hypoxia, which has been shown to contribute to therapy resistance of malignant cells ${ }^{32,33}$. Previously, we showed that the killing capacity of NK cells is reduced under hypoxia, which can be restored by IL-2 activation of the NK cells ${ }^{25}$. Here, we show that IL-2 activated expanded mature NK cells kill cancer cells under hypoxia, also in the presence of AA, confirming the functionality in a more physiological relevant setting.

Others already succeeded in generating clinical grade NK cells applicable for therapy, as extensively reviewed by Cheng et al. ${ }^{7}$. Media regularly used for NK cell expansions are Glycostem, RPMI 1640, DMEM and CellGro SCGM ${ }^{7,19}$. While in general some commercially available cell culture media already contain AA, most of the media used for NK cell expansion do not. Furthermore, if present, AA is in the non-phosphorylated form, which is less stable and has far less potency to stimulate cells to proliferate than the phosphorylated compound ${ }^{24,34}$. Therefore, our observations strongly suggest the controlled addition of phosphorylated AA in any NK cell expansion system will be advantageous, and if already present, optimized concentrations are recommended. Potentially, this could result in faster expansion of NK cells resulting in higher yields of NK cells in a shorter culture time. This will lead to a marked cost reduction and the availability of a higher number of NK cells for immunotherapy. Our recent results show that only subpopulations of the NK cell pool (KIR-ligand mismatched NK cell subsets) are efficient effector cells ${ }^{22}$. Because these subsets have a relatively low frequency, really high cell numbers are needed to be infused into patients. Fortunately, AA is available in clinical grade and could immediately be added to existing NK cell culture methods.

In summary, AA promotes the proliferation of NK cell populations in different culture systems without affecting their functionality. These findings are relevant for the improvement of methods to generate sufficient NK cells for adoptive therapy. 


\section{Acknowledgements}

This work was supported by a grant from the Dutch Cancer Society KWF: UM2010-4671 and with financial support from the Cancer Research Fund Limburg of the Health Foundation Limburg. SS was supported by PhD student grant from GROW, School of Oncology and Developmental Biology, Maastricht University Medical Center ${ }^{+}$. LW was supported by a personal grant from the Dutch Cancer Society. 


\section{References}

1. Caligiuri MA. Human natural killer cells. Blood. 2008 Aug 1;112(3):461-9.

2. Lanier LL. Up on the tightrope: natural killer cell activation and inhibition. Nat Immunol. 2008 May;9(5):495-502.

3. Moretta L, Moretta A. Unravelling natural killer cell function: triggering and inhibitory human NK receptors. Embo J. 2004 Jan 28;23(2):255-9.

4. Kang L, Voskinarian-Berse V, Law E, Reddin T, Bhatia M, Hariri A, et al. Characterization and ex vivo Expansion of Human Placenta-Derived Natural Killer Cells for Cancer Immunotherapy. Front Immunol. 2013;4:101.

5. Karre K, Ljunggren HG, Piontek G, Kiessling R. Selective rejection of H-2-deficient lymphoma variants suggests alternative immune defence strategy. Nature. 1986 Feb 2026;319(6055):675-8.

6. Moretta A, Bottino C, Vitale M, Pende D, Cantoni C, Mingari MC, et al. Activating receptors and coreceptors involved in human natural killer cell-mediated cytolysis. Annu Rev Immunol. 2001;19:197-223.

7. Cheng M, Chen Y, Xiao W, Sun R, Tian Z. NK cell-based immunotherapy for malignant diseases. Cell Mol Immunol. 2013 May;10(3):230-52.

8. Carbone E, Neri P, Mesuraca M, Fulciniti MT, Otsuki T, Pende D, et al. HLA class I, NKG2D, and natural cytotoxicity receptors regulate multiple myeloma cell recognition by natural killer cells. Blood. 2005 Jan 1;105(1):251-8.

9. Shi J, Tricot G, Szmania S, Rosen N, Garg TK, Malaviarachchi PA, et al. Infusion of haploidentical killer immunoglobulin-like receptor ligand mismatched NK cells for relapsed myeloma in the setting of autologous stem cell transplantation. Br J Haematol. 2008 Dec;143(5):641-53.

10. Siegler U, Kalberer CP, Nowbakht P, Sendelov S, Meyer-Monard S, Wodnar-Filipowicz A. Activated natural killer cells from patients with acute myeloid leukemia are cytotoxic against autologous leukemic blasts in NOD/SCID mice. Leukemia. 2005 Dec;19(12):221522.

11. Alici E, Konstantinidis KV, Sutlu T, Aints A, Gahrton G, Ljunggren HG, et al. Anti-myeloma activity of endogenous and adoptively transferred activated natural killer cells in experimental multiple myeloma model. Exp Hematol. 2007 Dec;35(12):1839-46.

12. Ishikawa E, Tsuboi K, Saijo K, Harada H, Takano S, Nose T, et al. Autologous natural killer cell therapy for human recurrent malignant glioma. Anticancer Res. 2004 MayJun;24(3b):1861-71.

13. deMagalhaes-Silverman M, Donnenberg A, Lembersky B, Elder E, Lister J, Rybka W, et al. Posttransplant adoptive immunotherapy with activated natural killer cells in patients with metastatic breast cancer. J Immunother. 2000 Jan;23(1):154-60.

14. Ruggeri L, Capanni M, Mancusi A, Aversa F, Martelli MF, Velardi A. Natural killer cells as a 
therapeutic tool in mismatched transplantation. Best Pract Res Clin Haematol. 2004 Sep;17(3):427-38.

15. Velardi A, Ruggeri L, Mancusi A, Burchielli E, Perruccio K, Aversa F, et al. Clinical impact of natural killer cell reconstitution after allogeneic hematopoietic transplantation. Semin Immunopathol. 2008 Dec;30(4):489-503.

16. Frings PW, Van Elssen CH, Wieten L, Matos C, Hupperets PS, Schouten HC, et al. Elimination of the chemotherapy resistant subpopulation of $4 \mathrm{~T} 1$ mouse breast cancer by haploidentical NK cells cures the vast majority of mice. Breast Cancer Res Treat. 2011 Dec;130(3):773-81.

17. Krause SW, Gastpar R, Andreesen R, Gross C, Ullrich H, Thonigs G, et al. Treatment of colon and lung cancer patients with ex vivo heat shock protein 70-peptide-activated, autologous natural killer cells: a clinical phase i trial. Clin Cancer Res. 2004 Jun 1;10(11):3699-707.

18. Stern M, Passweg JR, Meyer-Monard S, Esser R, Tonn T, Soerensen J, et al. Pre-emptive immunotherapy with purified natural killer cells after haploidentical SCT: a prospective phase II study in two centers. Bone Marrow Transplant. 2013 Mar;48(3):433-8.

19. Sutlu T, Alici E. Natural killer cell-based immunotherapy in cancer: current insights and future prospects. J Intern Med. 2009 Aug;266(2):154-81.

20. Luhm J, Brand JM, Koritke P, Hoppner M, Kirchner H, Frohn C. Large-scale generation of natural killer lymphocytes for clinical application. J Hematother Stem Cell Res. 2002 Aug;11(4):651-7.

21. McKenna DH, Jr., Sumstad D, Bostrom N, Kadidlo DM, Fautsch S, McNearney S, et al. Good manufacturing practices production of natural killer cells for immunotherapy: a six-year single-institution experience. Transfusion. 2007 Mar;47(3):520-8.

22. Sarkar S, Van Gelder M, Willy Xu Y, Rouschop K, Groen R, Schouten H, et al. Optimal selection of Natural Killer cells to kill myeloma: the role of HLA-E and NKG2A. In submission. 2014.

23. Meek B, Cloosen S, Borsotti C, Van Elssen CH, Vanderlocht J, Schnijderberg MC, et al. In vitro-differentiated $\mathrm{T} /$ natural killer-cell progenitors derived from human CD34+ cells mature in the thymus. Blood. 2010 Jan 14;115(2):261-4.

24. Huijskens MJAJ, Walczak M, Koller N, Briedé J, Senden-Gijsbers B, Schnijderberg M, et al. Ascorbic acid induces development of double-positive $\mathrm{T}$ cells from human hematopoietic stem cells in the absence of stromal cells. Journal of Leukocyte Biology. 2014; In press.

25. Sarkar S, Germeraad WTV, Rouschop KM, Steeghs EM, van Gelder M, Bos GMJ, et al. Hypoxia induced impairment of NK cell cytotoxicity against multiple myeloma can be overcome by IL-2 activation of the NK cells. PLoS One. 2013;8(5):e64835.

26. Miller JS, Soignier Y, Panoskaltsis-Mortari A, McNearney SA, Yun GH, Fautsch SK, et al. Successful adoptive transfer and in vivo expansion of human haploidentical NK cells in patients with cancer. Blood. 2005 Apr 15;105(8):3051-7.

27. Ikawa T, Kawamoto H, Fujimoto S, Katsura Y. Commitment of common T/Natural killer (NK) progenitors to unipotent $\mathrm{T}$ and $\mathrm{NK}$ progenitors in the murine fetal thymus revealed by a single progenitor assay. J Exp Med. 1999 Dec 6;190(11):1617-26. 
28. Weerkamp F, Baert MR, Brugman MH, Dik WA, de Haas EF, Visser TP, et al. Human thymus contains multipotent progenitors with T/B lymphoid, myeloid, and erythroid lineage potential. Blood. 2006 Apr 15;107(8):3131-7.

29. Dik WA, Pike-Overzet K, Weerkamp F, de Ridder D, de Haas EF, Baert MR, et al. New insights on human $\mathrm{T}$ cell development by quantitative $\mathrm{T}$ cell receptor gene rearrangement studies and gene expression profiling. J Exp Med. 2005 Jun 6;201(11):1715-23.

30. Cany J, van der Waart AB, Tordoir M, Franssen GM, Hangalapura BN, de Vries J, et al. Natural killer cells generated from cord blood hematopoietic progenitor cells efficiently target bone marrow-residing human leukemia cells in NOD/SCID/IL2Rg(null) mice. PLoS One. 2013;8(6):e64384.

31. Yoon SR, Lee YS, Yang SH, Ahn KH, Lee JH, Kim DY, et al. Generation of donor natural killer cells from CD34(+) progenitor cells and subsequent infusion after HLA-mismatched allogeneic hematopoietic cell transplantation: a feasibility study. Bone Marrow Transplant. 2010 Jun;45(6):1038-46.

32. Rohwer N, Cramer T. Hypoxia-mediated drug resistance: novel insights on the functional interaction of HIFs and cell death pathways. Drug Resist Updat. 2011 Jun;14(3):191-201.

33. Harris AL. Hypoxia--a key regulatory factor in tumour growth. Nat Rev Cancer. 2002 Jan;2(1):38-47.

34. May JM. The SLC23 family of ascorbate transporters: ensuring that you get and keep your daily dose of vitamin C. Br J Pharmacol. 2011 Dec;164(7):1793-801. 


\section{Supplemental information}
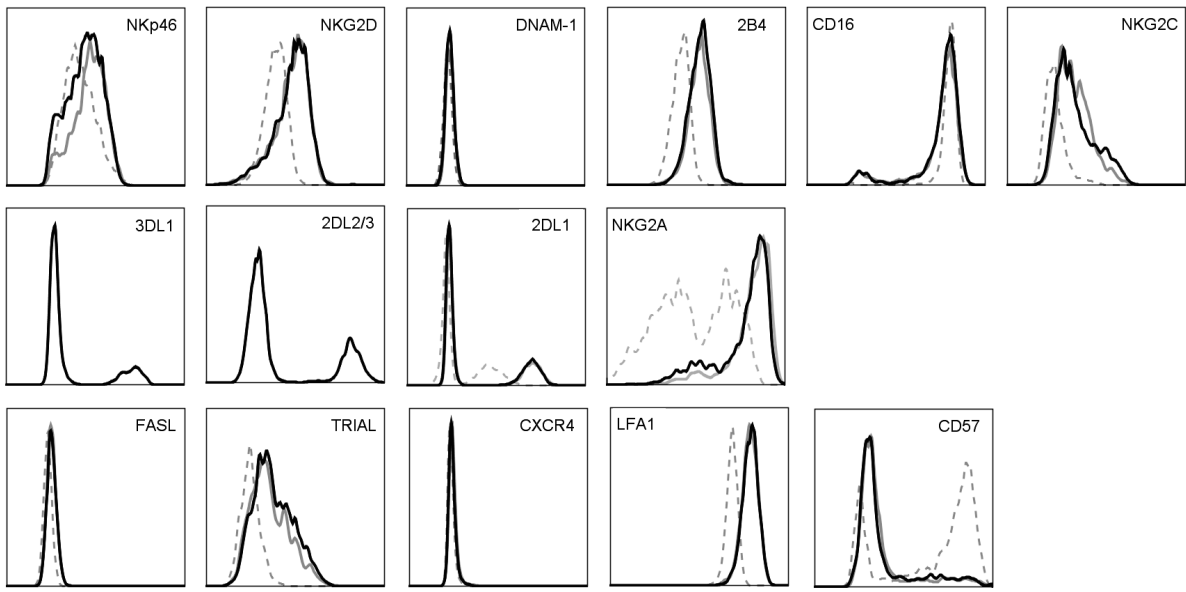

Supplemental Figure 1: NK cells expanded in the presence of ascorbic acid express all required activation and inhibitory molecules. NK cells were expanded from PBMCs in the presence of OKT3 and IL-2 and in the presence (black lines) or absence of AA (grey lines). After 3 weeks of culture, expanded NK cells were stained with several phenotypic markers, one representative donor of $n=7$ is shown. Dotted line represents phenotype of NK cells at day 0.
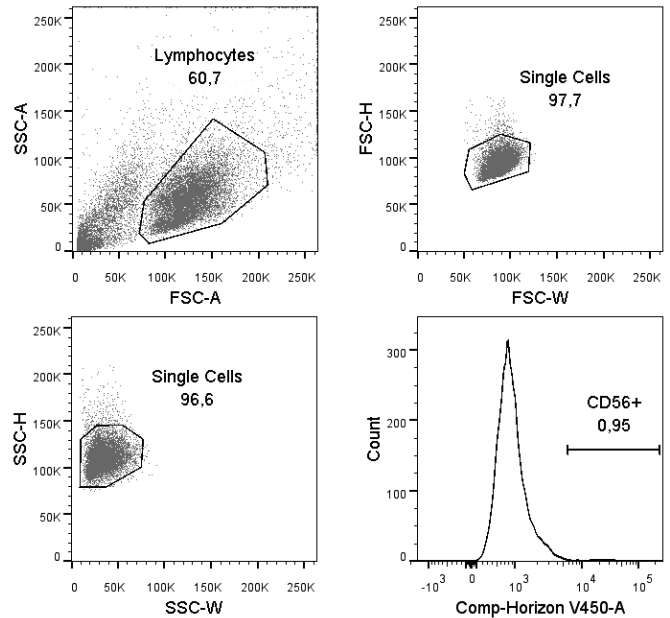

Supplemental Figure 2: Gating strategy of NK cell generation from haematopoietic stem cells Cells were first gated on FSC and SSC area to select the lymphocyte population. Subsequently, doublets were removed in the FSC-H, FSC-W and SSC-H and SSC-W plots. Then, cells were gated on the expression of CD56. 

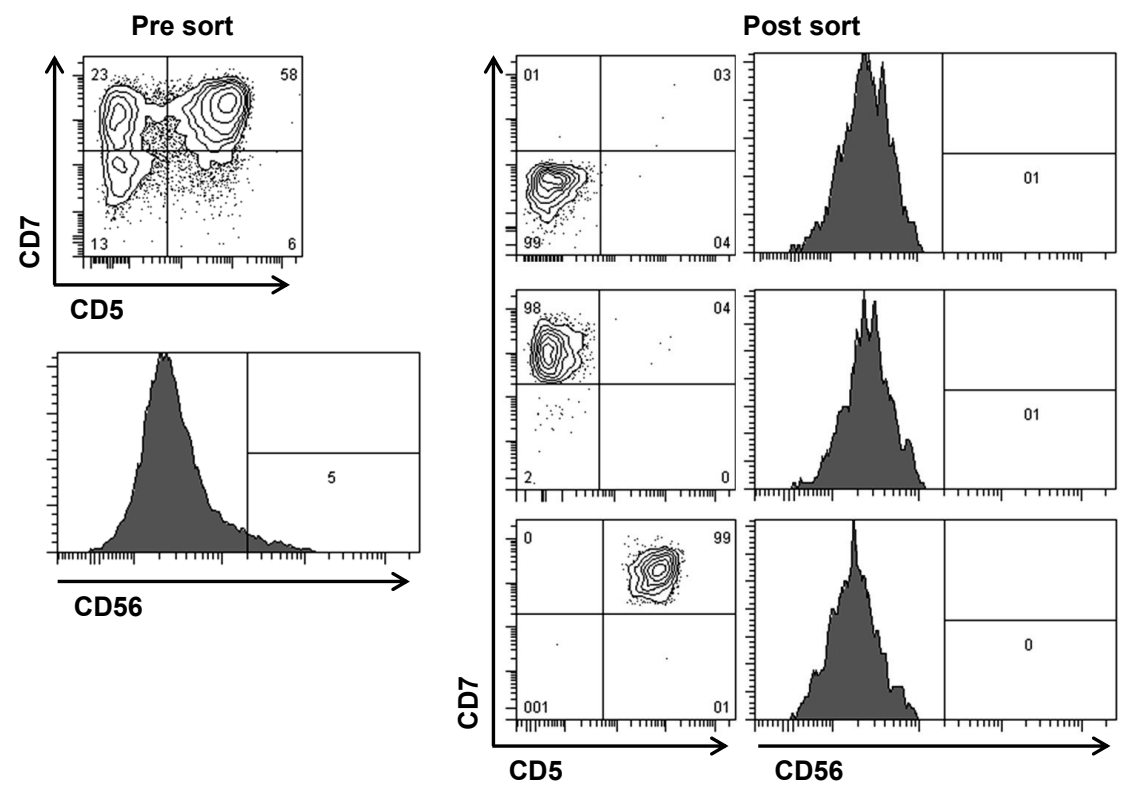

Supplemental Figure 3: Generation of different populations of $\mathrm{T}$ cell progenitors. Sorted $\mathrm{CD} 34^{+} \mathrm{CD} 38^{- \text {dim }}$ stem cells were co-cultured with TSt-4/DLL4 feeder cells for 3 weeks. On day 21 cells were stained with anti-CD7 and -CD5 antibodies and 3 different $\mathrm{T}$ cell progenitor populations were sorted: $\mathrm{CD} 7 \mathrm{CD}^{-}, \mathrm{CD}^{+} \mathrm{CD}^{-}$and $\mathrm{CD}^{+} \mathrm{CD}^{+}$. All sorted populations were depleted of $\mathrm{CD}^{-} 6^{+}$cells. A representative pre-sort and post-sort purity of all three populations is shown $(n=2)$.

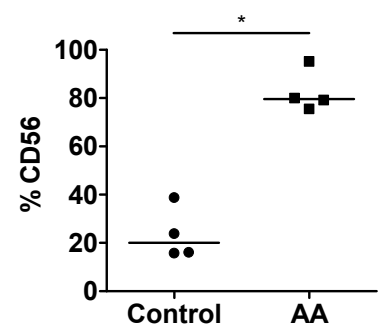

Supplemental Figure 4: Ascorbic acid promotes differentiation towards NK cells from progenitor cells. Percentages of $\mathrm{CD}^{+} 6^{+}$cells generated from HSCs or early T/NK progenitors (CD7 ${ }^{-}{ }^{-} 5^{-}$) after 35 days of culture in NK cell skewing conditions from experiments depicted in Figure 3 and 4 in the absence (control) or presence of AA. Experiments were combined and analysed resulting in $n=4$ and $\mathrm{p}=0.0286$. 


\section{Ascorbic acid serum levels are reduced in patients with haematological malignancies}

Mirelle J.A.J. Huijskens, Will K.W.H. Wodzig, Mateusz Walczak, Wilfred T.V. Germeraad, Gerard M.J. Bos

Submitted for publication. 


\section{Abstract}

Ascorbic acid (AA) has a crucial role in cellular immune responses. Patients treated with chemotherapy and/or haematopoietic stem cell transplantation (HSCT) have low immune cell counts for weeks to months. Meanwhile, patients are highly susceptible to infections resulting in high mortality. Here, we show that patients with a haematological malignancy, either treated with chemotherapy or with autologous/allogeneic HSCT, have highly significant reduced serum AA levels compared to healthy controls. It might be of clinical relevance to study the function and recovery of immune cells after treatment, its correlation to AA serum levels and the possible effect of AA supplementation. 


\section{Introduction}

Vitamin $\mathrm{C}$ or ascorbic acid (AA) is an essential water-soluble vitamin with many functions 1,2 and has a crucial role in cellular immune responses ${ }^{3}$. Patients treated with chemotherapy and/or haematopoietic stem cell transplantation (HSCT) have low immune cell counts for weeks to months ${ }^{4}$. Especially allogeneic haplo-identical or cord blood transplantation results in a $\mathrm{T}$ cell regeneration time up to a year. Meanwhile, patients are highly susceptible to infections resulting in high mortality. We previously showed that human in vitro generated $\mathrm{T}$ cell progenitors home faster than stem cells to the thymus and mature completely in mice ${ }^{5}$, making T cell progenitors an interesting therapy to prevent infections in such patients. While optimizing the in vitro $\mathrm{T}$ cell generation procedure, we recently discovered the importance of AA during this process ${ }^{6}$. In the presence of AA, early haematopoietic progenitors commit and mature into $\mathrm{T}$ cells and proliferate faster. Moreover, we showed that AA enhances proliferation and maturation of $\mathrm{NK}$ cells ${ }^{7}$. As AA has a major influence on (re)generation of immune cells, we executed an observational study in which AA serum values of patients with haematological malignancies treated with and without HSCT were compared with those of healthy volunteers. 


\section{Materials and methods}

\section{Patients and controls}

Basic patient characteristics are shown in Table 1. AA levels were measured in left-over serum samples of 42 non-selected haemato-oncology patients admitted to the hospital because of treatment or complications. Samples were taken of all patients admitted on the day routine blood samples are taken. Blood serum, as side product, does not need ethical approval in the Netherlands, under the Dutch Code for Proper Secondary Use of Human Tissue. The individuals from whom the samples originated did not object to their use, an option that is a standard procedure in our hospital. Results of blood samples (AA levels) were anonymous to the investigators except for one of the authors (GMJB) who - as part of the treating physicians team - was aware of the clinical conditions and AA levels of all the patients, so correlation of the parameters could take place. As control group, healthy volunteers working in the hospital donated blood samples for reference values for our laboratory. The AA levels measured were used for reference values for our hospital. These healthy donors agreed to donate their blood for research purposes and had signed an informed consent. This study was performed in accordance with the Declaration of Helsinki and according to the Dutch Code for Proper Secondary Use of Human Tissue ${ }^{8}$.

\section{Ascorbic acid measurements}

Serum AA was indirectly determined by measuring ferrous ion and 2,4,6-tris(2-pyridyl)-striazine ( $\mathrm{Fe}^{2+}-\mathrm{TPTZ}$, Sigma-Aldrich). This reaction product is formed by nonspecific reduction of the corresponding ferric ion complex $\left(\mathrm{Fe}^{3+}\right.$-TPTZ) by biological reducing agents such as $\mathrm{AA}$ at $\mathrm{pH}$ 3.6. AA was specifically quantified by pretreating one of a pair of replicate samples with the enzyme ascorbate oxidase (Sigma-Aldrich), oxidizing AA to dehydroascorbic acid, then reacting both samples with $\mathrm{Fe}^{3+}$-TPTZ and measuring the difference in absorbances at $600 \mathrm{~nm}$ on the Cobas Mira Plus (Roche, Basel, Switzerland). The AA concentration was calculated from a standard addition curve with a $10 \mu \mathrm{M}$ detection limit. 
Table 1: Characteristic of the patients.

\begin{tabular}{lccc}
\hline Patient characteristics & HSCT & Non-HSCT & Total \\
\hline $\mathrm{n}$ & 26 & 16 & 42 \\
Sex; male/female & $15 / 11$ & $7 / 9$ & $22 / 20$ \\
Age; median (range), year & $56.5(39-72)$ & $62.5(40-71)$ & $59(39-72)$ \\
Disease & & & \\
AML & 8 & 8 & 16 \\
ALL & 2 & 2 & 4 \\
CML & 1 & & 1 \\
CLL & 1 & 2 & 1 \\
DLBCL & 1 & & 6 \\
MM & 6 & & 1 \\
Myelofibrosis & 1 & & \\
NHL & 6 & & \\
HSCT & 10 & & \\
Autologous & 16 & & \\
Allogeneic & 7 & & \\
GVHD & & & \\
\hline
\end{tabular}

HSCT: Haematopoietic stem cell transplantation; AML: Acute Myeloid Leukaemia; ALL: Acute Lymphatic Leukaemia; CML: Chronic Myeloid Leukaemia; CLL: Chronic Lymphoid Leukaemia; DLBCL: Diffuse Large B Cell Lymphoma; MM: Multiple Myeloma; NHL: non-Hodgkin Lymphoma; GVHD: Graft versus host disease. The non-transplanted patients were all admitted for chemotherapy treatment, except for one patient with CLL that was treated with prednisone only. The patients with MM and autologous transplantation were conditioned with high dose Melphalan and the patient with NHL undergoing autologous transplantation received BEAM conditioning. All patients undergoing donor transplantation were treated with Fludarabine and low dose total body irradiation, with or without anti-thymocyte globulin, depending on the Human Leukocyte Antigen mismatch. Only the one patient $<40$ years of age was treated with intensive chemotherapy regimen (Busulfan and Cyclophosphamide).

\section{Statistical analysis}

Data are represented as median with corresponding interquartile range and compared with the Mann-Whitney U test; $\mathrm{p}<0.05$ was considered statistically significant. Determinants of AA serum levels were corrected with regression analysis. Analyses were performed with Prism (GraphPad Software Inc) and IBM SPSS (SPSS). 


\section{Results}

Healthy volunteers had serum AA levels of $65 \mu \mathrm{Mol} / \mathrm{L}$ (median, 95\% CI 61.56-69.46), while a significant decrease was observed in patients with haematological malignancies who had AA serum levels of $20.5 \mu \mathrm{Mol} / \mathrm{L}$ (median, 95\% CI 21.27-32.68, Fig. 1A). Eight patients (19\% of total patients) had AA serum values $<11.4 \mu \mathrm{Mol}$ and are considered to be AA deficient ${ }^{9}$. The patient group was slightly older than the control group. After correction for age and sex the difference in serum AA was still significant ( $\mathrm{p}<0.0001$, Fig. 1B).

Within the patient group (although subgroup sizes are small), patients treated with HSCT or chemotherapy/prednisone did not have significantly different serum AA values, nor was there a difference between patients after autologous transplantation with high dose chemotherapy or allogeneic transplantation with non-myeloablative conditioning for all except one patient (Fig. 1C-D). Furthermore, within the allogeneic HSCT group, no difference was observed in patients suffering from GVHD (Fig. 1E).

Additionally, low serum AA values were not only observed during the acute phase of disease but even up to 360 days after transplantation in a patient admitted because of GVHD (Fig. $1 \mathrm{~F})$. 
A

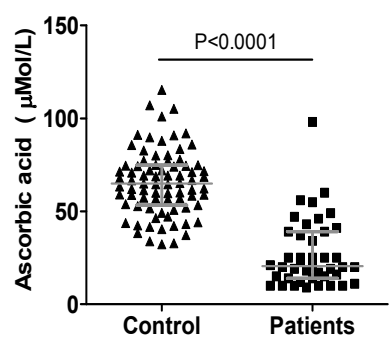

D

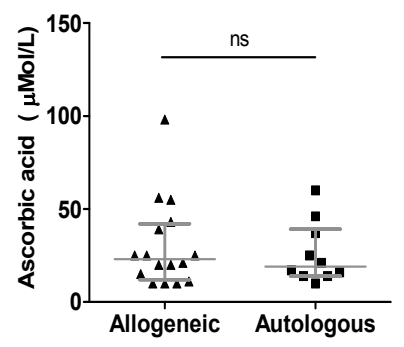

B

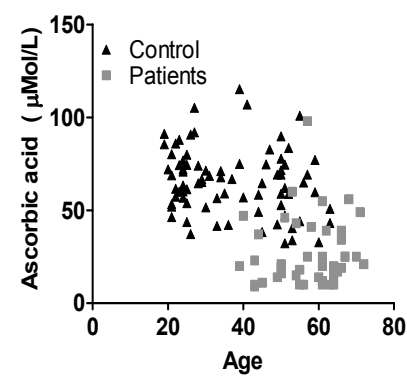

E

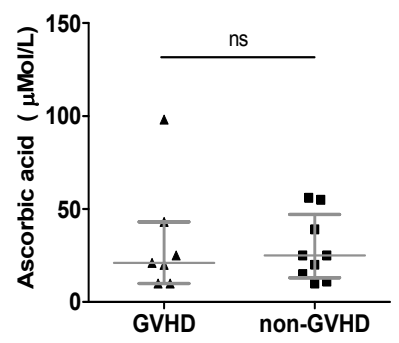

C

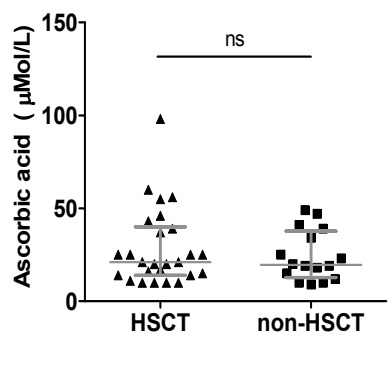

$F$

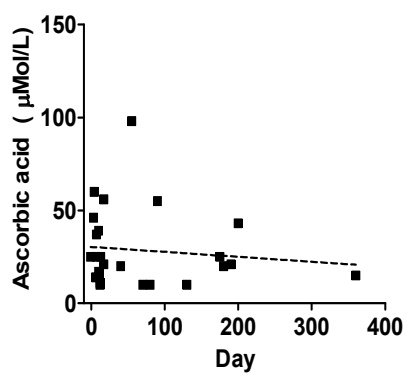

Figure 1: Serum ascorbic acid levels. A: Serum ascorbic acid values of controls and patients are represented as $\mu \mathrm{Mol} / \mathrm{L}$. Data were compared with Mann-Whitney $\mathrm{U}(\mathrm{p}<0.0001)$. For seven patients with undetectable AA levels $(<10 \mu \mathrm{Mol} / \mathrm{L}), 10 \mu \mathrm{Mol} / \mathrm{L}$ was appointed as AA value. B: Age (years) and serum AA values $(\mu \mathrm{Mol} / \mathrm{L})$ of controls and patients. The regression coefficient of AA comparing healthy controls to patients with haematological malignancies is - $38.5 \mu \mathrm{Mol} / \mathrm{L} \mathrm{AA}(95 \% \mathrm{CI}-45.29$ - -31.78). After correction for age and sex, being $-34.4 \mu \mathrm{Mol} / \mathrm{L}(95 \% \mathrm{CI}-43.04$ - -25.81) with $\mathrm{p}<0.0001$ comparing controls and patients. C: Serum AA values ( $\mu \mathrm{Mol} / \mathrm{L}$ ) of HSCT and non-HSCT patients $(\mathrm{p}=0.63)$. D: Serum AA values of allogeneic versus autologous HSCT. Significance was tested with Mann Whitney U test and results in $\mathrm{p}=0.83$. E: Serum AA values $(\mu \mathrm{Mol} / \mathrm{L})$ of allogeneic HSCT patients suffering from GVHD or not $(\mathrm{p}=0.87)$. F: Serum ascorbic acid values of HSCT patients plotted to day of AA measurement after $\operatorname{HSCT}(\mathrm{p}=0.58)$. 


\section{Discussion and Conclusion}

We show that patients with a haematological malignancy, either treated with chemotherapy or with autologous or allogeneic HSCT have highly significant reduced serum AA levels compared to healthy controls. Recently was shown that patients receiving allogeneic HSCT have low serum AA levels in the acute phase post-transplantation ${ }^{10}$. We show that low AA levels are also present in the chronic phase post-transplantation. Furthermore, our findings are not limited to HSCT patients, but are also convincing for non-transplanted patients.

Human AA levels depend on dietary intake; therefore limited food intake following treatment may explain the observed vitamin C deficiency. Moreover, impaired metabolism is observed in cancer patients ${ }^{11}$. Although AA serum levels in the patients are low, it should be considered that intracellular levels of leukocytes might not be reflected by serum levels since immune cells might accumulate AA ${ }^{12}$. However, serum measurements are the current gold standard and it is accepted that values $<11.4 \mu \mathrm{Mol} / \mathrm{L}$ indicate vitamin $\mathrm{C}$ deficiency ${ }^{13}$, present in a substantial proportion of our patient group. Serum AA values of patients with GVHD after allogeneic HSCT - all with the gastrointestinal tract involved - were not further decreased compared to patients without GVHD, with the limitation of small group sizes and therefore with a small power to detect differences.

Since AA is crucial for immune function and for in vitro development and expansion of $\mathrm{T}$ and NK cells from stem cells ${ }^{6,7,12}$, it might be of clinical relevance to study the function and recovery of immune cells after treatment, its correlation to AA serum levels and the possible effect of vitamin $\mathrm{C}$ supplementation. Not only in patients with intensive chemotherapy regimens but also with less intensive regimens, where recovery of granulocytes is often a limiting factor for adequate dosing of chemotherapy regimens responsible for substantial morbidity. Whether oral vitamin $\mathrm{C}$ supplementation will give the desired increase in serum levels is an important concern. Therefore, it might be necessary to use intravenous supplementation as it can increases plasma AA levels by $\sim 30-70$ fold because of bypassing the renal absorptive system ${ }^{14}$.

In conclusion, we show that patients with haematological malignancies have significantly reduced serum AA values compared to healthy controls, possibly influencing their immune status. Additionally, AA deficiency might also account for other disease symptoms in these patients ${ }^{15}$. 


\section{Acknowledgements}

The authors would like to thank Rene van Oerle, Department of Biochemistry, Maastricht University for supplying the samples of the control group. This work was supported by a grant from the Dutch Cancer Society KWF: UM2010-4671 and with financial support from the Cancer Research Fund Limburg of the Health Foundation Limburg. 


\section{References}

1. Englard S, Seifter S. The biochemical functions of ascorbic acid. Annu Rev Nutr. 1986;6:365-406.

2. Monfort A, Wutz A. Breathing-in epigenetic change with vitamin C. EMBO Rep. 2013 Apr;14(4):337-46.

3. Strohle A, Wolters M, Hahn A. Micronutrients at the interface between inflammation and infection--ascorbic acid and calciferol. Part 2: calciferol and the significance of nutrient supplements. Inflamm Allergy Drug Targets. 2011 Feb;10(1):64-74.

4. Bosch M, Dhadda M, Hoegh-Petersen M, Liu Y, Hagel LM, Podgorny P, et al. Immune reconstitution after anti-thymocyte globulin-conditioned hematopoietic cell transplantation. Cytotherapy. 2012 Nov;14(10):1258-75.

5. Meek B, Cloosen S, Borsotti C, Van Elssen CH, Vanderlocht J, Schnijderberg MC, et al. In vitro-differentiated $\mathrm{T} /$ natural killer-cell progenitors derived from human CD34+ cells mature in the thymus. Blood. 2010 Jan 14;115(2):261-4.

6. Huijskens M, Walczak M, Koller N, Briedé J, Senden-Gijsbers B, Schnijderberg M, et al. Ascorbic acid induces development of double-positive $\mathrm{T}$ cells from human hematopoietic stem cells in the absence of stromal cells. Journal of Leukocyte Biology. 2014;In press.

7. Huijskens M WM, Sarkar S, Atrafi F, Senden-Gijsbers B, Tilanus M, Bos G, Wieten L, Germeraad W. Ascorbic acid promotes the generation and proliferation of NK cell populations in different culture systems applicable for NK cell therapy. Submitted. 2014.

8. Code for Proper Secondary Use of Human Tissue in the Netherlands. http://www.federa. org/sites/default/files/bijlagen/coreon/codepropersecondaryuseofhumantissue1_0.pfd. Accesed September 2014.

9. Schleicher RL, Carroll MD, Ford ES, Lacher DA. Serum vitamin C and the prevalence of vitamin C deficiency in the United States: 2003-2004 National Health and Nutrition Examination Survey (NHANES). Faseb J. 2009 Apr;23.

10. Nannya Y, Shinohara A, Ichikawa M, Kurokawa M. Serial profile of vitamins and trace elements during the acute phase of allogeneic stem cell transplantation. Biol Blood Marrow Transplant. 2014 Mar;20(3):430-4.

11. Nitenberg G, Raynard B. Nutritional support of the cancer patient: issues and dilemmas. Crit Rev Oncol Hematol. 2000 Jun;34(3):137-68.

12. Strohle A, Wolters M, Hahn A. Micronutrients at the interface between inflammation and infection--ascorbic acid and calciferol: part 1, general overview with a focus on ascorbic acid. Inflamm Allergy Drug Targets. 2011 Feb;10(1):54-63.

13. Schleicher RL, Carroll MD, Ford ES, Lacher DA. Serum vitamin C and the prevalence of vitamin C deficiency in the United States: 2003-2004 National Health and Nutrition Examination Survey (NHANES). Am J Clin Nutr. 2009 Nov 1;90(5):1252-63.

14. Padayatty SJ, Sun H, Wang Y, Riordan HD, Hewitt SM, Katz A, et al. Vitamin C 
pharmacokinetics: implications for oral and intravenous use. Ann Intern Med. 2004 Apr 6;140(7):533-7.

15. Kletzel M, Powers K, Hayes M. Scurvy: A new problem for patients with chronic GVHD involving mucous membranes; an easy problem to resolve. Pediatr Transplant. 2014 Aug;18(5):524-6. 


\section{General}

Discussion 


\section{Introduction}

The global growing incidence of cancer is an important problem. Cancer is one of the major causes of death in the Western world and even the second cause of death in developing countries. Even though cancer mortality is declining because of more effective early detection in combination with early treatment, the burden on society remains enormous. Because not all cancers can be cured with conventional methods like surgery, chemotherapy and radiotherapy, an urgent need for other therapies exists. More recently, other therapies like immunotherapy became of great interest. The major aims of immunotherapy are to trigger the patient's immune system to enhance the response against cancer cells or to supply immune cells or components to the patient providing a strong immune reaction after administration.

Great improvements have already been made in the field of immunotherapy. The most successful and applied cellular immunotherapy is haematopoietic stem cell transplantation (HSCT), where the complete immune system of the patient is deleted and rebuild from donor stem/progenitor cells. However, most other cellular immunotherapies are only effective in certain patient populations and many therapies are still in pre-clinical stages, leaving great room for improvement. Furthermore, the success of certain immunotherapies like allogeneic mismatched HSCT that can result in complete remission is hampered by post-treatment complications, in this case immune deficiency resulting in high morbidity and mortality because of uncommon and opportunistic infections.

Initially, we aimed to develop specific T cells against pathogens that are most common to cause infections after HSCT. Unfortunately, these attempts were unsuccessful as reported in chapter 4. Therefore, a stromal based system using TSt-4/DLL was set up that resulted in the generation of $\mathrm{T}$ cell progenitors capable of homing to the thymus and maturing into single positive $\mathrm{T}$ cells ${ }^{1}$. The major aim of this thesis is the development of a clinical grade culture method to produce $\mathrm{T}$ cell progenitors suitable for the adoptive transfer to immunocompromised patients after HSCT. The idea is that patients can be protected by an adequate but temporary mature $\mathrm{T}$ cell pool, obtained from in vitro generated $\mathrm{T}$ cell progenitors that mature and undergo selection in the thymus of the patient, and are capable of combating infections. This temporary $\mathrm{T}$ cell pool should be present until new definitive T cells have developed from the graft stem cells able to protect the patient from infections. 


\section{The unique environment of the thymus}

In chapter 2 we studied the network formation during normal thymus development in the mouse. We showed that hypoxia contributes to the mesenchymal network development required for the unique thymus structure. For many years it was believed that $\mathrm{T}$ cells can only develop in the three dimensional (3D) environment of the thymus. However, the overexpression of Delta like ligand (DLL) on stromal cells resulted in feeder cell based cultures capable of supporting in vitro $\mathrm{T}$ cell development ${ }^{1,2}$. In the OP-9 based system, even single positive mature $\mathrm{T}$ cells can develop ${ }^{3-5}$. Moreover, in chapter 5 we described the development of HSCs towards early $\mathrm{CD} 4^{+} \mathrm{CD}^{+}$double positive $\mathrm{T}$ cells even in the absence of stromal cells. This culture requires the presence of medium, cytokines, vitamin $\mathrm{C}$ and immobilized DLL4:Fc to mimic the thymus environment. However, in our system we were not able to generate mature single positive T cells expressing CD3 and TCR, indicating that the current culture components are not sufficient to fully replace the thymic environment. As shown recently in another culture setting, the addition of tetramers, anti-CD28, anti-CD3 and OP-9/ DL1 conditioned medium did result in a very small population of antigen specific $\mathrm{T}$ cells ${ }^{6}$, indicating that especially for proper positive and negative selection, the unique environment of the thymus is still required. Especially for the efficient generation of a $\mathrm{T}$ cell pool with a broad TCR repertoire, interactions with thymic epithelial cells and dendritic cells are essential.

\section{Generation of sufficient cell numbers for therapy by stem cell expansion}

As source of stem cells, both peripheral blood stem cells and more recently cord blood (CB) stem cells are used for HSCT. Stem/progenitor cell numbers obtained from peripheral blood via granulocyte-colony stimulating factor (G-CSF) mobilization and subsequent leukapheresis are much higher compared to $\mathrm{CB} C D 34^{+}$stem cells. For proper engraftment, injection of high numbers of stem/progenitor is required. Therefore, expansion of the relative small CB stem/ progenitor cell product before transplantation could lead to better engraftment. However, not only for HSCT but also for adoptive immune therapy, great cell numbers are required. So in general, in vitro stem cell expansion could improve the therapeutic applicability of certain adoptive cell based therapies.

In chapter 3, we show that a simple blockage of early B cell differentiation results in the generation of induced leukocyte stem cells; a stem cell like population with great expansion potential and the capacity to differentiate into leukocyte lineages. This straightforward method does not require the reprogramming or de-differentiation as is necessary to induce pluripotent stem (iPS) cells via introduced expression of four transcription factors, namely OCT4, SOX2 with KLF4 and c-Myc, or NANOG and LIN28 in mice and humans ${ }^{7,8}$. This 
system holds great promises to generate enough cells for adoptive cell therapy, as these cells still have the capacity to differentiate into mature immune cells.

Based on our findings in chapter 5 and $\mathbf{6}$ where we show that vitamin $C$ increases expansion of both T/NK progenitor cells and mature NK cells, the controlled addition of vitamin $\mathrm{C}$ to these experiments could have resulted in even more efficient stem cells expansion. Furthermore, Esteban et al. showed that the generation of iPS cells in both mouse and human is enhanced in the presence of vitamin $\mathrm{C}^{9}$.

In the current study, a retroviral approach to introduce Id3 is used, required for the block in B cell development resulting in induced leukocyte stem cells. For clinical application, a more safe method of Id 3 introduction has to be applied. This also holds true for the therapeutic usage of induced pluripotent stem cells. Genes that are retro- or lenti-virally introduced in the genome permanently integrate at a random place, which could cause harmful mutations potentially resulting in tumour formation. Moreover, gene therapy could result in inactivation or activation of host genes, resulting in tumour development as shown in patients ${ }^{10,11}$. Furthermore, integration could cause tumour formation in mice by reactivation of for example the oncogene c-Myc, used for iPS cell generation ${ }^{12}$. Current research focusses on methods to circumvent genome integration by the use of Adenovirus, Sendai virus, small molecules, direct protein introduction and mRNA delivery (reviewed in reference ${ }^{13}$ ). Although, the Sendai virus method results in comparable efficiency, the costs and labour intensiveness are major drawbacks. Unfortunately, the other methods show less efficiency than retro- and lentiviruses. Although these methods need further improvement and additional research, they are nonetheless more suitable for the use of clinical grade cell products than integrating methods.

In addition to our above mentioned stem/progenitor cell expansion method, other methods are of great interest. Initial stem cell expansion protocols using cytokine cocktails showed limited fold expansions, therefore other systems aiming at the expansion of haematopoietic stem cells are introduced. For example the DLL1 system, which results in expansion of progenitor cells. However, these cells favour rapid but transient myeloid reconstitution in vivo, making them not useful for e.g. T cell reconstitution and long-term repopulation ${ }^{14}$. Recently, the addition of StemRegenin 1 to this system resulted in a further increase in expansion of these stem/progenitor cells, however, it remains to be determined if this cell population has (myeloid and/or lymphoid) repopulation ability in humans ${ }^{15}$.

Other methods, for example copper chelators, mesenchymal co-cultures, aryl hydrocarbon receptor antagonists, PGE2 stimulation, small molecules, epigenetic reprogramming by valproic acid, have also been used resulting in an increase of stem/progenitor expansions ${ }^{16-20}$. However, most of these cell products are thus far only tested in mice. Therefore, clinical studies have to confirm the safety of these products and have to define if these expanded cell 
products result in clinical improvements. De Lima et al. already performed such clinical trial with copper chelator tetraethylenepentamine ex vivo expanded CB cells. Despite engraftment and safety, no improved clinical outcome/faster engraftment was observed ${ }^{19}$. Another clinical trial using a different expansion method, where a CB unit is co-cultured with mesenchymal stem cells and injected together with an non-manipulated $\mathrm{CB}$ unit into patients with an haematological malignancy, resulted in safe engraftment and resulted in faster neutrophil and platelet recovery ${ }^{20}$. Unfortunately, no improvement in long-term repopulation was observed; these cells only came from the non-manipulated CB unit. Although results are promising concerning early repopulation, further improvement of long-term repopulation is required.

Moreover, it has to be considered whether in vitro expanded cells still have sufficient engrafting and self-renewal ability in vivo. In addition to previous mentioned human data, some murine data is available concerning engraftment. It was shown that ex vivo expansion of $\mathrm{CB}$ progenitor cells impaired their repopulating ability in immune deficient mice ${ }^{21}$. However, details about the used expansion protocol and cell numbers are unfortunately not provided. Another study showed that engraftment and lineage potential of human stem/progenitor cells in immune deficient mice expanded in the presence of an aryl hydrocarbon receptor antagonist is reduced ${ }^{22}$.

One reason for reduced engraftment could be a limitation in the amount of cell divisions of expanded cells. Since the injected stem/progenitor cells have already divided multiple times in vitro, cells could potentially have aged too much to still have the capacity to proliferate in vivo where perhaps also less stimuli (e.g. cytokines) are present. During cell division, the end of chromosomes, named telomeres, shorten, enhancing cellular aging and eventually resulting in cell senescence ${ }^{23}$. In germ cells, stem cells and actively dividing cells a special reverse transcriptase called telomerase is active, synthesizing telomeres ${ }^{24}$. Human HSCs show telomerase activity and undergo telomere shortening upon aging ${ }^{25-27}$. It might be interesting to investigate the result of in vitro expansion on telomere length of stem/progenitor cells, and the influence of telomere length on the repopulation ability. Although influencing telomerase activity of cell products sounds tempting, this could result in tumour induction since $80 \%$ of human cancer overexpress telomerase ${ }^{28}$.

Recapitulated, evaluation of expanded stem/progenitor cells, with any produced method, should be addressed before clinical trials are started. Furthermore, it can be tested if these expanded cell products are suitable as starting material for the generation of specialized adoptive cellular products like (progenitor) T cells or NK cells. As mentioned previously, enormous cell numbers are required for immunotherapy. When expansion of, in our case, $\mathrm{T}$ and/or NK cells is not sufficient, first expansion of stem cells and subsequent differentiation of stem/progenitor cells could result in adequate cell numbers required for therapy. 


\section{T cell recovery after HSCT}

T cell reconstitution after HSCT can occur via thymus dependent and thymus independent mechanisms. The thymus independent reconstitution occurs via homeostatic peripheral expansion (HPE) of mature T cells that survived treatment regimen or expansion of mature $\mathrm{T}$ cells from the graft. However, the T cell repertoire of this population is limited. Furthermore, the high expansion induced by relative high homeostatic cytokine levels (because of low $\mathrm{T}$ cell counts and decreased consumption) and recognition of endogenous antigens results in a high number of apoptotic cells ${ }^{29}$. The HPE can provide some initial immune competence, but is insufficient for broad range and long-term protection ${ }^{30} . \mathrm{CD}^{+} \mathrm{T}$ cell recovery is less efficiently supported by HPE because of the increase in peripheral interleukin (IL)-7 levels, resulting in a prolonged $\mathrm{CD} 4^{+} \mathrm{T}$ cell cytopenia ${ }^{31}$. $\mathrm{CD}^{+} \mathrm{T}$ cells are more sensitive to HPE and therefore recover quicker, although the TCR repertoire and the number of naive T cells remain abnormal for months to years ${ }^{32}$.

Only de novo thymus dependent $\mathrm{T}$ cell generation can result in a naive $\mathrm{T}$ cell pool with a broad TCR repertoire. Unfortunately, delivery of progenitors to the thymus limits T-lineage reconstitution after transplantation ${ }^{33}$. Furthermore, the thymus structure is influenced by treatment regimen and GVHD ${ }^{34}$. Moreover, age associated thymic involution is accompanied by a decreased thymus size and function resulting in slower recovery after treatment, especially affecting older patients. The generation of naive T cells from the thymus requires 6-12 months in child patients and may take even up to several years in adult patients ${ }^{35,36}$.

\section{The skin explant system for the production of $\mathrm{T}$ cells}

For a long time it was believed that a $3 \mathrm{D}$ environment is required for $\mathrm{T}$ cell development. The skin-explant system uses human skin-derived fibroblasts and keratinocytes grown on a $3 \mathrm{D}$ scaffold, resembling the structure of the thymus. Although in theory, this system is applicable and also clinical grade because the patient's own skin cells can be used, we were not able to reproduce previously published results ${ }^{37}$, as reported in chapter 4 . We showed that keratinocytes did express the Notch ligand Jagged-1, however, expression of Delta like ligands (DLL), known to be required for proper $\mathrm{T}$ cell development was very low ${ }^{38}$. Furthermore, skin derived cells could lead to possible T cell contamination in this system as skin has been reported to be a large storage place for $\mathrm{T}$ cells ${ }^{39}$ that may be difficult to remove in the isolation procedure. More recently, two other studies reported on similar skin-explant systems to generate $\mathrm{T}$ cells ${ }^{40,41}$. One study used commercial available keratinocytes and fibroblasts ${ }^{41}$ and the other study showed that by using keratinocytes and fibroblast cell lines in a similar $3 \mathrm{D}$ system, T lineage development from CD $34^{+}$cells could be observed ${ }^{40}$. In this latter study, elevation of DLL4 expression on the keratinocyte cell lines when cultured on the matrix was observed in some experiments, what could contribute to the observed T lineage development in contrast to our culture with primary cells where very low DLL expression was observed. 
Strangely, T lineage development was only observed from $\mathrm{CB} \mathrm{CD}_{3} 4^{+}$cells and not from peripheral HSCs ${ }^{40}$. The first study only used peripheral HSCs, however, the purity of this population was around $80 \%$ when seeded in the culture, resulting in possible contaminating mature T cells from the donor's blood. Furthermore, in both studies the efficiency of T lineage development was very low and also not the complete range of $\mathrm{T}$ cell development was observed ${ }^{40,41}$. Unfortunately, these limitations in combination with difficult reproducibility, designate this system still inappropriate for the generation of sufficient cell numbers for adoptive $\mathrm{T}$ cell therapy.

\section{Adoptive $\mathrm{T}$ cell progenitor therapy}

Previously, we showed that G-CSF mobilized stem cells differentiate to proT2/preT T cells in co-culture with TSt-4/DLL4 feeder cells ${ }^{1}$. Importantly, we showed that these early T cell progenitors homed to the thymus in immune deficient mice faster than non-manipulated stem cells. We earlier argued that these cells are the ideal population to inject into patients, because of their retained thymus homing capacity and further education in the thymus to prevent the emergence of auto-reactive T cells.

In chapter 5, we developed a clinical applicable feeder free culture system resulting in a large progenitor population from both CB and G-CSF mobilized HSCs similar to progenitors obtained in co-culture with TSt-4/DLL4. It needs to be confirmed whether these cells are capable of homing to the thymus and complete their education in vivo. Therefore, a next step is to inject these cells into immune deficient mice. Based on the similar phenotype of both progenitor populations in vitro it is likely that the cells generated in the feeder free culture are also capable of this migration and maturation. In our previous study, we did not observe mature T cells in the periphery of the injected mice. Up till now, only few studies found mature $\mathrm{T}$ cells in the periphery after injection of T-cell progenitors ${ }^{42}$. This could be because of the thymic selection process where the majority of the thymocytes die because of neglect $(\sim 65 \%)$ or negative selection because of reaction to self $(\sim 90 \%){ }^{43}$. The injection of more cells could possibly result in adequate cell numbers surviving selection and being able to exit the thymus. However, the species difference between mice and men could also result in limited to no egress of human T cells from the murine thymus. Perhaps human thymocytes do not have the proper chemokine/integrin profile to egress from the murine thymus. It is debatable whether the peripheral $\mathrm{T}$ cells found in these studies came directly from the thymus, or developed in the periphery. It is shown that $\mathrm{T}$ cell maturation can occur in gut associated tissues after bone marrow transplantation in mice ${ }^{44}$. Unfortunately only limited studies are available on murine extrathymic $\mathrm{T}$ cell development and researchers remain skeptical about this phenomenon and its contribution to $\mathrm{T}$ cell immunity ${ }^{45}$. In humans, it is shown that tonsils can support early $\mathrm{T}$ cell development resulting in T/NK cell progenitors ${ }^{46}$. Also for humans, further research is required to confirm extrathymic $\mathrm{T}$ cell development, the contribution of these cells, and whether this knowledge can be used for future therapies generating the T cell pool of patients. 
One phase I clinical study with the transfer of CB CD $34^{+}$DLL1 culture derived progenitors showed enhanced engraftment and myeloid reconstitution ${ }^{14}$. However, the lack of improvement in $\mathrm{T}$ cell reconstitution in these patients indicates that these progenitor cells, only expressing CD7 (proT1), were probably not committed enough to the T cell lineage. We obtain more mature $\mathrm{T}$ cell progenitors (proT2/preT T cells) in a similar system, perhaps these cells could result in better $\mathrm{T}$ cell reconstitution.

The route of injection should also be considered. Intravenous injection of human $\mathrm{T}$ cell progenitors, which is used in several mouse studies, does result in thymus repopulation. Though, direct intrathymic injection could give better results. At least in mice, intrathymic injection of stem/progenitor cells in a bone marrow transplant setting results in the generation of peripheral mature SP T cells ${ }^{47}$. Moreover, in a severe combined immune deficient (SCID) mouse model, intrathymic injection of bone marrow progenitors resulted in long-term thymopoiesis while intravenous injection only resulted in short-term thymopoiesis, probably because of decreased thymic entry ${ }^{48}$.

In summary, when human $\mathrm{T}$ cells are indeed capable of migration to (when injected extrathymically) and maturing in the human thymus, it needs to be confirmed that enough cells will pass thymic selection and egress the thymus resulting in a diverse $T$ cell pool capable of exerting proper $\mathrm{T}$ cell immunity. Moreover, it needs to be determined if a single injection of $\mathrm{T}$ cell progenitors together with the transplant will result in sufficient improvement of thymopoiesis and $\mathrm{T}$ lineage recovery, or that multiple injections are required. Multiple injections could be required when cells show limited in vivo self-renewal capacity or expansion resulting in a limited $\mathrm{T}$ cell population insufficient to provide broad immunity.

\section{Other strategies to enhance T cell recovery after HSCT}

Besides $\mathrm{T}$ cell progenitor therapy, other therapies are currently under investigation aiming to enhance $\mathrm{T}$ cell recovery in patients with low $\mathrm{T}$ cell counts. Some therapies aim at adoptive cellular therapy, while others try to improve $\mathrm{T}$ cell production or expansion with cytokines and growth factors within the patient. Research also focusses on the improvement of thymopoiesis by targeting the thymus.

\section{Donor lymphocyte infusion}

Donor lymphocyte infusions (DLIs) have been broadly used for anti-tumour therapy, and to a lesser extent to provide immunity to pathogens after HSCT. Unfortunately this therapy is limited by the low frequencies of specific $\mathrm{T}$ cells for pathogens that often cause post-transplant infections. Furthermore, in a haplo-identical setting the occurrence of GVHD limits the use of these cells ${ }^{49}$. 
The depletion of alloreactive T cells, allodepletion, enhances the safety of DLI. Alloreactive donor T cells can be activated against major human leukocyte antigen (HLA)-incompatible antigens by mixed lymphocyte reactions (MLRs). These activated $\mathrm{T}$ cells upregulate specific molecules, for example CD25 or CD69, and can subsequently be removed or eliminated using antibody magnetic depletion, apoptosis induction, immunotoxin-conjugated antibodies or by photodepletion ${ }^{49}$. Some clinical trials using allodepleted $\mathrm{T}$ cells have already been performed in the last decades, whereby infusion of $8 \times 10^{5}$ allodepleted cells $/ \mathrm{kg}$ are found to be safe ${ }^{50}$. Additionally, 3 patients showed specific antiviral responses. However, another clinical trial with alloreactive depleted DLI resulted in severe GVHD in some patients ${ }^{51}$. A phase I clinical trial using photodepletion to remove alloreactive $\mathrm{T}$ cells, indicated that allodepleted DLI resulted in accelerated $\mathrm{T}$ cell reconstitution and decreased the incidence and severity of infections ${ }^{52}$. Our clinical group participated in a phase II study using the photodepletion technology. Unfortunately, this procedure failed because insufficient vital cell numbers could be given back to the patients (Kiadis Pharma, unpublished results). At present, a new clinical trial has started with improved technology. Stringent allodepletion is required to achieve safety. Especially when there is a large mismatch between donor and recipient, robust allodepletion is required, since only few alloreactive $\mathrm{T}$ cells $\left(<10^{5} / \mathrm{kg}\right)$ can already induce severe GVHD. In addition, suicide genes have been introduced in pre-clinical settings, for example inducible human caspase 9, that can be activated with small molecules to induce apoptosis for example when GVHD would be initiated in vivo ${ }^{53}$. Several clinical trials using the concept of suicide genes are performed, as reviewed in reference ${ }^{54}$, and are in general found to be safe. However, results are variable because of difficulties in standardizing the culture procedure. Interestingly, Vago and colleagues reported that $\mathrm{T}$ cell suicide gene therapy resulted in the recovery of thymic activity, contributing to immune reconstitution ${ }^{55}$. The selection of sufficient cell numbers for therapy remains a struggle, since only 10 percent or less of cells survive after allodepletion. Techniques increasing safety, like suicide genes, even further reduce these numbers.

Besides in vitro depletion of alloreactive $\mathrm{T}$ cells, a concept of in vivo depletion has been introduced into the clinic. After transplantation, cyclophosphamide is given to the patient, selectively depleting in vivo activated $\mathrm{T}$ cells. This technology has been successfully introduced in the context of haplo-identical transplantation where because of the HLA mismatch rapid in vivo activation of donor T cells, and therefore elimination of these $\mathrm{T}$ cells by cyclophosphamide, can be expected ${ }^{56-58}$. Two studies will soon start in our clinical department where cyclophosphamide will be administered to haplo-identical transplanted patients suffering from acute myeloid leukaemia and multiple myeloma. Furthermore, currently it is tested in the Netherlands whether this technology will also work in a transplantation setting with less extensive HLA mismatches (HOVON 96). Of course, it still needs to be proven that this concept will prevent GVHD caused by alloreactive T cells and will lead to accurate $\mathrm{T}$ cell reconstitution sufficient to overcome infectious related mortality after transplantation. 


\section{Specific cytotoxic T cells}

The adoptive transfer of ex vivo expanded $\mathrm{T}$ cells with pathogen specificity is another approach to generate immunity after HSCT. Especially cytotoxic T lymphocytes (CTLs) directed against Cytomegalovirus (CMV) and Epstein-Barr virus (EBV) are investigated. Clinical trials with CMV CTLs show that administration is safe and that also anti-viral responses are detected in certain patients ${ }^{59}$. Besides these encouraging results, responses decline after weeks resulting in only short-term protection and even reactivation of CMV occurred in some cases ${ }^{60}$. EBV specific therapy is successful to treat post-transplant viral EBV-associated lymphoproliferative disorders ${ }^{49}$. More recently, tri-virus specific CTLs against CMV, EBV and Adenovirus were developed. Infusion of these cells was safe and showed activity to all three viruses ${ }^{61}$. The presence of the antigen in vivo is very important for the efficiency of these therapies; otherwise fast decline in specific $\mathrm{T}$ cell levels occurs resulting in loss of protection. Furthermore, production time and complexity, competition of multiple antigens for the production of multi-viral therapy and the potential risk of GVHD caused by infused T cells are difficulties concerning this approach. Furthermore, the wide range of pathogens patients can encounter after HSCT requires the production of a large variety of pathogen specific $\mathrm{T}$ cells for infusion.

\section{Cytokines and growth factors for the stimulation of $\mathrm{T}$ cells and/or the thymus}

Several cytokines and growth factors are involved in peripheral $\mathrm{T}$ cell survival and expansion, and others in thymus development and regeneration and could therefore be used to enhance immunity after HSCT.

Keratinocyte growth factor (KGF), for example, is a fibroblast growth factor and induces proliferation of thymic epithelial cells (TECs) in the thymus ${ }^{62}$. KGF administration increases thymic cellularity in aged mice, furthermore administration to HSCT treated mice show an increase in naive $\mathrm{T}$ cells counts ${ }^{63,64}$. Additionally, KGF administration induces peripheral expansion of regulatory T cells in mice after transplantation ${ }^{65}$. Moreover, GVHD disease is ameliorated upon KGF administration before bone marrow transplantation ${ }^{66}$ and improves allogeneic bone marrow engraftment in mice ${ }^{67}$. A study in Rhesus Macaques confirmed the positive effect of KGF administration on thymopoiesis ${ }^{68}$. Clinical trials are performed to assess the effect of KGF in patients; mainly an ameliorating effect on mucositis has been observed as reviewed in reference ${ }^{69}$. After allogeneic HSCT no influence was observed on the incidence of GVHD, infections or mortality, indicating that the immune reconstitution of these patients was not improved ${ }^{70}$. Currently, additional clinical trials are ongoing investigating whether KGF administration improves thymic immune reconstitution following haplo-identical transplantation in patients.

In mice, Flt-3L enhances thymus dependent $\mathrm{T}$ cell regeneration and also enhances thymus recovery ${ }^{71,72}$. Moreover, Flt-3L administration resulted in better immunocompetence 
against murine CMV in bone marrow transplanted mice ${ }^{73}$. Also stem cell factor (SCF) was capable of improving thymopoiesis after stem cell transplantation in mice ${ }^{74}$. Unfortunately, combined administration of SCF and KGF in Rhesus Macaques resulted in severe adverse effects, including severe weight loss and respiratory failure ${ }^{68}$. Interestingly, IL-22 has recently been found to drive endogenous thymus regeneration in mice ${ }^{75}$. Further pre-clinical and clinical studies should address whether these cytokines are safe and can also stimulate human thymopoiesis after chemotherapy and/or HSCT.

The most studied cytokine concerning immune reconstitution is IL-7. Mutation in the IL-7 receptor results in severe combined immunodeficiency with absence of T cells. IL-7 is produced by stromal cells in the bone marrow and thymus, keratinocytes, intestinal epithelial cells and dendritic cells ${ }^{30,76}$. In the thymus, IL-7 is required for proliferation and survival, in the periphery it has proliferative and anti-apoptotic effects and is a regulator of $\mathrm{T}$ cell homeostasis ${ }^{77}$. Although an increase in peripheral IL-7 levels is already present during lymphopenia, therapies aim at far higher levels. Clinical trials have proven the safety of IL-7 administration and showed that IL-7 promoted expansion of peripheral T cells and increased TCR repertoire diversity in refractory cancer patients starting with a T cell count of 300cells/ $\mathrm{mm}^{3}{ }^{78,79}$. Perales and colleagues performed a clinical trial supplementing IL-7 in patients receiving HLA-matched allogeneic HSCT, also resulting in an increase of peripheral $\mathrm{T}$ cell counts ${ }^{80}$. Both studies did not result in increased thymus size and thymopoiesis. Because there was no change in TREC levels, it is thought that IL-7 administration had primarily an effect on peripheral expansion, especially on effector memory T cells. Further (randomized) studies are required to extend on these findings and determine if IL-7 treated patients show clinical benefits. Moreover, additional studies in patients treated with other types of HSCT (Haplo or CB) should be performed. One concern of this last example is that this therapy could contribute to GVHD, by inducing expansion of allogeneic T cells.

\section{Hormones and sex steroids influencing the thymus}

Administration of growth hormone $(\mathrm{GH})$ or insulin-like growth factor-1 (IGF-1) inverts thymic involution and supports TEC proliferation in mice ${ }^{81,82}$. In HIV-infected patients, GH administration increased thymus size, thymic output and augmented the number of naive $\mathrm{CD}^{+} \mathrm{T}$ cells ${ }^{83}$. Whether this therapy could also improve thymic cellularity and output in HSCT patients is currently under investigation.

One of the main causes of thymic involution is believed to be the increased production of sex steroids after puberty. Sex steroid ablation either by surgical or chemical (with antagonist against luteinizing hormone releasing hormone, LHRH-A) castration in aged mice increased thymic cellularity, improved thymic architecture and increased peripheral T cell counts ${ }^{84}$. Also in patients prior to receiving autologous or allogeneic HSCT, LHRH-A accelerated engraftment, augmented thymopoiesis and immune regeneration without causing GVHD 
85. Even though in the autologous HSCT setting an increase in disease-free survival was observed, unfortunately, there was no increase in patient survival. Further studies should address a longer follow up time (>12 months) and test whether different administration schemes could lead to an increase in patient survival.

\section{Thymus crafting}

The creation of a new thymus could result in the life long development of a naive polyclonal T cell repertoire after HSCT. Efforts have been made for example by placing specific murine TECs under the murine kidney capsule, resulting in the formation of a thymus, capable of producing T cells ${ }^{86,87}$. This specific TEC population expresses the MTS24 surface glycoprotein and specifies primordial TECs, especially abundant in embryonic thymi. Unfortunately, the human equivalent of these cells is still unknown. Thus far, human studies using foetal thymic tissue of cultured TECs transplanted in patients of allogeneic HSCT were unsuccessful 88. Recent studies have been more successful; here transplantation of cultured thymic fragments in DiGeorge patients resulted in mature T cells exerting immune responses to a variety of antigens ${ }^{89,90}$. However, patients remain immune deficient for at least 6 months after transplantation ${ }^{90}$. Unfortunately, human thymi are only limited available. Recently, also a system using vascularized tissue chambers was introduced. In mice, these chambers containing human thymic cells show murine and human $\mathrm{T}$ cell production ${ }^{91}$. However, this method is still in the pre-clinical phase. Furthermore, it needs to be considered that not only thymic atrophy limits thymopoiesis, but perhaps more critically a major limitation in the generation of $\mathrm{T}$ cells is the generation of thymic seeding progenitors ${ }^{33}$.

In conclusion, much progress in the field of $\mathrm{T}$ cell immune reconstitution is achieved. However, various therapies are still in a pre-clinical phase and current clinical trials still need additional follow up or additional studies before final conclusions can be drawn. Concerning the best approach, probably a combination of the discussed approaches will result in optimal $\mathrm{T}$ cell recovery. This approach should address both thymopoiesis, in combination with providing thymic seeding progenitors for example by adoptive $\mathrm{T}$ cell progenitor therapy.

Not only cancer patients receiving HSCT as part of their cancer therapy could benefit from therapies improving $\mathrm{T}$ cell reconstitution. Also other patients receiving HSCT for example as part of their auto-immune disease, SCID, amyloidosis, anemia, and thalassemia treatment could benefit from adoptive $\mathrm{T}$ cell progenitor therapy. Furthermore, it could be suitable for patients with decreased $\mathrm{T}$ cell immunity like patients with acquired immunodeficient syndrome (AIDS). 


\section{NK cell therapy}

Although the initial focus of this thesis was to develop a clinical grade T cell progenitor therapy, we also studied NK cells because of the positive effects observed on T cell progenitors and their expansion mediated by vitamin C. Adoptive NK cell therapy is not aimed to improve immune reconstitution but opted as alternative cancer therapy. Pre-clinical and clinical studies by our group ${ }^{92-94}$ and others have shown that, if infused in large numbers, NK cells can be used to eliminate malignant cells, reviewed in reference ${ }^{95}$. Interestingly, it was recently shown that in vivo regulatory $\mathrm{T}$ cell depletion improves acute myeloid leukaemia clearance by high-dose haplo-identical NK cell therapy ${ }^{96}$. As already mentioned previously, one option to produce sufficient cell numbers for therapy is to generate a large batch of stem/progenitor cells and subsequently differentiate them to the cells of interest. Another method is to expand the cells of interest directly. In chapter $\mathbf{6}$ we show that in the presence of vitamin $\mathrm{C}$ the expansion of both NK cells differentiated from stem/progenitor cells as well as mature NK cells is greatly enhanced without influencing their phenotype or cytotoxic capacity. However, the systems used in this study were not yet clinical applicable and therefore, further clinical translation is required. Currently, we are working with a closed bioreactor system to expand mature NK cells that are constantly exposed to fresh medium and IL-2. Potentially, vitamin C can also increase the expansion of NK cells in this system. It needs to be tested whether these cells, expanding in high folds, still have the proper NK cell phenotype and are able to exert their cytotoxic capacity in vitro and in vivo. Thereafter, clinical trials can be started to address the feasibility of this NK cell product in patients.

\section{Vitamin C}

In chapters 5 and $\mathbf{6}$ we show that ascorbic acid/vitamin $C$ has a pivotal effect on both $T$ and NK cell maturation and expansion. Vitamin C is not only important for the expansion of these cells, but also for the differentiation from HSCs into these cells. This is especially pronounced in $\mathrm{T}$ cell development, where a block in early development in the proT1 stage occurs in the absence of vitamin C. Finding this prominent role for vitamin $\mathrm{C}$ in in vitro lymphocyte development, we hypothesized that patients with low lymphocyte counts, for example after chemotherapy and/or stem cell transplantation might have low vitamin C levels. In chapter 7 we were able to confirm this hypothesis. Indeed, patients with haematological malignancies treated with chemotherapy and/or stem cell transplantation do have significantly reduced serum vitamin $\mathrm{C}$ levels persisting at least up to 1 year after treatment. Of course, further research is required to investigate whether there is a link between vitamin $C$ levels and lymphocyte counts. It might be of clinical relevance to study the function and recovery of immune cells after treatment in respect to vitamin $\mathrm{C}$ serum levels and the possible effect of vitamin $\mathrm{C}$ supplementation. Since vitamin $\mathrm{C}$ has many functions, patients could in general 
benefit from vitamin $\mathrm{C}$ supplementation as shown recently by Kletzel and colleagues who showed that 6 out of 19 patients with chronic GVHD suffered from vitamin C deficiency. Vitamin $\mathrm{C}$ supplementation of these patients resulted in a decrease in mucositis and in an increase of their ability to eat, improving patient's wellbeing ${ }^{97}$.

\section{Functions of vitamin C}

Vitamin C is required for multiple biochemical and physiological processes. For example in collagen synthesis, carnitine synthesis, serving as co-factor for norephinephrine production, being essential for the synthesis of catecholamines and cholesterol catabolism ${ }^{98}$. Furthermore, vitamin $\mathrm{C}$ is an important antioxidant, as it scavenges free radicals ${ }^{99}$. Humans are not able to synthesize vitamin $\mathrm{C}$ because of a lack of the enzyme gulonolactone oxidase and are therefore dependent on supplementation via their diet. Vitamin $\mathrm{C}$ deficiency is for example associated with fatigue, inflammation of the gums, scurvy, anemia, poor wound healing and infections ${ }^{98}$. Because of its water solubility, administration in high doses is generally non-toxic ${ }^{100}$.

\section{Vitamin $C$ and the immune system}

The vitamin $\mathrm{C}$ concentration in immune cells is 10-100 fold higher compared with serum ${ }^{101,} 102$ and rapidly decreases during infection ${ }^{103}$, suggesting an important role for vitamin C during infection. In murine studies, vitamin $\mathrm{C}$ improves resistance to infections caused by bacteria and viruses ${ }^{104}$, although the role for vitamin $\mathrm{C}$ in human infections is still debatable. Many studies are performed concerning the common cold, where vitamin $\mathrm{C}$ reduces the severity and duration of infection, however, it does not have a prophylactic effect ${ }^{105}$.

There is great uncertainty about the precise effect of vitamin $\mathrm{C}$ on immune functions. Unfortunately, implications are often generalized and based on single studies performed around the seventies. Here, some findings concerning vitamin $\mathrm{C}$ are listed. Vitamin $\mathrm{C}$ does have an effect on the cell mediated immune response in humans as investigated in Crohn's disease patients ${ }^{106}$. While in the latter study, no effect on the humoral response was observed, decreased IgG and IgM levels in elderly can be restored by vitamin C supplementation ${ }^{107}$. Vitamin $\mathrm{C}$ also influences neutrophil function by for example affecting chemotaxis and phagocytosis in mice ${ }^{108}$. Moreover, decreased phagocyte function of aged human neutrophils can be restored by vitamin C supplementation ${ }^{107}$. Furthermore, vitamin $\mathrm{C}$ stimulates the IL-12 production of murine DCs resulting in the differentiation of T helper cells ${ }^{109}$ and stimulates $\mathrm{CD}^{+}$memory $\mathrm{T}$ cell production ${ }^{110}$. After toxin chemical induced reduction of $\mathrm{NK}$, $\mathrm{T}$ and $\mathrm{B}$ cell function, vitamin $\mathrm{C}$ supplementation can restore cellular function in humans ${ }^{111}$. Additionally, vitamin $\mathrm{C}$ increases $\mathrm{T}$ cell proliferation in vitro ${ }^{112}$ and inhibits $\mathrm{T}$ cell apoptosis by decreasing their sensitivity to death signals ${ }^{113}$. An interesting finding is that although thymus and spleen tissue in general have moderate vitamin $\mathrm{C}$ levels ${ }^{103}$, patients supplemented with vitamin $\mathrm{C}$ have a larger thymus ${ }^{114}$. Unfortunately, no further studies concerning the thymus and vitamin $\mathrm{C}$ are conducted to our knowledge. 
The working mechanism of vitamin $\mathrm{C}$ concerning its role on immune cells is partially understood. Immune cells are very sensitive to oxidative stress because of their high content of fatty acids in their cell membranes and their reactive oxygen species (ROS) production ${ }^{115}$. Vitamin C can protect cells because of its antioxidant properties. Since vitamin C is involved in many different pathways and has many functions, it is highly unlikely that only its antioxidant capacity can result in a multitude of effects on the immune system. As we show in chapter 5, other antioxidants did not result in the improvement of $\mathrm{T}$ cell development. We showed that vitamin $\mathrm{C}$ seems to be involved in the citrulline/NO pathway in $\mathrm{T}$ cell progenitors, as its blockage resulted in less $\mathrm{T}$ cell development and proliferation. Additionally, Manning and colleagues hint for vitamin $\mathrm{C}$ as epigenetic regulator during murine $\mathrm{T}$ cell development ${ }^{116}$. Although there are quite some leads concerning vitamin C's function, further research is required to study how vitamin $\mathrm{C}$ precisely influences all these components of the immune system. This knowledge could result in further therapy strategies interfering with the immune system.

\section{Vitamin C supplementation}

Since Linus Pauling presented vitamin $C$ as a panacea in the early seventies, many supplementation studies have been performed. Because of its high safety profile and inexpensiveness, vitamin $\mathrm{C}$ is a very appealing supplement for the prevention or treatment of certain diseases.

As already mentioned before, vitamin $\mathrm{C}$ supplementation does not result in prophylaxis of the common cold, however, it reduces the severity and duration of infection ${ }^{105}$. However, when people are exposed to cold stress or extreme physical exercise, vitamin C supplementation does have a prophylactic effect ${ }^{105}$. For other infections, for example pneumonia, evidence at this moment is too weak to advocate for a prophylactic effect of vitamin $\mathrm{C}^{117}$.

Vitamin $\mathrm{C}$ is also tested as cancer therapy in patients. In several studies, intravenous administration of vitamin $C$ is used. With this method, plasma vitamin C levels can be increased by $\sim 30-70$ fold because of bypassing the renal absorptive system ${ }^{118}$. When present in such a high concentration, vitamin C's antioxidant role switches to a pro-oxidant role by producing the reactive oxygen species hydrogen peroxide ${ }^{119}$. Normal cells have multiple mechanisms to neutralize hydrogen peroxide, while tumour cells lack these mechanisms, making them vulnerable for high vitamin C concentrations ${ }^{119}$. Unfortunately also here, results are not conclusive yet, although some promising results are already achieved, reviewed in ${ }^{120}$.

In summary, the role of vitamin $\mathrm{C}$ in the immune system still needs to be thoroughly investigated. Above mentioned studies advocate that vitamin $\mathrm{C}$ at least influences the immune system. Together with our own findings, it supports our previous proposal to investigate the supplementation of HSCT patients with vitamin C to faster recover their immune system. 


\section{Conclusions}

Taken together, the results presented in this thesis contribute to the current progress in the field of immunology in relation to immune therapy. As described throughout this chapter, the discussed results require further research before our proposed cell therapies will be available in the clinic.

The current developed retroviral method blocking B lineage development resulted in the generation of leukocyte stem cells. Future research should focus on optimizing this method to a clinical applicable, non-integrating method. Furthermore, the long-term repopulation capability of ex vivo expanded stem and progenitor cells needs to be addressed.

We also described a clinical grade culture method to generate $\mathrm{T}$ cell progenitors from $\mathrm{CB}$ and G-CSF mobilized stem cells. Research should focus on the validation of adoptive $\mathrm{T}$ cell progenitor therapy in mice and humans; whether in vitro generated progenitors indeed mature to functional $\mathrm{T}$ cells in murine infection models. Subsequent human studies are required to verify the potential benefit of $\mathrm{T}$ cell progenitor therapy. Moreover, will these cells have a broad enough TCR repertoire to protect patients after HSCT from infections? Additionally, combinational therapies consisting of the enlargement of the thymic seeding progenitor population in combination with thymic rejuvenation strategies could be addressed.

In this thesis, we describe that vitamin $\mathrm{C}$ is important in both in vitro $\mathrm{T}$ and $\mathrm{NK}$ cell development and expansion. We also report that patients with haematological malignancies have decreased vitamin $\mathrm{C}$ levels compared to healthy controls. Therefore, it would be of great interest to investigate whether vitamin $\mathrm{C}$ supplementation can contribute to the immune reconstitution in patients receiving cancer therapy. 


\section{References}

1. Meek B, Cloosen S, Borsotti C, Van Elssen CH, Vanderlocht J, Schnijderberg MC, et al. In vitro-differentiated $\mathrm{T} /$ natural killer-cell progenitors derived from human CD34+ cells mature in the thymus. Blood. 2010 Jan 14;115(2):261-4.

2. Awong G, Herer E, Surh CD, Dick JE, La Motte-Mohs RN, Zuniga-Pflucker JC. Characterization in vitro and engraftment potential in vivo of human progenitor $\mathrm{T}$ cells generated from hematopoietic stem cells. Blood. 2009 Jul 30;114(5):972-82.

3. De Smedt M, Hoebeke I, Plum J. Human bone marrow CD34+ progenitor cells mature to T cells on OP9-DL1 stromal cell line without thymus microenvironment. Blood Cells Mol Dis. 2004 Nov-Dec;33(3):227-32.

4. Dervovic DD, Ciofani M, Kianizad K, Zuniga-Pflucker JC. Comparative and functional evaluation of in vitro generated to ex vivo CD8 T cells. J Immunol. 2012 Oct 1;189(7):341120.

5. Van Coppernolle S, Verstichel G, Timmermans F, Velghe I, Vermijlen D, De Smedt M, et al. Functionally mature CD4 and CD8 TCRalphabeta cells are generated in OP9-DL1 cultures from human CD34+ hematopoietic cells. J Immunol. 2009 Oct 15;183(8):4859-70.

6. Fernandez I, Ooi TP, Roy K. Generation of functional, antigen-specific CD8+ human T cells from cord blood stem cells using exogenous Notch and tetramer-TCR signaling. Stem Cells. 2014 Jan;32(1):93-104.

7. Takahashi K, Tanabe K, Ohnuki M, Narita M, Ichisaka T, Tomoda K, et al. Induction of pluripotent stem cells from adult human fibroblasts by defined factors. Cell. $2007 \mathrm{Nov}$ 30;131(5):861-72.

8. Yu J, Vodyanik MA, Smuga-Otto K, Antosiewicz-Bourget J, Frane JL, Tian S, et al. Induced pluripotent stem cell lines derived from human somatic cells. Science. 2007 Dec 21;318(5858):1917-20.

9. Esteban MA, Wang T, Qin B, Yang J, Qin D, Cai J, et al. Vitamin C enhances the generation of mouse and human induced pluripotent stem cells. Cell Stem Cell. 2010 Jan 8;6(1):71-9.

10. Check E. Gene therapy put on hold as third child develops cancer. Nature. 2005 Feb 10;433(7026):561.

11. Hacein-Bey-Abina S, Von Kalle C, Schmidt M, McCormack MP, Wulffraat N, Leboulch P, et al. LMO2-associated clonal T cell proliferation in two patients after gene therapy for SCID-X1. Science. 2003 Oct 17;302(5644):415-9.

12. Okita K, Ichisaka T, Yamanaka S. Generation of germline-competent induced pluripotent stem cells. Nature. 2007 Jul 19;448(7151):313-7.

13. Rao MS, Malik N. Assessing iPSC reprogramming methods for their suitability in translational medicine. J Cell Biochem. 2012 Oct;113(10):3061-8.

14. Delaney C, Heimfeld S, Brashem-Stein C, Voorhies H, Manger RL, Bernstein ID. Notchmediated expansion of human cord blood progenitor cells capable of rapid myeloid 
reconstitution. Nat Med. 2010 Feb;16(2):232-6.

15. Dahlberg A, Brashem-Stein C, Delaney C, Bernstein ID. Enhanced generation of cord blood hematopoietic stem and progenitor cells by culture with StemRegenin1 and Delta1. Leukaemia. 2014 Jun 6.

16. Boitano AE, Wang J, Romeo R, Bouchez LC, Parker AE, Sutton SE, et al. Aryl hydrocarbon receptor antagonists promote the expansion of human hematopoietic stem cells. Science. 2010 Sep 10;329(5997):1345-8.

17. Nishino T, Miyaji K, Ishiwata N, Arai K, Yui M, Asai Y, et al. Ex vivo expansion of human hematopoietic stem cells by a small-molecule agonist of c-MPL. Exp Hematol. 2009 Nov;37(11):1364-77 e4.

18. Chaurasia P, Gajzer DC, Schaniel C, D’Souza S, Hoffman R. Epigenetic reprogramming induces the expansion of cord blood stem cells. J Clin Invest. 2014 Jun 2;124(6):2378-95.

19. de Lima M, McMannis J, Gee A, Komanduri K, Couriel D, Andersson BS, et al. Transplantation of ex vivo expanded cord blood cells using the copper chelator tetraethylenepentamine: a phase I/II clinical trial. Bone Marrow Transplant. 2008 May;41(9):771-8.

20. de Lima M, McNiece I, Robinson SN, Munsell M, Eapen M, Horowitz M, et al. Cordblood engraftment with ex vivo mesenchymal-cell coculture. N Engl J Med. 2012 Dec 13;367(24):2305-15.

21. Holmes T, Yan F, Ko KH, Nordon R, Song E, O’Brien TA, et al. Ex vivo expansion of cord blood progenitors impairs their short-term and long-term repopulating activity associated with transcriptional dysregulation of signalling networks. Cell Prolif. 2012 Jun;45(3):266-78.

22. Gu A, Torres-Coronado M, Tran CA, Vu H, Epps EW, Chung J, et al. Engraftment and Lineage Potential of Adult Hematopoietic Stem and Progenitor Cells Is Compromised Following Short-Term Culture in the Presence of an Aryl Hydrocarbon Receptor Antagonist. Hum Gene Ther Methods. 2014 Aug;25(4):221-31.

23. Saeed H, Iqtedar M. Stem cell function and maintenance - ends that matter: role of telomeres and telomerase. J Biosci. 2013 Sep;38(3):641-9.

24. Kassem M, Abdallah BM, Yu Z, Ditzel N, Burns JS. The use of hTERT-immortalized cells in tissue engineering. Cytotechnology. 2004 Jun;45(1-2):39-46.

25. Vaziri H, Dragowska W, Allsopp RC, Thomas TE, Harley CB, Lansdorp PM. Evidence for a mitotic clock in human hematopoietic stem cells: loss of telomeric DNA with age. Proc Natl Acad Sci U S A. 1994 Oct 11;91(21):9857-60.

26. Chiu CP, Dragowska W, Kim NW, Vaziri H, Yui J, Thomas TE, et al. Differential expression of telomerase activity in hematopoietic progenitors from adult human bone marrow. Stem Cells. 1996 Mar;14(2):239-48.

27. Morrison SJ, Prowse KR, Ho P, Weissman IL. Telomerase activity in hematopoietic cells is associated with self-renewal potential. Immunity. $1996 \mathrm{Sep}$;5(3):207-16.

28. Satyanarayana A, Manns MP, Rudolph KL. Telomeres, telomerase and cancer: an endless search to target the ends. Cell Cycle. 2004 Sep;3(9):1138-50.

29. Williams KM, Hakim FT, Gress RE. T cell immune reconstitution following 
lymphodepletion. Semin Immunol. 2007 Oct;19(5):318-30.

30. Fry TJ, Mackall CL. Immune reconstitution following hematopoietic progenitor cell transplantation: challenges for the future. Bone Marrow Transplant. 2005 Mar;35 Suppl 1:S53-7.

31. Guimond M, Veenstra RG, Grindler DJ, Zhang H, Cui Y, Murphy RD, et al. Interleukin 7 signaling in dendritic cells regulates the homeostatic proliferation and niche size of CD4+ T cells. Nat Immunol. 2009 Feb;10(2):149-57.

32. Mackall CL, Fleisher TA, Brown MR, Andrich MP, Chen CC, Feuerstein IM, et al. Distinctions between $\mathrm{CD8}+$ and $\mathrm{CD} 4+\mathrm{T}$-cell regenerative pathways result in prolonged $\mathrm{T}$-cell subset imbalance after intensive chemotherapy. Blood. 1997 May 15;89(10):3700-7.

33. Zlotoff DA, Zhang SL, De Obaldia ME, Hess PR, Todd SP, Logan TD, et al. Delivery of progenitors to the thymus limits $\mathrm{T}$-lineage reconstitution after bone marrow transplantation. Blood. 2011 Aug 18;118(7):1962-70.

34. Krenger W, Blazar BR, Hollander GA. Thymic T-cell development in allogeneic stem cell transplantation. Blood. 2011 Jun 23;117(25):6768-76.

35. Hakim FT, Memon SA, Cepeda R, Jones EC, Chow CK, Kasten-Sportes C, et al. Agedependent incidence, time course, and consequences of thymic renewal in adults. J Clin Invest. 2005 Apr;115(4):930-9.

36. Klein AK, Patel DD, Gooding ME, Sempowski GD, Chen BJ, Liu C, et al. T-Cell recovery in adults and children following umbilical cord blood transplantation. Biol Blood Marrow Transplant. 2001;7(8):454-66.

37. Clark RA, Yamanaka K, Bai M, Dowgiert R, Kupper TS. Human skin cells support thymusindependent T cell development. J Clin Invest. 2005 Nov;115(11):3239-49.

38. Meek B, Van Elssen CH, Huijskens MJ, van der Stegen SJ, Tonnaer S, Lumeij SB, et al. T cells fail to develop in the human skin-cell explants system; an inconvenient truth. BMC Immunol. 2011;12:17.

39. Clark RA, Chong B, Mirchandani N, Brinster NK, Yamanaka K, Dowgiert RK, et al. The vast majority of CLA+ T cells are resident in normal skin. J Immunol. 2006 Apr 1;176(7):4431-9.

40. Lapenna A, C BL, Kapeni C, Aspinall R. A simple model system enabling human CD34(+) cells to undertake differentiation towards T cells. PLoS One. 2013;8(7):e69572.

41. Palamaro L, Guarino V, Scalia G, Antonini D, De Falco L, Bianchino G, et al. Human skinderived keratinocytes and fibroblasts co-cultured on 3D poly epsilon-caprolactone scaffold support in vitro HSC differentiation into T-lineage committed cells. Int Immunol. 2013 Dec;25(12):703-14.

42. Eyrich M, Schreiber SC, Wollny G, Ziegler H, Schlenker R, Koch-Buttner K, et al. Predifferentiated human committed T-lymphoid progenitors promote peripheral T-cell reconstitution after stem cell transplantation in immunodeficient mice. Eur J Immunol. 2011 Dec;41(12):3596-603.

43. Sawicka M, Stritesky GL, Reynolds J, Abourashchi N, Lythe G, Molina-Paris C, et al. From pre-DP, post-DP, SP4, and SP8 Thymocyte Cell Counts to a Dynamical Model of Cortical 
and Medullary Selection. Front Immunol. 2014;5:19.

44. Holland AM, Zakrzewski JL, Tsai JJ, Hanash AM, Dudakov JA, Smith OM, et al. Extrathymic development of murine T cells after bone marrow transplantation. J Clin Invest. $2012 \mathrm{Dec}$ 3;122(12):4716-26.

45. Sun W, Hu ZW. Making T cells functional: a new solution for the athymic BMT recipients. Acta Pharmacol Sin. 2013 Feb;34(2):189-90.

46. McClory S, Hughes T, Freud AG, Briercheck EL, Martin C, Trimboli AJ, et al. Evidence for a stepwise program of extrathymic $\mathrm{T}$ cell development within the human tonsil. J Clin Invest. 2012 Apr 2;122(4):1403-15.

47. Tuckett AZ, Thornton RH, Shono Y, Smith OM, Levy ER, Kreines FM, et al. Image-guided intrathymic injection of multipotent stem cells supports lifelong T-cell immunity and facilitates targeted immunotherapy. Blood. 2014 May 1;123(18):2797-805.

48. Vicente R, Adjali O, Jacquet C, Zimmermann VS, Taylor N. Intrathymic transplantation of bone marrow-derived progenitors provides long-term thymopoiesis. Blood. 2010 Mar 11;115(10):1913-20.

49. Leen AM, Tripic T, Rooney CM. Challenges of $\mathrm{T}$ cell therapies for virus-associated diseases after hematopoietic stem cell transplantation. Expert Opin Biol Ther. 2010 Mar;10(3):33751.

50. Andre-Schmutz I, Le Deist F, Hacein-Bey-Abina S, Vitetta E, Schindler J, Chedeville G, et al. Immune reconstitution without graft-versus-host disease after haemopoietic stem-cell transplantation: a phase 1/2 study. Lancet. 2002 Jul 13;360(9327):130-7.

51. Solomon SR, Mielke S, Savani BN, Montero A, Wisch L, Childs R, et al. Selective depletion of alloreactive donor lymphocytes: a novel method to reduce the severity of graft-versushost disease in older patients undergoing matched sibling donor stem cell transplantation. Blood. 2005 Aug 1;106(3):1123-9.

52. Roy D-C, Lachance S, Kiss T, Cohen S, Busque L, Fish D, et al. Haploidentical Stem Cell Transplantation: High Doses of Alloreactive-T Cell Depleted Donor Lymphocytes Administered Post-Transplant Decrease Infections and Improve Survival without Causing Severe Gvhd. ASH Annual Meeting Abstracts. 2009 November 20, 2009;114(22):512-.

53. Tey SK, Dotti G, Rooney CM, Heslop HE, Brenner MK. Inducible caspase 9 suicide gene to improve the safety of allodepleted $\mathrm{T}$ cells after haploidentical stem cell transplantation. Biol Blood Marrow Transplant. 2007 Aug;13(8):913-24.

54. Bonini C, Bondanza A, Perna SK, Kaneko S, Traversari C, Ciceri F, et al. The suicide gene therapy challenge: how to improve a successful gene therapy approach. Mol Ther. 2007 Jul;15(7):1248-52.

55. Vago L, Oliveira G, Bondanza A, Noviello M, Soldati C, Ghio D, et al. T-cell suicide gene therapy prompts thymic renewal in adults after hematopoietic stem cell transplantation. Blood. 2012 Aug 30;120(9):1820-30.

56. Thakar MS, Bonfim C, Sandmaier BM, O’Donnell P, Ribeiro L, Gooley T, et al. Cyclophosphamide-based in vivo T-cell depletion for HLA-haploidentical transplantation 
in Fanconi anemia. Pediatr Hematol Oncol. 2012 Sep;29(6):568-78.

57. Munchel A, Kesserwan C, Symons HJ, Luznik L, Kasamon YL, Jones RJ, et al. Nonmyeloablative, HLA-haploidentical bone marrow transplantation with high dose, post-transplantation cyclophosphamide. Pediatr Rep. 2011 Jun 22;3 Suppl 2:e15.

58. Raiola AM, Dominietto A, Ghiso A, Di Grazia C, Lamparelli T, Gualandi F, et al. Unmanipulated haploidentical bone marrow transplantation and posttransplantation cyclophosphamide for hematologic malignancies after myeloablative conditioning. Biol Blood Marrow Transplant. 2013 Jan;19(1):117-22.

59. Micklethwaite KP, Clancy L, Sandher U, Hansen AM, Blyth E, Antonenas V, et al. Prophylactic infusion of cytomegalovirus-specific cytotoxic T lymphocytes stimulated with Ad5f35pp65 gene-modified dendritic cells after allogeneic hemopoietic stem cell transplantation. Blood. 2008 Nov 15;112(10):3974-81.

60. Peggs KS, Verfuerth S, Pizzey A, Khan N, Guiver M, Moss PA, et al. Adoptive cellular therapy for early cytomegalovirus infection after allogeneic stem-cell transplantation with virusspecific T-cell lines. Lancet. 2003 Oct 25;362(9393):1375-7.

61. Leen AM, Christin A, Myers GD, Liu H, Cruz CR, Hanley PJ, et al. Cytotoxic T lymphocyte therapy with donor $\mathrm{T}$ cells prevents and treats adenovirus and Epstein-Barr virus infections after haploidentical and matched unrelated stem cell transplantation. Blood. 2009 Nov 5;114(19):4283-92.

62. Rossi SW, Jeker LT, Ueno T, Kuse S, Keller MP, Zuklys S, et al. Keratinocyte growth factor (KGF) enhances postnatal T-cell development via enhancements in proliferation and function of thymic epithelial cells. Blood. 2007 May 1;109(9):3803-11.

63. Min D, Panoskaltsis-Mortari A, Kuro OM, Hollander GA, Blazar BR, Weinberg KI. Sustained thymopoiesis and improvement in functional immunity induced by exogenous KGF administration in murine models of aging. Blood. 2007 Mar 15;109(6):2529-37.

64. Min D, Taylor PA, Panoskaltsis-Mortari A, Chung B, Danilenko DM, Farrell C, et al. Protection from thymic epithelial cell injury by keratinocyte growth factor: a new approach to improve thymic and peripheral T-cell reconstitution after bone marrow transplantation. Blood. 2002 Jun 15;99(12):4592-600.

65. Bruinsma M, van Soest PL, Leenen PJ, Lambrecht BN, Cupedo T, Lowenberg B, et al. Keratinocyte growth factor induces expansion of murine peripheral CD4+Foxp3+ regulatory T cells and increases their thymic output. J Immunol. 2007 Dec 1;179(11):742430.

66. Panoskaltsis-Mortari A, Lacey DL, Vallera DA, Blazar BR. Keratinocyte growth factor administered before conditioning ameliorates graft-versus-host disease after allogeneic bone marrow transplantation in mice. Blood. 1998 Nov 15;92(10):3960-7.

67. Bruinsma M, van Soest PL, Leenen PJ, Lowenberg B, Cornelissen JJ, Braakman E. Keratinocyte growth factor improves allogeneic bone marrow engraftment through a CD4+Foxp3+ regulatory T cell-dependent mechanism. J Immunol. 2009 Jun 15;182(12):7364-9.

68. Wils EJ, Aerts-Kaya FS, Rombouts EJ, van Mourik I, Rijken-Schelen A, Visser TP, et al. 
Keratinocyte growth factor and stem cell factor to improve thymopoiesis after autologous CD34+ cell transplantation in rhesus macaques. Biol Blood Marrow Transplant. 2012 Jan;18(1):55-65.

69. Vadhan-Raj S, Goldberg JD, Perales MA, Berger DP, van den Brink MR. Clinical applications of palifermin: amelioration of oral mucositis and other potential indications. J Cell Mol Med. 2013 Nov;17(11):1371-84.

70. Levine JE, Blazar BR, DeFor T, Ferrara JL, Weisdorf DJ. Long-term follow-up of a phase I/ II randomized, placebo-controlled trial of palifermin to prevent graft-versus-host disease (GVHD) after related donor allogeneic hematopoietic cell transplantation (HCT). Biol Blood Marrow Transplant. 2008 Sep;14(9):1017-21.

71. Fry TJ, Sinha M, Milliron M, Chu YW, Kapoor V, Gress RE, et al. Flt3 ligand enhances thymic-dependent and thymic-independent immune reconstitution. Blood. 2004 Nov 1;104(9):2794-800.

72. Kenins L, Gill JW, Boyd RL, Hollander GA, Wodnar-Filipowicz A. Intrathymic expression of Flt3 ligand enhances thymic recovery after irradiation. J Exp Med. 2008 Mar 17;205(3):52331.

73. Wils EJ, Braakman E, Verjans GM, Rombouts EJ, Broers AE, Niesters HG, et al. Flt3 ligand expands lymphoid progenitors prior to recovery of thymopoiesis and accelerates $\mathbf{T}$ cell reconstitution after bone marrow transplantation. J Immunol. 2007 Mar 15;178(6):3551-7.

74. Wils EJ, Rombouts EJ, van Mourik I, Spits H, Legrand N, Braakman E, et al. Stem cell factor consistently improves thymopoiesis after experimental transplantation of murine or human hematopoietic stem cells in immunodeficient mice. J Immunol. 2011 Sep 15;187(6):2974-81.

75. Dudakov JA, Hanash AM, Jenq RR, Young LF, Ghosh A, Singer NV, et al. Interleukin-22 drives endogenous thymic regeneration in mice. Science. 2012 Apr 6;336(6077):91-5.

76. Tal N, Shochat C, Geron I, Bercovich D, Izraeli S. Interleukin 7 and thymic stromal lymphopoietin: from immunity to leukaemia. Cell Mol Life Sci. 2014 Feb;71(3):365-78.

77. Mackall CL, Fry TJ, Gress RE. Harnessing the biology of IL-7 for therapeutic application. Nat Rev Immunol. 2011 May;11(5):330-42.

78. Sportes C, Babb RR, Krumlauf MC, Hakim FT, Steinberg SM, Chow CK, et al. Phase I study of recombinant human interleukin-7 administration in subjects with refractory malignancy. Clin Cancer Res. 2010 Jan 15;16(2):727-35.

79. Sportes C, Hakim FT, Memon SA, Zhang H, Chua KS, Brown MR, et al. Administration of rhIL-7 in humans increases in vivo TCR repertoire diversity by preferential expansion of naive T cell subsets. J Exp Med. 2008 Jul 7;205(7):1701-14.

80. Perales MA, Goldberg JD, Yuan J, Koehne G, Lechner L, Papadopoulos EB, et al. Recombinant human interleukin-7 (CYT107) promotes T-cell recovery after allogeneic stem cell transplantation. Blood. 2012 Dec 6;120(24):4882-91.

81. Chu YW, Schmitz S, Choudhury B, Telford W, Kapoor V, Garfield S, et al. Exogenous insulinlike growth factor 1 enhances thymopoiesis predominantly through thymic epithelial cell 
expansion. Blood. 2008 Oct 1;112(7):2836-46.

82. Clark R. The somatogenic hormones and insulin-like growth factor-1: stimulators of lymphopoiesis and immune function. Endocr Rev. 1997 Apr;18(2):157-79.

83. Napolitano LA, Schmidt D, Gotway MB, Ameli N, Filbert EL, Ng MM, et al. Growth hormone enhances thymic function in HIV-1-infected adults. J Clin Invest. 2008 Mar;118(3):108598.

84. Heng TS, Goldberg GL, Gray DH, Sutherland JS, Chidgey AP, Boyd RL. Effects of castration on thymocyte development in two different models of thymic involution. J Immunol. 2005 Sep 1;175(5):2982-93.

85. Sutherland JS, Spyroglou L, Muirhead JL, Heng TS, Prieto-Hinojosa A, Prince HM, et al. Enhanced immune system regeneration in humans following allogeneic or autologous hemopoietic stem cell transplantation by temporary sex steroid blockade. Clin Cancer Res. 2008 Feb 15;14(4):1138-49.

86. Bennett AR, Farley A, Blair NF, Gordon J, Sharp L, Blackburn CC. Identification and characterization of thymic epithelial progenitor cells. Immunity. 2002 Jun;16(6):803-14.

87. Gill J, Malin M, Hollander GA, Boyd R. Generation of a complete thymic microenvironment by MTS24(+) thymic epithelial cells. Nat Immunol. 2002 Jul;3(7):635-42.

88. Atkinson K, Storb R, Ochs HD, Goehle S, Sullivan KM, Witherspoon RP, et al. Thymus transplantation after allogeneic bone marrow graft to prevent chronic graft-versus-host disease in humans. Transplantation. 1982 Feb;33(2):168-73.

89. Markert ML, Sarzotti M, Ozaki DA, Sempowski GD, Rhein ME, Hale LP, et al. Thymus transplantation in complete DiGeorge syndrome: immunologic and safety evaluations in 12 patients. Blood. 2003 Aug 1;102(3):1121-30.

90. Markert ML, Devlin BH, Alexieff MJ, Li J, McCarthy EA, Gupton SE, et al. Review of 54 patients with complete DiGeorge anomaly enrolled in protocols for thymus transplantation: outcome of 44 consecutive transplants. Blood. 2007 May 15;109(10):4539-47.

91. Seach N, Mattesich M, Abberton K, Matsuda K, Tilkorn DJ, Rophael J, et al. Vascularized tissue engineering mouse chamber model supports thymopoiesis of ectopic thymus tissue grafts. Tissue Eng Part C Methods. 2010 Jun;16(3):543-51.

92. Sarkar S, Germeraad WT, Rouschop KM, Steeghs EM, van Gelder M, Bos GM, et al. Hypoxia induced impairment of NK cell cytotoxicity against multiple myeloma can be overcome by IL-2 activation of the NK cells. PLoS One. 2013;8(5):e64835.

93. Sarkar S, Van Gelder M, Willy Xu Y, Rouschop K, Groen R, Schouten H, et al. Optimal selection of Natural Killer cells to kill myeloma: the role of HLA-E and NKG2A. In submission. 2014.

94. Frings PW, Van Elssen CH, Wieten L, Matos C, Hupperets PS, Schouten HC, et al. Elimination of the chemotherapy resistant subpopulation of $4 \mathrm{~T} 1$ mouse breast cancer by haploidentical NK cells cures the vast majority of mice. Breast Cancer Res Treat. 2011 Dec;130(3):773-81.

95. Cheng M, Chen Y, Xiao W, Sun R, Tian Z. NK cell-based immunotherapy for malignant diseases. Cell Mol Immunol. 2013 May;10(3):230-52. 
96. Bachanova V, Cooley S, Defor TE, Verneris MR, Zhang B, McKenna DH, et al. Clearance of acute myeloid leukaemia by haploidentical natural killer cells is improved using IL-2 diphtheria toxin fusion protein. Blood. 2014 Jun 19;123(25):3855-63.

97. Kletzel M, Powers K, Hayes M. Scurvy: A new problem for patients with chronic GVHD involving mucous membranes; an easy problem to resolve. Pediatr Transplant. 2014 Aug;18(5):524-6.

98. Chambial S, Dwivedi S, Shukla KK, John PJ, Sharma P. Vitamin C in disease prevention and cure: an overview. Indian J Clin Biochem. 2013 Oct;28(4):314-28.

99. Arrigoni O, De Tullio MC. Ascorbic acid: much more than just an antioxidant. Biochim Biophys Acta. 2002 Jan 15;1569(1-3):1-9.

100. Johnston CS. Biomarkers for establishing a tolerable upper intake level for vitamin C. Nutr Rev. 1999 Mar;57(3):71-7.

101. Moser U. Uptake of ascorbic acid by leukocytes. Ann N Y Acad Sci. 1987;498:200-15.

102. Strohle A, Wolters M, Hahn A. Micronutrients at the interface between inflammation and infection--ascorbic acid and calciferol. Part 2: calciferol and the significance of nutrient supplements. Inflamm Allergy Drug Targets. 2011 Feb;10(1):64-74.

103. Thomas WR, Holt PG. Vitamin C and immunity: an assessment of the evidence. Clin Exp Immunol. 1978 May;32(2):370-9.

104. Hemila H. Vitamin C supplementation and the common cold--was Linus Pauling right or wrong? Int J Vitam Nutr Res. 1997;67(5):329-35.

105. Hemila H, Chalker E. Vitamin C for preventing and treating the common cold. Cochrane Database Syst Rev. 2013;1:CD000980.

106. Animashaun A, Kelleher J, Heatley RV, Trejdosiewicz LK, Losowsky MS. The effect of zinc and vitamin $\mathrm{C}$ supplementation on the immune status of patients with Crohn's disease. Clin Nutr. 1990 Jun;9(3):137-46.

107. Jayachandran M, Rani PJA, Arivazhagan P, Panneerselvam C. Neutrophil Phagocytic Function and Humoral Immune Response with Reference to Ascorbate Supplementation in Aging Humans. J Anti-Aging Med. 2000;3:37-42.

108. Goldschmidt MC. Reduced bactericidal activity in neutrophils from scorbutic animals and the effect of ascorbic acid on these target bacteria in vivo and in vitro. Am J Clin Nutr. 1991 Dec;54(6 Suppl):1214S-20S.

109. Jeong YJ, Hong SW, Kim JH, Jin DH, Kang JS, Lee WJ, et al. Vitamin C-treated murine bone marrow-derived dendritic cells preferentially drive naive $\mathrm{T}$ cells into Th1 cells by increased IL-12 secretions. Cell Immunol. 2011;266(2):192-9.

110. Jeong YJ, Kim JH, Hong JM, Kang JS, Kim HR, Lee WJ, et al. Vitamin C treatment of mouse bone marrow-derived dendritic cells enhanced CD8(+) memory $\mathrm{T}$ cell production capacity of these cells in vivo. Immunobiology. 2014 Jul;219(7):554-64.

111. Heuser G, Vojdani A. Enhancement of natural killer cell activity and T and B cell function by buffered vitamin $\mathrm{C}$ in patients exposed to toxic chemicals: the role of protein kinase-C. Immunopharmacol Immunotoxicol. 1997 Aug;19(3):291-312. 
112. Molina N, Morandi AC, Bolin AP, Otton R. Comparative effect of fucoxanthin and vitamin $\mathrm{C}$ on oxidative and functional parameters of human lymphocytes. Int Immunopharmacol. 2014 Sep;22(1):41-50.

113. Campbell JD, Cole M, Bunditrutavorn B, Vella AT. Ascorbic acid is a potent inhibitor of various forms of T cell apoptosis. Cell Immunol. 1999 May 25;194(1):1-5.

114. Dieter MP. Further studies on the relationship between vitamin $\mathrm{C}$ and thymic humoral factor. Proc Soc Exp Biol Med. 1971 Jan;136(1):316-22.

115. Pavlovic V, Sarac M. A short overview of vitamin C and selected cells of the immune system. Central European Journal of Medicine. 2011;6(1):1-10.

116. Manning J, Mitchell B, Appadurai DA, Shakya A, Pierce LJ, Wang H, et al. Vitamin C promotes maturation of T-cells. Antioxid Redox Signal. 2013 Dec 10;19(17):2054-67.

117. Hemila H, Louhiala P. Vitamin C for preventing and treating pneumonia. Cochrane Database Syst Rev. 2013;8:CD005532.

118. Padayatty SJ, Sun H, Wang Y, Riordan HD, Hewitt SM, Katz A, et al. Vitamin C pharmacokinetics: implications for oral and intravenous use. Ann Intern Med. 2004 Apr 6;140(7):533-7.

119. Putchala MC, Ramani P, Sherlin HJ, Premkumar P, Natesan A. Ascorbic acid and its prooxidant activity as a therapy for tumours of oral cavity -- a systematic review. Arch Oral Biol. 2013 Jun;58(6):563-74.

120. Fritz H, Flower G, Weeks L, Cooley K, Callachan M, McGowan J, et al. Intravenous Vitamin C and Cancer: A Systematic Review. Integr Cancer Ther. 2014 May 26;13(4):280-300. 
Summary 
Cancer is one of the major causes of death in the world. The treatment of the majority of the cancer patients consists of a combination of surgery, chemo- or radiotherapy. Not all cancers can be cured with these conventional methods, therefore, other therapies like immunotherapy became of great interest. The major aims of immunotherapy are to trigger the patient's immune system to enhance the response against cancer cells or to supply immune cells or components to the patient that provide a strong immune reaction after administration.

We performed a fundamental study of the thymus, as described in chapter 2 , to obtain further understanding of thymus development, which could be helpful in the development of therapeutic strategies aiming at thymus rejuvenation, potentially resulting in increased thymopoiesis. In this chapter we show that during normal thymus development, fibroblast - that are of mesenchymal origin - ingrowth occurs towards areas where crosstalk between thymic epithelial cells and thymocytes is abrogated. Additionally, we provide candidate factors that are potential important in thymus mesenchymal network formation.

For adoptive cellular immunotherapy, the generation of high cell numbers of interest is often a requirement as well as a limitation of current protocols. In order to provide sufficient cell numbers, attempts to expand haematopoietic stem cells are of great value and of great interest. By first expanding haematopoietic stem cells and subsequent differentiation towards specific cell types, higher total cell numbers of interest can be generated. In chapter 3, we provide a method for haematopoietic progenitor expansion. A simple blockage of differentiation by overexpression of the ID3 transcriptional inhibitor in haematopoeitic stem cells in combination with B cell inducing culture conditions, results in a cell population with arrested differentiation and great self-renewal capacity. Since these cells are capable to differentiate into various cell types in an in vivo mouse model, these cells could be used as potential starting population for different kinds of cell therapies.

$\mathrm{T}$ cell progenitor therapy aims at a more rapid recovery of a patient's $\mathrm{T}$ cell pool after receiving haematopoietic stem cell transplantation (HSCT) as cancer treatment. Although, the combination of chemotherapy and HSCT is successful to eliminate cancer in certain cases, opportunistic infections cause high morbidity and mortality among these patients. This high infection incidence is caused by the patient's low T cell counts due to slow recovery of the $\mathrm{T}$ cells from the stem cell graft. A process that can take up from several months to years. Adoptive $\mathrm{T}$ cell precursor therapy could provide faster recovery of patient's $\mathrm{T}$ cell pool and thereby provide protection for infections. In chapter 4 we reply on a skin-explant method for the generation of T cells as described by Clark and colleagues ${ }^{1}$. We show that keratinocytes express minimal Delta Like Ligand (DLL), while this signalling is essential for $\mathrm{T}$ cell differentiation and commitment. We concluded that the method by Clark et al. is unfortunately not suitable for the production of T cells. Meanwhile, it was shown by us and others that haematopoietic stem cells derived from healthy volunteers have the capacity to 
differentiate to $\mathrm{T}$ cell progenitors in the presence of certain growth factors in co-culture with $\mathrm{DLL}^{+}$murine stromal cell ${ }^{2-5}$. It was also shown that these $\mathrm{T}$ cell progenitors are capable to migrate to the thymus of immune deficient mice faster than unmanipulated stem cells.

Murine stromal-cell based systems for cell therapy production are less suitable for clinical application. Therefore, we aimed to generate a culture method without the use of retrovirally transduced murine stromal cells overexpressing Delta ligands in chapter 5 . Here, we generated a system consisting of plate bound DLL4:Fc, fibronectin and a cytokine cocktail resulting in the differentiation of haematopoietic stem cells to T cell progenitors. Nonetheless, these T cell progenitors did not reach the same maturation stage as in the stromal cell culture validated previously ${ }^{2}$. Consequently, we searched for factors that could make up for this difference. We found that ascorbic acid, also known as vitamin $\mathrm{C}$, improves not only maturation of $\mathrm{T}$ cell progenitors but also improves the proliferation of these cells. Additionally, we show that different haematopoietic stem cell sources, cord blood and G-CSF mobilized stem cells, have the capacity to differentiate into $\mathrm{T}$ cell progenitors in the developed system. The differentiation and expansion of both cell sources are improved by ascorbic acid, proposing a clinical grade culture system for the generation of $\mathrm{T}$ cell progenitors that could improve the patient's immunity after stem cell transplantation. Moreover, we show a role for ascorbic acid in the transition from double negative to double positive $\mathrm{T}$ cells. We show that the discrepancy in the extent of supporting T cell development between TSt-4/DLL4 (ProT2/PreT) and OP-9/ $\mathrm{DL} 1$ (DP/SP) is because of the presence of ascorbic acid in the later co-culture. Furthermore, we concluded that Delta ligand expressing feeder cells nor conditioned media are required for DP T cell development when culturing stem cells with plate bound DLL4, a defined cytokine cocktail and ascorbic acid.

T and natural killer (NK) cells share a common progenitor. NK cell therapy is another cellular immunotherapy for cancer that is currently under investigation. NK cells have an important role in cancer immunosurveillance and can eliminate tumour cells. However, cell numbers required for adoptive therapy are enormous. In chapter $\mathbf{6}$, we show that ascorbic acid has a positive influence on the expansion of peripheral NK cells, a finding that can be of great value for the improvement of the production of adoptive NK cell therapy. Moreover, we provide a culture methods were NK cell progenitors can be generated from haematopoietic stem cells or $\mathrm{T}(/ \mathrm{NK})$ cell progenitors, processes that are improved by ascorbic acid. Since ascorbic acid is an inexpensive and clinical grade available compound, it can easily be implemented in clinical protocols and clinical trials.

Because of the positive effect of ascorbic acid on both $\mathrm{T}$ and NK cell development and expansion, we determined ascorbic acid serum concentrations in patients with haematological malignancies. We show in chapter 7 that patients treated with autologous/allogeneic stem cell transplantation and/or chemotherapy have significantly reduced serum ascorbic acid levels 
compared to healthy controls. This interesting observation makes further research to the possible correlation of ascorbic acid serum levels and the function and recovery of immune cells plausible. Moreover, the effect of ascorbic acid supplementation on these parameters would be interesting to investigate.

The findings described in this thesis contribute to the current promising progression in the field of cellular immunotherapy. Therapies that could improve the life expectancy of patients with cancer in the near future and should therefore be of main interest for current research and clinical translation. 


\section{References}

1. Clark RA, Yamanaka K, Bai M, Dowgiert R, Kupper TS. Human skin cells support thymusindependent T cell development. J Clin Invest. 2005 Nov;115(11):3239-49.

2. Meek B, Cloosen S, Borsotti C, Van Elssen CH, Vanderlocht J, Schnijderberg MC, et al. In vitro-differentiated $\mathrm{T} /$ natural killer-cell progenitors derived from human CD34+ cells mature in the thymus. Blood. 2010 Jan 14;115(2):261-4.

3. Awong G, Herer E, Surh CD, Dick JE, La Motte-Mohs RN, Zuniga-Pflucker JC. Characterization in vitro and engraftment potential in vivo of human progenitor $\mathrm{T}$ cells generated from hematopoietic stem cells. Blood. 2009 Jul 30;114(5):972-82.

4. De Smedt M, Hoebeke I, Plum J. Human bone marrow $\mathrm{CD} 4^{+}$progenitor cells mature to $\mathrm{T}$ cells on OP9-DL1 stromal cell line without thymus microenvironment. Blood Cells Mol Dis. 2004 Nov-Dec;33(3):227-32.

5. Eyrich M, Schreiber SC, Wollny G, Ziegler H, Schlenker R, Koch-Buttner K, et al. Predifferentiated human committed T-lymphoid progenitors promote peripheral $\mathrm{T}$-cell reconstitution after stem cell transplantation in immunodeficient mice. Eur J Immunol. 2011 Dec;41(12):3596-603. 


\section{Samenvatting}


Kanker is wereldwijd een van de belangrijkste doodsoorzaken. De meerderheid van behandelingen voor kankerpatiënten bestaat uit een combinatie van chirurgie, chemo- of radiotherapie. Helaas kunnen niet alle vormen van kanker met de conventionele methodes adequaat worden behandeld en genezen. Derhalve is de ontwikkeling van nieuwe vormen van therapie, zoals immuuntherapie, noodzakelijk. Immuuntherapie activeert het immuunsysteem van de patiënt, zodat de afweerreactie tegen de kankercellen toeneemt. Tevens kan extra toediening van immuuncellen of componenten de afweerreactie versterken.

Hoofdstuk 2 behandelt een fundamentele studie over de zwezerik, oftewel de thymus, om meer inzicht te verkrijgen in de ontwikkeling van dit orgaan. Informatie welke uiteindelijk zal kunnen bijdragen aan de ontwikkeling van therapeutische strategieën die zich richten op thymus verjonging, gekenmerkt door een verhoogde $\mathrm{T}$ cel productie. T cellen zijn essentieel voor de specifieke afweer tegen pathogenen. In het hoofdstuk laten we zien dat tijdens normale thymus ontwikkeling, fibroblasten (embryonale bindweefselcellen) ingroeien naar gebieden waar communicatie, ook wel crosstalk genoemd, tussen thymus epitheelcellen en thymocyten afwezig is. We beschrijven kandidaat factoren welke mogelijk essentieel zijn voor het vormen van het mesenchymale netwerk in de thymus.

Voor adoptieve cellulaire immuuntherapie zijn een hoog aantal cellen vereist. Het vergroten van de productie van immuuncellen kent momenteel een grote belangstelling, echter zijn er nog steeds beperkingen aan de huidige protocollen. Er zijn vele pogingen gedaan om hematopoëtische stamcellen eerst te laten vermeerderen om ze vervolgens te differentiëren naar specifieke, gewenste cel typen, resulterend in een groter aantal cellen van interesse. In hoofdstuk 3 dragen we een methode voor om hematopoëtische voorloper cellen te laten vermeerderen. Een eenvoudige blokkering van differentiatie in stamcellen, bereikt door de overexpressie van de transcriptie remmer ID3 in combinatie met B lymfocyt inducerende condities, resulteert in een celpopulatie met geremde differentiatie en een grote capaciteit tot zelfvernieuwing, beide kenmerken van een stamcel. Deze cellen zijn in staat te differentiëren tot diverse celtypes in een muismodel, waardoor ze potentieel bruikbaar zijn als startpopulatie voor verschillende therapieën, waaronder adoptieve voorloper $\mathrm{T}$ cel therapie. Voorloper $\mathrm{T}$ cel therapie heeft als doel de populatie $\mathrm{T}$ cellen van de patiënt na een hematopoëtische stamcel transplantatie (HSCT) sneller te herstellen. Hoewel de combinatie van chemotherapie en HSCT in bepaalde gevallen afdoende is om kanker te elimineren, sterven veel van de patiënten aan (opportunistische) infecties. Deze hoge infectie-incidentie is te wijten aan de lage $\mathrm{T}$ cel waarden van de patiënt door trage ontwikkeling van $\mathrm{T}$ cellen vanuit het stamcel transplantaat, een herstel dat maanden tot jaren kan duren. Wij hanteerden de hypothese dat adoptieve voorloper $\mathrm{T}$ cel therapie sneller herstel van de $\mathrm{T}$ cel populatie van de patiënt bewerkstelligt en op deze wijze bescherming biedt tegen infecties. Hoofdstuk 4 reageert op een in de literatuur beschreven kweek methode waar huidcellen op een driedimensionale matrix gekweekt worden, waarin een goede productie van geschikte T cellen mogelijk zou 
zijn ${ }^{1}$. Onze studie wijst op een groot aantal problemen en geeft als belangrijkste verklaring voor het falen van de productie van T cellen dat keratinocyten het eiwit Delta Like Ligand (DLL) minimaal tot expressie brengen, terwijl deze signalering essentieel is voor $\mathrm{T}$ cel differentiatie en toewijding. Derhalve concludeerden we dat de door Clark et al. beschreven methode niet geschikt is voor de productie van T cellen voor therapeutische doeleinden. Bovendien hebben wij en anderen aangetoond dat hematopoëtische stamcellen van gezonde vrijwilligers kunnen differentiëren naar voorloper $\mathrm{T}$ cellen in de aanwezigheid van geselecteerde groeifactoren in co-cultuur met $\mathrm{DLL}^{+}$stromale cel lijnen uit muizen ${ }^{2-5}$. Deze voorloper $\mathrm{T}$ cellen kunnen na injectie naar de thymus van immuundeficiënte muizen migreren en doen dit bovendien sneller dan niet-gekweekte stamcellen.

Kweekmethodes welke gebaseerd zijn op retroviraal getransduceerde stromale cellen uit muizen voor de productie van celtherapie producten zijn minder geschikt als therapeutische/ klinische toepassing. Hoofdstuk 5 introduceert een kweekmethode welke geen gebruik maakt van stromale cellen uit muizen. Dit systeem, bestaande uit plaat-gebonden DLL4:Fc, fibronectine en een medium met geselecteerde groeifactoren, resulteerde in de differentiatie van stamcellen naar voorloper $\mathrm{T}$ cellen. Deze $\mathrm{T}$ cel voorlopers verkregen een minder gevorderd rijpingspatroon vergeleken met de cellen geproduceerd in de stromale cel gebaseerde methode. De zoektocht naar factoren die dit rijpingsverschil kunnen overbruggen, leverde het nieuwe inzicht dat ascorbinezuur (vitamine C) zowel de rijping als de proliferatie van de voorloper $\mathrm{T}$ cellen verbetert. Differentiatie van verschillende stamcel bronnen, zowel G-CSF gemobiliseerde als navelstrengbloed stamcellen, bezitten de capaciteit om tot voorloper $\mathrm{T}$ cellen te ontwikkelen in het opgezette systeem. De differentiatie en expansie van beide celbronnen wordt tevens verbeterd door ascorbinezuur. Hierbij introduceren we een klinisch toepasbaar kweeksysteem, bruikbaar voor de productie van voorloper $\mathrm{T}$ cellen die het afweersystem van de patiënt na HSCT kunnen versterken. Bovendien tonen we een rol voor ascorbinezuur aan in de overgang van $\mathrm{CD} 4^{+} \mathrm{CD} 8^{+}$dubbel negatieve (DN) naar de verder gerijpte $\mathrm{CD}^{+} \mathrm{CD}^{+}$dubbel positieve (DP) T cellen. Het verschil in het kunnen ondersteunen van $\mathrm{T}$ cel ontwikkeling tussen het TSt-4/DLL4 (ProT2/PreT cellen) en het OP-9/DL1 (DP/ CD4 of CD8 enkel positief (SP) cellen) kweeksysteem, komt door de aanwezigheid van ascorbinezuur in het medium van deze laatste co-cultuur. We concluderen daarom dat Delta ligand tot expressie brengende stromale cellen niet nodig zijn voor vroege DP T cel ontwikkeling. Een gedefinieerd systeem waarin stamcellen gekweekt worden met DLL4:Fc, vier bekende groeifactoren en ascorbinezuur volstaat voor $\mathrm{T}$ cel differentiatie.

$\mathrm{T}$ cellen en natural killer (NK) cellen delen een gemeenschappelijke voorloper. NK cel therapie is een cellulaire immuuntherapie tegen kanker welke momenteel onderzocht wordt. NK cellen hebben onder andere een belangrijke rol in immuun controle en kunnen bovendien kankercellen elimineren. Het aantal cellen nodig voor therapie is enorm. Hoofdstuk 6 beschrijft dat ascorbinezuur een versterkende rol heeft op de expansie van 
perifere NK cellen, een ontdekking van grote waarde voor het verbeteren/versnellen van de productie van NK cellen voor therapie. Ook laten we zien dat voorloper NK cellen gedifferentieerd uit hematopoëtische stamcellen of voorloper $\mathrm{T}$ cellen ook positief worden beïnvloed door ascorbinezuur. Omdat ascorbinezuur goedkoop en klinisch beschikbaar is, kan het gemakkelijk worden geïmplementeerd in huidige klinische protocollen en klinische trials.

Door het positieve effect van ascorbinezuur op zowel $\mathrm{T}$ als NK cel ontwikkeling en expansie hebben we de ascorbinezuurwaarden uit serum bepaald van patiënten met hematologische maligniteiten, vanwege de mogelijke invloed hiervan op het herstel van het immuunsysteem. Hoofdstuk 7 beschrijft dat patiënten behandeld met chemotherapie of autologe/allogene stamcel transplantatie inderdaad significant verlaagde ascorbinezuur serumwaardes hebben. Deze interessante bevinding maakt verder onderzoek naar de mogelijke correlatie tussen ascorbinezuur serumwaardes en de functie en herstel van immuuncellen plausibel. Ook het effect van ascorbinezuur op deze parameters is interessant om te onderzoeken.

De bevindingen beschreven in deze thesis dragen bij aan de veelbelovende vooruitgang in het veld van immuuntherapie. Deze therapieën kunnen bijdragen aan een verbeterde levensverwachting van patiënten met kanker in de nabije toekomst en zijn daarom van essentieel belang voor huidig onderzoek en klinische vertaling. 


\section{Referenties}

1. Clark RA, Yamanaka K, Bai M, Dowgiert R, Kupper TS. Human skin cells support thymusindependent T cell development. J Clin Invest. 2005 Nov;115(11):3239-49.

2. Meek B, Cloosen S, Borsotti C, Van Elssen CH, Vanderlocht J, Schnijderberg MC, et al. In vitro-differentiated $\mathrm{T} /$ natural killer-cell progenitors derived from human CD34+ cells mature in the thymus. Blood. 2010 Jan 14;115(2):261-4.

3. Awong G, Herer E, Surh CD, Dick JE, La Motte-Mohs RN, Zuniga-Pflucker JC. Characterization in vitro and engraftment potential in vivo of human progenitor $\mathrm{T}$ cells generated from hematopoietic stem cells. Blood. 2009 Jul 30;114(5):972-82.

4. De Smedt M, Hoebeke I, Plum J. Human bone marrow $\mathrm{CD} 4^{+}$progenitor cells mature to $\mathrm{T}$ cells on OP9-DL1 stromal cell line without thymus microenvironment. Blood Cells Mol Dis. 2004 Nov-Dec;33(3):227-32.

5. Eyrich M, Schreiber SC, Wollny G, Ziegler H, Schlenker R, Koch-Buttner K, et al. Predifferentiated human committed T-lymphoid progenitors promote peripheral $\mathrm{T}$-cell reconstitution after stem cell transplantation in immunodeficient mice. Eur J Immunol. 2011 Dec;41(12):3596-603. 
Valorisation 
Cancer is one of the major causes of death in the Western world and the second cause of death in developing countries, with a global growing incidence of 22.2 million estimated cases in $2030^{1-3}$. In 2012, 14.1 million people were diagnosed with cancer and 8.2 million cancer deaths were counted worldwide ${ }^{4}$. Even though cancer mortality declines because of more effective, early detection in combination with early treatment, the burden on society remains enormous. The economic burden consists of costs associated with for example prevention, health-care and productivity losses due to morbidity and mortality. The estimated total cancer costs in the European Union were $€ 126$ billion in $2009^{5}$. Besides the economic burden, the social burden of cancer affecting the quality of life of both patients and their caregivers should also be acknowledged.

Because not all cancers can be cured with the current treatment protocols, an urgent need for novel therapies exists. More recently, therapies like immunotherapy became of great interest. Although great progress in the past decades has been made (e.g. the introduction of monoclonal antibodies), immunotherapy is often only effective in certain patients and only results in moderate prolonged survival instead of complete remission. Among cellular immunotherapies, adoptive T cell progenitor therapy and natural killer (NK) cell infusion are of great interest and are described in this thesis.

For adoptive cellular immunotherapy, the generation of high cell numbers of interest is often a requirement as well as a limitation. To treat for example a patient of $70 \mathrm{~kg}$, somewhere between $70 \times 10^{6}$ to $700 \times 10^{6}$ cells are believed to be required for a single dose of $\mathrm{T}$ cell progenitors. In order to generate such great cell numbers, attempts to expand haematopoietic stem cells are of importance and of great interest.

In chapter 3 we provide a method to expand haematopoietic stem cells. For human cells, this resulted in 160 fold more cells. Subsequent differentiation towards specific cell types could result in higher total cell numbers for therapy. However, since these cells produced by manipulation with a retroviral construct, first an alternative method should be generated to meet good manufacturing practices (GMP) and ensure safety. Nevertheless, this method provides a good basis for further research.

In chapter 5, we propose a clinical grade culture system for the production of $\mathrm{T}$ cell progenitors that can easily be translated to a clinical product and that could strengthen the patient's immune system after stem cell transplantation. Although stromal cell based systems that were previously developed by others and us could potentially be used for the generation of cellular therapy, getting approval for such product would be difficult, expensive and time consuming. Especially because cellular products are rather new and no extensive regulations are written. Moreover, the potential risks are not completely known. The stromal-based cocultures use murine stromal cells lines that are retrovirally transduced to overexpress Delta 
Like ligand. EMA and FDA advise against the use of products of animal origin, although it is not prohibited. In this case, the use of both the stromal cells and the FCS required to produce the cellular product will be debatable. Another concern is that the stromal cells are retrovirally transduced. Although these cells will not be in the actual product, it has to be assessed whether viral load is present in the cell products to assure safety. Besides safety regulations, there are other concerns regarding this product. Prior sorting to eliminate stromal cells and to select the proper $\mathrm{T}$ cell populations is required, which are as said time consuming and expensive. Moreover, reproducibility in a system with cell lines and FCS is more difficult than in a feeder- and serum-free culture. It is know that FCS and even cell lines have large batch to batch variation, resulting in lower reproducibility, increase in quality control and thereby increasing costs.

To circumvent the indicated undesired components, we generated a system using plate bound DLL4:Fc, fibronectin and a growth factor cocktail to differentiate haematopoietic stem cells to $\mathrm{T}$ cell progenitors, which can be clinical applicable. We discovered that ascorbic acid, also known as vitamin $\mathrm{C}$, improves maturation of $\mathrm{T}$ cell progenitors and also improves the proliferation of these cells. Adoptive T cell progenitor therapy could provide faster recovery of patient's T cell levels and thus providing protection against infections. Currently, the low $\mathrm{T}$ cell levels of patients and subsequent infections account for high morbidity and mortality of these patients ${ }^{6}$. Moreover, the use of $\mathrm{T}$ cell progenitors is not limited to cancer patients, but could also be used to improve the immune system of other immunocompromised patient groups like AIDS patients. A first step towards the development of a clinical product would be the verification of the $\mathrm{T}$ cell progenitors in vivo in a humanized mouse model. Hereafter, production needs to be scaled up to obtain sufficient cell numbers for human cell infusions. Currently, the product is produced in 96 or 48 well plates resulting in limited yield and high maintenance. Culturing in special bags or bioreactors with controlled supplementation of required nutrients and cytokines could increase yield and reduce handling time resulting in a better product with less costs. Moreover, progenitor T cells need to be produced in a GMP facility before clinical trials can be initiated. Clinical trials should asses if injection of both stem cells and progenitor $\mathrm{T}$ cells will result in a faster recovery of the patient $\mathrm{T}$ cell pool and if this leads to reduced infection incidence.

Another cellular immunotherapy that is currently under investigation is NK cell therapy as treatment for types of cancer that are not curable by the conventional therapies as surgery, chemotherapy or radiation. Cell numbers required for adoptive therapy are estimated to run in the billions especially because only a minor population of the total NK cell fraction is capable of eliminating tumour cells ${ }^{7-8}$. In chapter $\mathbf{6}$, we show that ascorbic acid has a positive influence on the expansion of peripheral NK cells, a finding that can be of great value for the improvement of the production of adoptive NK cell therapy. The generation of more cells in a shorter time could lead to a better cost-effective product. Since ascorbic acid is already a 
FDA-approved compound, this can easily be implemented in clinical protocols and clinical trials. First, the current proposed culture method needs to be upgraded to a GMP compliant method. Currently, this is performed in our lab in collaboration with the German company Zellwerk. The culture system is a bioreactor in a GMP qualified safety cabinet with a constant supply of fresh media. Also glucose, $\mathrm{pH}$, temperature are constantly monitored and adjusted if needed. Currently, NK cells generated in this bioreactor are evaluated on their proliferative capacity, phenotype and function. After subsequent verification of our results in vivo mouse models, phase I clinical trials will be started.

As mentioned shortly, for both $\mathrm{T}$ cell progenitor and NK cell therapy, clinical product translation is still required. For GMP, products need to be prepared in closed systems in special facilities with high quality control and standardized protocols. Before starting clinical research, approval by the Medical Research Ethical Committee needs to be granted. Financial support for the trial can be obtained from private funding or funding from organizations like the Dutch Cancer Society (KWF) and the Cancer research Fund of the Limburg Health Foundation. To ultimately bring these products to the patients, charities will not be able to provide sufficient money to pay for the involved costs. It is foreseen that spin-off companies that attract venture capital can bring these needed therapies several steps further. Phase III clinical trials will need so much money that the big pharmaceutical companies will be needed to further co-develop the products.

Besides the developed and improved culture methods to generate cells applicable for adoptive cellular therapy, we investigated the vitamin C status of patients with a haematological malignancy. In chapter 7 we show that these patients, either treated with stem cell transplantation and/or chemotherapy have significantly reduced vitamin C levels. This information has a high new value and further research could be performed to investigate whether these low vitamin C levels correlate to patients' lymphocyte counts. This information, especially in combination with the in vitro effects of vitamin $C$ shown in chapter 5 and 6 , could therefore be used to start clinical trials. For example, the effect of vitamin C supplementation on lymphocyte recovery and infection incidence could be studied. Since vitamin C is inexpensive to produce, readily available, known for many years and already proven to be safe when supplemented in high doses, clinical trials could be initiated fast. Furthermore, it would be of great interest to investigate the effect of vitamin $\mathrm{C}$ supplementation on thymus regeneration, potentially resulting in increased thymic output and higher $\mathrm{T}$ cell levels.

These findings contribute to the current promising progress in the field of cellular immunotherapy. Our results promise a good feasibility; however, these data need to be strengthened with in vivo experiments with our proposed clinical products. Subsequently clinical trials need to demonstrate the scientific and clinical value of these therapies. Cellular immunotherapies require patient specific products that are labour-intensive and therefore 
high costs will be involved in the production ${ }^{9-10}$. Since several cellular immunotherapies are already in use, for example stem cells for transplantation and a dendritic cell based vaccine for prostate cancer (Provenge ${ }^{\circledR}$ ), cellular immunotherapies already prove to be effective. This opened the road for novel therapies as proposed in this thesis. These therapies could improve the life expectancy of patients with cancer in the near future and should therefore be of main interest for current research and clinical translation. 


\section{References}

1. Vineis P, Wild CP. Global cancer patterns: causes and prevention. Lancet. 2014 Feb 8;383(9916):549-57.

2. Bray F, Jemal A, Grey N, Ferlay J, Forman D. Global cancer transitions according to the Human Development Index (2008-2030): a population-based study. The Lancet Oncology. 2012 Aug;13(8):790-801.

3. Umar A, Dunn BK, Greenwald P. Future directions in cancer prevention. Nature reviews Cancer. 2012 Dec;12(12):835-48.

4. World Health Organization. GLOBOCAN 2012: Estimated Cancer Incidence, Mortality and Prevalence Worldwide in 2012. 2012.

5. Luengo-Fernandez R, Leal J, Gray A, Sullivan R. Economic burden of cancer across the European Union: a population-based cost analysis. The Lancet Oncology. 2013 Nov;14(12):1165-74.

6. Aversa F, Terenzi A, Tabilio A, Falzetti F, Carotti A, Ballanti S, et al. Full haplotypemismatched hematopoietic stem-cell transplantation: a phase II study in patients with acute leukemia at high risk of relapse. Journal of clinical oncology : official journal of the American Society of Clinical Oncology. 2005 May 20;23(15):3447-54.

7. Sarkar S, Van Gelder M, Willy Xu Y, Rouschop K, Groen R, Schouten H, et al. Optimal selection of Natural Killer cells to kill myeloma: the role of HLA-E and NKG2A. In submission. 2014.

8. Cheng M, Chen Y, Xiao W, Sun R, Tian Z. NK cell-based immunotherapy for malignant diseases. Cellular \& molecular immunology. 2013 May;10(3):230-52.

9. Simaria AS, , Farid S, Hassan S. Cost-effectiveness of Single-Use Technologies for Commercial Cell Therapy Manufacture. The American pharmaceutical review. 2013 Apr.

10. Fulton BD, Felton MC, Pareja C, Potischman A, Scheffler RM. Coverage, Cost-Control Mechanisms, and Financial Risk-Sharing Alternatives of High-Cost Health Care Technologies. Report by the California Institute for Regenerative Medicine. 2009 Oct. 


\title{
Acknowledgements
}

\author{
Dankwoord
}


Dit proefschrift was niet tot stand gekomen zonder de hulp van collegae, familie en vrienden. Ik wil jullie hier ontzettend voor bedanken.

Allereerst wil ik het promotieteam bestaande uit Prof. dr. Gerard Bos, Prof. dr. Hiroshi Kawamoto en dr. Wilfred Germeraad ruimhartig bedanken. Wilfred, bedankt dat jij mij de mogelijkheid hebt gegeven om de senior stage in dr. Kawamoto's lab uit te voeren. Dear Kawamoto-sensei, thank you so much for the opportunity to work in your laboratory. Working with you was very inspiring. Thank you both for the great science, but also for the chance to experience a new culture! I also fell in love with Japan. Bedankt dat jullie na dit avontuur genoeg vertrouwen hadden om mij op het KWF project als $\mathrm{PhD}$ student aan te stellen. Wilfred, ik wil je bedanken voor je enthousiasme en toegankelijkheid. Voor elk gedachtespinsel, vraag of probleem kon ik altijd binnen lopen. Gerard, met uw helicopterview hield $\mathrm{u}$ altijd het overzicht, bewaakte $\mathrm{u}$ dat we het doel niet uit ogen verloren en niet teveel "hobbyden". Ik heb uw kritische blik zeer gewaardeerd. Kawamoto-sensei, thank you for our collaboration and your involvement in the projects, resulting in a major contribution to this thesis. I am very honoured to have you in the promotionteam.

Bob, jij stond aan de basis van dit project. Ik vind het erg jammer dat we niet samen aan de slag konden gaan! Tijdens mijn stage heb ik veel van je geleerd, ook heb je me ontzettend uitgedaagd en geënthousiasmeerd. Bedankt!

De leden van de leescommissie bestaande uit Prof. dr. Vooijs (voorzitter), Prof. dr. Cornelissen, dr. ir. Henskens, Prof. dr. Ramaekers, en Prof. dr. Staal en de leden van de corona wil ik hartelijk danken voor het lezen en beoordelen van mijn proefschrift.

Natuurlijk wil ik iedereen van het lab bedanken: Melanie, Birgit, Tammy, Ans, Thomas, Niken, Silvie, Ariane, Mateusz, Subhashis, Michel en Prof. Schouten. Mateusz, thanks for your participation in the project. Michel bedankt voor de input tijdens meetings. Melanie, wat dacht ik tijdens FACS kleuringen vaak dat je het tegen mij had terwijl je tegen je computer aan het vertellen was! Ik vond het erg gezellig om met jou te werken en te kletsen! Birgit, wat hebben wij veel uren samen doorgebracht achter de FACS ARIA. Ontzettend bedankt dat je altijd bereid was tijd vrij te maken en dat je je niets van reguliere werktijden aantrok! Ook bedankt voor al je wijze raad..! Subhashis, you are already finished.. good job!! Thanks for all your advice, especially to put things into perspective. Hope we will still get opportunities to see each other despite the distance! Thomas, wat ben jij handig met computers zeg. Dankjewel voor de gezelligheid en het vormgeven van mijn plaatjes! Niken, you are such a bright person. I am sure you will get wherever you want to! Ans, ook al werk je al een tijdje niet meer bij ons, hier heb ik je wel leren kennen.. en dat vond ik heel gezellig. Heerlijk om samen met jou en Tammy koffie te drinken, van het zonnetje te genieten of te high tea-en! Tammy, I really enjoyed working with you.. troubleshooting in the lab, talking about data, sharing rooms at 
conferences but also the social stuff.. decorating my room, baking, knutselen, getting lost even with navigation.. ahhh I will miss you so much!! Good luck with the laatste loodjes!

"From the other side", oftewel Weefsel Typering: Joris en Lotte bedankt voor jullie inbreng! Joris voor je wijze raad en goede ideeën, naast deze kwaliteiten ben je ook nog eens super sociaal en weet ik waarom Kwak bier deze naam heeft. Lotte, ik vond het leuk om met je samen te werken en over NK cellen te praten. Erg mooi hoe jij het voor elkaar hebt. Kevin en Nina, bedankt voor alle lol, zeker tijdens carnaval.. tot vrijdag?!

Dear Ikawa-san, thank you for supervising me during my senior internship. I am very greatfull that I have learned so much from you. Thank you for the collaboration, especially on the ID3 project. I wish you all the luck in science (and Nature) and also with your beautiful family.

De studenten welke hebben mee-gepipetteerd wil ik ook bedanken, Ferry, Bibian en Nicole. Nicole, thank you so much for your help and dedication to the project. Good luck with your $\mathrm{PhD}$, ganbatte!!

Ook dank aan mijn kamergenootjes, in het bijzonder Petra en Anne-Hilde. Anne-Hilde, dankjewel voor alle hulp met statistiek, andere toverijen en natuurlijk de gezelligheid. Jouw oplossingsgerichte aanpak kan ik erg waarderen! Heel veel succes met het afronden van je promotie en het vinden van een leuke nieuwe baan, dat gaat zeker goed komen!! Petra, wat vond ik het gezellig om jou als kamergenootje te hebben. Lekker kletsen over van alles en nog wat, zegeltjes en mini's sparen (niet alleen voor jouw kinderen, maar ook voor mij), en zeker ook je adviezen. Omdat jij hetzelfde traject hebt doorgelopen, wist je precies wat me te wachten stond en kon ik altijd bij jou terecht. Ik mis jullie al ontzettend!

Ook wil ik alle dames van de verloskamers hartelijk danken voor de afnames van het navelstrengbloed. Ondanks de drukte bleven jullie bellen als jullie weer een zakje hadden.

Studiegenootjes.. maar vooral vrienden.. Auke, Bram, Emiel, Irene, Marten, Peter en Sarah. Alleen Bram was zo verstandig nooit aan een promotie te beginnen, ik vind het knap dat je een andere weg hebt bewandeld! De anderen.. allemaal in hetzelfde schuitje.. wat hebben we samen lekker kunnen klagen en jammeren over het hoe en waarom. Maar vooral bedankt voor het vertier... weekendjes weg, bubbelen, sinterklaas, kolonisten.. heerlijk! Auke, jouw humor maakt alles minder erg. Op jouw woorden kon ik vaak wel een week teren! Emiel.. dit is de eerste ;) Irene, ik bewonder hoe jij je promotie bent doorgewandeld, erg mooi hoe je alles voor elkaar hebt! Marten, gelukkig kom je nog vaak naar het Zuiden.. jouw nuchterheid is verademend! Peet, ook al woon je helemaal in Frankfurt, voor mijn gevoel ben je nog altijd hier! Ik ben ontzettend blij met jou als vriend! Saar, samen koken of terrassen.. heerlijk om even te ontsnappen! Super thanks!! Ik hoop dat we elkaar allemaal niet uit het oog zullen 
verliezen.. ook al worden het aantal kilometers en de spreiding groter..

Emiel, dankjewel..! Ik kon bij jou altijd terecht voor pipetpuntjes, kweekflessen, multichannels en andere lab attributen. Maar nog veel belangrijker.. je bent er altijd voor mij! Jij kwam mij mandarijntjes brengen, zelfs voordat ik wist dat vitamine $\mathrm{C}$ zo belangrijk voor me was! Bon Jovi, Muse, the Stones, Linkin Park.. met jou kan ik altijd helemaal los gaan! Ook de broodnodige ontspanning.. samen op vakantie, tv kijken (het liefst Phineas and Ferb), koken (ik koken.. jij eten), en niet te vergeten onze picknickavonturen op het werk. Tja.. in het weekend moet je het natuurlijk ook gezellig maken op de uni! Je bent een lieverd!

Paul, jij had vaak geen idee waar ik het over had. En vond het maar een apart wereldje.. ach, vaak snappen we het zelf ook niet;) Dankjewel dat ik me in Eindhoven altijd kon uitleven met Mario kart en meters hoge cocktails :)

F.C. Den Duiker, beste fietsvrienden, jullie hebben de afgelopen jaren gezorgd dat ik toch nog genoeg beweging kreeg. Het was ontzettend leuk om deze nieuwe hobby met jullie te ontdekken. Tijdens de ritten kon ik mijn hoofd vrijmaken. Wat waren de tochten en weekendjes gezellig! Dankzij jullie weet ik pas echt hoe mooi Zuid-Limburg is! Dank jullie wel!

Inge, (je)zus, zonder jou als ambitieus voorbeeld had ik het nooit zo ver geschopt! Ik ben trots op je. Rudolf, dankjewel, niet alleen voor computer hulp maar ook voor de gekkigheid (Oishi!!). Heel veel geluk met mijn lieve petekindje, Eline :) Mamma en pappa, jullie liefde en toewijding hebben mij gebracht waar ik ben. Bij jullie ben ik altijd thuis (ook al raadde mam me veelvuldig aan een stretcher op het werk te zetten), een plek om tot rust te komen en af te schakelen van "in de kast zitten" (flow cabinet), "faxen" (flow cytometrie) en andere bezigheden, dankjewel! Ik houd van jullie!

\footnotetext{
"Don't waste your time

Or time will waste you"
}

Muse 


\section{List of publications}


T cells fail to develop in the human skin-cell explant system; an inconvenient truth. B. Meek, C.H.M.J. Van Elssen, M.J.A.J. Huijskens, S.J. Van der Stegen, S. Tonnaer, S.B. Lumeij, J. Vanderlocht, M.A. Kirkland, R. Hesselink, W.T.V. Germeraad, G.M.J. Bos.

BMC Immunol. 2011 Feb 18;12:17.

Ascorbic acid induces development of double-positive T cells from human haematopoietic stem cells in the absence of stromal cells.

M.J.A.J. Huijskens ${ }^{\star}$, M. Walczak ${ }^{\star}$ N. Koller, B.L.M.G. Senden-Gijsbers, M.C. Schnijderberg, G.M.J. Bos, W.T.V. Germeraad. * Shared first authorship.

J Leukoc Biol. 2014 Dec; 96(6): 1165-75

Thymic epithelial cells induce formation of mesenchymal network structure after abrogation of thymic crosstalk.

R. Satoh, M.J.A.J. Huijskens, K. Masuda, T. Ikawa, E. Vroegindeweij, M. Itoi, G.A. Holländer, Y. Katsura, H. Kawamoto and W.T.V. Germeraad.

Submitted for publication.

Induced developmental arrest of early haematopoietic progenitors leads to the generation of leukocyte stem cells.

T. Ikawa, K. Masuda, M.J.A.J. Huijskens, R. Satoh, K. Kakugawa, Y. Agata, W.T.V. Germeraad, Y. Katsura and H. Kawamoto.

Submitted for publication.

Ascorbic acid promotes proliferation of NK cell populations in culture systems applicable for NK cell therapy.

M.J.A.J. Huijskens*, M. Walczak*, S. Sarkar, F. Atrafi, B.L.M.G. Senden-Gijsbers, M.G.J. Tilanus, G.M.J. Bos, L. Wieten ${ }^{\$}$ and W.T.V. Germeraad ${ }^{\star}{ }^{*} / \$$ Shared first/last authorship.

Submitted for publication.

Ascorbic acid serum levels are reduced in patients with haematological malignancies. M.J.A.J. Huijskens, W.K.W.H. Wodzig, M. Walczak, W.T.V. Germeraad, G.M.J. Bos.

Submitted for publication. 


\section{Curriculum Vitae}


Mirelle Johanne Angelina Jacobus Huijskens was born on July 17th, 1987 in Naarden, the Netherlands. The main part of her youth, she lived in "the white village" Thorn. Her secondary school, finished in 2005 at Sint Ursula in Horn, was followed by the bachelor education Molecular Life Sciences at Maastricht University. Subsequently, Mirelle studied the master Clinical Molecular Sciences, also at the Maastricht University. She performed her senior internship at the Laboratory for Lymphocyte Development of Prof. dr. Kawamoto at the RIKEN RCAI in Yokohama, Japan. In 2010 she graduated with honours and started her doctoral research within GROW, School for Oncology and Developmental Biology, at the department of haematology at the MUMC+ under the supervision of Prof. dr. Gerard Bos, Prof. dr. Hiroshi Kawamoto and dr. Wilfred Germeraad. Results obtained during this training are described in this thesis. From January 2015, she has started as clinical chemist in training at the Albert Schweitzer hospital in Dordrecht, with dr. F.M. Verheijen as supervisor and dr. M.A. Fouraux as co-supervisor.

Mirelle Johanne Angelina Jacobus Huijskens werd geboren op 17 juli 1987 te Naarden. Het grootste gedeelte van haar jeugd bracht ze door in "het witte stadje" Thorn. Het behalen van haar VWO diploma in 2005 aan de scholengemeenschap Sint Ursula te Horn, werd vervolgd met de bachelor opleiding Moleculaire Levenswetenschappen aan de Universiteit van Maastricht. Aansluitend is Mirelle de master Clinical Molecular Sciences gaan studeren, eveneens aan de Universiteit van Maastricht. Tijdens de afstudeerstage heeft ze onderzoek uitgevoerd in het Laboratory for Lymphocyte Development van Prof. dr. Kawamoto aan het RIKEN RCAI in Yokohama, Japan. In 2010 is ze cum laude afgestudeerd en vervolgens gestart met haar promotietraject bij de School for Oncology and Developmental Biology, GROW, op de afdeling Hematologie van het MUMC+ onder leiding van Prof. dr. Gerard Bos, Prof. dr. Hiroshi Kawamoto en dr. Wilfred Germeraad. De resultaten behaald tijdens dit traject zijn beschreven in dit proefschrift. Vanaf januari 2015 is ze werkzaam als klinisch chemicus in opleiding in het Albert Schweitzer ziekenhuis te Dordrecht met als opleider dr. F.M. Verheijen en plaatsvervangend opleider dr. M.A. Fouraux. 